
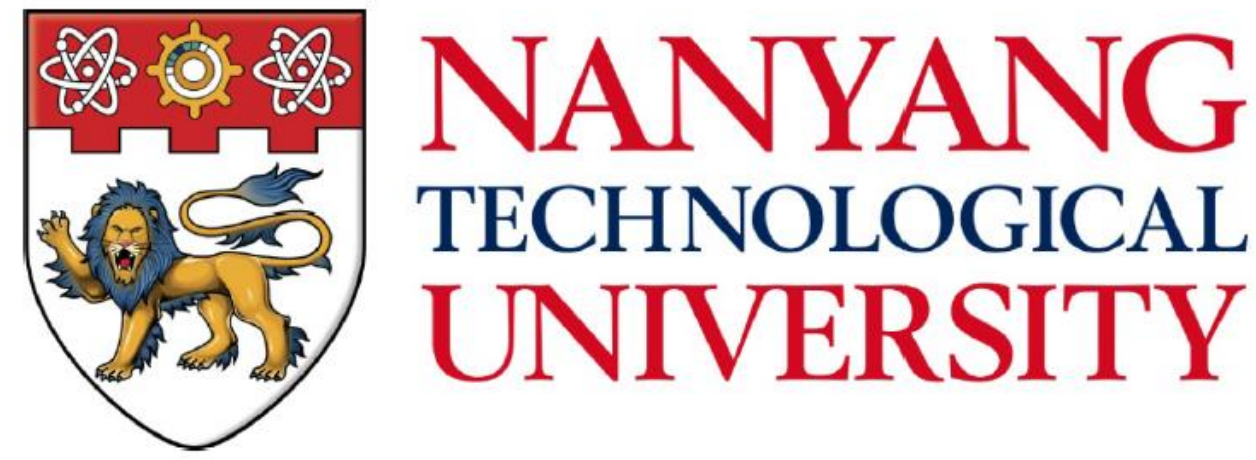

\title{
IMPACTS OF NANOMATERIALS ON SOCIAL BEHAVIOUR OF MICROORGANISMS
}

\author{
ANEE MOHANTY
}

SCHOOL OF CIVIL AND ENVIRONMENTAL ENGINEERING 


\title{
Impacts of Nanomaterials on Social Behaviour of Microorganisms
}

\author{
Anee Mohanty \\ School of Civil and Environmental Engineering \\ A thesis submitted to the Nanyang Technological University in \\ partial fulfilment of the requirements for the degree of \\ Doctor of Philosophy
}




\section{ACKNOWLEDGEMENT}

Working in NTU as a graduate student was really an enriching experience and there are a lot of people who were instrumental in making this dream come true and I would like to thank all of them sincerely.

First of all, I would take this opportunity to extend my immense gratitude to my supervisor Asst. Prof. Cao Bin, CEE/SCELSE, NTU, for his guidance and confidence in my abilities. This thesis would not have been possible without his consistent encouragement and constructive criticism. His enthusiasm and positive attitude towards work will always remain a source of inspiration.

I am also very grateful to my co-supervisor Asst. Prof. Liang Yang, for his invaluable suggestions and kind teaching. I am thankful to him for always being available whenever guidance and help was needed.

Special thanks to Dr. Tan Chuan Hao for the active collaborations and his continuous guidance and endless supply of solutions and troubleshooting. It was indeed a learning experience working with him. Thank you for all the help with mass spectroscopy and metatranscriptomics data analysis.

I would like to thank my collaborators Dr. Li Wei and Prof Yuan Chen for supplying the Single-wall carbon nanotubes, Prof. Willian Chen at SCBE, NTU for help with proteomics and Assoc. Prof. Loo Say Chye Joachim at MSE, NTU for help with cytotoxicity assay.

Heartfelt thanks to all my colleagues in CEE and SCELSE for their friendships and constant support, without which this journey would not have been so enjoyable. There have been many people who helped me both at a professional and personal level and I would like to thank them. I am thankful to Dr. Manisha Mukherjee (for being there always as a friend and her help with learning confocal and biofilm setup), Kavita Kumari Kushwaha (for teaching me the basics of qPCR and for patiently listening to all my complaints and problems), Sudha Shukla (for spending endless hours in lab helping me with plating and many other experiments and for all the delicious foods) Krithika 
Arumugam (for all her invaluable help with sequencing data analysis and for all the fun activities we did together), last but not the least Gayatri Shankar Chilambi for being a sport she is and for providing much needed dose of fun in lab work. A very special thanks to Chitrakala Ramasamy and her whole family for the love and warmth during my stay at their house. I would also like to thank Jun kit for all the help with the formatting of the thesis. I would also like to thank Jun kit for all the help with the formatting of the thesis.

I would also like to express my appreciation towards my lab mates (Krish, Yichao, Yingdan, Ding, Calvin, Amit and Daphne) for their constructive ideas, suggestions and constant support.

I am also privileged to have some friends for life and they need a special mention as they were the inspiration behind pursuing $\mathrm{PhD}$ and they have been there through the thick and thin. I am really thankful to all my friends for their endless love and appreciation.

Lastly, this thesis is dedicated to my beloved parents and my younger brother who have been extremely supportive throughout my life. If not for the sacrifices that my family has made, it would not have been possible for me to have made it this far in my education.

I would like to acknowledge the scholarship provided by Nanyang Technological University during my candidature. 


\section{TABLE OF CONTENTS}

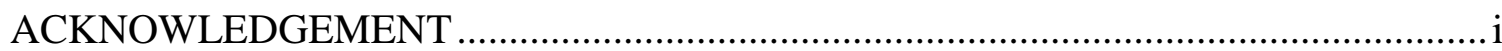

TABLE OF CONTENTS ...................................................................................ii

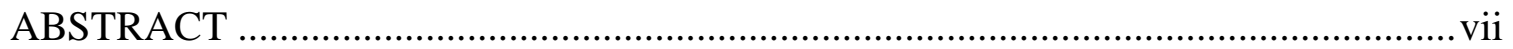

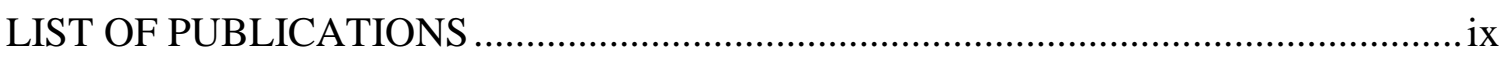

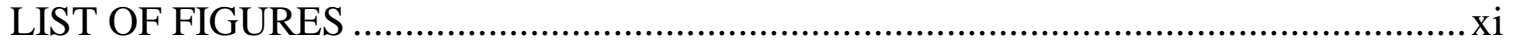

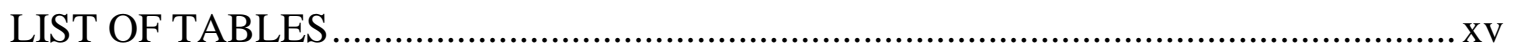

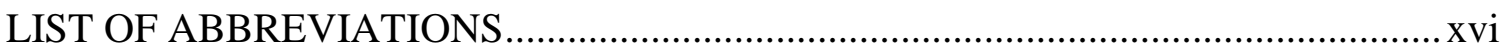

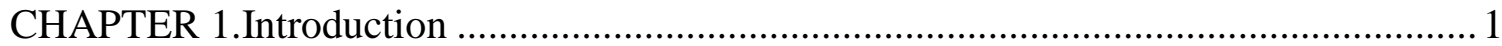

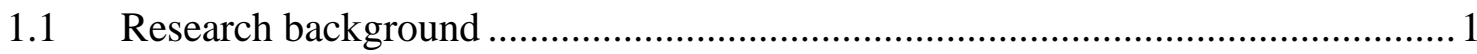

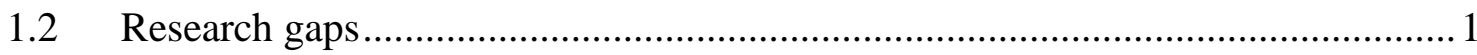

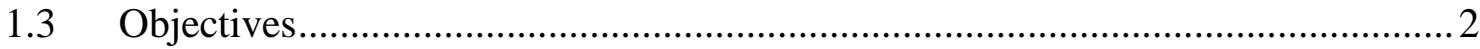

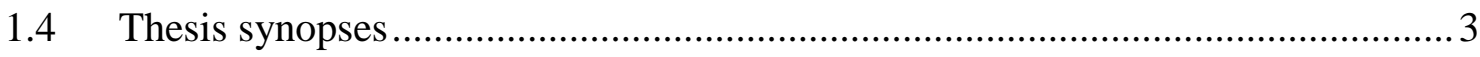

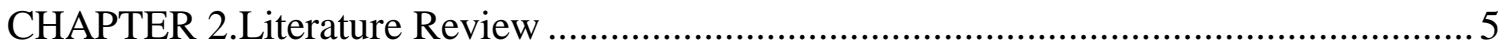

$2.1 \quad$ Nanomaterials (NMs) and applications.......................................................

2.2 NMs as emerging environmental contaminants ...............................................

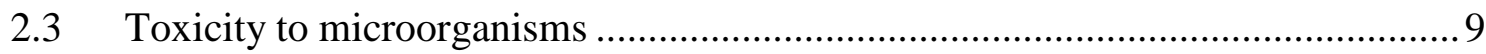

2.4 Mechanisms of toxicity of NMs to microorganisms............................................. 10

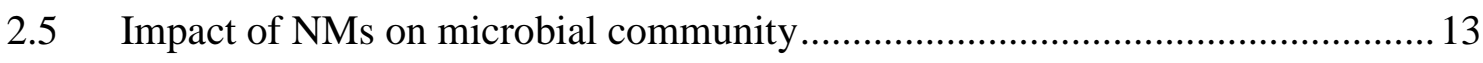

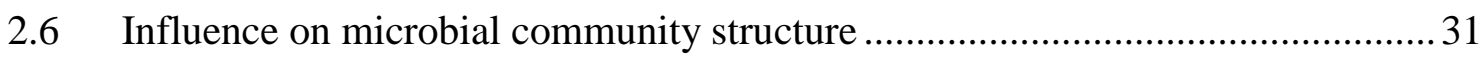

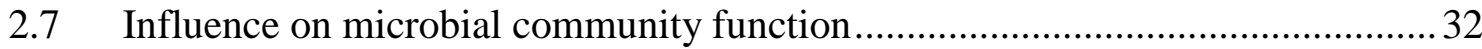

2.8 Commonly studied NMs for impacts on microbial community ………….............34

2.9 Commonly used techniques to study impacts NMs on microbial community ....35

2.10 Mechanisms of toxicity to microbial community …………................................... 37

2.11 Social behaviour: the key to community structure and function ...........................37

2.11.1 Production of communal resources .............................................................. 38

2.11.2 Cell-cell communication through quorum sensing signals ............................ 41

2.11.3 Collective antibiotic tolerance .................................................................... 42 
2.12 Summary .

CHAPTER 3.Biogenic Tellurium Nanorods Inhibit Pyoverdine Production in Pseudomonas aeruginosa.... 45

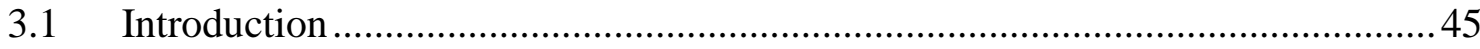

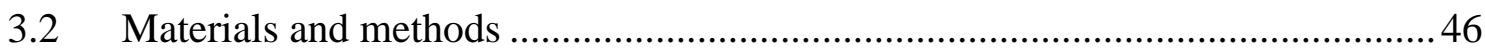

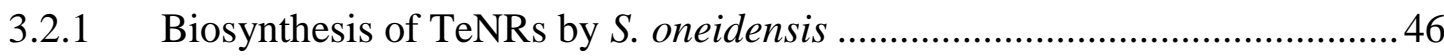

3.2.2 Inductively coupled plasma mass spectrometry …....................................4 47

3.2.3 Quantification of pyoverdine in P. aeruginosa cultures............................ 47

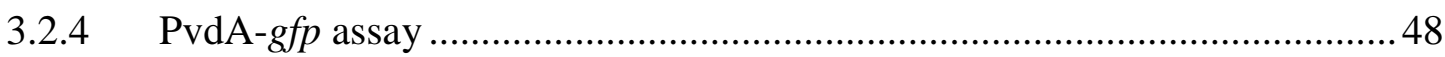

3.2.5 Quantitative Polymerase Chain Reaction (qPCR) ................................... 48

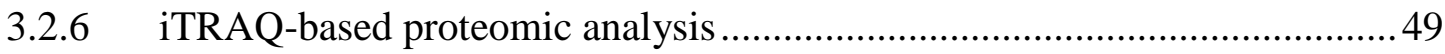

3.2.7 Transposon mutagenesis library and mutant screening ................................ 50

3.2.8 Cytotoxicity assay of biogenic TeNRs .................................................. 50

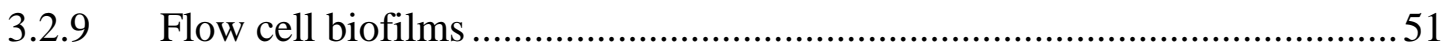

3.2.10 Confocal Laser Scanning Microscopy (CLSM) imaging ........................... 51

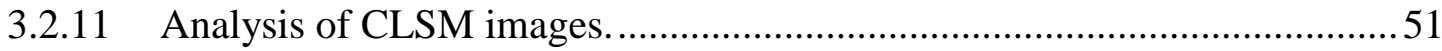

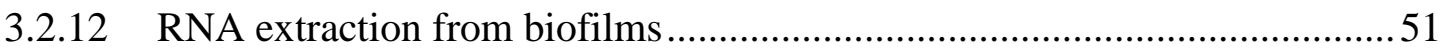

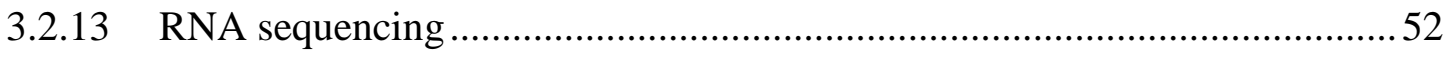

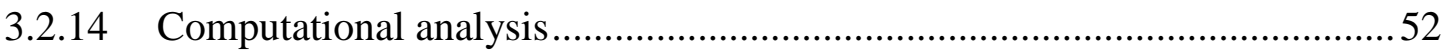

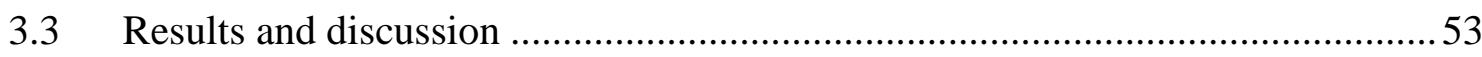

3.3.1 Biogenic TeNRs from $\mathrm{TeO}_{3}{ }^{2-}$ reduction by $S$. oneidensis ........................... 53

3.3.2 Inhibition of PVD biosynthesis by biogenic TeNRs ................................54

3.3.3 Polysaccharides, amyloids, and flagellar motility in cell-TeNRs interaction ................................................................ 58

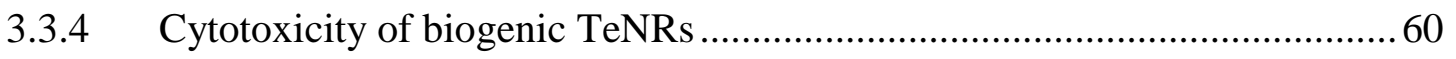

3.3.5 TeNRs reduce PVD production in P. aeruginosa biofilms ......................... 61

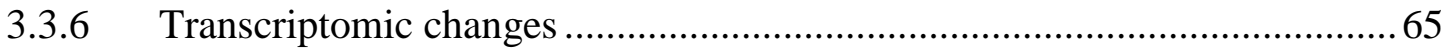

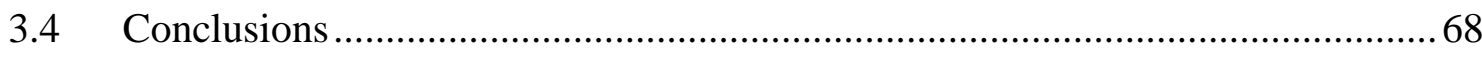

CHAPTER 4.Impact of Sublethal levels of Single-Wall Carbon Nanotubes on $P$. aeruginosa and its Environmental Implications 69

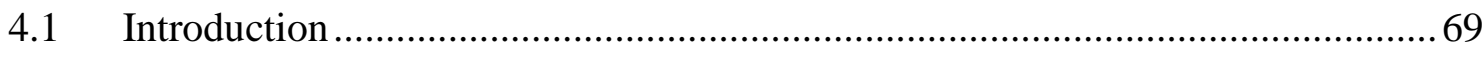

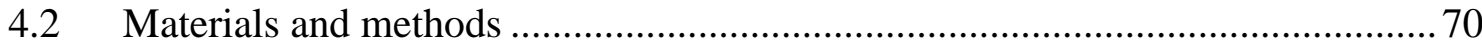




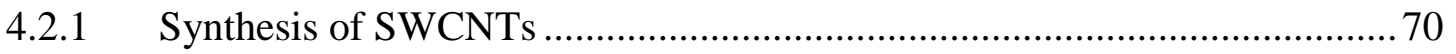

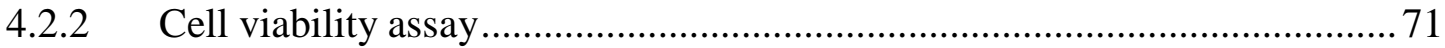

4.2.3 Quantification of PVD in P. aeruginosa cultures....................................... 71

4.2.4 Transcriptional assay for $p v d A$............................................................... 71

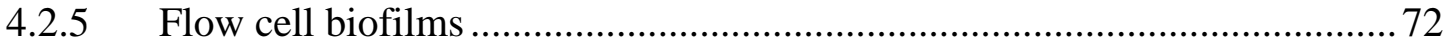

4.2.6 Confocal Laser Scanning Microscopy (CLSM) imaging ………………...... 72

4.2.7 Quantification of cell detachment .............................................................. 72

4.2.8 Inhibition of PVD biosynthesis by SWCNTs in P. fluorescence ……..........72

4.2.9 Quantitative Polymerase Chain Reaction (qPCR) ......................................... 73

4.2.10 Inductively Coupled Plasma Optical Emission Spectroscopy (ICP-OES) ...73

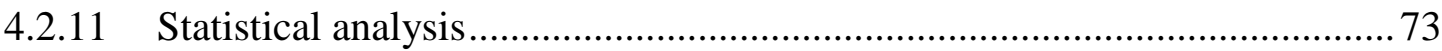

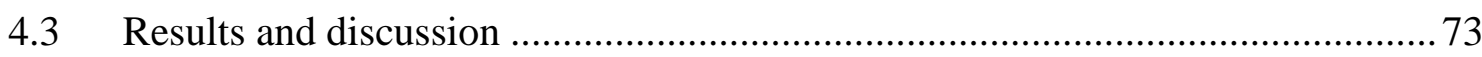

4.3.1 SWCNTs inhibit PVD production ............................................................ 73

4.3.2 SWCNTs reduce PVD production in $P$. aeruginosa biofilms ....................... 79

4.3.3 SWCNTs inhibit PVD production in other Pseudomonas species ................82

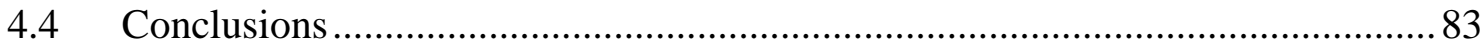

CHAPTER 5.Impacts of Nanomaterials on Bacterial Quorum Sensing: Differential Effects on Different Signals ................................................................................................ 84

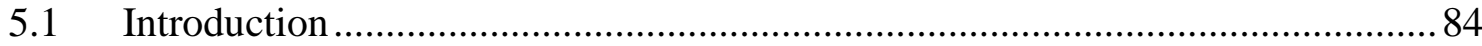

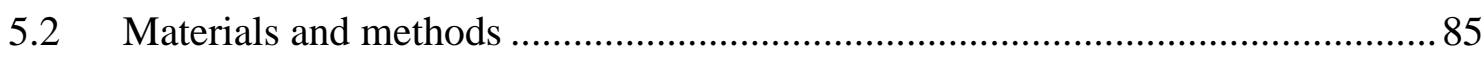

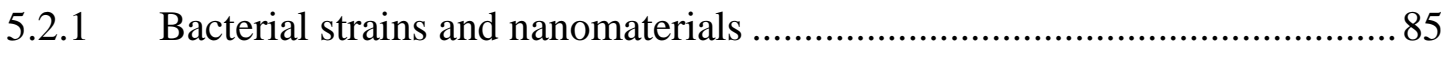

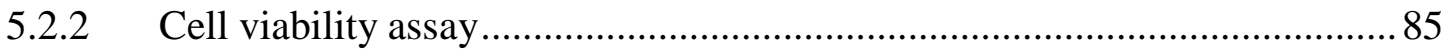

5.2.3 Inductively Coupled Plasma Mass Spectroscopy (ICP-MS) ......................... 85

5.2.4 Extraction of AHLs from bacterial cultures ................................................... 86

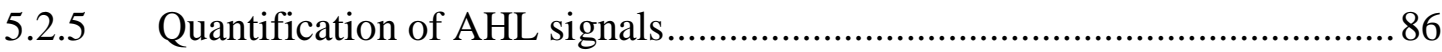

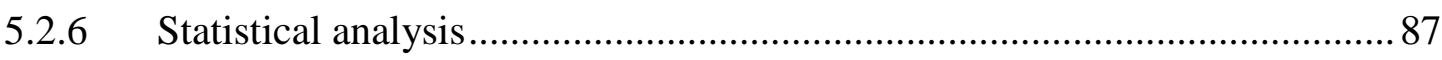

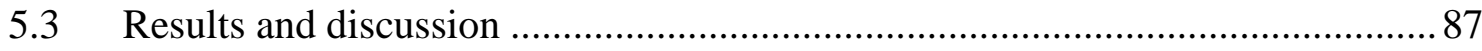

5.3.1 Determination of sub-inhibitory concentrations for AgNPs and SWCNTs . 87

5.3.2 Identification of key AHLs produced by $P$. syringae and $P$. stewartii......... 88

5.3.3 Influence of AgNPs and SWCNTs on production of different AHLs ..........89

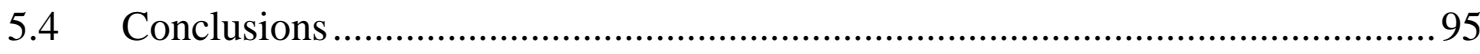


CHAPTER 6.Effect of Silver Nanoparticles on Collective Antibiotic Tolerance of Wastewater Sludge Microbial Community ............................................................... 96

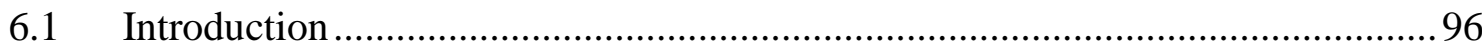

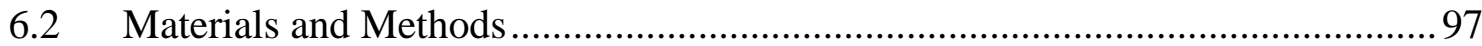

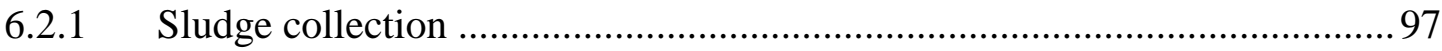

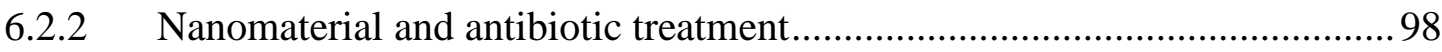

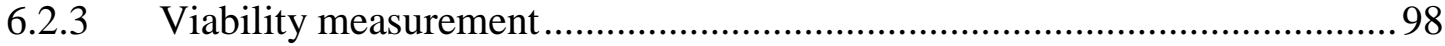

6.2.4 Phosphate measurement using ion chromatography................................ 98

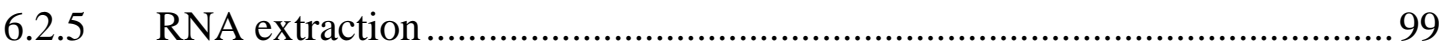

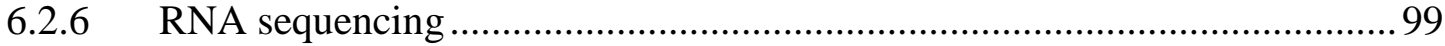

6.2.7 Sequence analysis using RiboTagger ................................................. 100

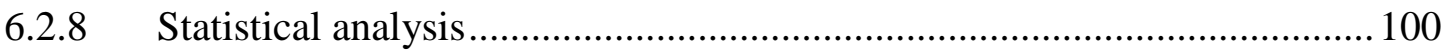

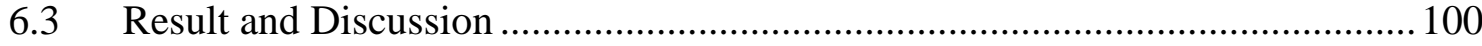

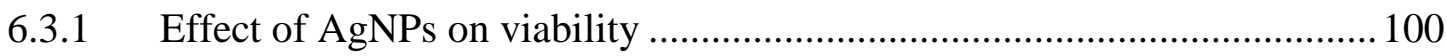

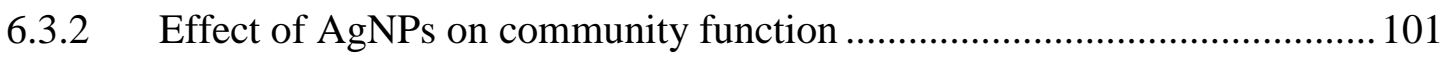

6.3.3 Effect of AgNPs on overall community composition.............................. 102

6.3.4 Effect of AgNPs on the collective antibiotic tolerance ........................... 107

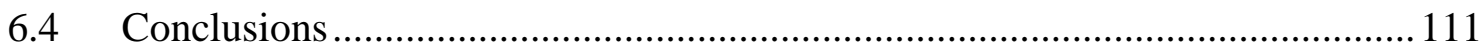

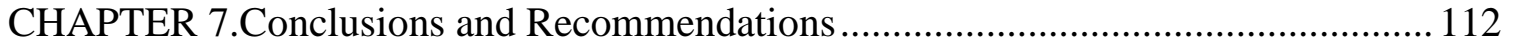

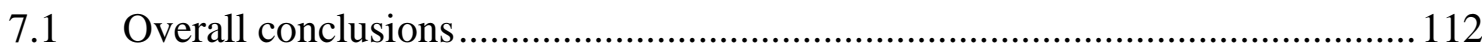

7.2 Recommendations for future research ..................................................... 113

7.2.1 Impacts of NMs on production of communal resources ........................... 113

7.2.2 Impacts of NMs on cell-to-cell communication .................................... 114

7.2.3 Impacts of NMs on collective antibiotic tolerance ................................ 114

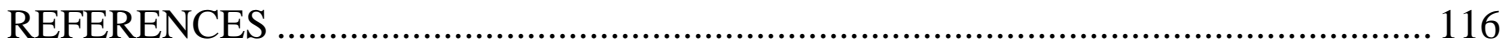




\section{ABSTRACT}

Increasing use of nanomaterials (NMs) in a wide range of consumer products has raised concerns about their impacts on natural and engineered ecosystems. NMs released into the ecosystems will potentially influence organisms at all levels of the food chain. Microorganisms are at a low trophic level and play critical roles in maintaining the health of ecosystems. Hence, the impacts of NMs on microorganisms have attracted great interests. However, majority of the toxicological studies of NMs have focused on their bactericidal (killing) and bacteriostatic (growth-inhibiting) effects. Although the concentration of NMs in the environments is expected to be much lower than those used in most nanotoxicity studies, little is known about the influences of NMs at sublethal concentrations on critical functions of microorganisms. The objective of this study was to elucidate the impact of NMs on microbial functions. Specifically, the focus was on the influence of NMs at sublethal levels on bacterial social behaviours including production of communal resources, intercellular communication, and collective antibiotic tolerance.

Cells of Pseudomonas species often produce siderophores, a group of organic compounds that facilitate iron uptake for the producers and their neighboring non-producers in microbial communities. Pyoverdine (PVD) is one of the most important siderophores produced by Pseudomonas aeruginosa and it is an important communal resource in environmental microbial communities and also a key virulence factor in establishing infections in medical settings. Tellurium nanorods (TeNRs) produced using a metalreducing bacterium Shewanella oneidensis and physicochemically synthesized single-wall carbon nanotubes (SWCNTs) significantly inhibited PVD production in P. aeruginosa. Quantitative polymerase chain reaction (qPCR) and RNA-sequencing based transcriptomics analyses revealed that the inhibition was at transcriptional level.

Quorum sensing (QS) is one of the most important signalling systems that bacteria use to coordinate cooperative behaviours. QS signalling has been shown to play a critical role in various natural and engineered bioprocesses. The acylated homoserine lactones (AHLs) is

one of the predominant QS signals used by most Gram-negative bacteria. Using Pseudomonas syringae and Pantoea stewartii as model organisms, the key AHLs 
produced by these two organisms were identified and quantified the influences of silver nanoparticles (AgNPs) and single-wall carbon nanotubes (SWCNTs) on the production of different AHLs. P. syringae mainly produced 6 short-chain AHLs, while P. stewartii produced 11 short- and long-chain AHLs. The presence of AgNPs in P. syringae cultures resulted in overall reduction of AHLs. Intriguingly, the production of most AHLs in $P$. stewartii was not significantly affected by either $0.5 \mu \mathrm{g} / \mathrm{ml}$ AgNPs or $20 \mu \mathrm{g} / \mathrm{ml}$ SWCNTs. This study reports the differential effects exhibited by NMs on the production of different signals.

The impact of AgNPs on collective antibiotic tolerance of a sludge wastewater community in terms of live/active community composition was also evaluated. There was no significant change in the community structure in response to the nanomaterial treatment. Moreover, treatment with tetracycline followed by AgNPs treatment did not result in significant change in the antibiotic tolerance profile under the testing conditions.

Taken together, these findings provide a novel insight into environmental impacts of NMs. This study will aid in comprehensive understanding the effect of NMs on various aspects of cell-cell interactions in microbial communities that often play critical roles in maintaining the health of ecosystems in various natural and engineered ecosystems. 


\section{LIST OF PUBLICATIONS}

\section{JOURNAL PAPERS}

Mohanty A, Tan CH, Cao B* (2016) Impacts of nanomaterials on bacterial quorum sensing: Differential effects on different signals. Environmental Science: Nano 3:351-356.

Mohanty A, Wei L, Lu L, Chen Y, Cao B* (2015) Impact of sublethal levels of singlewall carbon nanotubes on pyoverdine production in Pseudomonas aeruginosa and its environmental implications. Environmental Science \& Technology Letters 2(4): 105-111.

Mohanty A, Liu Y, Yang L, Cao B* (2015) Extracellular biogenic nanomaterials inhibit pyoverdine production in Pseudomonas aeruginosa: A novel insight into impacts of metal(loid)s on environmental bacteria. Applied Microbiology and Biotechnology 99(4): 1957- 1966.

Mohanty A, Wu Y, Cao B* (2014) Impacts of engineered nanomaterials on microbial community structure and function in natural and engineered ecosystems. Applied Microbiology and Biotechnology 98: 8457-8468. (Review)

Mohanty A, Kathawala MH, Zhang J, Chen WN, Loo JSC, Kjelleberg S, Yang L*, Cao $\mathrm{B}^{*}$ (2014) Biogenic tellurium nanorods as a novel antivirulence agent inhibiting pyoverdine production in Pseudomonas aeruginosa. Biotechnology and Bioengineering 111(5): 858-865.

Chen Y, Yuan M, Mohanty A, Yam JKH, Liu Y, Chua SL, Nielsen TE, Tolker-Nielsen T, Givskov M, Cao B*, Yang L* (2015) Multiple-diguanylate cyclase-coordinated regulation of pyoverdine synthesis in Pseudomonas aeruginosa. Environmental Microbiology Reports 7:498- 507.

Wu Y, Arumugam K, Tay M, Seshan H, Mohanty A, Cao B* (2015) Comparative genome analysis reveals genetic adaptation to versatile environmental conditions and importance of biofilm lifestyle in Comamonas testosteroni. Applied Microbiology and Biotechnology 99(8): 3519-3532. 


\section{BOOK CHAPTER}

Ng CK, Mohanty A, Cao B* (2014) Biofilms in Bionanotechnology: Opportunities and Challenges, in Bio-nanoparticles: Biosynthesis and Sustainable Biotechnological Implications. John Wiley \& Sons.

\section{CONFERENCE PRESENTATIONS}

249th American Chemical Society National Meeting \& Exposition, Denver, CO, USA. (Mar, 2015). Sublethal impacts of engineered and biogenic nanomaterials on social behaviour of environmental bacteria. Anee Mohanty, Bin Cao. (Oral presentation)

2013 AIChE Annual Meeting, San Francisco, USA. (Nov, 2013). Novel Biogenic Nanomaterials as Nanocatalysts and Anti-Virulence Agents. Chuan Kiat Ng, Anee Mohanty, Liang Yang and Bin Cao. (Poster presentation)

Small Science Symposium Frontiers in Nanomedicine, Singapore. (Dec, 2012). Biogenic Tellurium Nanoparticles Inhibit Pyoverdine Production in Pseudomonas aeruginosa. Anee Mohanty, Krishnakumar Sivakumar, Michael Givskov, Staffan Kjelleberg, Liang Yang and Bin Cao. (Poster presentation) 


\section{LIST OF FIGURES}

Figure 2.1 Flow chart depicting the leaching of nanomaterials to the environment from different sources and their fate in the natural environment. Reprinted with permission from (Wiesner et al., 2006).....

Figure 2.2 Mechanisms of toxicity of NMs: (A) toxicity of metal and metal oxide NMs, (B) toxicity of carbon NMs (i) Physical damages to cell membrane through insertion, extraction and "nano-knives" (ii) ROS- mediated oxidative damages to redox chains in cell membrane and intracellular components such as proteins and DNA (iii) Wrapping of NMs onto bacterial cell surface blocks nutrient access. Although the cells in this illustration are Gram-negative bacteria, the toxicity mechanisms shown here are also applicable to Gram-positive bacteria. Panel (B) was reprinted with permission from (Hegab, ElMekawy et al. 2016).

Figure 2.3 (A) Structures of different types of siderophores. Schematic representation of siderophore-mediated iron uptake in (B) Gram-negative and (C) Gram-positive bacteria. Reprinted with permission from (Saha, Saha et al. 2013) and from (Andrews, Robinson et al. 2003) for panel (A) and (B, C) respectively.

Figure 2.4 Representative bacterial QS molecules. Reprinted with permission from (Waters and Bassler 2005).

Figure 3.1 (A) Extracellular precipitates of TeNRs (black) in a suspension of cells (blue) visualized by overlay of bright-field and fluorescence imaging. Cells were stained with DAPI. (B) TEM image and (C) EDX spectrum of the biogenic TeNRs.

Figure 3.2 Influence of TeNRs $(0,25,50,100 \mu \mathrm{g} / \mathrm{ml})$ on PVD fluorescence (normalized by cell density) in $P$. aeruginosa PAO1 cultures growing in ABTGC media in the exponential $(6 \mathrm{~h})$ and stationary phase of growth $(12 \mathrm{~h})$. Data shown are mean \pm standard deviation $(\mathrm{n}=3)$.

Figure 3.3 (a) Influence of TeNRs $(0,25,50,100 \mu \mathrm{g} / \mathrm{ml})$ on GFP fluorescence (normalized by cell density) in $P$. aeruginosa reporter strain $p v d A$-gfp growing in ABTGC media at the exponential phase $(6 \mathrm{~h})$ and stationary phase $(12 \mathrm{~h})$ of growth. (b) Influence of TeNRs $(50 \mu \mathrm{g} / \mathrm{ml})$ on the expression level of key genes involved in PVD production and uptake. Values were normalized to the housekeeping gene $t s f$. PvdS: a transcriptional regulator; PvdE: an export $\mathrm{ABC}$ transporter to transport PVD precursors across the inner membrane; PvdN and PvdP: periplasmic enzymes involved in chromophore formation; PvdQ: a periplasmic enzyme for removal of fatty acid chains from PVD precursors; PvdT: a subunit of the ATP-dependent efflux pump for PVD secretion; FpvA: an outer membrane transporter for import of ferri-pyoverdine. Data shown are mean \pm standard deviation $(n=3)$.

Figure 3.4 PVD fluorescence (normalized by cell density) in $12 \mathrm{~h}$ cultures of $P$.

aeruginosa PAO1 wild type and mutants lacking polysaccharides or amyloids in ABTGC media with $(50 \mu \mathrm{g} / \mathrm{ml})$ or without TeNRs. Data shown are mean \pm standard deviation $(n=3)$. 
Figure 3.5 PVD fluorescence (normalized by cell density) in $12 \mathrm{~h}$ cultures of $P$. aeruginosa $\mathrm{PAO} 1$ wild type and motility-deficient mutants $\Delta m o t B$ and $\Delta f l i F$ in ABTGC media with $(50 \mu \mathrm{g} / \mathrm{ml})$ or without TeNRs. Data shown are mean \pm standard deviation $(\mathrm{n}=3)$.

Figure 3.6 CCK-8 viability assay for RAW cells and BEAS-2B cells in the presence of TeNRs at different concentrations: $0,25,50,100 \mu \mathrm{g} / \mathrm{ml}$. Metabolic rate is shown as the dehydrogenase activity which reduces WST-8 salt to formazon dye. Untreated cells were used a controls. Data shown are mean \pm standard deviation $(n=3)$.

Figure 3.7 Distribution of PVD in P. aeruginosa biofilms. Biofilms were grown using GFP-labeled $P$. aeruginosa for 5 days in modified ABTG medium. CLSM images contain top-down views (x-y planes) and side views (x-z, y-z planes). Scale bar $20 \mu \mathrm{m}$. Results are representative of three separate experiments. 62

Figure 3.8 Biogenic TeNRs reduce PVD production in mature $P$. aeruginosa biofilms. $\mathrm{a}-\mathrm{b}$ CLSM images of 5-day-old GFP-labeled $P$. aeruginosa biofilms upon exposure to TeNRs $(50 \mu \mathrm{g} / \mathrm{ml})$ for $12 \mathrm{~h}(\mathrm{~A})$ and $24 \mathrm{~h}(\mathrm{~B})$. The control biofilms were grown in parallel with the TeNR-treated biofilms in different flow cell channels. Controls in a and $\mathrm{b}$ were biofilms grown in the absence of TeNRs for $144 \mathrm{~h}(120 \mathrm{~h}+12 \mathrm{~h})$ and $154 \mathrm{~h}(120 \mathrm{~h}+24 \mathrm{~h})$, respectively. C-D Biovolume ratio of PVD-producing biomass to total biofilm biomass, indicating the amount of PVD in unit biovolume of the biofilms. CLSM images contain top-down views (x-y planes) and side views (x-z, y-z planes). Scale bar $20 \mu \mathrm{m}$. Results are representative of three separate experiments.

Figure 3.9 (A) Cell detachment rate from 5-day-old $P$. aeruginosa biofilms during 24-h further growth in modified ABTG medium with or without TeNRs $(50 \mu \mathrm{g} / \mathrm{ml})$. Experiments were carried out with at least three replicates for each condition. Paired Student's t test, $\mathrm{p}=0.145$. (B) PVD fluorescence in effluents from 5-day-old $P$. aeruginosa biofilms during 24-h further growth in modified ABTG medium with or without TeNRs $(50 \mu \mathrm{g} / \mathrm{ml})$. Experiments were carried out in triplicate.

Figure 4.1 Influence of SWCNTs on PVD fluorescence (normalized by cell density) in $P$. aeruginosa cultures growing in ABTGC medium. Data shown are means \pm the standard deviation $(\mathrm{n}=3)$. A two-way ANOVA shows that no significant effect from time or timeconcentration interaction can be found (both $p>0.9995$ ), while the effect of concentration is significant $(p<0.0005)$. .74

Figure 4.2 Influence of SWCNTs on GFP fluorescence in $P$. aeruginosa reporter strain $p v d A$-gfp growing in ABTGC medium. Data shown are means \pm the standard deviation (n $=3$ ). A two-way ANOVA shows that no significant effect from time or the timeconcentration interaction can be found (both $p>0.9995$ ), while the effect of concentration is significant $(p<0.0005)$. .76

Figure 4.3 Influence of SWCNTs $(40 \mu \mathrm{g} / \mathrm{ml})$ on the expression level of key genes involved in PVD production at $9 \mathrm{~h}$ in the midexponential growth phase. Values were normalized to the housekeeping gene $t s f$. The $\mathrm{C}_{\mathrm{T}}$ values for $t s f$ remained unchanged for the control and the treated cells (24.68 \pm 0.92 and $23.84 \pm 0.30$, respectively), suggesting that the expression of $t s f$ is not affected by SWCNTs. Abbreviations: PvdS, transcriptional regulator; PvdE, export $\mathrm{ABC}$ transporter to transport PVD precursors across the inner 
membrane; PvdN, periplasmic enzymes involved in chromophore formation; PvdT, subunit of the ATP-dependent efflux pump for PVD secretion; FpvA, outer membrane transporter to import ferri-pyoverdine; PvdA, lysine/ornithine $N$-monooxygenase. Data shown are means \pm the standard deviation $(n=3)$. Statistical significance determined by a paired Student's $t$ test $(p<0.001)$.

Figure 4.4 The expression level of key quorum sensing genes $p q s A$, rhlA and lasA in the absence or presence of SWCNTs $(40 \mu \mathrm{g} / \mathrm{ml})$ as revealed by qPCR analysis. Values were normalized to the housekeeping gene $r p o D$. Data shown are mean \pm standard deviation $(\mathrm{n}=3)$.

Figure 4.5 Mature biofilm structure showing PVD expression. Biofilms were grown using GFP-labeled $P$. aeruginosa for 4 days in M9 medium. CLSM images contain top-down views (x-y planes) and side views (x-z, y-z planes). Scale bar $10 \mu \mathrm{m}$. Results are representative of three separate experiment.

Figure 4.6 CLSM images of mature $P$. aeruginosa biofilms upon exposure to SWCNTs $(20 \mu \mathrm{g} / \mathrm{ml}$ ) for (A) 12, (B) 24, and (C) $48 \mathrm{~h}$. The control biofilms were grown in parallel with the SWCNT-treated biofilms. Controls in panels A-C were biofilms grown in the absence of SWCNTs for $108 \mathrm{~h}(96 \mathrm{~h}+12 \mathrm{~h}), 120 \mathrm{~h}(96 \mathrm{~h}+24 \mathrm{~h})$, and $144 \mathrm{~h}(96 \mathrm{~h}+48 \mathrm{~h})$, respectively. (D) Biovolume ratio of PVD-producing biomass to total biofilm biomass, indicating the amount of PVD in the unit biovolume of the biofilms. CLSM images contain top-down views ( $x-y$ planes) and side views ( $x-z$ and $y-z$ planes). The scale bar is $10 \mu \mathrm{m}$. Results are representative of three separate experiments.

Figure 4.7 (A) Cell detachment and (B) PVD fluorescence in effluents from mature $P$. aeruginosa biofilms in the absence or presence of SWCNTs $(20 \mu \mathrm{g} / \mathrm{ml})$. Experiments were conducted in triplicate.

Figure 4.8 Concentration-dependent inhibitory effect of SWCNTs on PVD production in $P$. fluorescence. Relative fluorescence intensity (normalized by $\mathrm{OD}_{600}$ ) indicates the amount of PVD produced in the cultures.

Figure 5.1 (A) Total ion chromatogram of a mixture of 13 standard AHLs (spiked into the sample matrix). (B) Profile of AHLs produced by P. syringae. (C) Profile of AHLs produced by $P$. stewartii. For a better clarity, the peaks for certain AHL signals with low abundance are shown with a $10 \times(*), 100 \times(* *)$, or $1000 \times(* * *)$ amplification.

Figure 5.2 Influence of AgNPs $(0.5 \mu \mathrm{g} / \mathrm{ml})$ and SWCNTs $(20 \mu \mathrm{g} / \mathrm{ml})$ on the production of different AHLs by P. syringae. The identity and quantity of individual AHLs present in each sample were compared with the multiple reaction monitoring profiles of 13 standard AHLs. A total of 6 AHLs are shown (the remaining 7 AHLs were below the detection limit). $* * * p<0.001, * * p<0.01, * p<0.05)$. Error bars are defined as standard error of the mean $(n=6)$.the dotted line represents the limit of detection. 91

Figure 5.3 Influence of AgNPs $(0.5 \mu \mathrm{g} / \mathrm{ml})$ and SWCNTs $(20 \mu \mathrm{g} / \mathrm{ml})$ on the production of different AHLs by P. stewartii. The identity and quantity of individual AHLs present in each sample were compared with the multiple reaction monitoring profiles of 13 standard AHLs. A total of 11 AHLs are shown (the remaining 2 AHLs were below the detection limit). $(* * p<0.01)$ Error bars are defined as standard error of the mean $(\mathrm{n}=6)$. 
Figure 5.4 Overall AHL profiles in (A) P. syringae and (B) P. stewartii by nonmetric Multidimensional Scaling (nMDS) in the nanomaterial-treated $(0.5 \mu \mathrm{g} / \mathrm{ml} \mathrm{AgNPs} \mathrm{or} 20$ $\mu \mathrm{g} / \mathrm{ml} \mathrm{SWCNTs}$ ) and no-treatment control conditions. Experiments were conducted in 6 replicates.

Figure 6.1 Viability of sludge biomass over time was assessed through Live/Dead staining. The total biovolume of viable (live) and non-viable (dead) communities were calculated from CLSM images. Ratio of live cells biovolume to total biovolume represents the $\%$ live cells. Error bars are defined as standard error of mean $(n=8)$. 101

Figure 6.2 Phosphate concentration was measured in the spent media at every $24 \mathrm{~h}$ interval. A decreasing trend is observed across all the group over time. Error bars are defined as standard error of mean ( $n=3$, biological replicates).

Figure 6.3 (A) Shannon index (B) Simpson index. Mean value of diversity for multiple OTUs were compared for seed culture and different groups ( $\mathrm{Ctrl}, \mathrm{Ag}^{+}$and $\left.\mathrm{AgNP}\right)$ after $144 \mathrm{~h}$ Significant differences are indicated as follows: $* * * p<0.001, * * * * p<0.0001$. Error bars defined as standard error of mean ( $n=3$, biological replicates).

Figure 6.4 Nonmetric multidimensional scaling (nMDS) based on rRNA sequences compares the seed culture and different groups (Ctrl, Ag+ and AgNP) after $144 \mathrm{~h}$. The seed culture form a separate cluster compared to the rest of the samples.

Figure 6.5 Bar chart displaying the community composition of each sample, including the 100 most abundant taxa in all samples.

Figure 6.6 Viability of sludge biomass after tetracycline treatment was assessed through Live/Dead staining. The total biovolume of viable (live) and non-viable (dead) communities were calculated from CLSM images. Ratio of live cells biovolume to total biovolume represents the \% live cells. Error bars are defined as standard error of mean $(n=8)$.

Figure 6.7 Nonmetric multidimensional scaling (nMDS) based on rRNA sequences compares the three groups (Ctrl, Ag+ and AgNP) before and after tetracycline treatment. Three distinct clusters are: pretreatment samples, the ethanol and tetracycline treated samples.

Figure 6.8 (A) Shannon index (B) Simpson index. Mean value of diversity of multiple OTUs were compared for prior treatment, ethanol treatment and tetracycline treatment for all the three groups (Ctrl, Ag+ and AgNP). Significant differences are indicated as follows: $* p<0.05, * * p<0.01$. Error bars are defined as standard error of mean $(n=3$, biological replicates).

Figure 6.9 Heatmap of top 10 most abundant taxa. Each column in the heat-map represents one sample, while each row represents a taxa. The color intensity of the panel is abundance as percentage of the total community. 


\section{LIST OF TABLES}

Table 2.1 Summary of recent research work (2008 onwards) on influence of NMs on microbial communities. 14

Table 3.1 PCR primer details 49

Table 3.2 Influence of TeNRs on growth of $P$. aeruginosa PAO1 in ABTGC media at $37^{\circ} \mathrm{C}$. Specific growth rate was determined from $\mu=\mathrm{d} \ln \left(\mathrm{OD}_{600}\right) / \mathrm{dt}$, where $\mathrm{OD}_{600}$ was the optical density at a wavelength of $600 \mathrm{~nm}$. Values are means \pm standard deviation $(\mathrm{n}=3)$.

Table 3.3 Down-regulation of proteins involved in siderophore production and uptake in P. aeruginosa PAO1 in the presence of biogenic TeNRs $(50 \mu \mathrm{g} / \mathrm{ml})$. ${ }^{a}$ The percentage of matching amino acids from identified peptides divided by the total number of amino acids in the sequence; ${ }^{\text {b}}$ The ratio of protein production level in biogenic TeNRs-incubated cells to control cells without TeNRs.

Table 3.4 Siderophore related genes that are down regulated in treated samples compared to control.

Table 4.1 Density of viable cells in P. aeruginosa cultures with or without SWCNTs. Data shown are mean \pm standard deviation $(\mathrm{n}=8)$.

Table 5.1 Growth of $P$. syringae and $P$. stewartii cells in LB medium in the absence (control) and presence of $0.5 \mu \mathrm{g} / \mathrm{ml}$ AgNPs or $20 \mu \mathrm{g} / \mathrm{ml} \mathrm{SWCNTs.} \mathrm{Data} \mathrm{shown} \mathrm{are} \mathrm{mean}$ \pm standard deviation $(\mathrm{n}=5)$. 


\section{LIST OF ABBREVIATIONS}

\begin{tabular}{|c|c|c|c|}
\hline$\times \mathbf{g}$ & g-force in centrifuge & & \\
\hline$\mu \mathrm{g}$ & Microgram & & \\
\hline$\mu \mathbf{L}$ & Microlitre & & \\
\hline$\mu \mathbf{M}$ & Micromolar concentration & & \\
\hline AgNPs & Silver nanoparticles & & \\
\hline AHL & Acyl homoserine lactone & & \\
\hline ATCC & American type culture collection & & \\
\hline bp & Base-pair & & \\
\hline c-di-GMP & Cyclic di-guanylate monophosphate & & \\
\hline CFU & Colony forming unit & & \\
\hline CLSM & Confocal laser scanning microscopy & & \\
\hline CNTs & Carbon nanotubes & & \\
\hline DAPI & 4', 6-diamidino-2-phenylindole & & \\
\hline DNA & Deoxyribonucleic acid & & \\
\hline eDNA & Extracellular deoxyribonucleic acid & & \\
\hline ENMs & Engineered nanomaterials & & \\
\hline EPS & Extracellular polymeric substances & & \\
\hline g & Gram & & \\
\hline GFP & Green fluorescent protein & & \\
\hline $\mathbf{h}$ & Time in hour & & \\
\hline ICP-OES & $\begin{array}{l}\text { Inductively coupled Plasma } \\
\text { Spectroscopy }\end{array}$ & Optical & Emission \\
\hline $\mathbf{L}$ & Litre & & \\
\hline $\mathbf{L B}$ & Luria Bertani medium & & \\
\hline
\end{tabular}




\begin{tabular}{|c|c|}
\hline M9 & M9 minimal media \\
\hline mg & Milligram \\
\hline $\min$ & Time in minute \\
\hline $\mathbf{m L}$ & Millilitre \\
\hline $\mathbf{m M}$ & Millimolar concentration \\
\hline MWCNTS & Multi-wall carbon nanotubes \\
\hline NCBI & National Center for Biotechnology Information \\
\hline nm & Nanometre \\
\hline NMs & Nanomaterials \\
\hline${ }^{\circ} \mathbf{C}$ & Degree Celcius \\
\hline OD & Optical density \\
\hline PBS & Phosphate buffer saline \\
\hline PCR & Polymerase chain reaction \\
\hline PVD & Pyoverdine \\
\hline q-PCR & Quantitative polymerase chain reaction \\
\hline RNA & Ribonucleic Acids \\
\hline RPKM & Reads Per Kilobase of transcript per Million mapped reads \\
\hline rpm & Revolutions per minute \\
\hline rRNA & Ribosomal Ribonucleic Acids \\
\hline SWCNTs & Single-wall carbon nanotubes \\
\hline
\end{tabular}




\section{CHAPTER 1. Introduction}

\subsection{Research background}

Nanomaterials (NMs) have a wide range of applications in biology, medicine, agriculture, electronics, environmental monitoring, and consumer goods (Murty, Shankar et al. 2013). The increasing use of products containing NMs over the past decade has posed a great concern of their negative impacts to the environment. NMs can enter the environment through atmospheric emission or as solid or liquid waste from the production facilities, contaminating soils, surface water, and groundwater. Considering the potential release of NMs into the environment, assessing their risks to the health of the ecosystem has been the topic of interest in environmental science and engineering.

The NMs in the environment will potentially impact organisms at all levels of the food chain. Over the past decade, in vivo and in vitro nanotoxicity studies have been conducted to evaluate the toxicity of various NMs to various living organisms. The impacts of NMs exerted on bacteria are of particular interest because being at the low trophic level they will affect NMs fate, including transfer to higher trophic levels through biomagnification. Furthermore, bacteria play critical roles like nutrient recycling in natural and engineered ecosystems (Peralta-Videa, Zhao et al. 2011). There are plethora of evidences showing many NMs exhibit bactericidal (killing) and bacteriostatic (growth-inhibiting) effects through damaging cell membrane, denaturing proteins and nucleic acids, and generating oxidative stress (Klaine, Alvarez et al. 2008, Neal 2008).

\subsection{Research gaps}

The toxicity of NMs in terms of bactericidal or bacteriostatic effect has mostly been concentration dependent (Rai, Yadav et al. 2009, Liu, Zeng et al. 2011). However, the discharge concentrations of NMs in the environments is expected to be much lower than those used in majority of nanotoxicity studies and environmentally relevant concentration is expected to be mostly sublethal (see Section 2.2). How NMs at sublethal concentrations affect environmental bacteria in terms of functions is largely unexplored, which has been 
recently recognized as a critical gap toward a comprehensive understanding of the impacts of NMs on ecosystems. In various natural and engineered environments, microorganisms are often present as polymicrobial communities in which cells actively interact with each other (Keller and Surette 2006). Microorganisms in communities are functionally linked to each other and any changes in functions of specific bacteria may cause re-structuring of the whole microbial communities and affect the ecosystems (see Section 2.5). One of the most important aspects influencing the function of an ecosystem is the interaction between individual cells, i.e., bacterial social behaviour (Crespi 2001). These social behaviours are partly governed by production of communal resources such as siderophores, quorum sensing signals and other secondary metabolites which are key to cell-cell interaction in a microbial community (West, Griffin et al. 2006, Hibbing, Fuqua et al. 2009) (see Section 2.11). Therefore it is quite plausible to assume that any alteration in the production of these communal resources can possibly alter the structure and function of the whole community in turn affecting the key ecological functions performed by these microbial communities. At sublethal concentrations, NMs may affect the community profile by affecting the production of communal resources and cell-cell interaction. Microbial communities in natural and engineered ecosystems are the drivers of key processes e.g., bioremediation, biogeochemical cycling and waste water treatment (Wagner and Loy 2002, Narihiro and Sekiguchi 2007, Van Der Heijden, Bardgett et al. 2008, Ahmed, Cao et al. 2012). Hence, it becomes very important to study the sublethal effects of different NMs on social behaviour of microorganisms.

\subsection{Objectives}

This study aims at exploring the sublethal impacts of NMs on the social behaviour of environmental bacteria. The specific tasks include:

(i) Investigate the impacts of NMs on the production of communal resources, i.e., microbial product that is beneficial to the community, by environmental bacteria. Specifically, the impacts of NMs, i.e., Tellurium nanorods (TeNRs) and single-wall carbon nanotubes (SWCNTs), on the production of siderophore by Pseudomonas aeruginosa will be explored. 
(ii) Explore the impacts of NMs on cell-cell communication through quorum sensing signals. Specifically, the effect of two types of NMs i.e., Silver nanoparticles (AgNPs) and SWCNTs, on the production of quorum sensing signals in two model gram negative bacteria Pseudomonas syringae and Pantoea stewartii will be tested.

(iii) Determine the effect of NMs on overall structure of microbial community and to study the impact on antibiotic tolerance. AgNPs will be used as model NM and its effect on the antibiotic tolerance of sludge microbial community will be assessed using transcriptomics approach.

\subsection{Thesis synopses}

Chapter 1 provides a brief background about NMs and their potential toxicity on microorganisms. This chapter emphasizes the need for more comprehensive and in depth understanding of sublethal impact of NMs on social behaviour of bacteria. The objective and scope of the work is described in detail.

Chapter 2 has detailed literature review for the whole thesis. This chapter summarizes and discusses recent research work on the impacts of NMs on microbial communities' structure and function in natural and engineered ecosystems, with an emphasis on their influences on the social behaviour of microorganisms at sublethal concentrations.

Chapter 3 presents the effect of biogenic tellurium nanorods on siderophore production in a model environmental bacteria $P$. aeruginosa both in planktonic as well as biofilm mode of life.

Chapter 4 presents the effect of engineered single-wall carbon nanotubes (SWCNTs) on pyoverdine production in a model environmental bacteria $P$. aeruginosa both in planktonic as well as biofilm mode of life.

Chapter 5 reports the impact of SWCNTs and silver nanoparticles (AgNPs) on quorum sensing signal production in model Gram-negative bacteria $P$. syringae and $P$. stewartii. 
Chapter 6 illustrates the impact of AgNP on wastewater treatment community structure and the effect of nanomaterial treatment on the collective antibiotic tolerance of the community.

Chapter 7 provides a summary of the thesis work and proposes some future recommendations 


\section{CHAPTER 2. Literature Review}

A portion of this chapter has been published as Mohanty A, Wu Y, Cao B* (2014) Impacts of engineered nanomaterials on microbial community structure and function in natural and engineered ecosystems. Applied Microbiology and Biotechnology 98: 8457-8468. Permission has been granted by the licensed content publisher "Springer Science" to use the published content as a chapter in this thesis.

\subsection{Nanomaterials (NMs) and applications}

Nanomaterials (NMs) are man-made materials with at least one dimension of nanometer size (less than $100 \mathrm{~nm}$ ). The physiochemical properties of NMs differ markedly from their larger counterparts because of a higher surface to volume ratio, which results in a higher reactivity and unique physicochemical properties (Roduner 2006). The physical, chemical, and mechanical properties manifested by NMs have been exploited for various applications in different industries including electronics, healthcare, water purification, and food packaging (Murty, Shankar et al. 2013). According to a recent survey there are over 1000 NM-enabled consumer products produced by 500 companies ranging over 20 different countries (Rejeski. 2009). The most commonly used NMs in consumer products in the order of their occurrences are silver which is present in highest number of product (259 products) second is carbon based nanomaterials (82), followed by zinc (including zinc oxide) (30), silica (35), titanium (including titanium dioxide) (50), and gold (27) (Weinberg, Galyean et al. 2011). Apart from these commonly used NMs there are many others metals, metal oxide, carbon nanostructures that are present in different consumer products.

Elaborating on the application in different fields, electronics is arguably the field where NMs have brought revolution in miniaturization and increased efficiency of nano electronics system. NMs are far more superior in respect to their optical properties, higher quantum efficiency and more stable to photobleaching. Moreover their optical properties are highly dependent on size. Owing to all these properties an entire gamut of nanosensors are currently being used (Wang 2005). There have been wide ranging application in healthcare industry like diagnosis, therapy and prevention (Lanone and Boczkowski 
2006). Because of their small size they can easily be taken up by the cells, but size is one of the many special features of nanoparticles. To list out few applications, they are used as bioconjugates for drug delivery, also used in biodetection of pathogens, fluorescent biological labels, useful in probing DNA and protein structures, used in MRI as contrast enhancers, in tissue engineering as scaffold material, nanomaterial coatings on implants to prevent microbial biofilm formation (Salata 2004, Lanone and Boczkowski 2006). NMs are also contributing in many ways to water purification and environment monitoring as nano-enhanced membranes are used for desalination and water purification ( $\mathrm{Li}$, Mahendra et al. 2008, Hoek and Ghosh 2009, Buonomenna 2013, Qu, Alvarez et al. 2013), currently nanomaterial based sensors are being used to monitor water quality against bacteria, heavy metals and toxins (Andreescu, Njagi et al. 2009). Other sectors where NMs find their application includes cosmetics and consumer goods, sunscreens are containing titanium dioxide or zinc oxide particles to prevent skin burn (www.nanotechproject.org/consumerproducts , $\mathrm{Mu}$ and Sprando 2010). In food and agriculture industry also NMs are used as nanocomposites for food packaging, antimicrobial nano-emulsions in the decontamination of food equipment, packaging or food processing, also as sensors to monitor pathogens (Weiss, Takhistov et al. 2006, Sozer and Kokini 2009, Duncan 2011), in agriculture they are also used in form of nano-porous zeolites for slow and efficient release of water and fertilisers for plants, NMs are also part of food nutrients and drugs for livestock (Srilatha 2011). From last few years NMs are increasingly being used in construction industry. The various usage includes mixing with reinforcement of concrete to increase the mechanical strength, to produce self-cleaning glass, impregnation of nano- $\mathrm{ZnO},-\mathrm{Ag}$ or $-\mathrm{TiO}_{2}$ particles in wood can prevent their decay as these materials are known to have antibacterial properties (Larsen-Basse, Chong et al. 2006). NMs are also being incorporated into textile to make fabrics which can be stain free, water repellent or attractant and especially to add antibacterial property (Wong, Yuen et al. 2006). Other major application includes making fouling resistant marine paint, in energy sector to make solar cell and hydrogen storage devices. 


\subsection{NMs as emerging environmental contaminants}

NMs can be released into the environment during different stages of the product life cycle, for example, manufacturing, waste disposal, and weathering of the product containing NMs. NMs can enter the environment through point sources such as manufacturing factories or landfills, and non-point sources including the attrition of NMs from products (Wiesner, Lowry et al. 2006) (Figure 2.1). For example, release of silver nanomaterials from washing of textiles (Lorenz, Windler et al. 2012), release of $\mathrm{TiO}_{2}$ nanomaterials from weathering of paints (Kaegi, Sinnet et al. 2010), and release of NMs from products like spray, sunscreens or cosmetics often occur. Ultimately the NMs released from all the above sources will end up in the air, water and soil through different routes. The above mentioned sources are few direct sources of NMs contamination in environment. Moreover there are several indirect sources of NMs contamination as well. Anthropogenic activities such as mining, smelting, and industrial use have caused serious problems of metal and metal(loid) pollution in nearly every country in the world. The natural and engineered ecosystems are often direct or indirect recipients of toxic metal and metal(loid)s (e.g., $\mathrm{Cu}, \mathrm{Zn}, \mathrm{Cr}, \mathrm{Te}, \mathrm{Se}$, and $\mathrm{As}$ ). A wide range of microorganisms in the ecosystems will potentially come in contact with these pollutants and are capable of transforming metals and metal(loid)s into relatively stable and less toxic NMs, which has been generally considered as one detoxification mechanism (Han and $\mathrm{Gu}$ 2010, Ng, Sivakumar et al. 2013). For example, uranyl $\left(\mathrm{UO}_{2}{ }^{2-}\right)$ can be reduced by certain bacteria to form extracellular uraninite $\left(\mathrm{UO}_{2}\right)$ nanoparticles (Suzuki, Kelly et al. 2002, Schofield, Veeramani et al. 2008, Cao, Ahmed et al. 2011). Although the bulk concentration of the biogenic NMs in the environment could be as low as ng per $\mathrm{kg}$ of water or sediment samples, local concentration of the biogenic NMs in microenvironments at the micron scale may be significantly higher because of the highly heterogeneous distribution of nanomaterials in biological matrices, particularly in biological systems with a high cell density such as microbial biofilms (Habimana, Steenkeste et al. 2011, Peulen and Wilkinson 2011). The potential influence of these in situ generated biogenic NMs in the environment to environmental organisms are largely unexplored. 
During the transport of these NMs in the environment, their physicochemical properties might change drastically because of photochemical transformation, oxidation/reduction, adsorption, combustion, precipitation, aggregation, and biotransformation etc. (Nowack, Ranville et al. 2012).

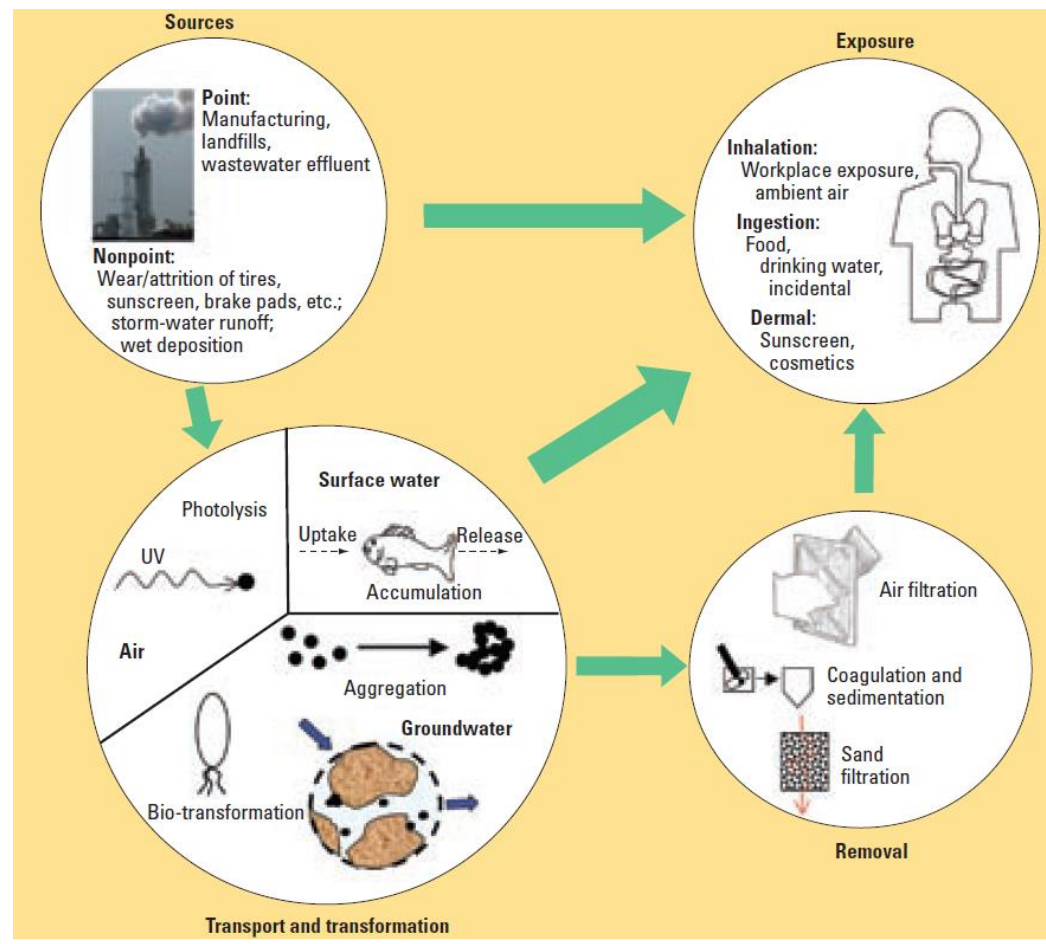

Figure 2.1 Flow chart depicting the leaching of nanomaterials to the environment from different sources and their fate in the natural environment. Reprinted with permission from (Wiesner et al., 2006).

To date, there have been no accurate detection and quantification methods for NMs in environmental samples. However, there have been many attempts to model the behaviour and concentration of these NMs in environment. Various models have been proposed to assess the environmental fate of the NMs but all vary to a wide extent in the methodologies, assumption and criteria used (Gottschalk and Nowack 2011). These modeling studies to predict environmental concentration acts as a valuable substitute in absence of actual measurement techniques.

Over the past decade, the toxicity of NMs has been widely studied. Toxicity of NMs have been tested with diverse prokaryotic and eukaryotic cells including microorganisms (Suresh, Pelletier et al. 2013), plants (Lin and Xing 2007, Miralles, Church et al. 2012), 
humans (Oberdörster, Maynard et al. 2005, Sharifi, Behzadi et al. 2012). NMs have also shown toxicity to aquatic organisms (Baun, Hartmann et al. 2008, Griffitt, Luo et al. 2008), crustaceans (Heinlaan, Ivask et al. 2008), nematodes(Ma, Bertsch et al. 2009). It is getting increasing clear that NMs are toxic to different organisms in various levels of food chains. Thus for risk assessment and regulatory purposes, a comprehensive understanding of ecotoxicological effect of NMs is required at several levels i.e., single organisms, communities and higher organisms (Kahru and Dubourguier 2010).

\subsection{Toxicity to microorganisms}

Microorganisms are ubiquitous in natural and engineered environments and they constitute about one third of earth's total biomass (Ash, Foley et al. 2008). Toxicity of NMs to microorganisms are of special interest as microorganisms play important roles in biogeochemical cycling and are critical in maintaining the health of the ecosystem (Arrigo 2005, Falkowski, Fenchel et al. 2008). Microbial communities are also key to bioprocesses in various engineering applications including wastewater treatment, food processing, and biofuel production (Madigan, Martinko et al. 1997, Antoni, Zverlov et al. 2007). Moreover, microorganisms are comparatively fast and inexpensive to grow which make them attractive model test organisms. Therefore, comprehensive understanding the effect on microorganisms is imperative for ecotoxicity studies of NMs.

In recent years the impacts of NMs on environmental microorganisms have been extensively studied, with an emphasis on antimicrobial activities of NMs at the single cell level, which have been summarized and discussed in several recent research reviews ( $\mathrm{Li}$, Mahendra et al. 2008, Hajipour, Fromm et al. 2012, Seil and Webster 2012, Ingle, Duran et al. 2014). Ecotoxicity studies on model microorganisms can focus on survival/viability, cell division, gene mutations and effect on biochemical pathways (e.g., enzyme production). Microbial nanotoxicity studies have mostly focused on the biocidal and biostatic effect of various NMs on different model organisms. The most standard methods include minimal inhibitory concentration (MIC) calculation and enzyme assays. 


\subsection{Mechanisms of toxicity of NMs to microorganisms}

A wide range of NMs exhibit antimicrobial activities (Stoimenov, Klinger et al. 2002, Lyon, Adams et al. 2006, Marambio-Jones and Hoek 2010, Dong, Tang et al. 2012). The small size and high surface area to volume ratio are the unique properties which allow them to closely interact with the microbial cell and the sub-cellular structures (Morones, Elechiguerra et al. 2005, Ng, Sivakumar et al. 2013). Hence, many of them are being widely used in coatings, membrane fabrications, and medical devices (Liu, Qi et al. 2013, Murty, Shankar et al. 2013). Although the exact mechanisms of the antimicrobial effects of NMs may vary for different NMs and different organisms, it has been generally recognized that NMs often have multidimensional effects which include damages caused by direct contact such as damaging the cell membrane and deactivating the membrane bound enzymes as well as indirect damages caused by reactive oxygen species (ROS) inside the cells (Figure 2.2) (Zhang, Jiang et al. 2007, Klaine, Alvarez et al. 2008, Li, Xie et al. 2010, Marambio-Jones and Hoek 2010).

Elaborating on the toxicity mechanism cell membrane is the most accessible site. It is also the site for important cellular functions like material transport, energy transduction and intracellular communication through surface receptors. NMs used in imaging applications target cell membranes for labelling (Dubertret, Skourides et al. 2002). Smaller NMs like quantum dots (less than $5 \mathrm{~nm}$ ), silver nanoparticles less than $80 \mathrm{~nm}$ size are able to enter bacterial cells (Xu, Brownlow et al. 2004, Kloepfer, Mielke et al. 2005). Though, larger particles cannot enter the cells some have shown to bind to cell surface and cause damage to the cell membrane e.g., silicon nanoparticles and fullerene derivatives get embedded in the membrane (Jang, Pell et al. 2003) and carboxy fullerene has been shown to cause cell membrane rupturing leading to cell death (Tsao, Kanakamma et al. 1999). 

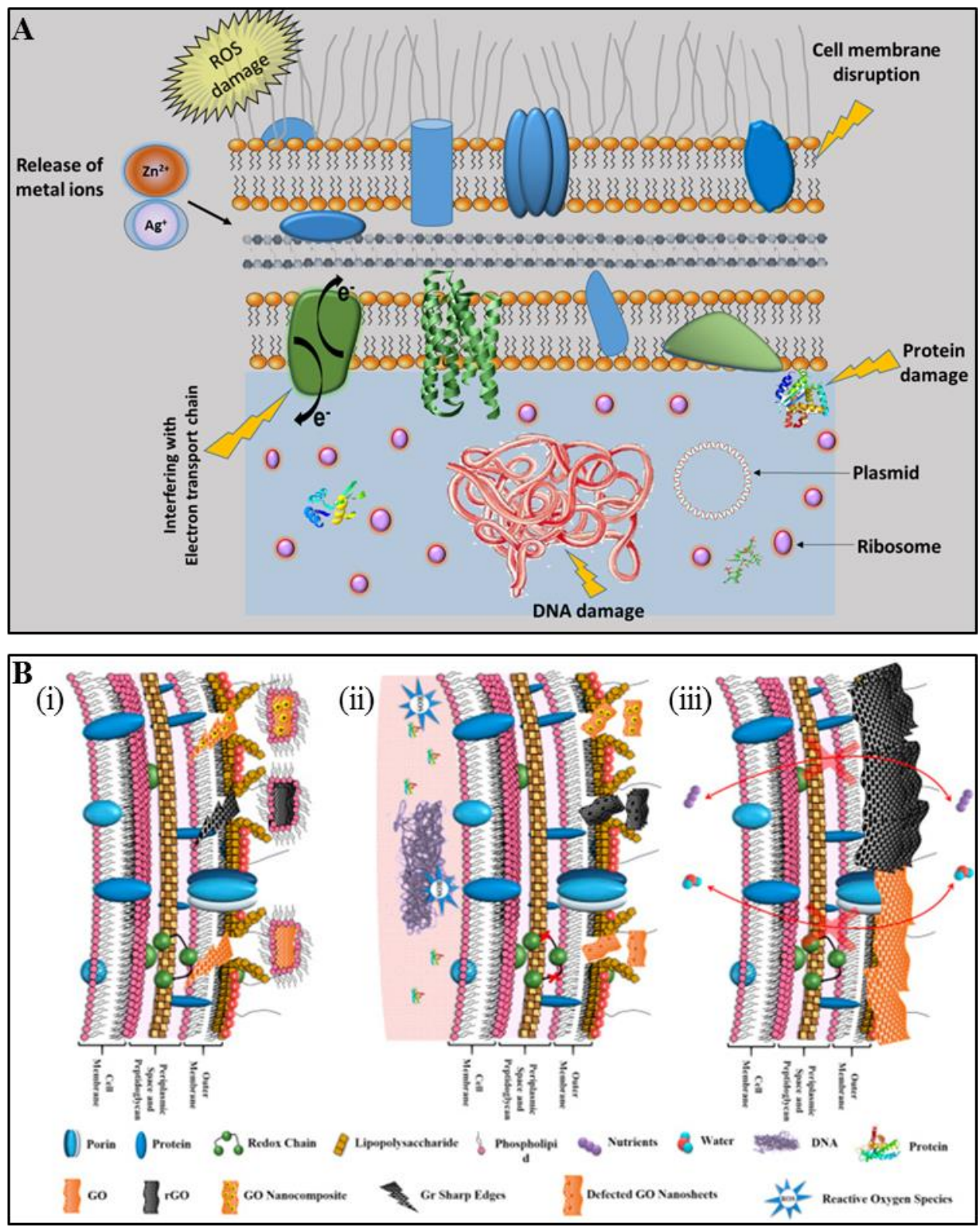

Figure 2.2 Mechanisms of toxicity of NMs: (A) toxicity of metal and metal oxide NMs, (B) toxicity of carbon NMs (i) Physical damages to cell membrane through insertion, extraction and "nano-knives" (ii) ROS- mediated oxidative damages to redox chains in cell membrane and intracellular components such as proteins and DNA (iii) Wrapping of NMs onto bacterial cell surface blocks nutrient access. Although the cells in this illustration are Gram-negative bacteria, the toxicity mechanisms shown here are also applicable to Gram-positive bacteria. Panel (B) was reprinted with permission from (Hegab, ElMekawy et al. 2016).

Toxicity of NMs also results due to protein destabilization and oxidation. Nanoparticleprotein conjugates are now being developed for variety of applications, but it has been 
shown that direct physical interaction with NMs can alter the structure and activity of the protein $e . g$., gold nanoparticle or SWCNTs containing electrodes could partially denature the enzyme glucose oxidase (Liu, Paddon-Row et al. 2004). NMs can also damage nucleic acids, fullerenes have been shown to cause deformation of DNA strand (Takenaka, Yamashita et al. 1999, Zhao, Striolo et al. 2005) and quantum dots can cause breakage of supercoiled DNA strand (Green and Howman 2005).

A large number of research focusing on the mechanism of NM toxicity, have attributed the toxicity to generation of Reactive Oxygen Species (ROS). ROS can damage every component of cell including the membranes, proteins, nucleic acid. In membranes ROS can oxidize the double bonds on membrane phospholipids resulting in lipid peroxidation. This will be followed by increase in membrane fluidity and increased membrane permeability (Cabiscol, Tamarit et al. 2010). These ROS generated by NMs can also damage iron-sulphur clusters in the protein cofactors, formation of disulphide bonds between the sulphur containing amino acids. DNA damage due to ROS results due to strand breaks, cross-linking and adducts of nitrogen bases and sugars. Measurement of ROS species by different assay methods can sometime give false readings due to interference of NMs with the assay reagents (Wörle-Knirsch, Pulskamp et al. 2006, Lyon, Brunet et al. 2008).

NMs exert their toxic effect by interfering with the energy transduction and electron transfer chain. These processes are indirectly affected by the membrane damage occurring due to NMs. They are also affected directly when they come in contact with any redox active NMs which can withdraw electrons from the electron transport chain. Fullerenes have been shown to inhibit respiration in E.coli (Mashino, Usui et al. 2003). Cerium dioxide nanoparticles cause the oxidation of membrane components involved in electron transport chain (Thill, Zeyons et al. 2006).

Another phenomenon which is widely linked to the toxicity of NMs, is release of toxic materials like ions or heavy metals from them. Silver ions has been widely implicated in the toxicity mechanism of silver nanoparticles (Kittler, Greulich et al. 2010). These metals 
or ions can accumulate inside the cells and exert toxic effects. Silver ions can interact with DNA, thiol groups of enzymes/proteins, thus inactivating them (Feng, Wu et al. 2000).

\subsection{Impact of NMs on microbial community}

To study the impact of NMs on microorganisms it is important to understand the microbial life style in natural environment. Over the past few decades, it has been increasingly clear that our understanding of microorganisms from laboratory-based pure culture studies is not true representation of their in situ lifestyle (Costerton, Cheng et al. 1987). Microorganisms in most natural, engineered, and medical settings are found to be growing as cooperative communities with complex physiology and behaviour (O'Toole, Kaplan et al. 2000, Hall-Stoodley, Costerton et al. 2004, Kjelleberg and Givskov 2007). Microorganisms often present in these microbial communities drive various biological processes such as biogeochemical cycling, nutrient removal in wastewater treatment, and anaerobic digestion (Wagner and Loy 2002, Narihiro and Sekiguchi 2007, Van Der Heijden, Bardgett et al. 2008, Ahmed, Cao et al. 2012). Although antimicrobial activities of NMs have been extensively studied at the single cell and population level, elucidating the influence of NMs on microbial communities is a critical aspect in the comprehensive understanding of econanotoxicity. In the past several years, the influence of NMs on microbial communities in various natural and engineered ecosystems has been explored and some representative studies are summarized in Table 2.1. Recent studies on the influence of NMs on natural and engineered ecosystems focused on effects of NMs on structure and function of microbial communities in soil, river, marine and wastewater treatment facilities. 
Table 2.1 Summary of recent research work (2008 onwards) on influence of NMs on microbial communities.

\begin{tabular}{llll}
\hline NMs (concentration, & Microbial & Approaches & Key findings \\
size, incubation period) & community & & \\
& & &
\end{tabular}

\section{CARBON BASED NANOMATERIALS}

\begin{tabular}{|c|c|c|c|c|}
\hline $\begin{array}{l}\mathrm{C}_{60}(1 \mu \mathrm{g} / \mathrm{g} \text { soil in aqueous } \\
\text { suspension or } 1000 \mu \mathrm{g} / \mathrm{g}\end{array}$ & $\begin{array}{l}\text { Soil microbial } \\
\text { community }\end{array}$ & $\begin{array}{l}\text { Phospholipid fatty acid } \\
\text { (PLFA) analysis and }\end{array}$ & $\begin{array}{l}\text { No significant changes in microbial } \\
\text { community structure. }\end{array}$ & $\begin{array}{l}\text { (Tong, Bischoff } \\
\text { et al. 2007) }\end{array}$ \\
\hline $\begin{array}{l}\text { soil in granular form; up } \\
\text { to } 180 \text { days ) }\end{array}$ & & $\begin{array}{lr}\text { community profiling } \\
\text { (PCR-DGGE); soil } \\
\text { enzyme activity assay } \\
\text { ( } \beta \text {-glucosidase, } \\
\text { acidphosphatase, } \\
\text { dehydrogenase, and } \\
\text { urease) }\end{array}$ & $\begin{array}{l}\text { Organic matter and salts control } \\
\text { availability of } \mathrm{C}_{60} \text { in soil, which will } \\
\text { ultimately control the exposure level and } \\
\text { toxicity of } \mathrm{C}_{60} \text {. }\end{array}$ & \\
\hline $\begin{array}{l}\mathrm{C}_{60} \text { (agglomerates of } 50 \\
\mathrm{~nm} \text { to } \mu \mathrm{m} \text { at } 0,5,25 \text {, and } \\
50 \mathrm{mg} / \mathrm{kg} \text { dry soil; up to } \\
14 \text { days) }\end{array}$ & $\begin{array}{l}\text { Soil microbial } \\
\text { community }\end{array}$ & $\begin{array}{l}\text { Substrate-induced } \\
\text { respiration (SIR) assay; } \\
\text { CFU count; PCR-DGGE }\end{array}$ & $\begin{array}{l}\text { No effect on total respiration; 3-4 fold } \\
\text { reduction of fast-growing bacteria } \\
\text { immediately after addition of } \mathrm{C}_{60} \text {. } \\
\text { Protozoan community is less sensitive. } \\
\text { Change in community profile is not in a } \\
\text { concentration-dependent manner. }\end{array}$ & $\begin{array}{l}\text { (Johansen, } \\
\text { Pedersen et al. } \\
\text { 2008) }\end{array}$ \\
\hline
\end{tabular}




\begin{tabular}{|c|c|c|c|c|}
\hline $\begin{array}{l}\mathrm{C}_{60} \quad(50 \mathrm{mg} / \mathrm{g} \text { of } \mathrm{dry} \\
\text { biomass })\end{array}$ & $\begin{array}{l}\text { Biosolids from } \\
\text { anaerobic } \\
\text { wastewater } \\
\text { treatment sludge }\end{array}$ & $\begin{array}{l}\text { Monitoring production } \\
\text { of } \mathrm{CO}_{2} \text { and } \mathrm{CH}_{4} \text {; PCR- } \\
\text { DGGE }\end{array}$ & $\begin{array}{l}\text { No change in microbial community } \\
\text { structure and function in methanogenesis. }\end{array}$ & $\begin{array}{l}\text { (Nyberg, Turco et } \\
\text { al. 2008) }\end{array}$ \\
\hline $\begin{array}{l}\text { Graphene oxide (up to } \\
3000 \mathrm{mg} / \mathrm{L} \text {; up to } 5 \mathrm{~h} \text { ) }\end{array}$ & $\begin{array}{l}\text { Microbial } \\
\text { community in } \\
\text { activated sludge }\end{array}$ & $\begin{array}{l}\text { Bacterial metabolic } \\
\text { activity and viability } \\
\text { assay; Scanning electron } \\
\text { microscope (SEM); } \\
\text { ROS and oxidative } \\
\text { stress measurement }\end{array}$ & $\begin{array}{l}\text { Bacterial metabolic activity, bacterial } \\
\text { viability, and biological removal of } \\
\text { nutrients, such as organics, nitrogen and } \\
\text { phosphorus were significantly impacted } \\
\text { by the presence of GO in the activated } \\
\text { sludge. }\end{array}$ & $\begin{array}{l}\text { (Ahmed and } \\
\text { Rodrigues 2013) }\end{array}$ \\
\hline $\begin{array}{l}\text { Single-walled carbon } \\
\text { nanotubes (SWCNTs) (up } \\
\text { to } 1000 \mu \mathrm{g} / \mathrm{g} \text { of soil; up to } \\
32 \text { days) }\end{array}$ & $\begin{array}{l}\text { Soil microbial } \\
\text { community }\end{array}$ & $\begin{array}{l}\text { Microbial biomass } \mathrm{C} \\
\text { and } \mathrm{N} \text { analysed for total } \\
\text { organic carbon and total } \\
\text { organic nitrogen } \\
\text { contents using a TOC- } \\
\text { VCPH/CPN analyzer; } \\
\text { enzyme activity assay }\end{array}$ & $\begin{array}{l}\text { SWCNTs of concentrations at } 300-1000 \\
\mu \mathrm{g} / \mathrm{g} \text { soil significantly lowered activities } \\
\text { of most enzymes and microbial biomass. } \\
\text { SWCNTs exhibited more severe impacts } \\
\text { on enzyme activity and biomass than } \\
\text { MWCNTs. }\end{array}$ & $\begin{array}{l}\text { (Jin, Son et al. } \\
\text { 2013) }\end{array}$ \\
\hline $\begin{array}{l}\text { SWCNTs }(0.03 \text { to } 1 \mathrm{mg} / \mathrm{g} \\
\text { soil; } 25 \text { days })\end{array}$ & $\begin{array}{l}\text { Soil microbial } \\
\text { community }\end{array}$ & PLFA & $\begin{array}{l}\text { Biomass of major microbial groups } \\
\text { including Gram-positive and Gram- }\end{array}$ & $\begin{array}{l}\text { (Jin, Son et al. } \\
\text { 2014) }\end{array}$ \\
\hline
\end{tabular}


negative bacteria and fungi decreased.

Gram-positive bacteria could adapt to soil disturbance by SWCNTs via changing lipid composition.

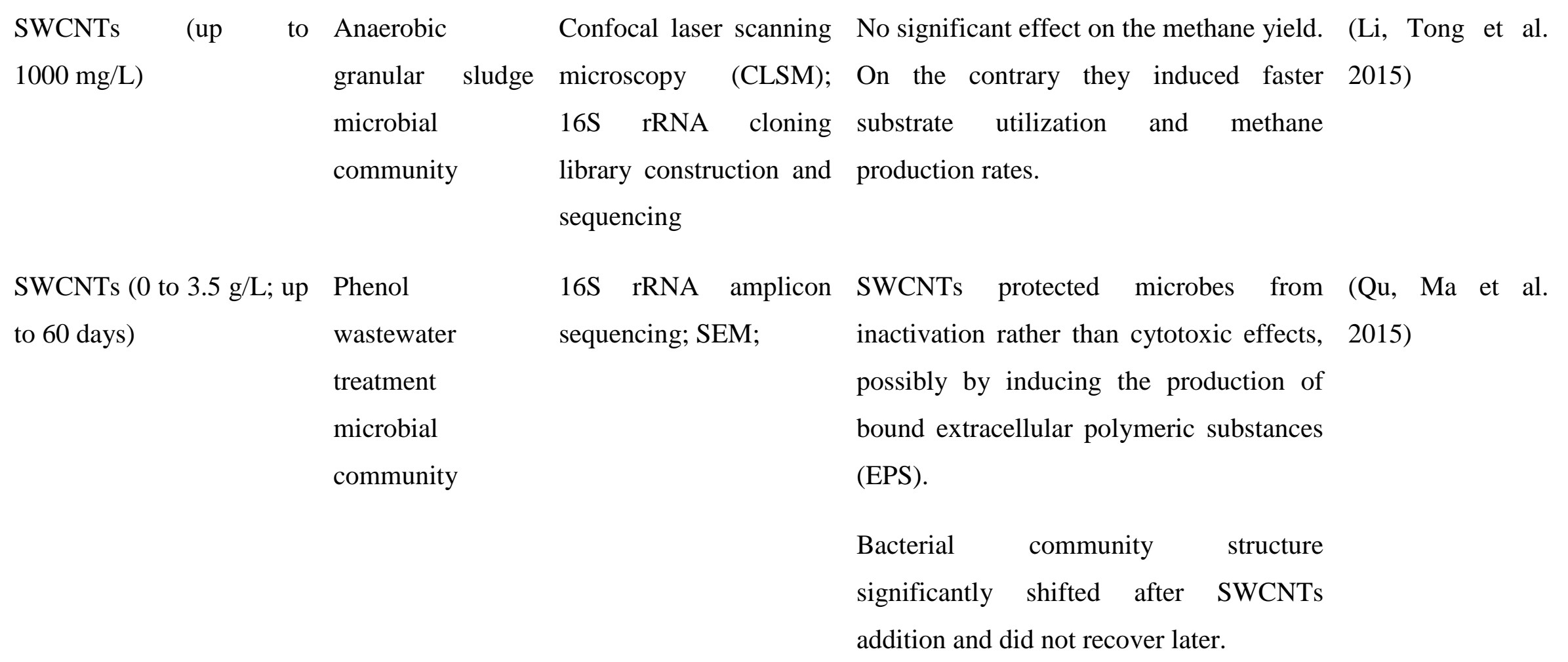

Multi-walled carbon Soil microbial Microbial biomass C, N, Enzymatic activities as well as microbial (Chung, Son et al. nanotubes (MWCNTs) (up community and C:N ratio biomass $\mathrm{C}$ and $\mathrm{N}$ decreased significantly. 2011)

to $5000 \mu \mathrm{g} / \mathrm{g}$ soil) 


\begin{tabular}{|c|c|c|c|c|}
\hline $\begin{array}{l}\text { MWCNTs (inner and } \\
\text { outer diameter of } 10 \mathrm{~nm} \\
\text { and } 25 \mathrm{~nm} \text {, respectively; }\end{array}$ & $\begin{array}{l}\text { Soil microbial } \\
\text { community }\end{array}$ & $\begin{array}{l}\text { PCR-DGGE and } \\
\text { pyrosequencing analysis }\end{array}$ & $\begin{array}{l}\text { Relative abundances of Bacteroidetes and } \\
\text { Firmicutes were found to increase, } \\
\text { whereas } \quad \text { Proteobacteria }\end{array}$ & $\begin{array}{l}\text { (Khodakovskaya, } \\
\text { Kim et al. 2013) }\end{array}$ \\
\hline 50 and $200 \mu \mathrm{g} / \mathrm{mL})$ & & & $\begin{array}{l}\text { Verrucomicorbia decreased with } \\
\text { increasing concentration of CNTs. } \\
\text { Dominant phylotypes maintained with } \\
\text { treatments. }\end{array}$ & \\
\hline $\begin{array}{l}\text { MWCNTs } \quad(10-10,000 \\
\mathrm{mg} / \mathrm{kg} \text { of soil })\end{array}$ & $\begin{array}{l}\text { Soil microbial } \\
\text { community }\end{array}$ & $\begin{array}{l}\text { Pyrosequencing and } \\
\text { fatty acid profiling }\end{array}$ & $\begin{array}{l}\text { No effects on soil respiration, enzymatic } \\
\text { activities, and microbial community } \\
\text { structure at } 10,100 \text { and } 1000 \mathrm{mg} / \mathrm{kg} \text {. } \\
\text { Increased fungal fatty acid methyl ester } \\
\text { markers at the highest treatment. } \\
\text { Decreased abundance of some bacterial } \\
\text { genera like Derxia, Holophaga, Opitutus } \\
\text { and Waddlia. Increased abudance of } \\
\text { Rhodococcus, } \\
\text { Nocardioides and Pseudomonas. }\end{array}$ & $\begin{array}{l}\text { (Shrestha, } \\
\text { Acosta-Martinez } \\
\text { et al. 2013) }\end{array}$ \\
\hline $\begin{array}{l}\text { SWNTs, MWNTs, } \mathrm{C}_{60}, \\
\text { and colloidal graphite }\end{array}$ & $\begin{array}{l}\text { River water and } \\
\text { wastewater } \\
\text { microbial } \\
\text { community }\end{array}$ & $\begin{array}{l}\text { Fluorescence-based, } \\
\text { nucleic acid assay }\end{array}$ & $\begin{array}{l}\text { Inactivation of microorganisms in river } \\
\text { water and wastewater treatment plant } \\
\text { (WWTP) samples. }\end{array}$ & $\begin{array}{l}\text { (Kang, Mauter et } \\
\text { al. 2009) }\end{array}$ \\
\hline
\end{tabular}




\begin{tabular}{|c|c|c|c|c|}
\hline METAL NANOPARTIC & & & & \\
\hline $\begin{array}{l}\text { Carboxy-functionalized } \\
\text { Silver Nanoparticle (Ag } \\
\text { NPs) }(0.01-1 \mathrm{mg} / \mathrm{L} \text {; up to } \\
5 \text { days })\end{array}$ & $\begin{array}{l}\text { Natural water } \\
\text { microbial } \\
\text { community }\end{array}$ & $\begin{array}{l}\text { PCR-DGGE; Terminal } \\
\text { restriction fragment } \\
\text { length polymorphism } \\
\text { (T-RFLP) }\end{array}$ & $\begin{array}{l}\text { Significantly changed the bacterial } \\
\text { community structure, affecting individual } \\
\text { cells and reduced bacterial metabolic } \\
\text { activity. Communities diverged by as } \\
\text { much as } 54-56 \% \text {. Compared to the } \\
\text { untreated samples. }\end{array}$ & $\begin{array}{l}\text { (Das, Williams et } \\
\text { al. 2012) }\end{array}$ \\
\hline $\begin{array}{l}\text { Ag-NPs (Gum Arabic } \\
(\mathrm{GA}) \text { and citrate } \\
\text { stabilized) (pulse and } \\
\text { continuous additions of } \\
0.2 \text { and } 2 \mathrm{ppm})\end{array}$ & $\begin{array}{l}\text { Wastewater } \\
\text { microorganisms } \\
\text { from sequencing } \\
\text { batch reactors } \\
\text { (SBRs) }\end{array}$ & T-RFLP & $\begin{array}{l}\text { COD and ammonia removal decreased by } \\
\text { as much as } 30 \% \text { or greater directly after } \\
\text { spikes, SBRs were able to recover within } \\
24 \mathrm{~h} \text { and resume removal near } 95 \% \text {. GA } \\
\text { AgNPs lowered diversity more than } \\
\text { citrate AgNPs. The citrate and GA AgNPs } \\
\text { treated SBRs never reached the same } \\
\text { diversity they had prior to Ag addition. }\end{array}$ & $\begin{array}{l}\text { (Alito and } \\
\text { Gunsch 2013) }\end{array}$ \\
\hline $\begin{array}{l}\text { Ag-NPs (1 mg/L; up to } 24 \\
\text { h) }\end{array}$ & $\begin{array}{l}\text { Activated sludge } \\
\text { microbial } \\
\text { communities }\end{array}$ & $\begin{array}{l}\text { Heterotrophic plate } \\
\text { counts (HPCs); PCR- } \\
\text { DGGE }\end{array}$ & $\begin{array}{l}\text { Certain microbial species in the intact } \\
\text { activated sludge were highly sensitive. } \\
\text { Can impact the cell culturability } \\
\text { depending on the physical structure of the } \\
\text { activated sludge flocs. }\end{array}$ & $\begin{array}{l}\text { (Sun, Sheng et al. } \\
\text { 2013) }\end{array}$ \\
\hline
\end{tabular}




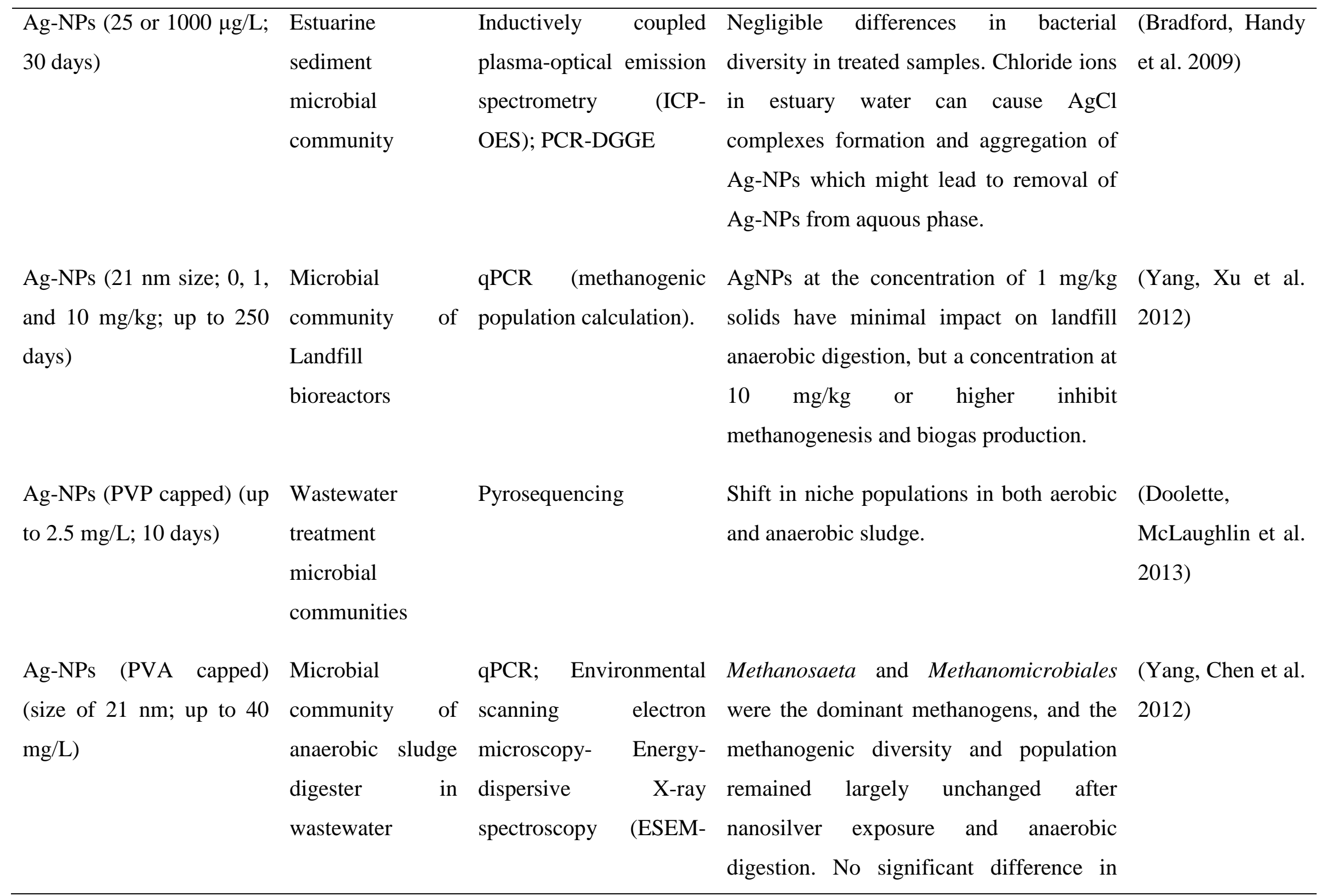




\begin{tabular}{|c|c|c|c|c|}
\hline & treatment plants & EDS) & $\begin{array}{l}\text { biogas and methane production between } \\
\text { the treated and control. }\end{array}$ & \\
\hline $\begin{array}{l}\text { Ag-NPs (Size less than } 15 \\
\mathrm{~nm} ; 1,50 \text {, or } 200 \mathrm{mg} / \mathrm{L} \text {; up } \\
\text { to } 24 \mathrm{~h} \text { ) }\end{array}$ & $\begin{array}{l}\text { Wastewater } \\
\text { biofilms }\end{array}$ & $\begin{array}{l}\text { HPC } \quad \text { (Bacterial } \\
\text { enumeration); } \\
\text { DGGE }\end{array}$ & Biofilms were highly tolerant to Ag-NPs. & $\begin{array}{l}\text { (Sheng and Liu } \\
\text { 2011) }\end{array}$ \\
\hline $\begin{array}{l}\text { Ag-NPs (size } 65 \pm 30 \mathrm{~nm} \text {; } \\
0-2000 \mu \mathrm{g} / \mathrm{L} ; \text { up to } 24 \mathrm{~h} \text { ) }\end{array}$ & Marine biofilms & T-RFLP; CLSM & $\begin{array}{l}\text { Ag-NPs significantly affected the } \\
\text { community structure. Even at the highest } \\
\text { concentrations studied the major } \\
\text { taxonomic groups are not displaced. } \\
\text { Treatment reduced normal biofilm } \\
\text { development and succession in the } \\
\text { samples. }\end{array}$ & $\begin{array}{l}\text { (Fabrega, Zhang } \\
\text { et al. 2011) }\end{array}$ \\
\hline $\begin{array}{l}\text { Ag-NPs }(\sim 29 \mathrm{~nm} ; 1 \mathrm{mg} / \mathrm{L} \text {; } \\
\text { up to } 25 \text { days })\end{array}$ & $\begin{array}{l}\text { Activated sludge } \\
\text { microbial } \\
\text { community }\end{array}$ & $\begin{array}{l}\text { T-RFLP; ICP-OES; } \\
\text { Respirometric assays }\end{array}$ & $\begin{array}{l}\text { Prolonged period of nitrification } \\
\text { inhibition and increase of ammonia/nitrite } \\
\text { concentration in wastewater effluent. } \\
\text { Nanosilver exposure did not affect the } \\
\text { growth of heterotrophs responsible for } \\
\text { organic matter removal. Population of } \\
\text { ammonium and nitrite-oxidizing bacteria, } \\
\text { Nitrospira decreased, while Nitrobacter }\end{array}$ & $\begin{array}{l}\text { (Liang, Das et al. } \\
\text { 2010) }\end{array}$ \\
\hline
\end{tabular}


was washed out after the shock loading.

Ag-NPs $(50 \mathrm{~nm}$ uncoated Surface soils (top Nitrate analysis and $15 \mathrm{~nm}$ PVP coated; 0- 10-30 cm) of

$300 \mathrm{mg} / \mathrm{L}$ for uncoated Toccoa sandy

and 1 and $10 \mathrm{mg} / \mathrm{L}$ for loam

coated; up to $24 \mathrm{~h}$ )

Ag-NPs (original size 13.0 Microbial Pyrosequencing

$\pm \quad 3.3 \mathrm{~nm} ; \quad$ after communities in rRNA

aggregation, $63.5 \pm 15.2$ sequential batch

to $79.2 \pm 18.1 \mathrm{~nm} ; 0.1$ to reactors

$50 \mathrm{mg} / \mathrm{L} ; 50$ days)

Ag-NPs ( $5 \mathrm{~nm}$ at Activated sludge Pyrosequencing; qPCR;

$0.05 \mathrm{ppm}$, and $35 \mathrm{~nm}$ at from waste water SEM
PVP coated Ag-NPs suppressed the soil (Masrahi,

nitrification process more effectively. Ag- VandeVoort et al.

NPs exhibited a greater toxicity to 2014)

nitrifying bacteria than $\mathrm{Ag}^{+}$in soils.

16S Rate constants of both biological (Jeong, Im et al.

nitrification and organic oxidation 2014)

decreased exponentially with an increase

in Ag-NP concentration, but nitrification

was more severely inhibited than organic

oxidation even at low Ag NP

concentrations $\quad\left(<1 \mathrm{mg} \quad \mathrm{Ag} \quad \mathrm{L}^{-1}\right)$.

Heterotrophic bacteria exhibited a higher

tolerance to Ag-NPs than nitrifying

bacteria. Diversity of microbial

community and treatment efficiency

decreased.

AgNP treated samples had less microbial (Yang, Quensen

diversity than control. The effect was et al. 2014)

more with $35 \mathrm{~nm}$ and decreased the 


\begin{tabular}{|c|c|c|c|}
\hline 40 ppm; 7 days) & treatment plant & & $\begin{array}{l}\text { abundance of Chloroflexi, Firmicutes } \\
\text { and WS3, but increased the population } \\
\text { of Acidobacteria. Biological nitrogen } \\
\text { removal was also hampered by reducing } \\
\text { the abundance of Nitrosomonas, and the } \\
\text { absence of Nitrosococcus. qPCR showed } \\
\text { a four-fold decrease in copy number of the } \\
\text { ammonia monooxygenase subunit A gene } \\
\text { (amoA), a functional gene marker for } \\
\text { ammonia-oxidizing bacteria. All the } \\
\text { above effect was not observed in } 5 \mathrm{~nm} \\
\text { AgNP or } \mathrm{AgNO}_{3} \text { treated samples. }\end{array}$ \\
\hline $\begin{array}{l}\text { Ag-NPs } \quad(6.0 \pm 2.0 \mathrm{~nm} \text {; } \\
\text { influent concentration of } \\
0.10 \mathrm{mg} / \mathrm{L} ; 61 \text { days })\end{array}$ & $\begin{array}{l}\text { Membrane } \\
\text { bioreactor } \\
\text { activated sludge } \\
\text { system }\end{array}$ & $\begin{array}{l}\text { Atomic Absorption } \\
\text { Spectroscopy (AAS); T- } \\
\text { RFLP; qPCR }\end{array}$ & $\begin{array}{l}\text { No significant change in the nitrifying (Zhang, Liang et } \\
\text { bacterial community structures after al. 2014) } \\
\text { treatment with Ag-NPs. } \\
\text { There was no significant changes in gene } \\
\text { copy numbers of amoA gene, the } 16 \mathrm{~S} \\
\text { rRNA genes of Nitrospira spp. And } \\
\text { Nitrobacter spp. after long-term treatment } \\
\text { with Ag-NPs. }\end{array}$ \\
\hline & & & EPS concentration increased significantly \\
\hline
\end{tabular}


after long-term Ag-NPs dosing.

$\mathrm{Au}$ and $\mathrm{Ag}$ nanoparticles AOB enrichment PCR-DGGE;

$(10-20 \mathrm{~nm} ; 50 \mu \mathrm{g} / \mathrm{L}$ - cultures from Pyrosequencing

$2 \mathrm{mg} / \mathrm{L} ; 45$ days)

river sediments

estuary wetlands

Copper nanoparticles $(\mathrm{Cu}$ Wastewater

NPs $)(220 \pm 25 \mathrm{~nm}$; treatment

$0.1-10 \mathrm{mg} / \mathrm{L}) \quad$ microbial

communities

Zero-valent

nanoparticles (nZVI)

iron Soil microbial PLFA;

community
qPCR

multiple

induced

(MSIR)
Ag-NPs significantly inhibited bacterial (Luo, Chen et al.

ammonia oxidation in aquatic 2014)

environment in a concentration dependent

manner; inhibition was resulted primarily

from a decrease in $\mathrm{AOB}$ biodiversity and

abundance reduction. AOB biodiversity

and abundance as well as activity were not

inhibited by Au-NPs.

Increased the number of denitrifiers (Chen, Wang et (especially $\mathrm{N}_{2} \mathrm{O}$ reducing denitrifiers) but al. 2012)

decreased nitrite accumulation. Total nitrogen $(\mathrm{TN})$ removal was enhanced and $\mathrm{N}_{2} \mathrm{O}$ generation was reduced. Ammonia and phosphorus removals were not affected.

Functional Microbial community structures in sandy

(Pawlett, Ritz et substrate- soils were the most, and clay soils the al. 2013) respiration least, vulnerable to nZVI (impact of nZVI on soil microbial communities is dependent on organic matter content and 


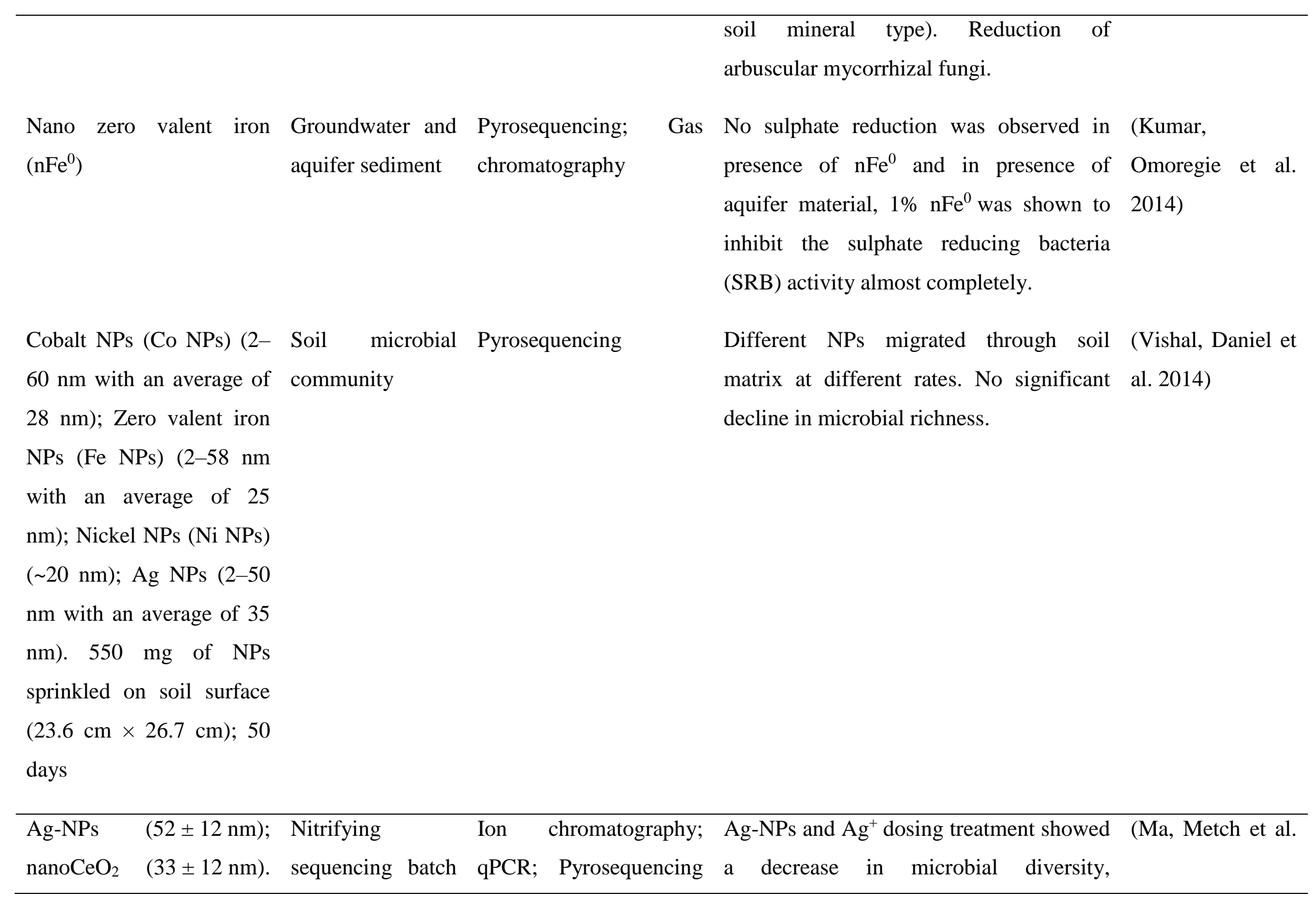




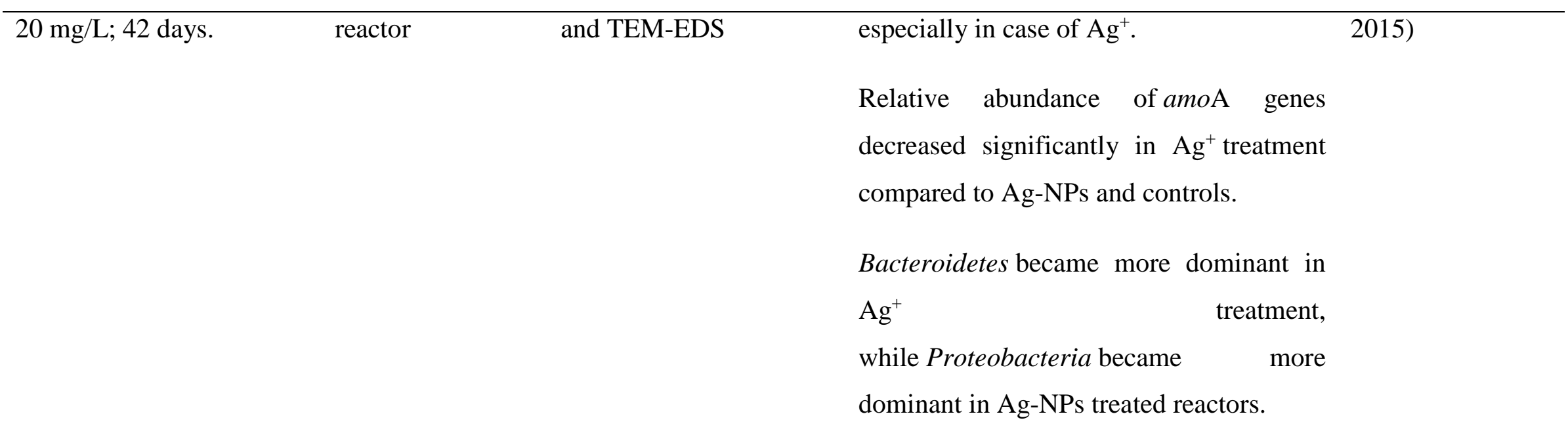

\section{METAL OXIDE NANOPARTICLES}

\begin{tabular}{|c|c|c|c|}
\hline $\begin{array}{l}\mathrm{TiO}_{2} \text { (size } 15-20 \mathrm{~nm} ; 0- \\
2.0 \mathrm{mg} / \mathrm{g} \text { soil) and } \mathrm{ZnO} \\
(\text { size } \quad 20-30 \mathrm{~nm} ; 0-0.5 \\
\mathrm{mg} / \mathrm{g} \text { soil); up to } 60 \text { days }\end{array}$ & $\begin{array}{l}\text { Soil bacterial } \\
\text { communities }\end{array}$ & $\begin{array}{l}\text { Respirometric assays; } \\
\text { RFLP }\end{array}$ & $\begin{array}{l}\text { Both nano- } \mathrm{TiO}_{2} \text { and nano- } \mathrm{ZnO} \text { reduced }(\mathrm{Ge} \text {, Schimel et } \\
\text { microbial biomass. Both NMs altered the al. 2011) } \\
\text { composition of the soil bacterial } \\
\text { community; } \mathrm{ZnO} \text { showed stronger effects. }\end{array}$ \\
\hline $\begin{array}{l}\mathrm{TiO}_{2} \text { NPs }(70-90 \mathrm{~nm} ; 50 \\
\mathrm{mg} / \mathrm{L} ; \text { up to } 70 \text { days })\end{array}$ & $\begin{array}{l}\text { Bacterial } \\
\text { community in } \\
\text { activated sludge }\end{array}$ & $\begin{array}{l}\text { PCR-DGGE; } \\
\text { SEM }\end{array}$ & $\begin{array}{l}\text { Significantly decrease total nitrogen (TN) (Zheng, Chen et } \\
\text { removal efficiency from } 80.3 \% \text { to } 24.4 \% \text {. al. 2011) } \\
\text { Biological phosphorus removal was } \\
\text { unaffected. Reduced the diversity of } \\
\text { microbial. Abundance of nitrifying } \\
\text { bacteria, especially ammonia-oxidizing }\end{array}$ \\
\hline
\end{tabular}




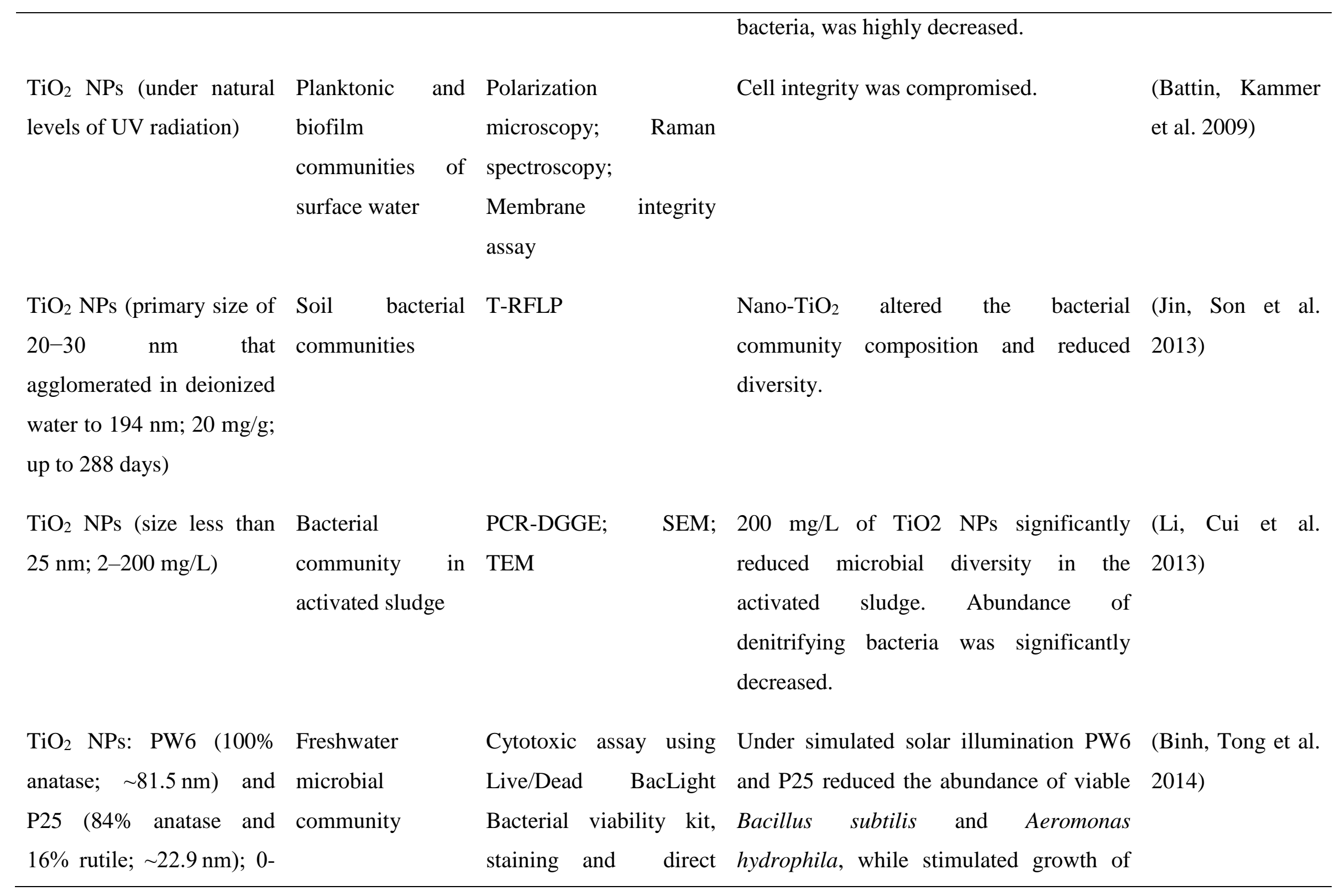




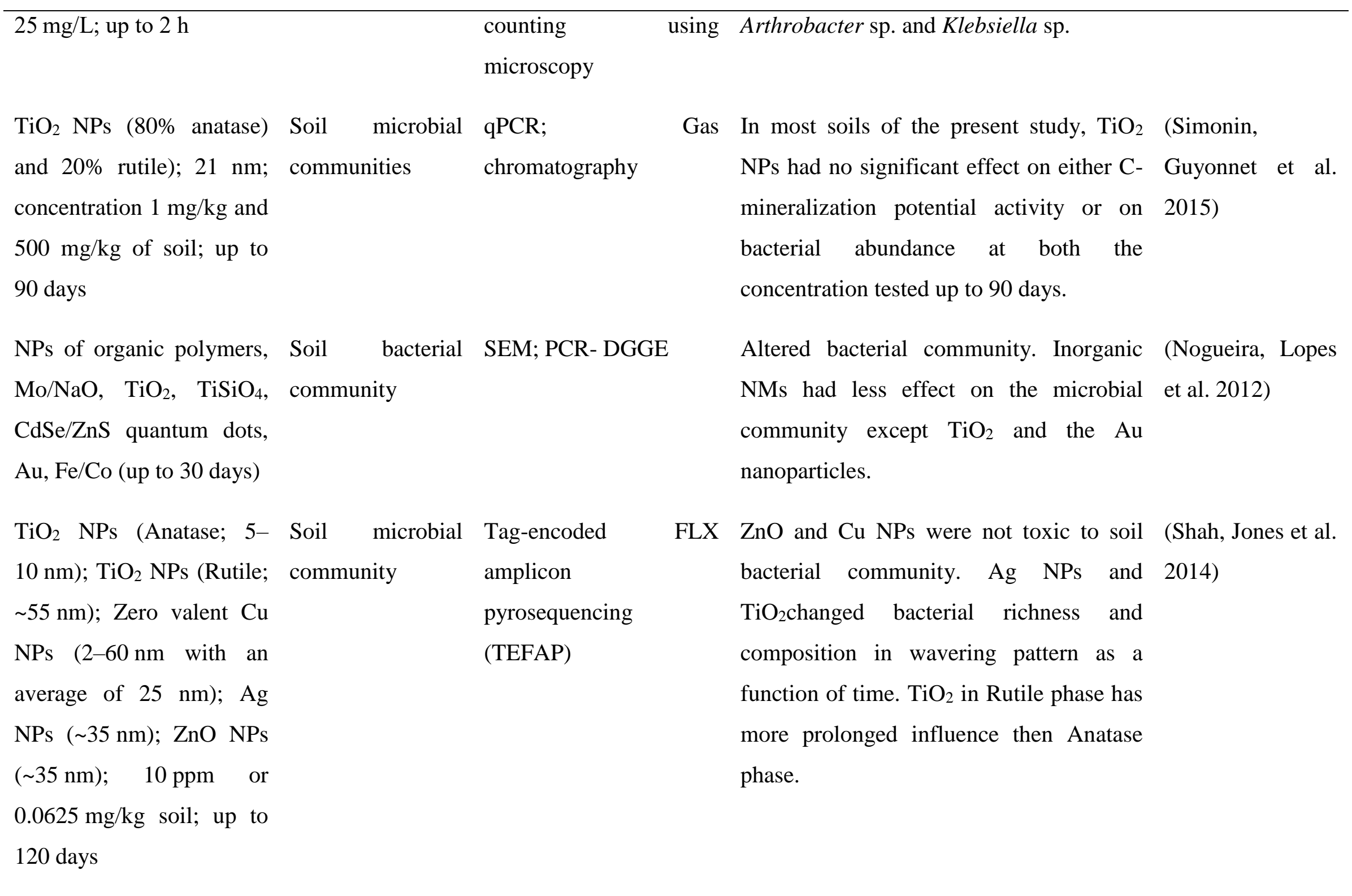




\begin{tabular}{|c|c|c|c|c|}
\hline $\begin{array}{l}\mathrm{Nano}_{-} \mathrm{Al}_{2} \mathrm{O}_{3}, \text { nano- } \mathrm{TiO}_{2}, \\
\text { nano-SiO} \\
\mathrm{Fe}_{2} \mathrm{O}_{3}, \text { and nano- }\end{array}$ & $\begin{array}{l}\text { E. coli and } \\
\text { Salmonella co- } \\
\text { culture }\end{array}$ & $\begin{array}{l}\text { Conjugative Transfer of } \\
\text { the RP4 Plasmid }\end{array}$ & $\begin{array}{l}\text { Nanoalumina can promote the conjugative } \\
\text { transfer of the RP4 plasmid from } \\
\text { Escherichia coli to Salmonella spp. by up } \\
\text { to 200-fold }\end{array}$ & $\begin{array}{l}\text { (Qiu, Yu et al. } \\
\text { 2012) }\end{array}$ \\
\hline $\begin{array}{l}\text { Copper oxide }(\mathrm{CuO}) \text { and } \\
\text { magnetite }\left(\mathrm{Fe}_{3} \mathrm{O}_{4}\right) \mathrm{NPs}(< \\
50 \mathrm{~nm} ; 1 \% \text { and } 0.1 \%)\end{array}$ & $\begin{array}{l}\text { Microbial } \\
\text { communities in a } \\
\text { sandy loam (Bet- } \\
\text { Dagan) and a } \\
\text { sandy clay loam } \\
\text { (Yatir) }\end{array}$ & $\begin{array}{l}\text { PCR-DGGE; } 454 \text { high } \\
\text { throughput sequencing } \\
\text { and qPCR }\end{array}$ & $\begin{array}{l}\text { In the Yatir soil, } 1 \% \mathrm{CuO} \text { exposure cause } \\
\text { a significant decrease in oxidative } \\
\text { potential and changes to community } \\
\text { composition. } \mathrm{Fe}_{3} \mathrm{O}_{4} \text { changed the } \\
\text { hydrolytic activity and bacterial } \\
\text { community composition in Bet-Dagan soil } \\
\text { but did not affect the Yatir soil bacterial } \\
\text { community. In Bet-Dagan soil, abundance } \\
\text { of bacteria from the Bacilli class } \\
\text { decreased after addition of } 0.1 \% \text { CuO but } \\
\text { increased with } 1 \% \text { CuO, while in Yatir } \\
\text { soil their abundance was reduced with } 1 \% \\
\text { CuO. Other important soil bacterial } \\
\text { groups, including Rhizobiales and } \\
\text { Sphingobacteriaceae, were negatively } \\
\text { affected. }\end{array}$ & $\begin{array}{l}\text { (Frenk, Ben- } \\
\text { Moshe et al. } \\
\text { 2013) }\end{array}$ \\
\hline $\mathrm{ZnO}$ & Microbial & PCR-DGGE & Nitrogen and phosphorus removal & (Puay, Qiu et al. \\
\hline
\end{tabular}




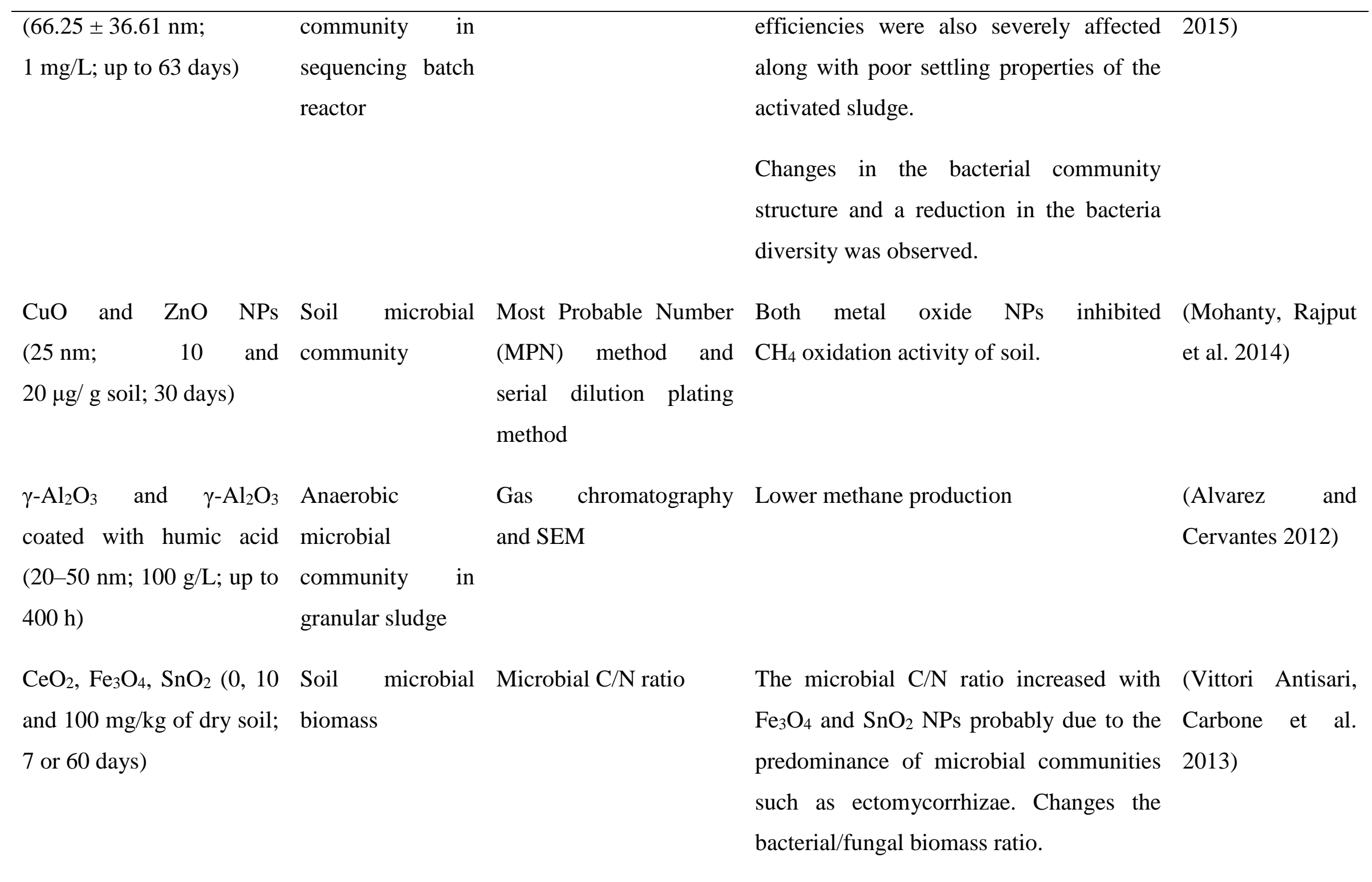




\begin{tabular}{lllll}
\hline Silica, palladium, gold and & Soil microbial & Fatty Acid Methyl Ester & Statistically insignificant influence of the (Shah \\
copper NPs $(0.013 \%$ w/w & community & (FAME) Profile analysis & nanoparticles on the soil microbial Belozerova 2009) \\
or $0.066 \%$ w/w; 15 days) & & & community profile.
\end{tabular}




\subsection{Influence on microbial community structure}

Microbial communities in soils play an essential role in biogeochemical cycling, agricultural production, and plant diversity (Jean-Marc, Tawna et al. 1994, Zak, Holmes et al. 2003, Falkowski, Fenchel et al. 2008). Studies have shown that of NMs, such as surface charge, size, aggregation, could be altered in environmental media (Lowry, Gregory et al. 2012, Dobias and Bernier-Latmani 2013, Liu, Jin et al. 2014). Different NMs migrate at different rates in the soil matrix thus exhibit different effects on the soil microbial community (Vishal, Daniel et al. 2014). Soil type also affects the influence of NMs. Microbial communities in sandy and clay soils have been shown to respond differently to $\mathrm{CuO}$ and magnetite nanomaterials. Beta-dragon soil which contains lower amount of organic matter and soil clay portion was shown to have significant shift in microbial composition. Both magnetite and $\mathrm{CuO}$ NMs showed an increase in Bacilli class members. Further the relative abundance of Actinobacteria increased significantly in response to treatment with $0.1 \% \mathrm{CuO}$ treatment whereas relative abundance of Betaproteobacteria was increased after treatment with $1 \% \mathrm{CuO}$. Yatir soil which has higher organic and clay content, after exposure to $1 \% \mathrm{CuO}$, the relative abundance of Bacilli class was reduced while the total population did not change significantly (Frenk, Ben-Moshe et al. 2013). Similar results were obtained with zero-valent iron nanomaterials where microorganisms in sandy soils were more susceptible than those in clay soils and was shown to have bactericidal effect on Gram negative bacteria and it also caused reduction in arbuscular mycorrhizal fungi (Pawlett, Ritz et al. 2013). The influence of NMs on soil microbial communities was also affected by organic matter and salt contents in the soil (Tong, Bischoff et al. 2007). Aquatic microbial communities were also examined for the effect of NMs. Reports on the impacts of NMs on microorganisms in both planktonic and biofilm modes of growth are available for freshwater and marine systems. Carbon based NMs were shown to inactivate cells in monocultures as well as in river water microbial communities (Kang, Mauter et al. 2009). Similarly, Ag nanoparticles changed the community profile of fresh water microbial communities (Das, Williams et al. 2012). In addition to planktonic cultures, aquatic biofilm communities as impacted by NMs have also been reported. Biofilms are surface-associated microbial communities with 
cells embedded in a polymeric matrix (Hall-Stoodley, Costerton et al. 2004, Flemming and Wingender 2010). Although biofilm communities often exhibit a higher tolerance to toxic contaminants or antimicrobial agents than their planktonic counterparts (HallStoodley, Costerton et al. 2004, Harrison, Ceri et al. 2007, Cao, Majors et al. 2012, Ding, Peng et al. 2014), the exposure to AgNPs changed community structure of marine biofilms, affecting biofilm development and succession; however, major taxonomic groups were not displaced (Fabrega, Zhang et al. 2011). Cell integrity in biofilm

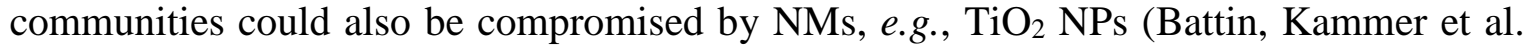
2009).

Although most studies have reported a reduction in microbial diversity upon NMs exposure, there were also reports of NMs not having significant effects on community structures (Tong, Bischoff et al. 2007, Nyberg, Turco et al. 2008, Bradford, Handy et al. 2009, Shah and Belozerova 2009).

For the effects of NMs on engineered ecosystems, microbial communities in waste or wastewater treatment bioprocesses are often used as model systems and most studies focused on the community composition and community function in terms of efficiency of the bioprocesses. The impacts of NMs on both anaerobic and aerobic treatment processes have been studied and the most commonly studied bioprocesses include methanogenesis and nitrogen and phosphorous removal (Table 2.1). Intriguingly, although many previous reports demonstrated that different types of NMs such as AgNPs and graphene oxide had negative impact on ammonium-oxidizing bacteria and nitrite-oxidizing bacteria (Nyberg, Turco et al. 2008, Liang, Das et al. 2010, Ahmed and Rodrigues 2013), there were also reports showing that anaerobic sludge digester microbial communities were not affected by these NMs (Nyberg, Turco et al. 2008, Yang, Chen et al. 2012). The discrepancies could be because of different physicochemical properties of the NMs and their complex interactions with the organic and inorganic matters in the microbial communities.

\subsection{Influence on microbial community function}

Whether the exposure to NMs affects microbial community functions is another important aspect that has been relatively less explored. Several recent studies examined the impacts 
of NMs on community function. Most commonly studied functions were methanogenesis and nutrient removal in waste water treatment plants. For example, methanogenesis was found to be inhibited by NMs such as $\mathrm{Al}_{2} \mathrm{O}_{3}$ and the toxicity of $\mathrm{Al}_{2} \mathrm{O}_{3}$ was reduced when coated with humic acids (Alvarez and Cervantes 2012). AgNPs were shown to inhibit methanogenesis in landfill bioreactor in concentration dependent manner where $1 \mathrm{mg} / \mathrm{kg}$ AgNPs didn't show any impact on biogass production but $10 \mathrm{mg} / \mathrm{kg}$ AgNPs reduced biogass production (Yang, Xu et al. 2012). However, another study showed that no effect on methanogenesis could be observed when biosolids from anaerobic sludge were exposed to fullerene (C60) for few months (Nyberg, Turco et al. 2008).

Nitrogen removal process was also reported to be inhibited by NMs like $\mathrm{TiO}_{2}$ (Zheng, Chen et al. 2011, Li, Cui et al. 2013) and AgNPs (Liang, Das et al. 2010, Masrahi, VandeVoort et al. 2014). Graphene oxide was shown to negatively impact the waste water treatment process specially it affected the nutrient removal (phosphorous and nitrogen) in a concentration dependent manner. It also increased the water turbidity and reduced the sludge dewaterability thus deteriorating the effluent quality (Ahmed and Rodrigues 2013). AgNPs were shown to inhibit nitrification process in soil microbial community as well as in waste water treatment plant (Jeong, Im et al. 2014, Masrahi, VandeVoort et al. 2014). In activated sludge treatment process, titanium dioxide was shown to reduce nitrogen and phosphorous removal efficiency (Zheng, Chen et al. 2011). In contrast, CuO NPs was reported to increase the abundance of denitrifiers (especially $\mathrm{N}_{2} \mathrm{O}$ reducing denitrifies) and enhanced total nitrogen removal (Chen, Wang et al. 2012).

To explain the influence of NMs on community structure and function, most studies suggested an organism-specific toxicity of NMs, i.e., different microorganisms in the community have different susceptibility to the NMs. For example, some bacteria are more tolerant to AgNPs than others (Sun, Sheng et al. 2013). Heterotrophic microorganisms were found more tolerant to AgNPs than nitrifying bacteria (Jeong, Im et al. 2014). It has also been shown that MWCNTs selectively reduced the population of a few phyla (e.g., Proteobacteria and Verrucomicorbia) and increased the cell count of several other phyla (e.g., Bacteroidetes and Firmicutes) (Khodakovskaya, Kim et al. 2013). MWCNTs were shown to increase the population of few bacteria genera like Rhodococcus, Cellulomonas, 
Nocardioides and Pseudomonas, which are well known degraders of recalcitrant aromatic compounds (Khodakovskaya, Kim et al. 2013, Shrestha, Acosta-Martinez et al. 2013). In another study, Gram-positive bacteria were found capable of adapting to SWCNTs by changing their membrane lipid composition (Jin, Son et al. 2014). The mechanisms of organism-specific effects of NMs remain largely unknown and need to be further explored.

\subsection{Commonly studied NMs for impacts on microbial community}

The most commonly used NMs in these studies include carbon based and of metal and metal oxides because these NMs are widely used in various consumer products and thus more likely to end up in the environments as emerging contaminants. $\mathrm{Ag}, \mathrm{ZnO}, \mathrm{TiO}_{2}$ nanomaterials and carbon based nanomaterials such as fullerene, single-wall carbon nanotubes (SWCNTs), and multi-walled carbon nanotubes (MWCNTs) are the mostly used NMs for elucidating impacts of NMs on microbial communities in natural and engineered ecosystems. Many studies used more than one type of NMs to examine material-specific effects on microbial communities (Ge, Schimel et al. 2011, Shah, Jones et al. 2014). Interestingly, even for the same type of NMs, the influences on microbial communities could vary significantly. For example, Johansen et al. (2008) reported that $\mathrm{C}_{60}$ significantly affected the soil microbial community and reduced the number of actively growing bacteria by 3-4 folds, while several other studies showed no significant effects on the microbial community profiles (Tong, Bischoff et al. 2007, Nyberg, Turco et al. 2008). The shape, size, and concentration of the NMs varied among previous studies, which could attribute to the inconsistencies reported in different studies. For example, rutile and anatase are the two mineral phases of $\mathrm{TiO}_{2}$ nanoparticles and the rutile phase has been shown to exhibit a longer effect than the anatase phase (Shah, Jones et al. 2014). In addition, surface modification of NMs also has profound effects on their influences on microbial communities. For example AgNPs coated with polyvinylpyrrolidone (PVP) were shown to be more toxic to nitrifying bacteria (Masrahi, VandeVoort et al. 2014). On the contrary, coating of humic acid on $\mathrm{Al}_{2} \mathrm{O}_{3}$ NPs reduced their toxicity to methanogenic activity (Alvarez and Cervantes 2012). In another study, compared with AgNPs stabilized 
with citrate, AgNPs stabilized with gum Arabic (GA) showed a stronger impact on microbial diversity (Alito and Gunsch 2013).

\subsection{Commonly used techniques to study impacts NMs on microbial community}

Most previous studies elucidating the impacts of NMs on microbial communities focused on the changes of microbial composition in the communities. Commonly used techniques to profile microbial communities in previous studies include PCR-DGGE, T-RFLP, quantitative real-time PCR, phospholipid fatty acid (PLFA) analysis, and functional multiple substrate-induced respiration (MSIR) profiles analysis, and fluorescent in situ hybridization (FISH). One of the powerful and widely used technique is use of microscopy like confocal laser scanning microscopy, electron microscopy (SEM and TEM) which are combined with different staining techniques and fluorescent probes to visualize the changes in response to NMs treatment. PCR-DGGE and T-RFLP are the most commonly and earliest community fingerprinting techniques used for studying the impact of NMs on microbial composition in environmental samples. The methods analyses total DNA extracted from all the microbes present in the sample. A particular gene or DNA region which is unique to each bacterial species, is then amplified by PCR. Advantages of these methods are they can be performed quickly and relatively cheaply, and the analyses can accommodate a large number of samples simultaneously. Although these methods remains to be the most widely used tool for community analysis, the trend of increasingly applying sequencing technologies such as pyrosequencing to investigate the impacts of NMs is clear (Zhang, Shao et al. 2011, Ye, Zhang et al. 2012).

As most of the microorganisms remain unculturable till now, culture independent techniques to study microbial community structure have gained popularity. Starting with low-throughput 16S rRNA pyrosequencing to high throughput genome-wide sequencing approaches, the field has made significant progress in last decade. Genome-wide sequencing such as metagenomics and metatranscriptomics have revolutionized the study of complex microbial community. 'Meta'omic' approach combines DNA/RNA sequencing with study of proteins and metabolites and is a powerful tool for collective analysis of 
biochemical function, systems-level interactions and quantification of complex microbial community.

Especially metagenomics and metatranscriptomic are most widely used tools for assessing the genomic composition and diversity in microbial community. While DNA-based metagenomics can identify the structure and metabolic potential of the whole community (Eisen 2007), metatranscriptomic can give more precise information about function and activity environmental community. Though metatranscriptomic is comparatively a new technical development but has been successfully used for characterization of structure and function within a variety of microbial communities. The major bottleneck in metatranscriptomics study remains the isolation of good quality RNA as it is prone to degradation and complex matrix of environmental samples makes it difficult to isolate pure and quality RNA required for sequencing. The Illumina platform is currently preferred for sequencing, and widely used in microbial community analysis for rRNA gene surveys (Bartram, Lynch et al. 2011, Caporaso, Lauber et al. 2012).

However, sequencing based approaches often generate large quantities of data and require reference genomes for the annotation of the sequencing data and great efforts on bioinformatics analysis, which remain major challenges of this approach. While next generation sequencing methods are gaining popularity because of the above stated challenges there are very few studies available so far which used these high throughput sequencing methods to study effect of NMs on microbial communities. Following are the most recent studies in this field and all of them have used amplicon sequencing method. To study the effect engineered nanomaterials on freshwater wetlands microbial communities, separate mesocosms were treated with $\mathrm{Ag}^{0}, \mathrm{Ag}_{2} \mathrm{~S}, \mathrm{CuO}$, or CuS NPs. 16S amplicon sequencing was used using Illumina MiSeq platform to study the composition of the community. Specifically, researchers suggest that Cyanobacteria was vulnerable to $\mathrm{Ag}^{0}$ but not $\mathrm{Ag}_{2} \mathrm{~S}$ NPs and they also observed a sharp decrease in $\alpha$-proteobacteria common across the $\mathrm{CuO}$ and $\mathrm{CuS} \mathrm{NPs}$ and $\mathrm{Cu}^{2+}$ treatments but overall the environmental community was evidently resilient despite a worst case scenario of high concentration (Moore, Stegemeier et al. 2016). Another study used the same 16S rRNA amplicon sequencing to study the effect of SWCNTs on the sludge microbes of phenol wastewater 
treatment system, the sequencing data showed that bacterial community structure significantly shifted after SWCNTs addition and did not recover afterward. Zoogloea increased significantly upon SWCNTs addition. Towards the final stage, Rudaea and Mobilicoccus increased, while Burkholderia, Singulisphaera, Labrys and Mucilaginibacter decreased notably (Qu, Ma et al. 2015). One more study uses the same technique of amplicon sequencing to study the effect of sulfidised-silver nanoparticles ( $\mathrm{Ag}_{2} \mathrm{~S}-\mathrm{NPs}$ ) on soil microbial community, they combined quantitative PCR and species sensitivity distribution (SSD) methods along with the sequencing to calculate the threshold toxicity concentration for silver based nanoparticle (Doolette, Gupta et al. 2016).

\subsection{Mechanisms of toxicity to microbial community}

Although extensive studies have been carried out to understand the impacts of NMs on microbial communities, most focused on the overall changes in community profiles and community function caused by organism-specific toxicity of NMs. To understand the exact mechanism behind the change in community structure and function, it will be interesting and important to explore the influence of NMs on intercellular interactions in defined multi-species cultures and in complex microbial communities in natural and engineered ecosystems. Intercellular interaction and communication between members of community in a given ecological niche is the key to fascinating group behaviours and many more critical functions (Jacob, Becker et al. 2004)

\subsection{Social behaviour: the key to community structure and function}

Communication and cooperation are long considered the crux of sociality. Increasing volume of research shows that unicellular microorganisms manifest complex and fascinating social lives (West, Griffin et al. 2006, West, Diggle et al. 2007). The social behaviour is reflected in many ways starting from cooperation to protect themselves from predators and adverse environmental condition, to secure food, to reproduction or dispersal to a new locality (Crespi 2001). The social lives of microbes have a significant impact on various members of ecosystem. Following are the major areas where cooperative behaviours of microbes play key roles $(i)$ in the ability of microbes to cause 
infection in humans, animals, and plants (Williams, Camara et al. 2000, André and Godelle 2005) and (ii) waste treatment and nutrient recycling (Valle, Bailey et al. 2004) (iii) promoting plant growth (Kiers, West et al. 2002).

Bacteria are known to have a myriad of ways to exhibit cell-cell interactions in community level. Following are few well studied systems involved in interactive behaviour.

\subsubsection{Production of communal resources}

Public goods are defined as metabolites secreted by certain members of the community but are beneficial to others occupying the same niche (West, Griffin et al. 2006). Some of the common examples of microbial public goods are siderophores (iron scavenging molecule), antibiotics, rhamnolipids, biosurfactants, exopolysaccharides and proteases (West, Diggle et al. 2007). These molecules are central to the cooperation and complex multicellular behaviour elucidated by microbial community in nature (Dunny, Brickman et al. 2008). Their importance lies in the myriad of cellular functions these molecules are involved in starting from nutrient acquisition to protection against predators. Hence, any alteration on the production of the public goods can alter the structure and function of the whole community and in turn affect the key ecological function performed by these microbial communities.

One primary example of public goods in environmental microbial communities is siderophore, a group of organic compounds produced by bacteria to facilitate the uptake of iron. Iron is an essential element for growth of all microorganisms but its bioavailability is low under circumneutral $\mathrm{pH}$. One mechanism to acquire iron is the production and secretion of siderophore to scavenge iron (Wandersman and Delepelaire 2004). Siderophores have very high affinity for $\mathrm{Fe}^{3+}$ with the affinity constant constant $>10^{30} \mathrm{M}^{-1}$ (Drechsel and Jung 1998, Haas, Eisendle et al. 2008). Apart from iron sequestering, siderophores are also known to enhance virulence (Lamont, Beare et al. 2002), enhance plant-microbe interactions (Ahmed and Holmström 2014), and drive microbial evolution (Keller and Surette 2006, Cordero, Ventouras et al. 2012). Siderophores also promote the growth of uncultured bacteria (D'Onofrio, Crawford et al. 2010). In addition, researchers 
have shown that siderophore deficient mutants lacks the ability to form biofilm in Pseudomonas aeruginosa (Harrison and Buckling 2009). The above wide ranging functions of siderophores suggest that any alteration in the production of these bioactive compounds can have ever lasting impact on bacterial community. There are over 500 types of siderophores known so far and mostly these are produced wide variety of bacteria and few of them are well studied (Figure 2.3 A). Siderophores are produced by several gene clusters and are assembled by nonribosomal cytoplasmic peptide synthetases (Neilands 1995). The production as well as uptake of siderophore-iron complex from the environment is a multi-step process (Figure 2.3 B and C). 

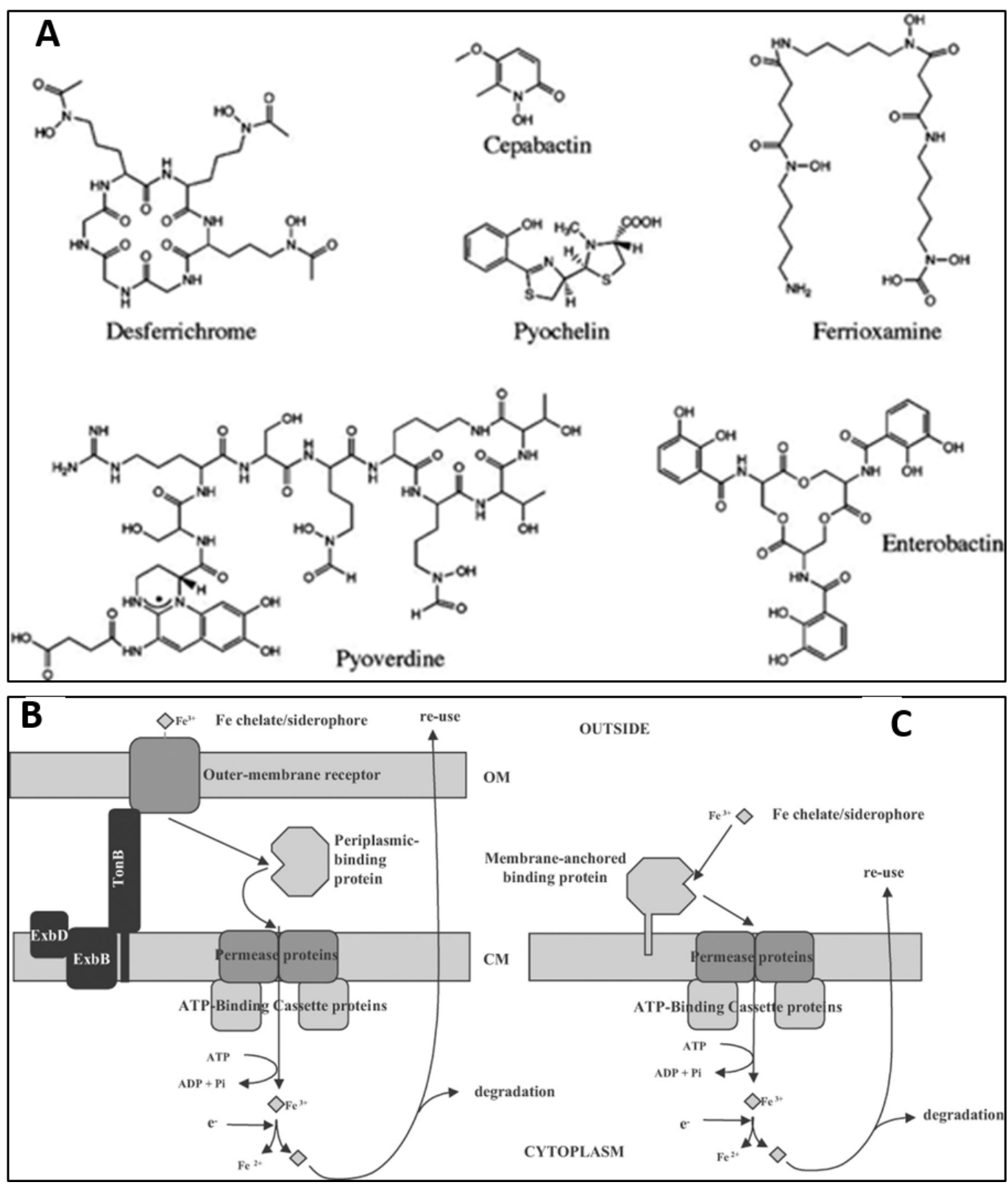

Figure 2.3 (A) Structures of different types of siderophores. Schematic representation of siderophore-mediated iron uptake in (B) Gram-negative and (C) Gram-positive bacteria. Reprinted with permission from (Saha, Saha et al. 2013) and from (Andrews, Robinson et al. 2003) for panel (A) and (B, C) respectively. 


\subsubsection{Cell-cell communication through quorum sensing signals}

Information supply and synchronizing the activity of a population mostly happens through production of chemical signalling molecules. The most common approach to supply information and synchronize social activity in bacteria is the production of certain chemicals as signalling molecules. Quorum sensing (QS) is one of the most important chemical-based signalling systems that bacteria commonly use to coordinate cooperative behaviours (Henke and Bassler 2004, Hodgkinson, Welch et al. 2007). QS allows individual bacteria to assess local cell density and to engage in cooperation once a threshold density has been reached (Miller and Bassler 2001). Many different organisms produce different types of QS signals (Figure 2.4).

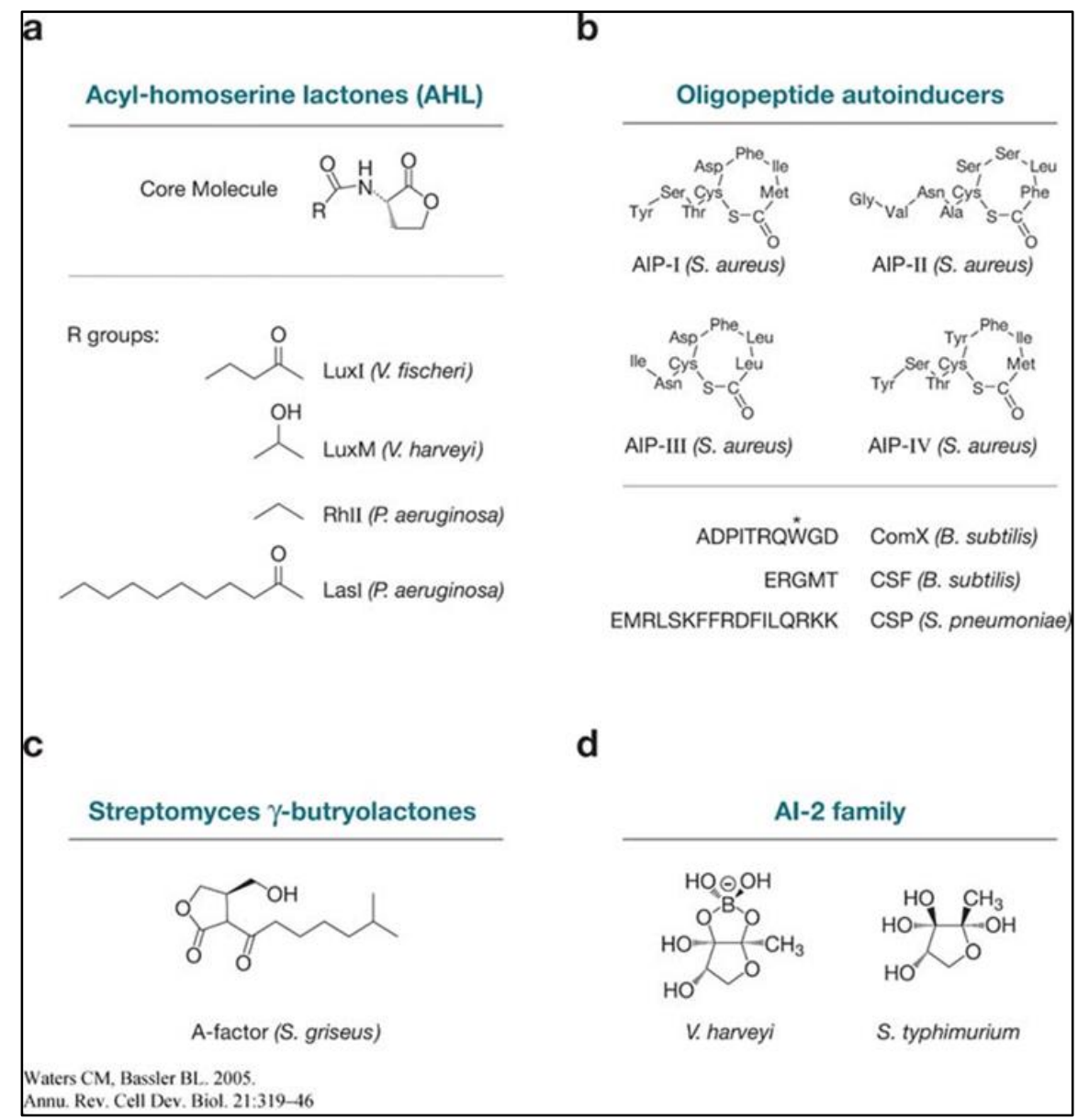

Figure 2.4 Representative bacterial QS molecules. Reprinted with permission from (Waters and Bassler 2005). 
The acylated homoserine lactones (AHLs) are QS signals used by most Gram-negative bacteria (Fuqua, Parsek et al. 2001). The AHL-type QS systems have been identified in a large number of Gram-negative bacterial species belonging to the $\alpha, \beta$, and $\gamma$ subclasses of proteobacteria (Eberl 1999) and have been shown to be highly conserved across different species. These include pathogens such as Pseudomonas aeruginosa, Yersinia enterolitica, Serratia liquefaciens, plant symbionts such as Rhizobium spp., environmental bacteria such as Nitrosomonas spp. and Geobacter uraniumreducens (Case, Labbate et al. 2008). In these bacteria, the AHL-type QS systems have been shown to regulate a wide variety of bacterial physiological processes including bioluminescence (Nealson and Hastings 1979), biofilm formation (Parsek and Greenberg 2005), host pathogenesis (de Kievit and Iglewski 2000, Miller, Skorupski et al. 2002), plasmid transfer, motility, secondary metabolite production (Latifi, Winson et al. 1995), and sporulation (Camilli and Bassler 2006). The AHL-type QS has also been demonstrated to play a critical role in engineering

processes such as membrane biofouling (Dobretsov, Teplitski et al. 2009) and granulation in biological wastewater treatment (Shrout and Nerenberg 2012, Tan, Koh et al. 2014). The ubiquitous presence of the AHL-type QS systems in environmental bacteria and their capability in regulating a broad range of bacterial functions suggest a pivotal role of the AHL-type QS in defining and shaping complex community structures and functions for ecological services. Environmental factors such as nutrient availability (Bollinger, Hassett et al. 2001), temperature, pH (Yates, Philipp et al. 2002) and environmental stresses (Lazazzera 2000) may contribute to different quorum sensing responses. For example, it has been shown that a short-term starvation may enhance quorum sensing signal production in Myxococcus xanthus (Shimkets 1999).

\subsubsection{Collective antibiotic tolerance}

In the past few decades, antibiotic resistance has emerged as a global crisis because of indiscriminate usage of antibiotics. The antibiotic resistance is widespread in most of the natural and engineered environment and spreading among environmental bacteria at an alarming rate (Ventola 2015). There have been a lot of efforts for detailed understanding of the evolution of antibiotic resistance in terms of origin and dissemination (Davies 1994, Martínez 2008, Davies and Davies 2010). But antibiotic resistance and different 
mechanisms associated with it has mainly been investigated at the single level and only recently focus has shifted to the community level studies. It is increasingly clear that bacteria at the community level can survive treatment even if they are not genetically resistant. "Inoculum effect" highlights the fact that cells at a higher density are more tolerant to drug treatment compared to culture with low cell density (Tan, Smith et al. 2012). Moreover, it is apparent now that population dynamics and social interactions play a very important role in development of resistance. Hence, there is effort to understand the underlying communal interactions and population level processes. This will help us answer the question of "how a population of bacteria survive antibiotics treatment when a single bacteria cannot". Such collective tolerance can be attributed to the various processes, e.g., QS, biofilm formation, cooperative production of antibiotic inactivating enzymes, antibiotic titration and mutualistic interactions. (Vega and Gore 2014, Meredith, Srimani et al. 2015).

Biofilms are more tolerant to antimicrobials than their planktonic counterparts (Lewis 2001). One main reasons for this phenomenon is attributed to the physical structure of biofilms which creates a diffusion barrier by secreting extracellular polysaccharide, DNA and proteins (Anderson and O'toole 2008). The cells are also in close contact with each other in biofilms which promotes plasmid transfer and as most of the environmental biofilms are multispecies communities they help in increasing the host range of the mobile genetic elements (Madsen, Burmølle et al. 2012).

\subsection{Summary}

Because of an increasing use of NMs in a wide range of industries, the presence of NMs in the environment is unavoidable. Most of the earlier studies to assess the toxicity of NMs focused on the mechanisms of bactericidal effects (Figure 2.2) on single species laboratory cultures at higher concentrations, which might not be a true representation of the environmentally relevant concentration. Further, extensive studies were carried out to understand the impacts of NMs on microbial communities (Table 2.1), most focused on the overall changes in community profiles and community function caused by organismspecific toxicity of NMs. In addition to bactericidal activities, sub-lethal impact of NMs 
on microbial physiology and functions is a novel and critical aspect of the NMsmicroorganism interactions, in particular, the impact of NMs on various social behaviours such as public goods production and intercellular communication via signaling molecules, which are key to fascinating structures and functions of microbial communities in ecosystem. Thus to comprehensively understand the impacts of NMs on the environment and the health of the ecosystem, it is imperative to elucidate the impacts of NMs on social behaviour of microorganisms. 


\section{CHAPTER 3. Biogenic Tellurium Nanorods Inhibit Pyoverdine Production in Pseudomonas aeruginosa}

A portion of this chapter has been published as Mohanty A, Kathawala MH, Zhang J, Chen WN, Loo JSC, Kjelleberg S, Yang L*, Cao B* (2014) Biogenic tellurium nanorods as a novel antivirulence agent inhibiting pyoverdine production in Pseudomonas aeruginosa. Biotechnology and Bioengineering 111(5): 858-865 and Mohanty A, Liu Y, Yang L, Cao B* (2015) Extracellular biogenic nanomaterials inhibit pyoverdine production in Pseudomonas aeruginosa: A novel insight into impacts of metal(loid)s on environmental bacteria. Applied Microbiology and Biotechnology 99(4): 1957- 1966. Permission has been granted by the licensed content publisher "John Wiley \& Sons"and "Springer Science"respectively to use the published content as a chapter in this thesis.

\subsection{Introduction}

Various microorganisms such as bacteria, fungi, yeast and plant extracts containing redox active enzymes and are capable of reducing metals and metal(loids) to produce NMs (Mohanpuria, Rana et al. 2008, Kumar and Yadav 2009, Durán, Marcato et al. 2011). Although both cells and biofilm matrix of environmental microorganisms are capable of transforming toxic metal(loid) contaminants into nanomaterials, the potential impacts of the biogenic nanomaterials (bio-NMs) on the ecosystems are largely unexplored. In addition, most econanotoxicity studies were conducted using engineered nanomaterials while the impacts of bio-NMs that may be generated in the environment have never been explored.

Tellurium (Te) is a rare metalloid element that has been widely used as an alloy component for products such as solar cells (Singh, Rangari et al. 2004), optical modulators (Staupendahl and Schindler 1982) and gas sensors (Tsiulyanu, Marian et al. 2001). The increasing usage of Te has led to environmental contamination by the highly soluble and toxic oxyanion $\mathrm{TeO}_{3}{ }^{2-}$ (Dopp, Hartmann et al. 2004). Various bacteria have been reported capable of reducing soluble $\mathrm{TeO}_{3}{ }^{2-}$ to insoluble $\mathrm{Te}(0)$ nanomaterials, as a result of either detoxification, redox maintenance, or respiration (Yurkov, Jappé et al. 1996, Moscoso, Saavedra et al. 1998, Trutko, Akimenko et al. 2000, Klonowska, Heulin et al. 2005). Some 
environmental bacteria such as Shewanella oneidensis are capable of producing bio-NMs extracellularly (Narayanan and Sakthivel 2010, Kalathil, Lee et al. 2011, Sintubin, Verstraete et al. 2012).

P. aeruginosa is an environmental bacterium and an opportunistic pathogen that can establish infections in immunocompromised patients. The infection caused by $P$. aeruginosa is very resistant to antimicrobials because of several reasons and the major one being the ability of this organism to form biofilms (Wagner and Iglewski 2008, Rybtke, Jensen et al. 2011).

Herein, it is described for the first time a biogenic nanomaterial that can significantly inhibit the production of PVD in P. aeruginosa. Specifically, tellurium nanorods (TeNRs) were obtained through bioreduction of tellurite by a metal-reducing bacterium Shewanella oneidensis MR-1 and demonstrated that the biogenic TeNRs could effectively inhibit the production of PVD. Although a variety of NMs have been demonstrated to exhibit excellent bactericidal activities (Klaine, Alvarez et al. 2008, Marambio-Jones and Hoek 2010), NMs that can effectively attenuate bacterial public goods production at sublethal concentrations have never been reported.

\subsection{Materials and methods}

\subsubsection{Biosynthesis of TeNRs by $S$. oneidensis}

Stock cultures of S. oneidensis MR-1 were maintained in LB medium with $20 \%$ glycerol at $-80^{\circ} \mathrm{C}$. The bacterial cells were grown in LB medium containing $100 \mu \mathrm{g} / \mathrm{ml}$ potassium tellurite. The cultures were bubbled with nitrogen gas for $5 \mathrm{~min}$ and the headspace in the culture was less than $3 \%$ of the total volume. After $72 \mathrm{~h}$, cells were removed by centrifugation at $5,000 \mathrm{~g}$ for $20 \mathrm{~min}$. The supernatant was then concentrated using Millipore Amicon centrifugal filter units (MWCO $\sim 3 \mathrm{kDa}$ ). Te nanorods (TeNRs) were harvested by using ultracentrifugation at 100,000g for $30 \mathrm{~min}$, washed three times with MilliQ water and dried at $50^{\circ} \mathrm{C}$ under vacuum.

After an overnight exposure to $\mathrm{TeO}_{3}{ }^{2-}$, S. oneidensis cell suspension was placed on a glass microscope slide and dried in an oven at $70^{\circ} \mathrm{C}$. The dried sample was then stained using 4'- 
6- diamidino-2-phenylindole (DAPI). Briefly, $5 \mu$ of DAPI solution $(1 \mathrm{mg} / \mathrm{mL})$ was dropped onto the sample and incubated at room temperature, in the dark, for 45 min. The glass slide was then rinsed with ultrapure water to remove excess DAPI. The stained samples were examined using an inverted epifluorescence microscope (Microscope Axio Observer.Z1, Carl Zeiss). Sample for Transmission electron microscopy (TEM) images and energy dispersive X-ray spectroscopy (EDX) were prepared by drying a drop of TeNRs solution on a carbon-coated copper grid (Shahjamali, Bosman et al. 2012).

\subsubsection{Inductively coupled plasma mass spectrometry}

To determine the dissolution of $\mathrm{TeO}_{3}{ }^{2-}$ from the biogenic TeNRs, the suspension of 100 $\mu \mathrm{g} / \mathrm{ml}$ TeNRs in ABTGC medium was filtered through a centrifugal filter unit (molecular weight cutoff $3 \mathrm{kDa}$; Amicon Ultra-4 3K). The total concentration was quantified using an inductively coupled plasma mass spectrometer (ICP-MS) (ELAN DRC-e, Perkin Elmer; Waltham, MA) as described previously (Klonowska, Heulin et al. 2005, Kim, Kanaly et al. 2012).

\subsubsection{Quantification of pyoverdine in P. aeruginosa cultures}

P. aeruginosa $\mathrm{PAO} 1$ wild type and mutant strains were cultivated at $37^{\circ} \mathrm{C}$ in $\mathrm{ABT}$ minimal medium (15 mM $\left(\mathrm{NH}_{4}\right)_{2} \mathrm{SO}_{4}, 40 \mathrm{mM} \mathrm{Na}_{2} \mathrm{HPO}_{4}, 20 \mathrm{mM} \mathrm{KH}_{2} \mathrm{PO}_{4}, 50 \mathrm{mM} \mathrm{NaCl}, 1$ $\mathrm{mM} \mathrm{MgCl} 2,0.1 \mathrm{mM} \mathrm{CaCl}_{2}$ and $0.01 \mathrm{mM} \mathrm{FeCl}_{3}$ ) supplemented with $30 \mathrm{mM}$ glucose and 5 $\mathrm{g} / \mathrm{l}$ casamino acids (ABTGC) (Chua, Tan et al. 2013) in the absence or presence of TeNRs at different concentrations. Pyoverdine fluorescence (Ex $398 \mathrm{~nm}$, Em $460 \mathrm{~nm}$ ) (Greenwald, Hoegy et al. 2007) and optical density at $600 \mathrm{~nm}\left(\mathrm{OD}_{600}\right)$ were recorded using a TECAN infinite M200PRO plate reader. All the fluorescence measurements were carried out together with cell-free controls to rule out the abiotic effects of TeNRs. In addition, conditioned media (cell-free supernatant of overnight cultures) supplemented with TeNRs were used as another set of controls to check for the interference of TeNRs on the fluorescence measurements. 


\subsubsection{PvdA-gfp assay}

P. aeruginosa strain containing $\mathrm{p}_{\mathrm{pvdA}}-g f p$ reporter (Kaneko, Thoendel et al. 2007, Yang, Nilsson et al. 2009) was cultivated in ABTGC medium at $37^{\circ} \mathrm{C}$ in the absence or presence of TeNRs at different concentrations. GFP fluorescence (Ex 395 nm, Em 509 nm) and OD 600 were measured using a TECAN infinite M200PRO plate reader.

\subsubsection{Quantitative Polymerase Chain Reaction (qPCR)}

P. aeruginosa PAO1 was cultivated in ABTGC medium at $37^{\circ} \mathrm{C}$ in the absence or presence of TeNRs $(50 \mu \mathrm{g} / \mathrm{ml})$. After $9 \mathrm{~h}, 0.5 \mathrm{ml}$ of the culture was mixed with $1 \mathrm{ml}$ of RNA protect (Qiagen mini RNA prep) and centrifuged at 6,000g for 10 min. Total RNA content was extracted using a commercially available kit (Qiagen mini RNA prep) following the instructions from the manufacturer. RNA concentration was determined using a NanoDrop spectrophotometer (Thermo Scientific, DE, USA). Two $\mu \mathrm{g}$ of the total RNA was used for first-strand cDNA synthesis by using a commercially available kit (Fermentas Life Sciences, EU). The resultant cDNA was used in qPCR reactions on ABI StepOnePlus system (Life Technologies, CA). Primers (efficiency $>90 \%$ for all primers) were obtained from Sigma Life Sciences and their sequences are listed in Table 3.1. PCR was carried out with $1 \mu 1$ of first-strand cDNA in a total volume of $20 \mu 1$ containing 0.2 $\mathrm{mM}$ of each primer, $10 \mu \mathrm{l}$ of PCR KAPA SYBR® FAST qPCR Master Mix ABI (2X) Prism ${ }^{\mathrm{TM}}, 0.4 \mu \mathrm{l}$ ROX high. Amplification parameters used were: initial activation $3 \mathrm{~min}$ at $95^{\circ} \mathrm{C}$, then 40 cycles of $3 \mathrm{~s}$ at $95^{\circ} \mathrm{C}$ and $30 \mathrm{~s}$ at respective appropriate annealing temperature. Experiments were performed in triplicates for all the genes. The amount of each target gene was normalized to a reference gene $t s f$ and compared to control samples

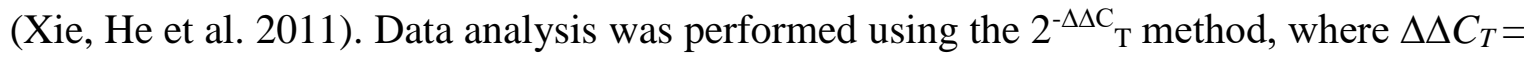
$\Delta C_{T}$ (treated sample) - $\Delta C_{T}$ (untreated sample), $\Delta C_{T}=C_{T}$ (target gene) $-C_{T}(t s f)$, and $C_{T}$ is the threshold cycle value for the amplified gene (Livak and Schmittgen 2001). 
Table 3.1 PCR primer details.

\begin{tabular}{|c|c|c|c|c|}
\hline $\begin{array}{l}\text { Gene } \\
\text { name }\end{array}$ & Forward primer & Reverse primer & Product length & $\begin{array}{l}\text { Annealing } \\
\text { temperature } \\
\left({ }^{0} \mathrm{C}\right)\end{array}$ \\
\hline$t s f$ & $\begin{array}{l}\text { CCTTCAACGAGAAG } \\
\text { CTGACC }\end{array}$ & $\begin{array}{l}\text { CTTTCAGGTTGAC } \\
\text { CACGACA }\end{array}$ & $180 \mathrm{bp}$ & 54.2 \\
\hline$p v d A$ & $\begin{array}{l}\text { GGGCGCCCTGGAA } \\
\text { GTGCTGTT }\end{array}$ & $\begin{array}{l}\text { GCTCTGCCCGCCG } \\
\text { CCGATAATG }\end{array}$ & $575 \mathrm{bp}$ & 64.0 \\
\hline$f p v A$ & $\begin{array}{l}\text { ACACCGGCGAAAC } \\
\text { CAAGAGCAACT }\end{array}$ & $\begin{array}{l}\text { TAGACCGCGCCGA } \\
\text { CGTAGGGAATG }\end{array}$ & 388 bp & 57.0 \\
\hline$p v d E$ & $\begin{array}{l}\text { CACCGCCCCCGTCG } \\
\text { CTATCG }\end{array}$ & $\begin{array}{l}\text { GGTCTTGTCCGGG } \\
\text { GCCTCCTGTT }\end{array}$ & 369 bp & 58.3 \\
\hline$p v d N$ & $\begin{array}{l}\text { CGAGCGACGCCGG } \\
\text { CAATAAATGG }\end{array}$ & $\begin{array}{l}\text { GTTGCACGGCGAA } \\
\text { GTAGCGACCTG }\end{array}$ & $240 \mathrm{bp}$ & 57.6 \\
\hline$p v d S$ & $\begin{array}{l}\text { TCGGGGCCGGAGG } \\
\text { AAGAAGG }\end{array}$ & $\begin{array}{l}\text { CGGCGGGCGCTGA } \\
\text { GATGG }\end{array}$ & 296 bp & 62.7 \\
\hline$p v d T$ & $\begin{array}{l}\text { AACCGCATCGCCAT } \\
\text { CСССТАCTCC }\end{array}$ & $\begin{array}{l}\text { TCACGCCGATCCC } \\
\text { GCCTACCAG }\end{array}$ & 277 bp & 62.7 \\
\hline
\end{tabular}

\subsection{6 iTRAQ-based proteomic analysis}

Proteomic analysis was conducted using an iTRAQ-coupled two-dimensional LC-MS/MS technique as described previously (Zhou and Chen 2011). Briefly, cells of $P$. aeruginosa PAO1 grown in ABTGC medium in the absence or presence of $50 \mu \mathrm{g} / \mathrm{ml} \mathrm{TeNRs} \mathrm{at} \mathrm{late}$ exponential growth phases were harvested by centrifugation at $3000 \mathrm{~g}$ for $20 \mathrm{~min}$ at $4{ }^{\circ} \mathrm{C}$ and lysed in lysis buffer (50 mM NaCl, $5 \mathrm{mM}$ DTT, $1 \mathrm{mM}$ PMSF and $50 \mathrm{mM}$ Tris-HCl, $\mathrm{pH}$ 8.0) by intermittent sonication. Unbroken cells were removed by centrifugation at $3000 \times g$ for $10 \mathrm{~min}$ at $4{ }^{\circ} \mathrm{C}$. The supernatants containing the cytoplasmic proteins were collected by centrifugation at $120,000 \mathrm{~g}$ for $60 \mathrm{~min}$ at $4^{\circ} \mathrm{C}$. Protein concentration was determined by Bradford assay using $\gamma$-globulin as a control. Proteins from each sample were precipitated by cold acetone at $-20{ }^{\circ} \mathrm{C}$. The proteins $(\sim 100 \mu \mathrm{g})$ were reduced, cysteine blocked, digested and labeled with respective isobaric tags using iTRAQ reagent Multiplex kit (Applied Biosystems Inc., CA, USA) according to manufacturer's protocol. The analysis of iTRAQ-labeled peptide mixtures were performed on a combination of an Agilent 1200 nanoflow LC system (Agilent Technologies Inc., USA) and a 6530 Q-TOF mass spectrometer (Agilent Technologies Inc., USA). The identification and quantification of the proteins were performed using Spectrum Mill MS Proteomics Workbench (Agilent Technologies, Software Revision A.03.03.084 SR4). Each MS/MS spectrum was searched for species $P$. aeruginosa against the UniProt protein database. 
The following criteria were required to consider a protein for further statistical analysis: two or more distinct peptides had to be identified and the fold change had to be greater than 2 or less than 0.5 .

\subsubsection{Transposon mutagenesis library and mutant screening}

The $P$. aeruginosa $\triangle m o t B$ and $\Delta f l i F$ mutants were identified from a transposon mutagenesis library screen, which was constructed by using the Mariner transposon vector pBT20, as previously described (Wang, Chua et al. 2013). Transconjugants carrying transposon insertion were picked from the selective plates and inoculated into microtiter plate wells containing LB medium. Mutants that produced PVD at a comparable level in the presence and absence of $50 \mu \mathrm{g} / \mathrm{ml}$ TeNRs were selected and saved for further analysis. For identification of the transposon insertion site, the sequence flanking the Mariner transposon in selected mutants was identified by arbitrary polymerase chain reaction (PCR), as previously described (Friedman and Kolter 2004).

\subsubsection{Cytotoxicity assay of biogenic TeNRs}

Human bronchial epithelial cells (BEAS-2B; ATCC, Manassas, VA, USA) and murine macrophages (RAW264.7; ATCC, Manassan, VA, USA) were used to test cytotoxicity of the biogenic TeNRs. Both cell types were cultured in complete DMEM (high glucose Dulbecco's Modified Eagle's Medium; PAA Laboratories Inc., MA, USA) supplemented with $10 \%$ fetal bovine serum, $1 \%$ L-glutamine and $1 \%$ Antibiotics/Antimycotics (PAA Laboratories) at standard culture conditions $\left(37^{\circ} \mathrm{C}, 5 \% \mathrm{CO}_{2}\right)$ and sub-cultured in the ratio of 1:2 to 1:4 at $90 \%$ confluency. All cells were passaged at least 3 times before using for the cytotoxicity experiments. Cytotoxicity was measured using the Cell Counting Kit-8 (CCK-8/WST-8; Dojindo Molecular Laboratories Inc., Japan) following the protocols provided by the manufacturer. Cells were seeded in 96-well plates at a seeding density of $10^{4}$ cells per well. After $24 \mathrm{~h}$ incubation, the culture medium was replaced by freshly prepared TeNRs suspension in the cell culture medium and incubated for another $22 \mathrm{~h} .10$ $\mu \mathrm{l}$ of CCK- 8 was then added to each well and the cells were further incubated for $2 \mathrm{~h}$ after which the absorbance at $450 \mathrm{~nm}$ was measured. Wells containing cells and TeNRs suspension without CCK-8 was used as background. 


\subsubsection{Flow cell biofilms}

Biofilm formation under hydrodynamic conditions was evaluated using multi-channel flow cells (BioCentrum-DTU, Denmark). The dimensions and assembly of the flow cell systems were described elsewhere (Crusz, Popat et al. 2012). Each channel of the flow cells was inoculated using $0.4 \mathrm{ml}$ diluted overnight cultures in modified ABTG medium $\left(\mathrm{OD}_{600} \sim 0.15\right)$. After inoculation, the medium flow was stopped for initial attachment ( 1 h) onto the glass slide used in the flow cells. Then air-saturated modified ABTG medium was continuously supplied with a flow rate of $6 \mathrm{ml} / \mathrm{h}$ for biofilm growth in each channel.

\subsubsection{Confocal Laser Scanning Microscopy (CLSM) imaging}

All CLSM image acquisitions were performed using a Zeiss LSM 710 confocal laser scanning microscope (Carl Zeiss, Jena, Germany) equipped with detectors and filter sets for monitoring of green fluorescence $(488 \mathrm{~nm})$ and cyan fluorescence $(458 \mathrm{~nm})$. Threedimensional images and sections were generated using the IMARIS software package (Biplane AG, Zürich, Switzerland). 40X oil immersion lens were used for visualizing the biofilm morphology at $24 \mathrm{~h}, 72 \mathrm{~h}, 120 \mathrm{~h}, 132 \mathrm{~h}$ and $144 \mathrm{~h}$. GFP fluorescence of the cells were observed with the excitation at $488 \mathrm{~nm}$ and emission at $509 \mathrm{~nm}$. PVD fluorescence was observed with the excitation and emission at $405 \mathrm{~nm}$ and $461 \mathrm{~nm}$, respectively. After $120 \mathrm{~h}$, TeNRs were introduced to the biofilms along with the media at a concentration of $50 \mu \mathrm{g} / \mathrm{ml}$. Confocal images were taken after $12 \mathrm{~h}$ and $24 \mathrm{~h}$ of TeNRs addition.

\subsubsection{Analysis of CLSM images.}

The CLSM images were analysed using IMARIS software (version 7.6.4; Bitplane, Zurich, Switzerland). The structure of macrocolonies was reconstructed from Z-series images.

\subsubsection{RNA extraction from biofilms}

Silicon tubing (Masterflex L/S 16, i.e., $3.2 \mathrm{~mm}$ ) of $20 \mathrm{~cm}$ long was used to grow biofilms for RNA extraction. Biofilms were grown for $120 \mathrm{~h}$ and then media was changed to ABTG supplemented with TeNRs at a concentration of $50 \mu \mathrm{g} / \mathrm{ml}$. Biofilms were harvested 
after $24 \mathrm{~h}$ exposure to TeNRs. Biofilm biomass obtained after $144 \mathrm{~h}$ growth in ABTG medium without TeNRs was used as the control. RNA was extracted from all the samples using commercially available Qiagen mini RNA prep kits following manufacturer's instructions (RNeasy Mini Kit, Qiagen). Experiments were conducted in triplicates.

\subsubsection{RNA sequencing}

Quality of the RNA samples was determined using the Quant-iT ${ }^{\mathrm{TM}}$ RiboGreen ${ }^{\circledR}$ RNA Assay Kit (Invitrogen) and Quant-iT ${ }^{\mathrm{TM}}$ PicoGreen ${ }^{\circledR}$ dsDNA Assay Kit (Invitrogen) on a Bioanalyzer RNA 6000 Nano Chip (Agilent). Next-generation sequencing library preparation was performed by following TruSeq RNA Sample Preparation v2 protocol (Illumina) with modifications: The mRNA purification step was omitted and instead, 200 ng of total RNA was directly added to the elute-fragment-prime step. The PCR amplification step, which selectively enriches for library fragments that have adapters ligated on both ends, was performed according to the manufacturer's recommendation but the number of amplification cycles was reduced to 12 . Each library was uniquely tagged with one of Illumina's TruSeq LT RNA barcodes to allow library pooling for sequencing. Library quantitation was performed using Invitrogen's Picogreen assay and the average library size was determined by running the libraries on a Bioanalyzer DNA 1000 chip (Agilent). Library concentration was normalized to $2 \mathrm{nM}$ and the concentration was validated by qPCR on a ViiA-7 real-time thermocycler (Applied Biosystems), using qPCR primers recommended in Illumina's qPCR protocol and Illumina's PhiX control library as a standard. Libraries were then pooled at equal volumes and sequenced in two lanes of an Illumina HiSeq2500 rapid run at a final concentration of $7.2 \mathrm{pM}$ and a read-length of 101 bp paired-end.

\subsubsection{Computational analysis}

The Illumina RNA sequencing raw data were deposited in the NCBI Sequence Read Archive database (http://www.ncbi.nlm.nih.gov/sra) with an accession number SRP045514. The sequence reads were assembled and analysed in RNA-Seq and expression analysis application of CLC genomics Workbench 6.0 (CLC Bio, Aarhus, $\begin{array}{lllll}\text { Denmark). } & \text { The } & P & \text { aeruginosa } & \text { PA01 }\end{array}$ 
(http://www.ncbi.nlm.nih.gov/nuccore/110645304) was utilized as the reference genome for the assembly. The following criteria were used to filter the unique sequence reads: minimum length fraction of 0.9 , minimum similarity fraction of 0.8 , and maximum number of two mismatches. Data were normalized by calculating the reads per kilobase per million mapped reads (RPKM) for each gene (Mortazavi, Williams et al. 2008). Results were annotated using databases PseudoCAP (http://www.geneontology.org/GO.current.annotations.shtml) www.pseudomonas.com. Statistical analyses ANOVA and t-test were performed. The fold change ratio (R) of each gene expression was calculated as the ratio of RPKM in treated sample to that of the control.

\subsection{Results and discussion}

\subsubsection{Biogenic TeNRs from $\mathrm{TeO}_{3}{ }^{2-}$ reduction by $\mathrm{S}$. oneidensis}

TeNRs have been successfully prepared via physicochemical routes including chemical reduction and photolytic preparation (Liu, Hu et al. 2004, Zhu, Wang et al. 2004, Gao, Lu et al. 2008, Webber and Brutchey 2009). The unique helical chain conformation of Te crystals typically leads to a highly anisotrophic growth to form one-dimensional (1D) structures such as nanorods (Webber and Brutchey 2009). TeNRs can also be produced by bacteria grown on $\mathrm{Te}$ oxyanions such as tellurite $\left(\mathrm{TeO}_{3}{ }^{2-}\right)$, which offers a "green" approach for the synthesis of Te nanomaterials under facile conditions in the absence of organic solvents. For example, although $\mathrm{TeO}_{3}{ }^{2-}$ is highly toxic to most microorganisms and has been used as an antimicrobial agent for decades (Turner, Borghese et al. 2012), $S$. oneidensis has been reported to be able to reductively transform $\mathrm{TeO}_{3}{ }^{2-}$ to $\mathrm{Te}(0)$ in the form of rod-like nanostructures, i.e., TeNRs, intracellularly and at the cell exterior (Klonowska, Heulin et al. 2005, Kim, Kanaly et al. 2012).

TeNRs used in this study were obtained through microbial reduction of $\mathrm{TeO}_{3}{ }^{2-}$ by $S$. oneidensis using lactate as an electron donor. It was observed that black precipitates, presumably aggregates of TeNRs, at the cell exterior upon the exposure of $S$. oneidensis

cells to $\mathrm{TeO}_{3}{ }^{2-}$ (Figure 3.1A). TEM-EDX showed that the biogenic TeNRs obtained here were about 10-20 nm wide, up to several hundreds of $\mathrm{nm}$ long, and were comprised 
entirely of Te (Figure 3.1B and C). In this study, focus was on the novel antivirulence activity of the biogenic TeNRs and further detailed material characterization of the TeNRs was not included. In fact, the reduction of $\mathrm{TeO}_{3}{ }^{2-}$ by $S$. oneidensis has been reported in literature and the $\mathrm{Te}(0)$ nanorods obtained from bacterial reduction of $\mathrm{TeO}_{3}{ }^{2-}$ under similar experimental conditions have been extensively characterized (Klonowska, Heulin et al. 2005, Kim, Kanaly et al. 2012)
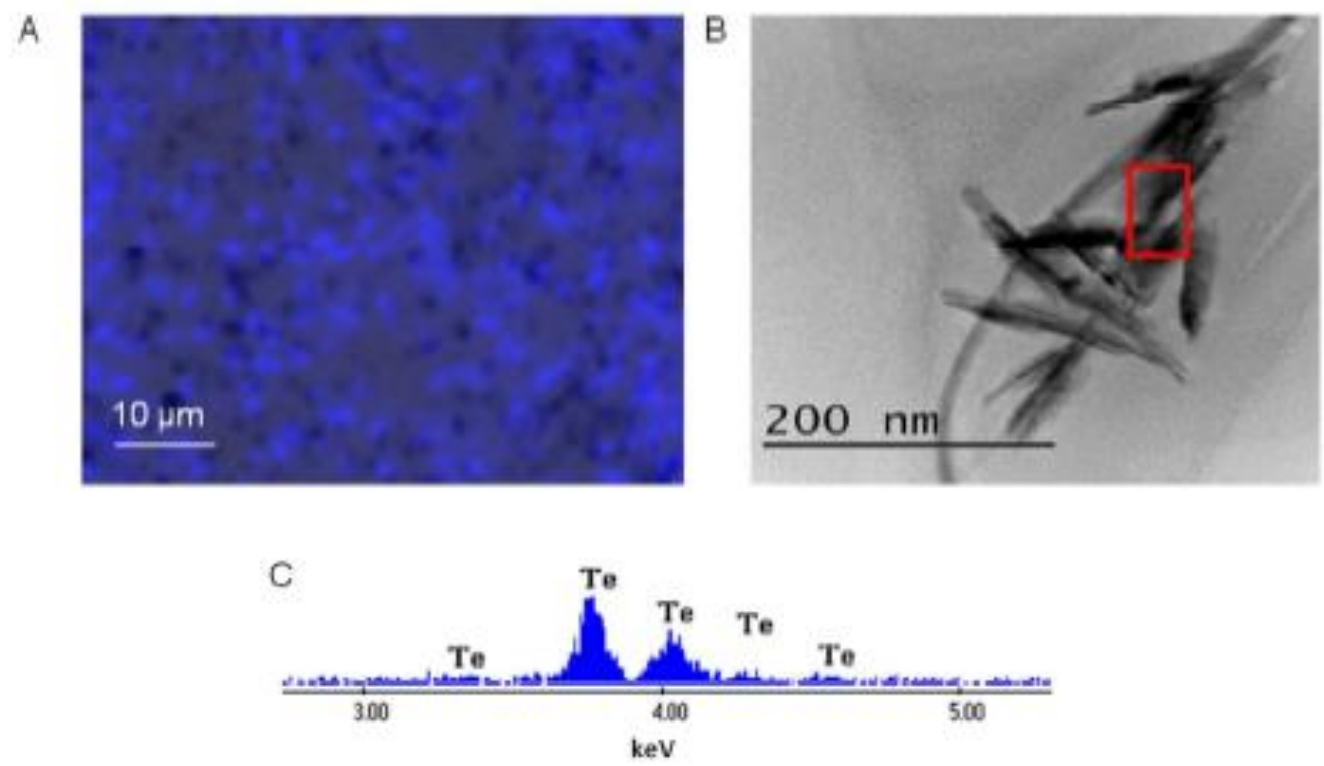

Figure 3.1 (A) Extracellular precipitates of TeNRs (black) in a suspension of cells (blue) visualized by overlay of bright-field and fluorescence imaging. Cells were stained with DAPI. (B) TEM image and (C) EDX spectrum of the biogenic TeNRs.

\subsubsection{Inhibition of PVD biosynthesis by biogenic TeNRs}

In an effort to elucidate impacts of the biogenic TeNRs on microorganisms, $P$. aeruginosa was grown in the presence of TeNRs. Interestingly, TeNRs (up to $100 \mu \mathrm{g} / \mathrm{ml}$ ) have no negative impact on bacterial growth, as evidenced by comparable or even slightly higher specific growth rate for all treated cultures, compared to the controls (Table 3.2), suggesting that the biogenic TeNRs do not exhibit bactericidal activity against $P$. aeruginosa. 
Table 3.2 Influence of TeNRs on growth of $P$. aeruginosa PAO1 in ABTGC media at $37^{\circ} \mathrm{C}$. Specific growth rate was determined from $\mu=d \ln \left(\mathrm{OD}_{600}\right) / \mathrm{dt}$, where $\mathrm{OD}_{600}$ was the optical density at a wavelength of $600 \mathrm{~nm}$. Values are means \pm standard deviation $(\mathrm{n}=3)$.

\begin{tabular}{cc}
\hline Concentration of TeNRs $(\mu \mathrm{g} / \mathrm{ml})$ & Specific growth rate $\left(\mathrm{h}^{-1}\right)$ \\
\hline 0 & $0.42 \pm 0.04$ \\
25 & $0.49 \pm 0.09$ \\
50 & $0.49 \pm 0.04$ \\
100 & $0.50 \pm 0.05$ \\
\hline
\end{tabular}

Chemically synthesized Te nanomaterials with different structures such as nanorice, nanopensil and nanowire have been reported to exhibit excellent antibacterial activity because of the oxidative dissolution of $\mathrm{TeO}_{3}{ }^{2-}$ from the Te nanomaterials (Lin, Lee et al. 2012).

Here, the biogenic TeNRs did not show bactericidal activity, possibly due to a high stability and resistance to molecular oxygen of the biogenic TeNRs. To confirm this, ICPMS was used to quantify the concentration of $\mathrm{TeO}_{3}{ }^{2-}$ in the ABTGC medium with the presence of $100 \mu \mathrm{g} / \mathrm{ml} \mathrm{TeNRs} \mathrm{but} \mathrm{no} \mathrm{TeO}_{3}{ }^{2-}$ could be detected after $24 \mathrm{~h}$. The resistance to oxidative dissolution and the lack of bactericidal activity of the biogenic TeNRs open a new window of novel applications other than being used as a bactericidal agent. Although the biogenic TeNRs did not exhibit bactericidal activity against $P$. aeruginosa, the fluorescence of pyoverdine (PVD) was significantly lower in the cultures with TeNRs compared to those without TeNRs at both exponential and stationary phases of growth, and the attenuation of PVD fluorescence by TeNRs occurred in a concentration dependant manner (Figure 3.2). 


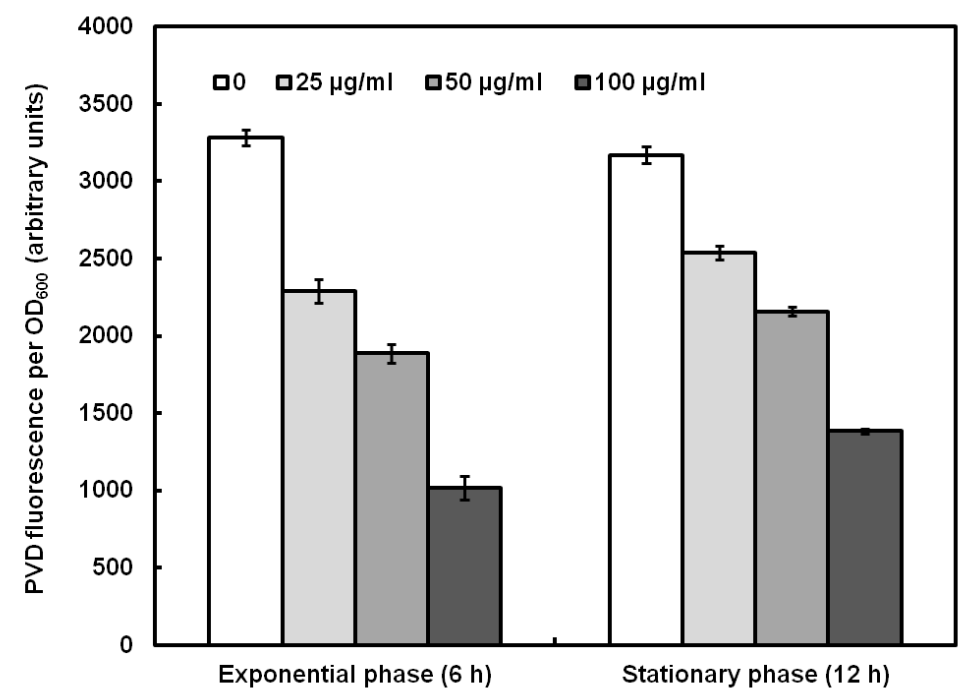

Figure 3.2 Influence of TeNRs $(0,25,50,100 \mu \mathrm{g} / \mathrm{ml})$ on PVD fluorescence (normalized by cell density) in $P$. aeruginosa PAO1 cultures growing in ABTGC media in the exponential $(6 \mathrm{~h})$ and stationary phase of growth $(12 \mathrm{~h})$. Data shown are mean \pm standard deviation $(n=3)$

The attenuation of PVD fluorescence by TeNRs suggests a potential for using TeNRs as a novel antivirulence agent by targeting PVD production. To further investigate whether the attenuation of PVD fluorescence by TeNRs was because of the inhibition of the production of PVD in the cultures, a $p v d A:: g f p$ reporter strain was employed which allowed the biosynthesis of PVD to be monitored based on GFP fluorescence. In the presence of TeNRs, the GFP fluorescence in the cultures of the reporter strain, in both exponential and stationary phases of growth, was significantly lower than for cultures without TeNRs (Figure 3.3 a), suggesting that the TeNRs inhibited the expression of $p v d A$ gene and, hence, PVD biosynthesis. Quantitative polymerase chain reaction (qPCR) analysis revealed that the expression levels of several other key PVD biosynthesis genes in P. aeruginosa exposed to $50 \mu \mathrm{g} / \mathrm{ml}$ of TeNRs were also significantly lower than the noTeNRs controls (Figure $3.3 \mathrm{~b}$ ), confirming the inhibitory effect of TeNRs on the biosynthesis of PVD in P. aeruginosa. 

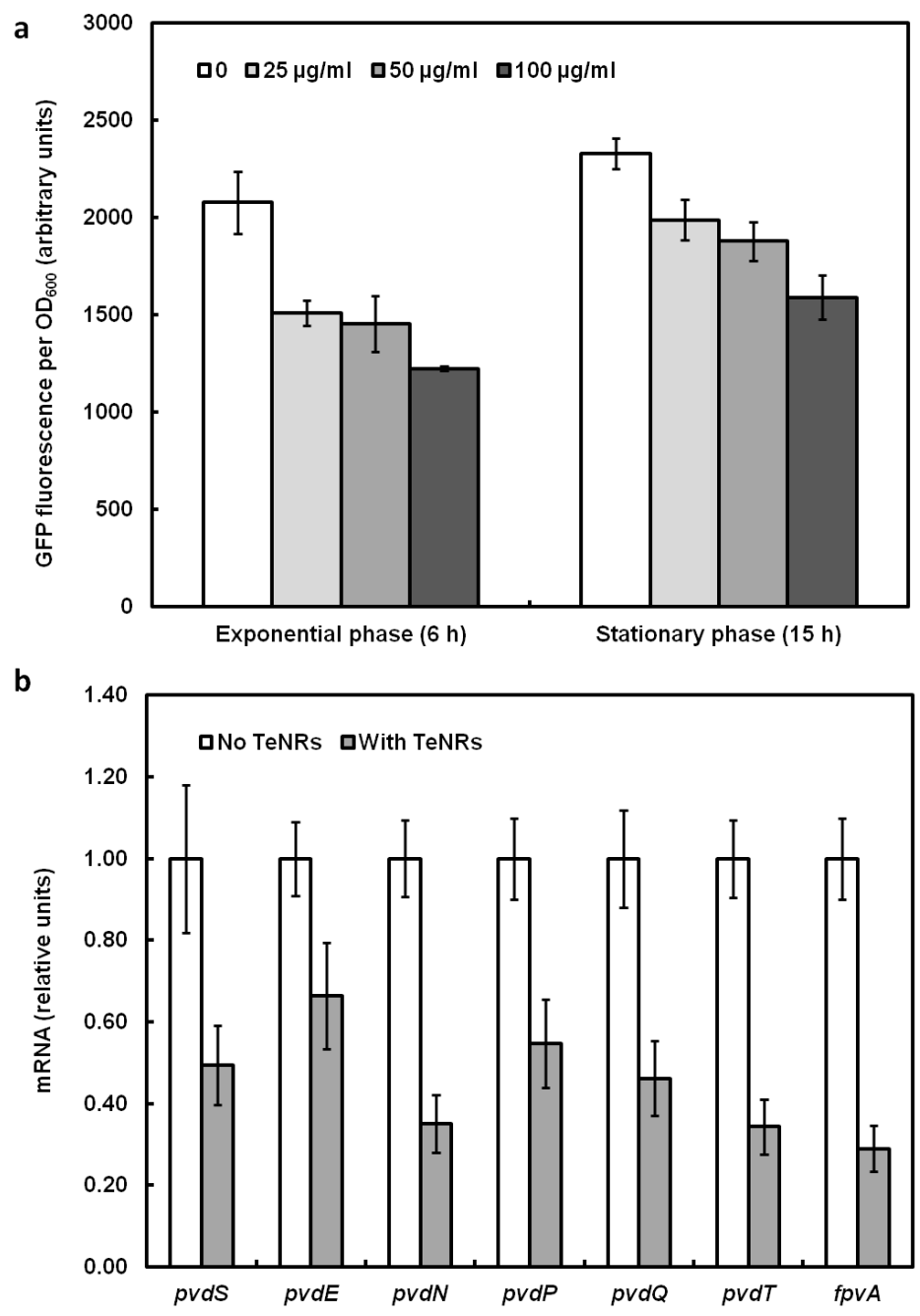

Figure 3.3 (a) Influence of TeNRs $(0,25,50,100 \mu \mathrm{g} / \mathrm{ml})$ on GFP fluorescence (normalized by cell density) in $P$. aeruginosa reporter strain $p v d A$-gfp growing in ABTGC media at the exponential phase $(6 \mathrm{~h})$ and stationary phase $(12 \mathrm{~h})$ of growth. (b) Influence of TeNRs $(50 \mu \mathrm{g} / \mathrm{ml})$ on the expression level of key genes involved in PVD production and uptake. Values were normalized to the housekeeping gene $t s f$. PvdS: a transcriptional regulator; PvdE: an export $\mathrm{ABC}$ transporter to transport PVD precursors across the inner membrane; PvdN and PvdP: periplasmic enzymes involved in chromophore formation; PvdQ: a periplasmic enzyme for removal of fatty acid chains from PVD precursors; PvdT: a subunit of the ATP-dependent efflux pump for PVD secretion; FpvA: an outer membrane transporter for import of ferri-pyoverdine. Data shown are mean \pm standard deviation $(n=3)$.

The inhibition of PVD biosynthesis by biogenic TeNRs at the transcriptional level was further validated at the protein level through a proteomics approach. Among the proteins 
differently expressed in $P$. aeruginosa in the presence or absence of TeNRs were siderophore-related proteins PvdA, FpvA, FptA and PchB (Table 3.3).

Table 3.3 Down-regulation of proteins involved in siderophore production and uptake in $P$. aeruginosa PAO1 in the presence of biogenic TeNRs $(50 \mu \mathrm{g} / \mathrm{ml})$. ${ }^{a}$ The percentage of matching amino acids from identified peptides divided by the total number of amino acids in the sequence; ${ }^{b}$ The ratio of protein production level in biogenic TeNRs-incubated cells to control cells without TeNRs.

\begin{tabular}{cccc}
\hline Locus tag & Protein & Cov $^{\mathrm{a}}$ & Ratio $^{\mathrm{b}}$ \\
\hline PA2386 & L-ornithine 5-monooxygenase, PvdA & 40 & 0.50 \\
PA2398 & Ferri-pyoverdine receptor, FpvA & 17 & 0.32 \\
PA4221 & Ferri-pyochelin receptor, FptA & 8 & 0.45 \\
PA4230 & Salicylate biosynthesis protein, PchB & 33 & 0.4 \\
\hline
\end{tabular}

Consistent with the qPCR data, both PvdA and FpvA, the key proteins involved in PVD biosynthesis and ferri-PVD uptake, respectively, were down-regulated in the presence of biogenic TeNRs. Interestingly, PchB and FptA, the proteins that play an important role in pyochelin biosynthesis and ferri-pyochelin uptake, were also found down-regulated, suggesting that the biogenic TeNRs also inhibit the production of pyochelin in $P$. aeruginosa. In addition to $\mathrm{PVD}$, pyochelin is another major siderophore that $P$. aeruginosa produces to meet its need for iron. Although PVD appears to be more essential than pyochelin in iron depleted conditions, both PVD and pyochelin are considered to be virulence factors of $P$. aeruginosa. The inhibitory effects of the biogenic TeNRs on the production of both PVD and pyochelin render them a promising antivirulence agent against $P$. aeruginosa.

\subsubsection{Polysaccharides, amyloids, and flagellar motility in cell-TeNRs interaction}

The inhibitory effect of TeNRs on PVD biosynthesis led us to address how TeNRs at the cell exterior inhibit intracellular gene expression. In $P$. aeruginosa, two major extracellular polysaccharides Pel and Psl as well as functional amyloids Fap have been demonstrated to play important roles protecting bacteria from various unfavourable conditions (Dueholm, Petersen et al. 2010, Colvin, Gordon et al. 2011, Mann and Wozniak 2012, Billings, Millan et al. 2013). In addition, the polysaccharide Psl has been 
reported to be able to act as a signal to stimulate biofilm formation of $P$. aeruginosa (Irie, Borlee et al. 2012). To test whether the extracellular polysaccharides and amyloids are involved in the interaction between TeNRs and $P$. aeruginosa, the production of PVD was monitored in mutant strains lacking extracellular polysaccharides ( $\triangle p e l A, \Delta p s l B C$, $\triangle p e l A \triangle p s l B C D)$ or amyloids $(\triangle f a p C)$ in the presence and absence of TeNRs. The results showed that the lack of extracellular polysaccharides Pel and Psl or amyloids did not abolish the inhibitory effect of TeNRs on PVD production (Figure 3.4), suggesting that the inhibition of PVD production by TeNRs is not mediated by extracellular polysaccharides and amyloids.

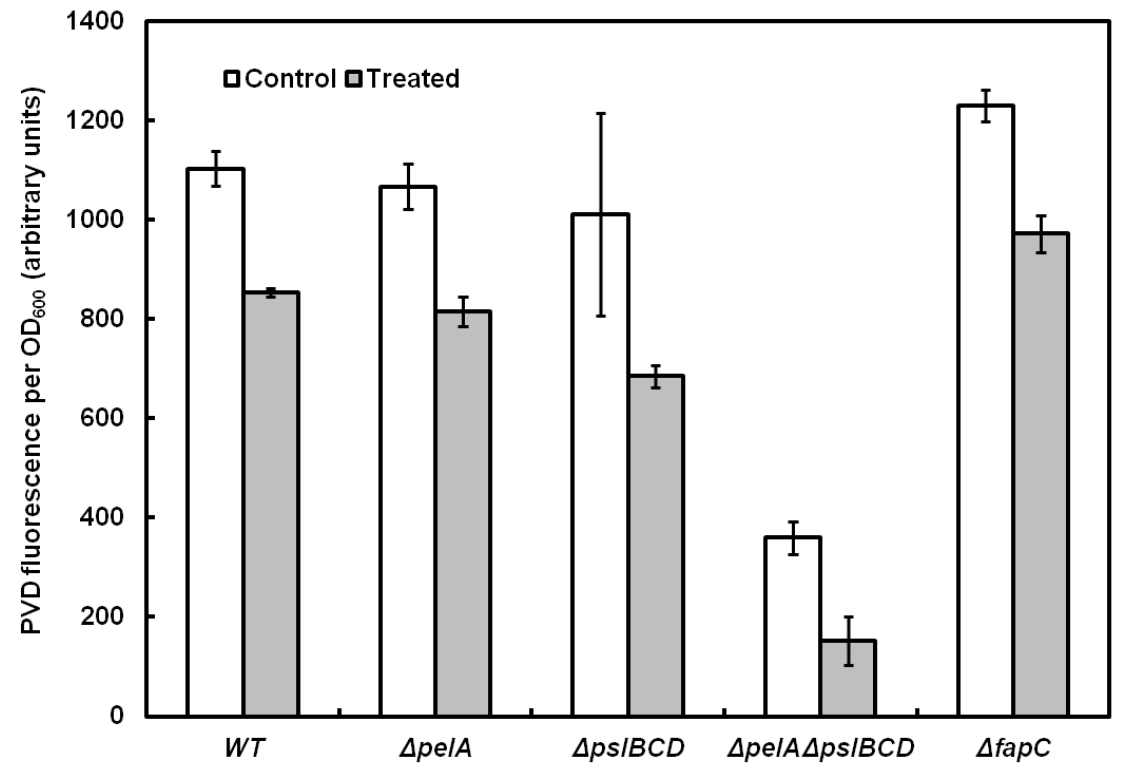

Figure 3.4 PVD fluorescence (normalized by cell density) in $12 \mathrm{~h}$ cultures of $P$. aeruginosa PAO1 wild type and mutants lacking polysaccharides or amyloids in ABTGC media with $(50 \mu \mathrm{g} / \mathrm{ml})$ or without TeNRs. Data shown are mean \pm standard deviation $(n=3)$.

Further the interaction of TeNRs with the mutants in a transponson mutagenesis library was tested. Interestingly, inhibition of PVD production could not be observed for mutant strains $\Delta m o t B$ and $\Delta f l i F$ (Figure 3.5). MotB and FliF are proteins involved in flagella mediated motility and it has been reported that the mutants lacking MotB or FliF has a significantly compromised motility (Grünenfelder, Gehrig et al. 2003, Doyle, Hawkins et al. 2004, Chevance and Hughes 2008). As an important appendage, bacterial flagella not 
only generate motility but can also sense physical properties of the local environment. For example, flagella have been reported to be used by Vibrio parahaemolyticus to sense surface contact, which triggers a programme of gene expression promoting colonization and virulence (Gode-Potratz, Kustusch et al. 2011). Here, the abolishment of the inhibitory effect of TeNRs on PVD production in the motility-deficient mutants implies an involvement of flagellar movement in the cell-TeNRs interaction. The molecular mechanism by which the interaction between biogenic TeNRs and flagellar movement negatively influences PVD biosynthesis, however, remains to be identified.

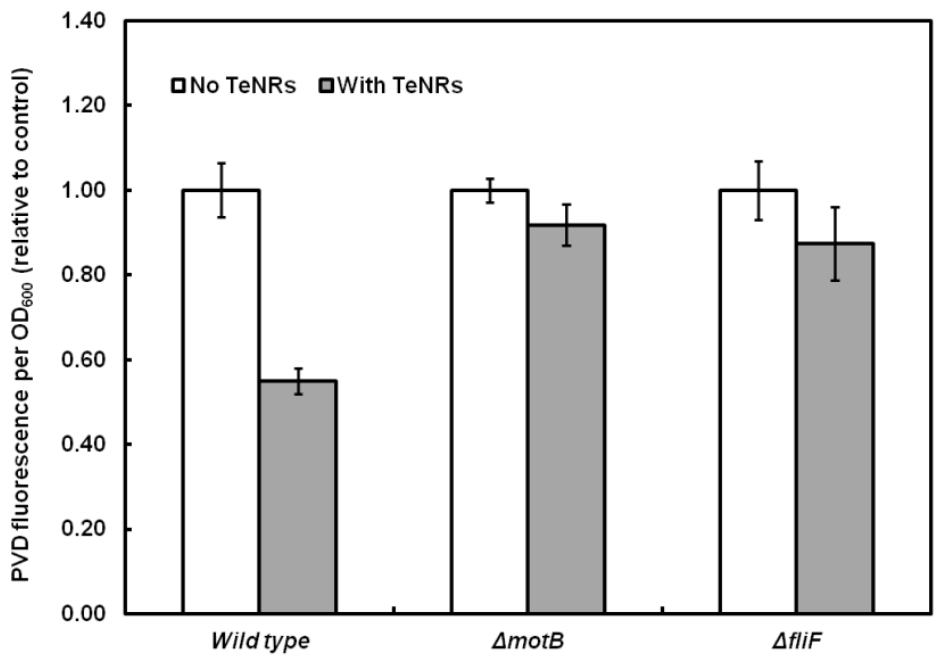

Figure 3.5 PVD fluorescence (normalized by cell density) in $12 \mathrm{~h}$ cultures of $P$. aeruginosa PAO1 wild type and motility-deficient mutants $\Delta m o t B$ and $\Delta f l i F$ in ABTGC media with $(50 \mu \mathrm{g} / \mathrm{ml})$ or without TeNRs. Data shown are mean \pm standard deviation $(n=3)$.

\subsubsection{Cytotoxicity of biogenic TeNRs}

It was demonstrated that the production of PVD in $P$. aeruginosa could be inhibited by biogenic TeNRs. To further demonstrate the clinical potential of the biogenic TeNRs, CCK-8 viability assay was carried out to evaluate their cytotoxicity by using human bronchial epithelial cells BEAS-2B and murine macrophages RAW264.7. The presence of TeNRs (up to $100 \mu \mathrm{g} / \mathrm{ml}$ ) did not influence the metabolic rate of BEAS-2B and RAW264.7 cells, suggesting a lack of cytotoxicity by the TeNRs against mammalian cells 
(Figure 3.6). Thus, the biogenic TeNRs hold a promise as a novel no-biocidal antivirulence agent against $P$. aeruginosa and possibly other bacterial pathogens.

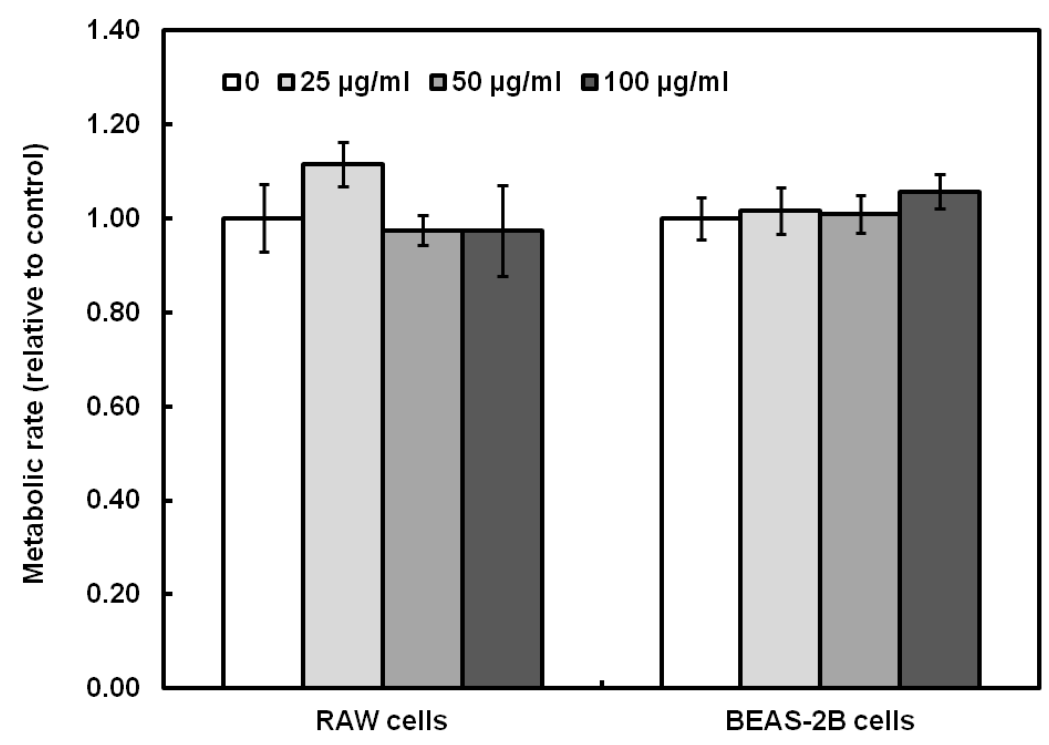

Figure 3.6 CCK-8 viability assay for RAW cells and BEAS-2B cells in the presence of TeNRs at different concentrations: $0,25,50,100 \mu \mathrm{g} / \mathrm{ml}$. Metabolic rate is shown as the dehydrogenase activity which reduces WST-8 salt to formazon dye. Untreated cells were used a controls. Data shown are mean \pm standard deviation $(n=3)$.

\subsubsection{TeNRs reduce PVD production in $P$. aeruginosa biofilms}

Biofilm mode of growth is predominant in environmental microorganisms. To study the impacts of TeNRs on siderophore production in biofilms, the GFP-tagged P. aeruginosa strain PAO1-gfp was grown in flow cell biofilm reactors and monitored the spatiotemporal production of PVD in biofilms. The production of PVD and the biofilm development in the flow cells examined using CLSM are shown in Figure 3.7. 


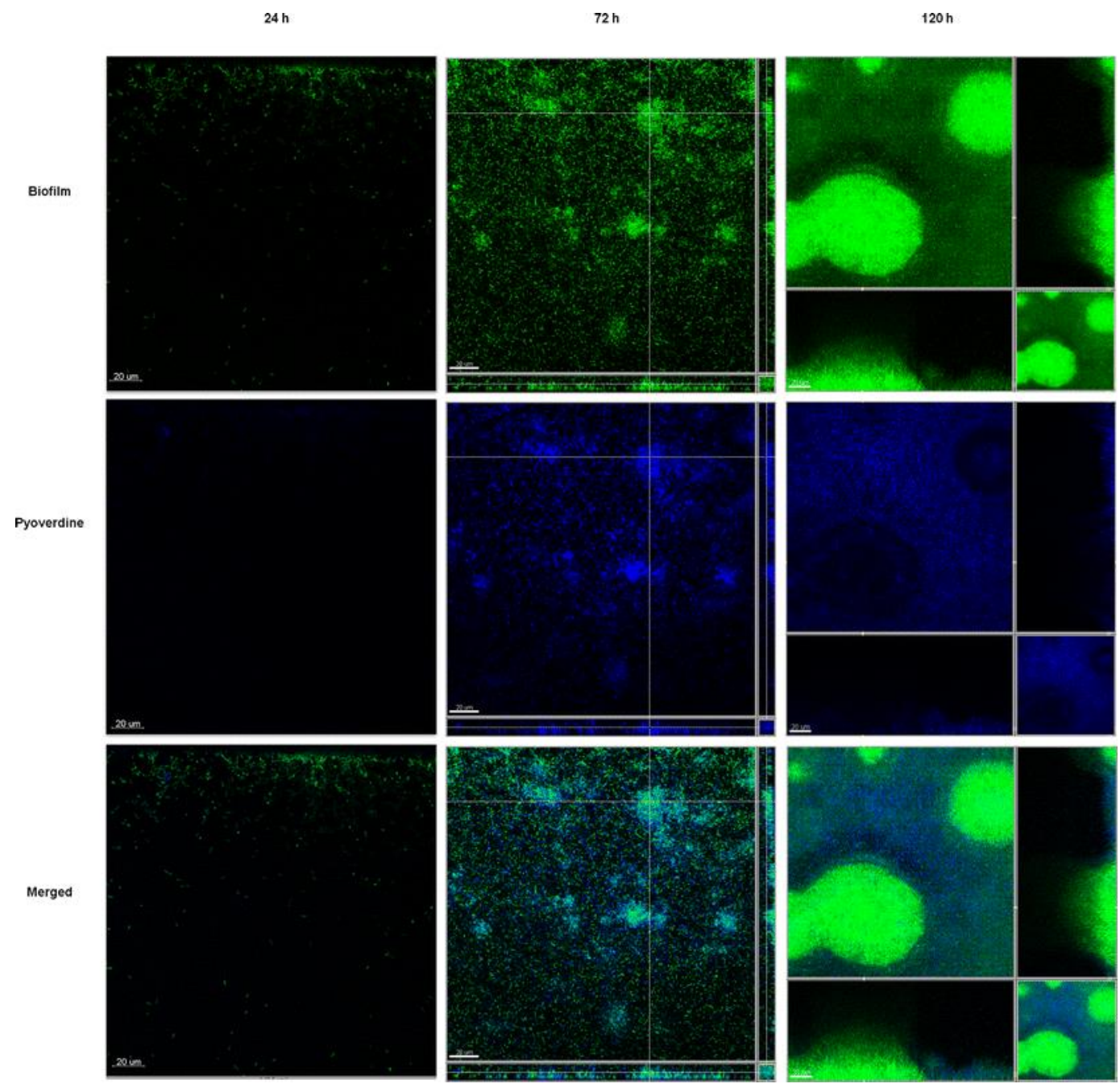

Figure 3.7 Distribution of PVD in P. aeruginosa biofilms. Biofilms were grown using GFP-labeled $P$. aeruginosa for 5 days in modified ABTG medium. CLSM images contain top-down views (x-y planes) and side views (x-z, y-z planes). Scale bar $20 \mu \mathrm{m}$. Results are representative of three separate experiments.

At the initial stage of biofilm growth $(24 \mathrm{~h})$, scattered cells attached to the bottom of the flow cells, while nearly no PVD fluorescence could be detected. After 72 h, surface coverage of $\sim 44 \%$ was achieved with an average biofilm thickness of $\sim 5 \mu \mathrm{m}$ and cell aggregates or microcolonies (up to $20 \mu \mathrm{m}$ in diameter) could be observed. At this stage, although most cells co-localized with PVD, the PVD fluorescence was highly intensified in microcolonies than that of scattered cells. In the 5-day old $(120 \mathrm{~h})$ biofilms of $P$. aeruginosa, mushroom-shaped multicellular structures (up to 80-100 $\mu \mathrm{m}$ in diameter and 40-50 $\mu \mathrm{m}$ in height) could be observed, which has been reported as the feature of mature biofilms for $P$. aeruginosa (Stoodley, Sauer et al. 2002). In mature P. aeruginosa biofilms, 
it was found that PVD fluorescence could only be observed in the thin "lawn" of the biofilm and the stalk surface of the mushroom-shaped structures, which is in agreement with previous reports on the spatially resolved expression of $p v d A$, a key gene in PVD biosynthesis (Kaneko, Thoendel et al. 2007, Yang, Nilsson et al. 2009).

Highly heterogeneous 3-dimensional (3-D) structures of mature biofilms often pose a challenge to diffusion of chemicals in biofilms, limiting the efficacy of conventional biocides such as antibiotics (Costerton, Lewandowski et al. 1995, Stewart and William Costerton 2001, Drenkard 2003, Stewart 2003). Diffusion of dispersed NMs in biofilms is even more problematic (Peulen and Wilkinson 2011). Here it was shown that PVD in mature $P$. aeruginosa biofilms mainly present in the thin bacterial "lawn" of the biofilms and the stalk surface of 3-D mushroom structures, suggesting that diffusion may not limit the interaction of NMs with the cells that are active in PVD production.

Because the 3-D mushroom-shaped structures, a key feature of a mature biofilms for $P$. aeruginosa, were observed in 5-day old biofilms under the above experimental conditions, TeNRs were introduced to the biofilms at $120 \mathrm{~h}$ to investigate the interaction between TeNRs and mature biofilms. Figure 3.8 shows the influence of biogenic TeNRs on PVD production in mature P. aeruginosa biofilms. As shown in Figure 3.8, PVD in the control biofilms was mainly observed in the thin bacterial "lawn" and the stalk surface of 3-D mushroom structures. 

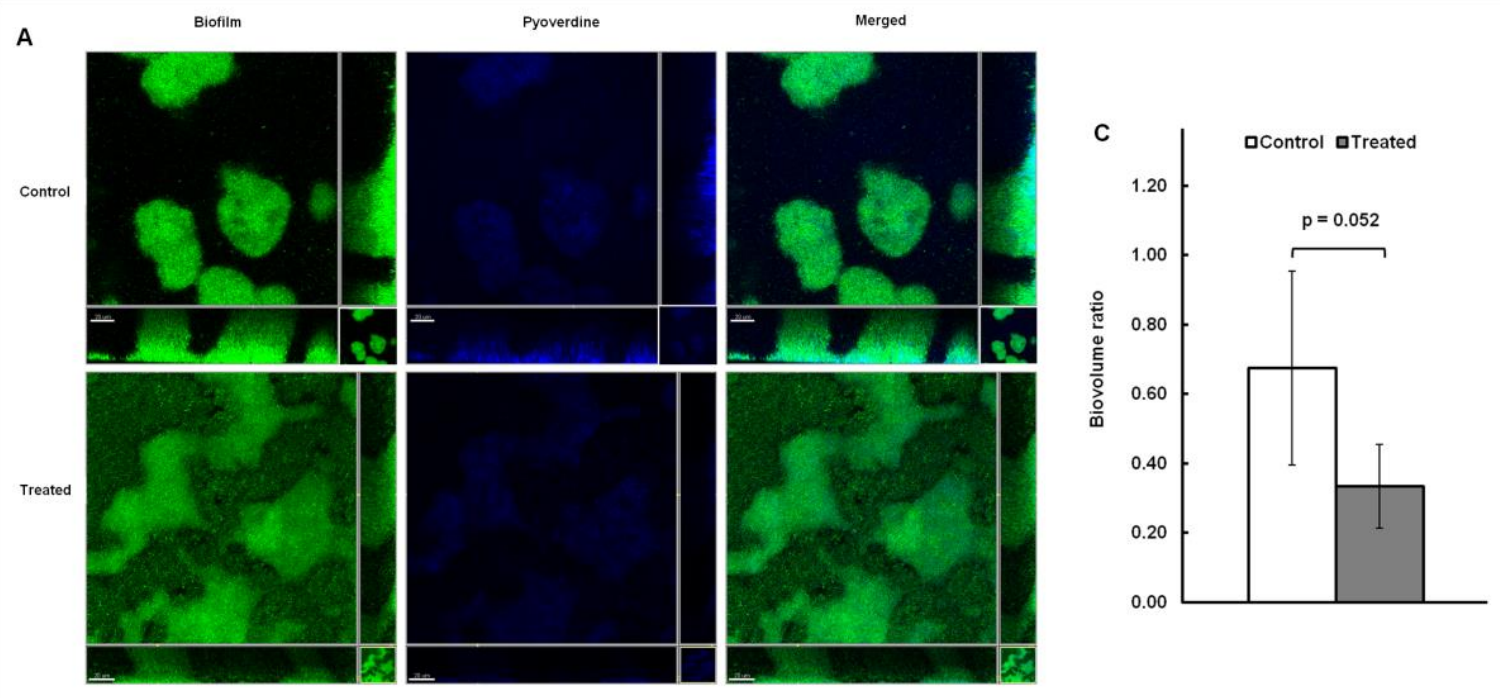

B

Biofilm
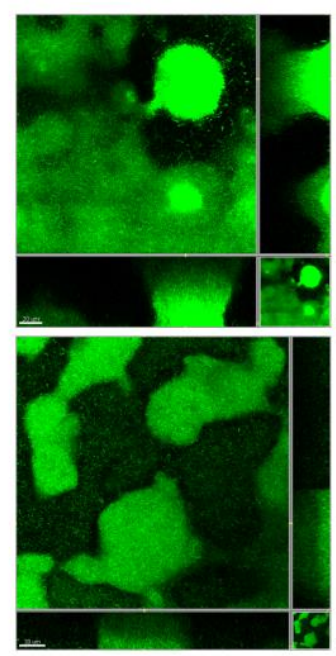

Pyoverdine
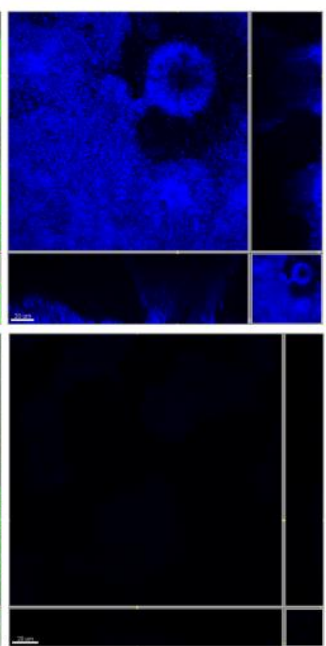

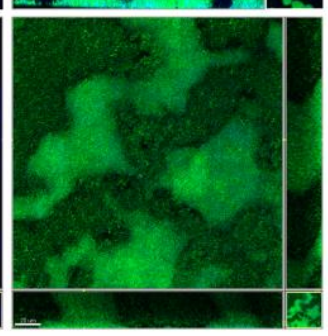

Merged
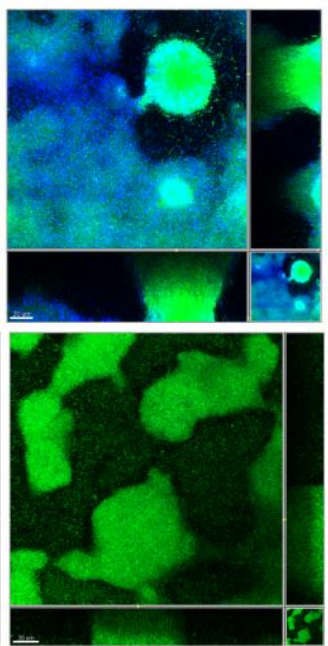

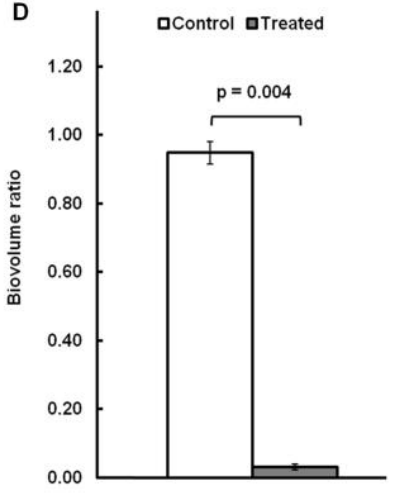

Figure 3.8 Biogenic TeNRs reduce PVD production in mature $P$. aeruginosa biofilms. ab CLSM images of 5-day-old GFP-labeled $P$. aeruginosa biofilms upon exposure to TeNRs $(50 \mu \mathrm{g} / \mathrm{ml})$ for $12 \mathrm{~h}(\mathbf{A})$ and $24 \mathrm{~h}(\mathbf{B})$. The control biofilms were grown in parallel with the TeNR-treated biofilms in different flow cell channels. Controls in a and b were biofilms grown in the absence of TeNRs for $144 \mathrm{~h}(120 \mathrm{~h}+12 \mathrm{~h})$ and $154 \mathrm{~h}(120 \mathrm{~h}+24 \mathrm{~h})$, respectively. C-D Biovolume ratio of PVD-producing biomass to total biofilm biomass, indicating the amount of PVD in unit biovolume of the biofilms. CLSM images contain top-down views ( $\mathrm{x}-\mathrm{y}$ planes) and side views (x-z, y-z planes). Scale bar $20 \mu \mathrm{m}$. Results are representative of three separate experiments.

After exposing to TeNRs for $12 \mathrm{~h}$ the biofilm showed a markedly lower PVD fluorescence, while little or no PVD fluorescence could be detected in the biofilm with a $24 \mathrm{~h}$ exposure to TeNRs. Quantitative image analysis further revealed that the PVD- 
producing biovolume fraction in mature biofilms decreased from $67 \%$ to $33 \%$ and from $95 \%$ to $3 \%$ after $12 \mathrm{~h}$ and $24 \mathrm{~h}$ treatment, respectively (Figure $3.8 \mathrm{C}$ and $\mathrm{D}$ ).

Intriguingly, although PVD production in mature biofilms was significantly inhibited by TeNRs, biofilm structures were still maintained, suggesting that TeNRs do not trigger massive cell detachment. To confirm this, cell detachment rate were quantified for the control and treated biofilms (Figure 3.9 A). Cell detachment rate for both the control and treated biofilms was about $10^{8}-10^{9} \mathrm{CFU} \cdot \mathrm{h}^{-1} \cdot \mathrm{mm}^{-2}$. Although the fluorescence intensity of PVD in the effluent of the biofilms exposed to TeNRs was found significantly lower (Figure 3.9 B), there was no significant difference in cell detachment from the control and treated biofilms $(\mathrm{p}=0.145)$. This result implies that, when exposed to the TeNRs, cells in biofilms decrease PVD production and most likely remain in the biofilms, creating local microenvironments lacking PVD, which will have a great impact on the structure and function of the microbial communities in the microenvironments.
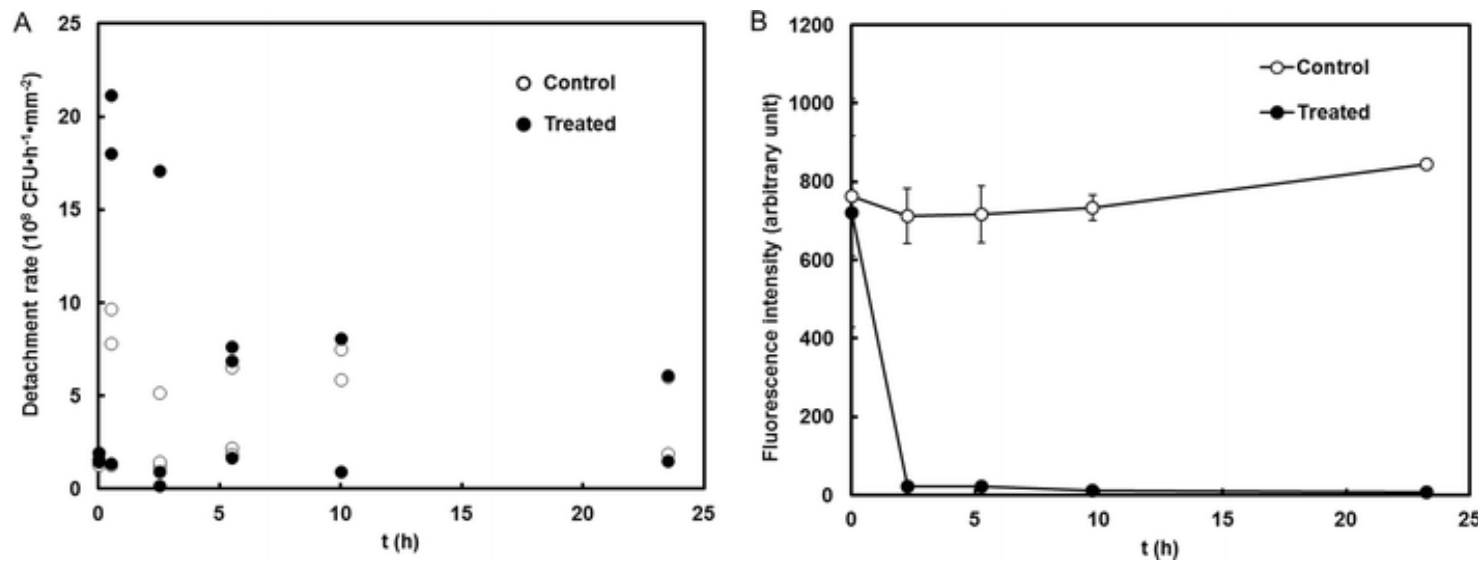

Figure 3.9 (A) Cell detachment rate from 5-day-old P. aeruginosa biofilms during 24-h further growth in modified ABTG medium with or without TeNRs $(50 \mu \mathrm{g} / \mathrm{ml})$. Experiments were carried out with at least three replicates for each condition. Paired Student's $\mathrm{t}$ test, $\mathrm{p}=0.145$. (B) PVD fluorescence in effluents from 5-day-old $P$. aeruginosa biofilms during 24-h further growth in modified ABTG medium with or without TeNRs $(50 \mu \mathrm{g} / \mathrm{ml})$. Experiments were carried out in triplicate.

\subsubsection{Transcriptomic changes}

The results show that TeNRs significantly inhibit PVD production in mature biofilms of $P$. aeruginosa while do not disrupt biofilm structures. To further investigate the 
mechanism of action, the effect of TeNRs was examined on gene expression profiles of $P$. aeruginosa cells in mature biofilms through a RNA-seq based transcriptomic approach. Genes involved in biosynthesis and transport of siderophores were of particular interest. The exposure to TeNRs resulted in a significant decrease in the expression of genes involved in siderophore production (Table 3.4).

Table 3.4 Siderophore related genes that are down regulated in treated samples compared to control.

\begin{tabular}{|c|c|c|c|}
\hline Annotation & Gene & Gene Product & $\log _{2}(\mathrm{R})$ \\
\hline PA0781 & - & $\begin{array}{l}\text { Outer membrane receptor proteins, mostly } \mathrm{Fe} \\
\text { transport }\end{array}$ & -5.7 \\
\hline PA4837 & - & $\begin{array}{l}\text { Outer membrane receptor proteins, mostly Fe } \\
\text { transport }\end{array}$ & -5.14 \\
\hline PA1922 & - & $\begin{array}{l}\text { Outer membrane receptor for ferrienterochelin } \\
\text { and colicins }\end{array}$ & -4.41 \\
\hline PA4224 & $\operatorname{pch} G$ & Pyochelin biosynthetic protein PchG & -2.93 \\
\hline PA2386 & $p v d A$ & L-ornithine N5-oxygenase & -2.66 \\
\hline PA2424 & $p v d L$ & PvdL & -2.48 \\
\hline PA2413 & $p v d H$ & $\mathrm{PvdH}$ & -2.37 \\
\hline PA4230 & $p c h B$ & Salicylate biosynthesis protein PchB & -2.28 \\
\hline PA4218 & ampP & Siderophore transporter activity & -2.25 \\
\hline PA4225 & $p c h F$ & Pyochelin synthetase & -2.2 \\
\hline PA4231 & $\operatorname{pch} A$ & Salicylate biosynthesis isochorismate synthase & -2.17 \\
\hline PA4226 & pchE & Dihydroaeruginoic acid synthetase & -2.12 \\
\hline PA2400 & $p v d J$ & PvdJ & -2.02 \\
\hline PA2399 & $p v d D$ & Pyoverdine synthetase D & -1.83 \\
\hline PA4288 & $\operatorname{pchD}$ & Pyochelin biosynthesis protein PchD & -1.82 \\
\hline PA2395 & $p v d O$ & Pyoverdine biosynthetic process & -1.82 \\
\hline PA4229 & $\operatorname{pch} C$ & Pyochelin biosynthetic protein PchC & -1.76 \\
\hline PA2392 & $p v d P$ & PvdP & -1.64 \\
\hline PA2385 & $p v d Q$ & PvdQ & -1.52 \\
\hline PA2425 & $p v d G$ & PvdG & -1.43 \\
\hline
\end{tabular}




\begin{tabular}{lllll} 
PA2390 & $p v d T$ & $\begin{array}{l}\text { ATP-binding cassette } \\
\text { complex }\end{array}$ & & \\
PA4221 & $f p t A$ & $\begin{array}{l}\text { Fe(III)-pyochelin outer membrane ransporter } \\
\text { precursor }\end{array}$ & -1.41 \\
& & receptor & -1.22 \\
PA2397 & $p v d E$ & Pyoverdine biosynthesis protein PvdE & -0.99 \\
PA2396 & $p v d F$ & Pyoverdine synthetase F & -0.86 \\
PA2398 & $f p v A$ & Ferripyoverdine receptor & -0.75 \\
\hline
\end{tabular}

The production of PVD in P. aeruginosa involves biosynthesis of PVD precursors in the cytoplasm (Schalk and Guillon 2013), the transport of the precursors into the periplasmic space where the precursors are enzymatically modified to PVD (Yeterian, Martin et al. 2010, Schalk and Guillon 2013), and the export of PVD through an efflux (Hannauer, Yeterian et al. 2010) system. Genes responsible for the biosynthesis of PVD precursors ( $p v d L, p v d J, p v d D, p v d H$, and $p v d A$ ), transferring PVD precursors from cytoplasm to the periplasmic space $(p v d E)$, maturation of PVD precursors in the periplasmic space ( $p v d Q$, $p v d O$, and $p v d N$ ), and exporting mature PVD out of the cells ( $p v d T)$ were found downregulated in the biofilm cells treated with TeNRs. Interestingly, it was found that, in addition to PVD related genes, several genes involved in the synthesis of pyochelin ( $p c h A$, $p c h B, p c h C, p c h D, p c h E$, and $p c h F)$, another important siderophore in $P$. aeruginosa for iron uptake, were also significantly down-regulated. In addition, the expression of two genes encoding siderophore-binding proteins ( $f p t A$ and $f p v A)$ also decreased in the biofilm cells treated with TeNRs.

The decreased expression of the siderophore genes in the biofilms suggests that TeNRs inhibited the production of iron-chelating siderophores PVD and pyochelin in mature biofilms at the transcriptional level. The molecular mechanism by which the TeNRs negatively influences the transcription of siderophore genes in the biofilms, however, remains elusive and merits further investigations. 


\subsection{Conclusions}

Using $P$. aeruginosa as a model environmental bacterium, it was shown that TeNRs generated from $\mathrm{TeO}_{3}{ }^{2-}$ inhibits the production of $\mathrm{PVD}$, a siderophore plays an important role in shaping environmental microbial communities, promoting plant growth, and causing infections. This study reports for the first time that TeNRs generated from metal(loid)s can alter function of environmental bacteria, providing a novel insight into the environmental impacts of NMs. In addition, most econanotoxicity studies were conducted using engineered NMs while the impacts of TeNRs that may be generated in the environment have never been explored. The results also provide a novel aspect of the environmental impacts of NMs. 


\section{CHAPTER 4. Impact of Sublethal levels of Single- Wall Carbon Nanotubes on $P$. aeruginosa and its Environmental Implications}

This chapter has been published as Mohanty A, Wei L, Lu L, Chen Y, Cao B* (2015) Impact of sublethal levels of single-wall carbon nanotubes on pyoverdine production in Pseudomonas aeruginosa and its environmental implications. Environmental Science \& Technology Letters 2(4): 105-111. Permission has been granted by the licensed content publisher "ACS Publications" to use the published content as a chapter in this thesis.

\subsection{Introduction}

In Chapters 3, it was shown the inhibition of PVD production in P. aeruginosa planktonic cultures and mature biofilms by biogenic TeNRs. Since the biogenic TeNRs used in Chapters 3 were produced by bacteria, whether commonly used engineered nanomaterials (ENMs) can cause similar impacts on bacterial functions still remains. This chapter focuses on the sublethal impacts of one of the commonly used ENMs on P. aeruginosa as a model environmental microorganism.

Carbon nanotubes (CNTs) are long, hollow cylindrical nanostructures wrapped up by graphene sheets (Iijima 1991). Based on the number of graphene sheets present, CNTs can be catalogued as single-wall CNTs (SWCNTs) and multi-wall CNTs (MWCNTs). CNTs have many potential applications in various fields due to their unique physical, electrical and mechanical properties. For example, CNTs can be used in environmental application as sensors, sorbents, filters for removing pathogens and viral particles (Brady-Estévez, Kang et al. 2008, Mauter and Elimelech 2008, Arias and Yang 2009), in biomedical applications such as detection, imaging and drug delivery (Kam, O'Connell et al. 2005, Liu, Tabakman et al. 2009, Lu, Gu et al. 2009), in high strength composites, energy storage devices (Baughman, Zakhidov et al. 2002). SWCNTs have been demonstrated to exhibit stronger antimicrobial activities than MWCNTs (Kang, Pinault et al. 2007, Kang, Herzberg et al. 2008, Liu, Wei et al. 2009, Vecitis, Zodrow et al. 2010, Tiraferri, Vecitis et al. 2011). 
The potential use of SWCNTs in commercial and industrial settings along with their strong antibacterial activities has raised serious concerns about their impacts on human health and the environment. Previous studies on the toxicity of SWCNTs mainly focused on human health and very recently some important work on their environment impacts have also been carried out (Helland, Wick et al. 2008). The SWCNTs in the environment will potentially impact organisms at all levels of the food chain. The impacts exerted on bacteria are of particular interest because these organisms are at low trophic level and play critical roles in natural and engineered ecosystems.(Peralta-Videa, Zhao et al. 2011) Most studies working on bacteria-SWCNT interactions focused on the toxicity to individual bacteria (Kang, Pinault et al. 2007, Liu, Wei et al. 2009). However, SWCNTs in the environment are expected to be present in low concentrations that may not significantly affect bacterial viability or growth (Petersen, Zhang et al. 2011). Little is known about the sublethal impacts of SWCNTs on bacterial functions, which is a critical gap toward a comprehensive understanding of the impacts of SWCNTs on ecosystems.

The objective of this study was to explore sublethal impacts of SWCNTs on environmental bacteria. Specifically, using $P$. aeruginosa as a model environmental bacterium, the impacts of SWCNTs was examined on the production of PVD, a "public goods" that has been implicated to play a critical role in environmental microbial communities.

\subsection{Materials and methods}

\subsubsection{Synthesis of SWCNTs}

SWCNTs were synthesized by arc-discharge method (AP-SWNT, tube diameter $\sim 1.4 \mathrm{~nm}$, Carbon Solutions, Inc. US) and purified by a centrifugation-based method (Wei, Li et al. 2010). Surface functional groups were added by refluxing purified nanotubes in concentrated nitric acid (68\%, Merck) for $3 \mathrm{~h}$. The functionalized nanotubes were recovered by filtration and washed with $0.2 \mathrm{M}$ sodium hydroxide solution (Merck) to remove small carbon debris generated during acid treatment (Wang, Shirley et al. 2009). The solid was then washed with $\sim 500 \mathrm{ml}$ distilled (DI) water to remove any adsorbed ions and dried in a vacuum oven overnight. Suspension of $1 \mathrm{mg} / \mathrm{ml}$ nanotubes was prepared by 
tip sonication performed at $20 \mathrm{~W}$ for $1 \mathrm{~h}$ in an ice-water bath (Sonics, VCX-130). Zetapotential of the nanotube suspension was measured using a ZetaPALS particle size analyzer (Brooks Instrument, US). At pH 6.3 the zeta potential was $-39.30 \pm 1.02 \mathrm{mV}$.

\subsubsection{Cell viability assay}

Bacterial viability was tested by drop-plate method (Chen, Nace et al. 2003, Ding, Peng et al. 2014, Wu, Ding et al. 2014). P. aeruginosa PAO1 (ATCC 15692) cultures were grown in presence of SWCNTs $(0,40,80 \mu \mathrm{g} / \mathrm{ml})$ at $37^{\circ} \mathrm{C}$ for $24 \mathrm{~h}$ in a shaking incubator 200 rpm) (initial $\mathrm{OD}_{600} \sim 0.08$ ). For viability assay, samples were withdrawn in regular intervals and diluted for 10 to $10^{8}$ times and $10 \mu$ of each dilution was dropped onto LB agar plates. Eight replicates for each dilution were used. After $24 \mathrm{~h}$ incubation, colonies were enumerated as colony forming unit (CFU) (Chen, Nace et al. 2003).

\subsubsection{Quantification of PVD in P. aeruginosa cultures}

PVD fluorescence (Greenwald, Hoegy et al. 2007) and optical density at $600 \mathrm{~nm}\left(\mathrm{OD}_{600}\right)$ were recorded using a TECAN infinite M200PRO plate reader (please refer to section 3.2.3 for detailed method). Cell density was determined by a drop-plate based CFU count method (Ding, Peng et al. 2014). All the fluorescence measurements were carried out together with cell-free controls to rule out the abiotic effects of SWCNTs. In addition, conditioned media (cell-free supernatant of overnight cultures) supplemented with SWCNTs $(40,80 \mu \mathrm{g} / \mathrm{ml})$ were used as another set of controls to check for the interference of SWCNTs on the fluorescence measurements.

\subsubsection{Transcriptional assay for $p v d A$}

The assay was performed according to the protocol mentioned in Section 3.2.4 of Chapter 3. The reporter strain was cultivated in $\mathrm{ABTGC}$ medium at $37^{\circ} \mathrm{C}$ with and without SWCNTs at different concentrations $(0,40,80 \mu \mathrm{g} / \mathrm{ml})$. TECAN infinite M200PRO plate reader was used to monitor GFP fluorescence (Ex $485 \mathrm{~nm}$, Em $535 \mathrm{~nm}$ ) and $\mathrm{OD}_{600}$. 


\subsubsection{Flow cell biofilms}

The influence of SWCNTs on biofilms was evaluated using multi-channel flow cells (BioCentrum-DTU, Denmark). The dimensions and assembly of the flow cell systems have been described elsewhere (Crusz, Popat et al. 2012, Zhang, Ng et al. 2014). Each channel of the flow cells was inoculated using $0.4 \mathrm{ml}$ diluted overnight cultures of $P$. aeruginosa PAO1 in M9 minimal medium (48 mM Na $2 \mathrm{HPO}_{4} ; 22 \mathrm{mM} \mathrm{KH} \mathrm{KO}_{4} ; 9 \mathrm{mM}$ $\mathrm{NaCl} ; 19 \mathrm{mM} \mathrm{NH} 4 \mathrm{Cl} ; 2 \mathrm{mM} \mathrm{MgSO}$; $0.1 \mathrm{mM} \mathrm{CaCl}_{2}$ supplemented with $0.4 \%$ glucose) $\left(\mathrm{OD}_{600} \sim 0.15\right)$. After inoculation, medium flow was stopped to allow the cells attach $(\sim 1$ h) onto the glass coverslips used in the flow cells. Then air-saturated medium was continuously supplied with a flow rate of $8 \mathrm{ml} / \mathrm{h}$ for biofilm growth in each channel. After $96 \mathrm{~h}$, SWCNTs were introduced to the biofilms along with the media at a concentration of $20 \mu \mathrm{g} / \mathrm{ml}$.

\subsubsection{Confocal Laser Scanning Microscopy (CLSM) imaging}

Biofilms grown in the flow cell systems were imaged (20X lens) using a confocal laser scanning microscopy (CLSM) (Carl Zeiss Microscopy LSM 780) equipped with detectors and filter sets using the method described in Section 3.2.10, Chapter 3.

\subsubsection{Quantification of cell detachment}

Detachment of cells from the biofilms was quantified using a drop-plate method (Chen, Nace et al. 2003). Briefly, the effluents from the flow cells were collected in regular intervals and were serially diluted. Then, 6 replicates of $10 \mu \mathrm{l}$ from each of selected dilutions were plated onto an LB agar medium. Colony forming units (CFU) were enumerated after overnight incubation at $37^{\circ} \mathrm{C}$.

\subsubsection{Inhibition of PVD biosynthesis by SWCNTs in P. fluorescence}

P. fluorescence strain OE28.3 (Demot and Vanderleyden 1991) was grown in ABTGC medium at $30^{\circ} \mathrm{C}$ in presence of varying concentration of SWCNTs. PVD fluorescence (Ex 398 nm, Em 460 nm) (Greenwald, Hoegy et al. 2007) and optical density at $600 \mathrm{~nm}$ $\left(\mathrm{OD}_{600}\right)$ were recorded using a TECAN infinite M200PRO plate reader. 


\subsubsection{Quantitative Polymerase Chain Reaction (qPCR)}

P. aeruginosa $\mathrm{PAO} 1$ was grown in $\mathrm{ABTGC}$ medium at $37^{\circ} \mathrm{C}$ in the absence or presence of SWCNTs $(40 \mu \mathrm{g} / \mathrm{ml})$. After $9 \mathrm{~h}$, cells were harvested and total RNA was extracted using a commercially available kit (Qiagen mini RNA prep) following the instructions from the manufacturer. qPCR was performed using the method described in Section 3.2.5.

\subsubsection{Inductively Coupled Plasma Optical Emission Spectroscopy (ICP-OES)}

Cells were grown both in presence and absence of $40 \mu \mathrm{g} / 1$ SWCNTs in ABTGC media for $24 \mathrm{~h}$ and harvested by centrifugation at $6000 \mathrm{~g}$ for $15 \mathrm{~min}$. The cell pellets were lysed at $4^{\circ} \mathrm{C}$ in lysis buffer $(0.1 \% \mathrm{SDS}, 0.5 \mathrm{M}$ TEAB, $50 \mathrm{mM}$ protease inhibitor tablet) with intermittent vortexing and 15-20 min sonication on an MSE-Soniprep-150 Sonicator (Sanyo Gallenkamp, Leicestershire, UK) for $5 \mathrm{~s}$ with a $10 \mathrm{~s}$ cooling interval between each pulse. The lysate was filtered through a $0.2 \mu \mathrm{m}$ syringe filter. The iron concentration was quantified using an ICP-OES (PerkinElmer Optima DV2000). To determine the leaching of iron from SWCNTs, iron in the suspension of $40 \mu \mathrm{g} / \mathrm{l}$ SWCNTs in the ABTGC medium was also measured.

\subsubsection{Statistical analysis}

The IBM SPSS (www.ibm.com/software/sg/analytics/spss/) was used for statistical analyses, including two-way ANOVA. Details of the statistical analyses can be found in respective result sections.

\subsection{Results and discussion}

\subsubsection{SWCNTs inhibit PVD production}

The fluorescence of PVD is often used to reflect PVD production in $P$. aeruginosa cultures because PVD is a water-soluble fluorescent siderophore ${ }^{31}$. In the presence of SWCNTs, the signal of PVD fluorescence (normalized by growth as indicated by cell density $\mathrm{CFU} / \mathrm{ml}$ ) in $P$. aeruginosa cultures was attenuated significantly in a SWCNTconcentration dependent manner (Figure 4.1). PVD fluorescence was quantified for the

conditioned media (cell-free culture supernatant) before and after supplemented with 
SWCNTs and found no interference of SWCNTs on PVD fluorescence measurement. At a concentration of 40 or $80 \mu \mathrm{g} / \mathrm{ml}$, SWCNTs caused a $51-70 \%$ or $85-96 \%$ decrease, respectively, in PVD production capability of $P$. aeruginosa cells in exponential $(6-12 \mathrm{~h})$ and stationary (15-24 h) growth stages. A two-way ANOVA was performed to investigate the effect of time and concentration. No significant effect from time or the timeconcentration interaction was found (both $p>0.9995$ ), while the effect of concentration is significant $(p<0.0005)$.

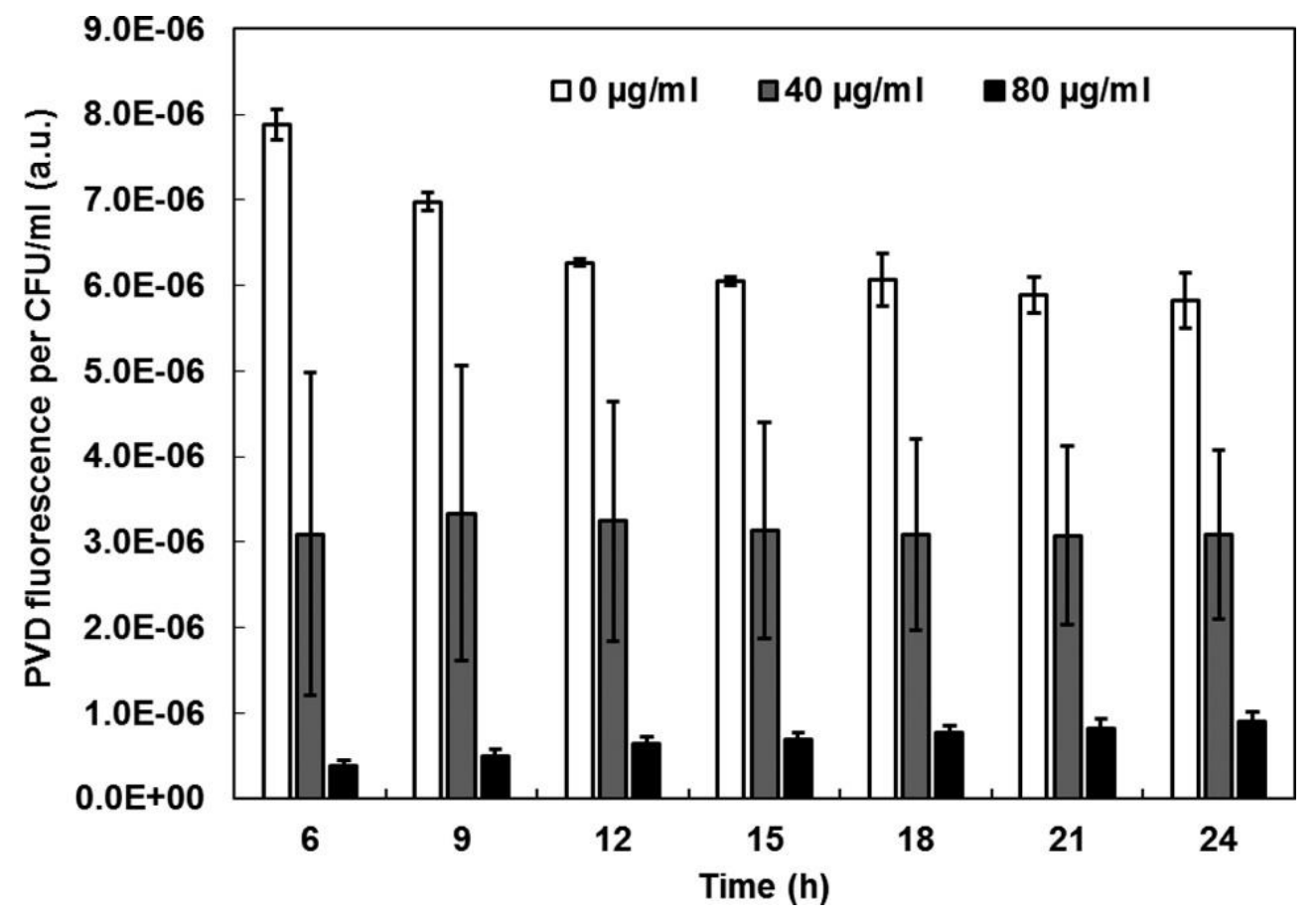

Figure 4.1 Influence of SWCNTs on PVD fluorescence (normalized by cell density) in $P$. aeruginosa cultures growing in ABTGC medium. Data shown are means \pm the standard deviation $(\mathrm{n}=3)$. A two-way ANOVA shows that no significant effect from time or timeconcentration interaction can be found (both $p>0.9995$ ), while the effect of concentration is significant $(p<0.0005)$.

A reduced growth of $P$. aeruginosa in the presence of SWCNTs was observed (Table 4.1), which is consistent with previous reports demonstrating an antibacterial activity of SWCNTs against P. aeruginosa (Kang, Pinault et al. 2007, Brady-Estévez, Kang et al. 2008). The minimal inhibitory concentration (MIC) of SWCNTs under the above experimental conditions was $\sim 200 \mu \mathrm{g} / \mathrm{ml}$. No cell growth could be observed at a dose of lethal levels (>200 $\mu \mathrm{g} / \mathrm{ml})$. In the presence of 40 or $80 \mu \mathrm{g} / \mathrm{ml} \mathrm{SWCNTs,} \mathrm{cell} \mathrm{growth} \mathrm{was}$ 
still observed, resulting in a final cell density of $1.25 \pm 0.33 \times 10^{9}$ and $1.18 \pm 0.24 \times 10^{9}$, respectively. Hence, a question arises: are there any sublethal impacts of SWCNTs on the cells? In particular, in this study whether SWCNTs affect the PVD production of viable cells was examined. To address this question, a biomarker strain that allows the monitoring of the expression of a key gene involved in PVD biosynthesis was employed.

Table 4.1 Density of viable cells in $P$. aeruginosa cultures with or without SWCNTs. Data shown are mean \pm standard deviation $(\mathrm{n}=8)$.

\begin{tabular}{llll}
\hline \multirow{2}{*}{ SWCNTs $(\mu \mathrm{g} / \mathrm{ml})$} & \multicolumn{2}{l}{ Cell density $(\mathrm{CFU} / \mathrm{ml})$} & \\
\cline { 2 - 4 } & $0 \mathrm{~h}$ & $24 \mathrm{~h}$ & Ratio $(24 \mathrm{~h}$ vs. 0 h) \\
\hline 0 & $1.30 \pm 0.19 \times 10^{7}$ & $1.15 \pm 0.26 \times 10^{11}$ & 8800 \\
40 & $1.77 \pm 0.27 \times 10^{7}$ & $1.25 \pm 0.33 \times 10^{9}$ & 71 \\
80 & $1.80 \pm 0.21 \times 10^{7}$ & $1.18 \pm 0.24 \times 10^{9}$ & 65 \\
\hline
\end{tabular}

Gene $p v d A$ codes an enzyme L-ornithine N5-oxygenase responsible for the hydroxylation of L-ornithine, which represents an early step in the biosynthesis of PVD in P. aeruginosa (Visca, Ciervo et al. 1994). To monitor PVD biosynthesis in viable cells, a reporter strain $\mathrm{P}_{p v d A^{-}} g f p$ in which a gene encoding green fluorescent protein (GFP) was under control of the promoter of gene $p v d A$ was employed and the GFP fluorescence was used as an indicator to monitor the biosynthesis of PVD. Figure 4.2 shows the GFP fluorescence (per $\mathrm{CFU} / \mathrm{ml}$ ) of the biomarker strain $\mathrm{P}_{p v d A}-g f p$ in planktonic cultures with or without SWCNTs. From a two-way ANOVA using the factors time and concentration, no significant effect from time or the time-concentration interaction was found (both $p>$ 0.9995), while the effect of concentration is significant $(p<0.0005)$. 


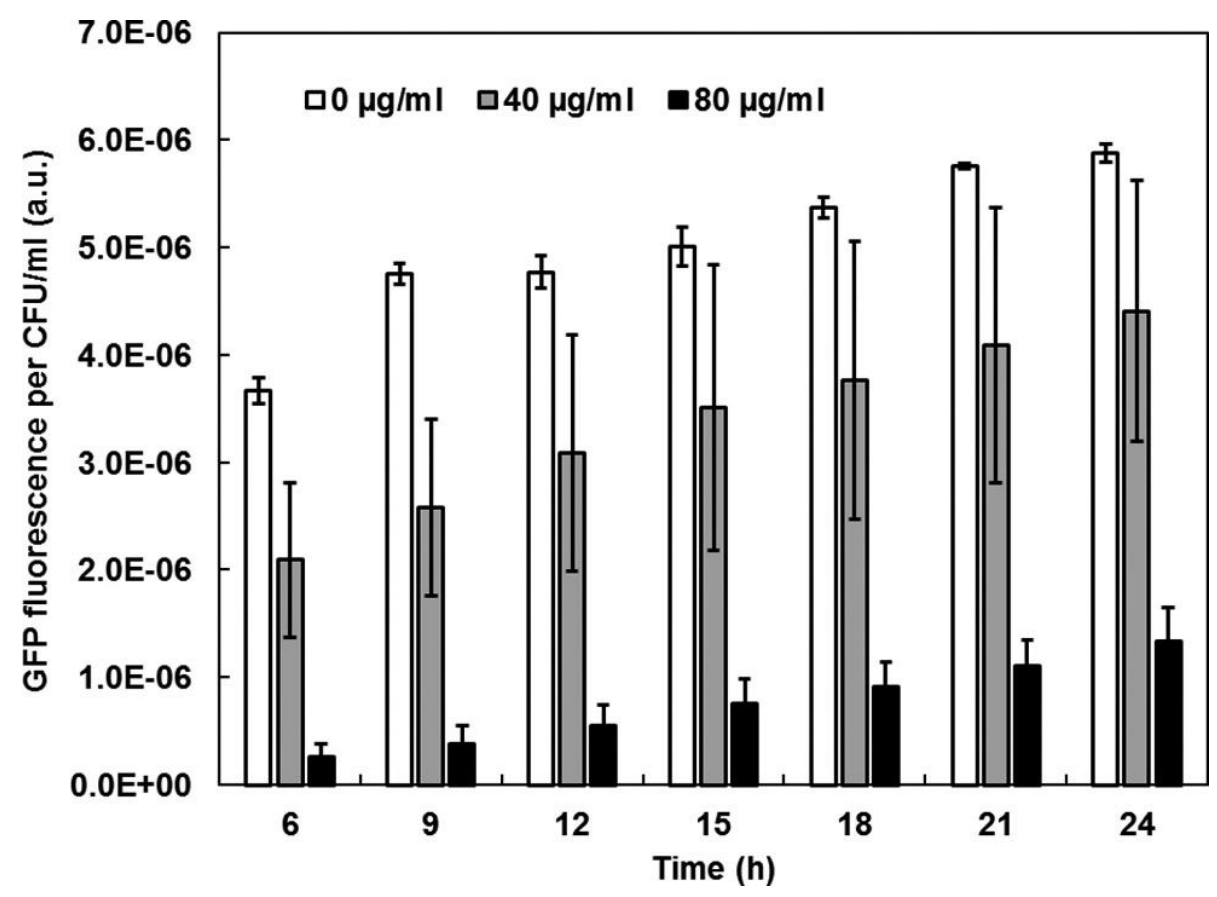

Figure 4.2 Influence of SWCNTs on GFP fluorescence in $P$. aeruginosa reporter strain $p v d A$-gfp growing in ABTGC medium. Data shown are means \pm the standard deviation (n $=3$ ). A two-way ANOVA shows that no significant effect from time or the timeconcentration interaction can be found (both $p>0.9995$ ), while the effect of concentration is significant $(p<0.0005)$.

In the presence of SWCNTs, GFP fluorescence was markedly lower than that of the cultures without SWCNTs, which suggests that the expression of gene $p v d A$, and hence, PVD biosynthesis, was significantly inhibited by SWCNTs. To confirm this, the expression of several key genes involved in PVD biosynthesis was quantified by using qPCR. Relative gene expression levels as impacted by SWCNTs at a concentration of 40 $\mu \mathrm{g} / \mathrm{ml}$ are shown in Figure 4.3.

Genes responsible for the biosynthesis of PVD precursors ( $p v d A$ ), transferring PVD precursors from cytoplasm to the periplasmic space $(p v d E)$, maturation of PVD precursors in the periplasmic space $(p v d N)$, and exporting mature PVD out of the cells ( $p v d T)$ were found down-regulated in the cells treated with SWCNTs (Figure 4.3). In addition, the expression of two genes encoding a transcriptional regulator $(p v d S)$ and a siderophorebinding protein $(f p v A)$ also decreased in the cells treated with SWCNTs (Figure 4.3). 


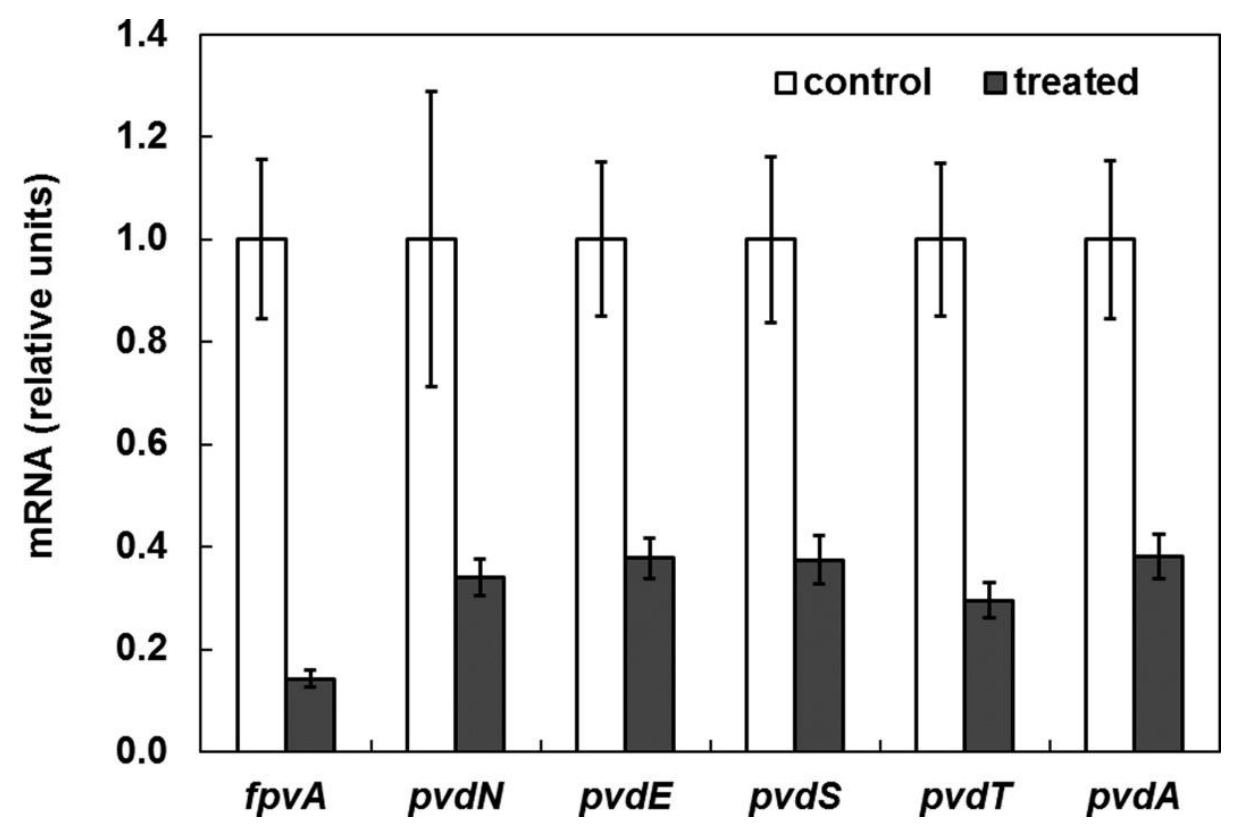

Figure 4.3 Influence of SWCNTs $(40 \mu \mathrm{g} / \mathrm{ml})$ on the expression level of key genes involved in PVD production at $9 \mathrm{~h}$ in the midexponential growth phase. Values were normalized to the housekeeping gene $t s f$. The $\mathrm{C}_{\mathrm{T}}$ values for $t s f$ remained unchanged for the control and the treated cells (24.68 \pm 0.92 and $23.84 \pm 0.30$, respectively), suggesting that the expression of tsf is not affected by SWCNTs. Abbreviations: PvdS, transcriptional regulator; PvdE, export ABC transporter to transport PVD precursors across the inner membrane; PvdN, periplasmic enzymes involved in chromophore formation; PvdT, subunit of the ATP-dependent efflux pump for PVD secretion; FpvA, outer membrane transporter to import ferri-pyoverdine; PvdA, lysine/ornithine $N$-monooxygenase. Data shown are means \pm the standard deviation $(n=3)$. Statistical significance determined by a paired Student's $t$ test $(p<0.001)$.

In $P$. aeruginosa, there are three well-characterized quorum sensing systems namely las, $r h l$, and pqs (Wilder, Diggle et al. 2011) which interact with each other and coordinate the expression of a number of genes including those responsible for PVD production (Stintzi, Evans et al. 1998, Hentzer, Wu et al. 2003, Williams and Cámara 2009). To further examined whether the inhibitory effect of SWCNTs on PVD production was because of an influence on bacterial quorum sensing signalling, by using qPCR the expression of the key quorum sensing genes lasA, rhlA and pqsA in the bacterial cultures were quantified with and without SWCNTs treatment. The results show that the presence of SWCNTs did not inhibit the expression of these quorum sensing genes (Figure 4.4). Compared with the cultures with no SWCNTs, the quorum sensing systems in the treated cultures were 
slightly enhanced, suggesting that the influence of SWCNTs on quorum sensing is not the primary cause for the decreased PVD production.

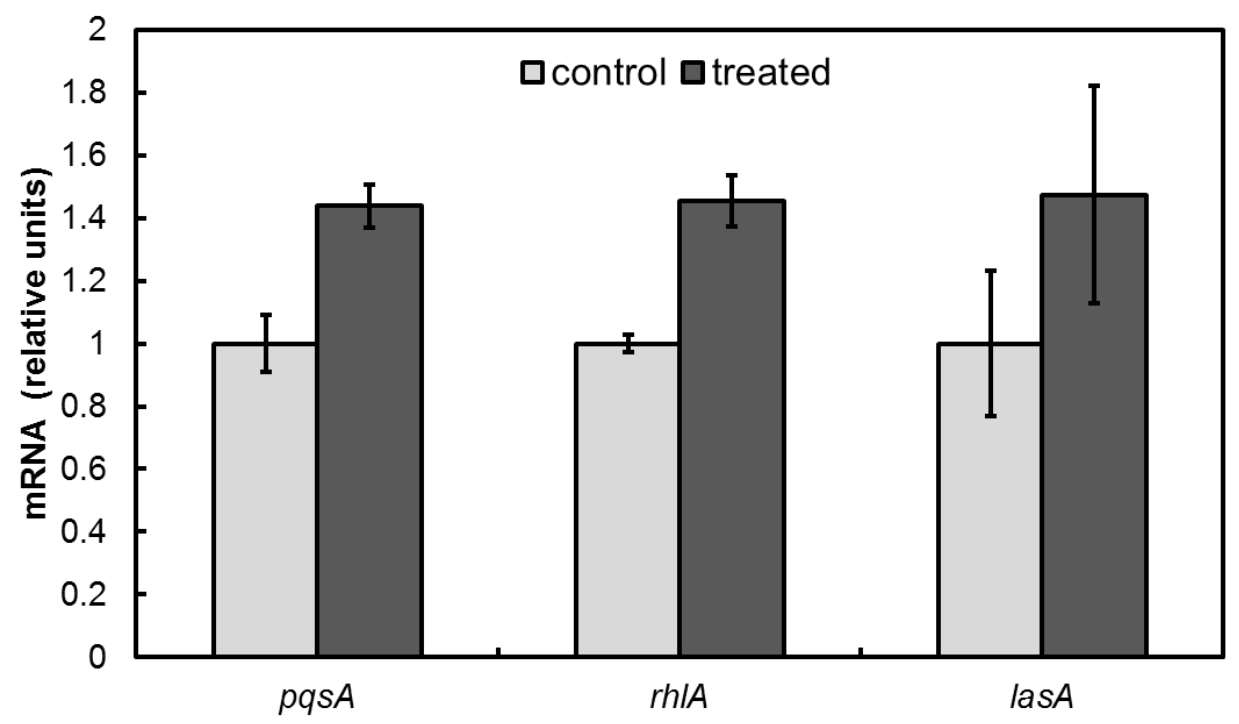

Figure 4.4 The expression level of key quorum sensing genes $p q s A, r h l A$ and las $A$ in the absence or presence of SWCNTs $(40 \mu \mathrm{g} / \mathrm{ml})$ as revealed by qPCR analysis. Values were normalized to the housekeeping gene $r p o D$. Data shown are mean \pm standard deviation $(n=3)$.

An intriguing question one would ask is how SWCNTs at cell exterior affect gene expression inside the cells. In previous studies, Dimpka et al. reported that $\mathrm{CuO}$ nanoparticles inhibited PVD production in $P$. chlororaphis $\mathrm{O6}$, where $\mathrm{Cu}$ ion release has been implicated to play a key role (Dimkpa, Mclean et al. 2012, Dimkpa, McLean et al. 2012). In this study, it was shown that SWCNTs inhibit PVD production at the gene transcriptional level. Could it be because that SWCNTs release ions, in particular, iron to the growth media? Iron level in growth media is known to be a key factor influencing PVD biosynthesis. A high iron level of inhibits PVD production. In this study, the synthesis of SWCNTs did not involve iron and the absence of iron in the SWCNTs was also confirmed by elemental mapping using Transmission Electron Microscopy- Energydispersive X-ray spectroscopy (TEM-EDX) (data not shown). Further ICP-OES was employed to quantify iron concentrations in the media with or without SWCNTs and found that the presence of SWCNTs slightly decreased the iron levels in the media $(0.89 \pm 0.01$ vs. $1.00 \pm 0.02 \mu \mathrm{M}, p<0.05)$, which could be due to the adsorption of iron onto 
the SWCNTs. Hence, the possibility of an additional iron supply from SWCNTs to the cultures can be ruled out. Interestingly, although SWCNTs inhibit PVD production, the iron level in the cells grown in the presence of SWCNTs was found slightly higher than that of the control cells $(350 \pm 1$ vs. $322 \pm 5 \mathrm{pmol} / \mathrm{mg}$ protein, $p<0.05)$. These results suggest that, in addition to PVD and hence, PVD-mediated iron uptake system, SWCNTs may also affect other iron uptake systems (Andrews, Robinson et al. 2003, Cornelis and Dingemans 2013).

Based on the data obtained in this study and previous work, the hypothesis is that certain extracellular appendages of the bacteria such as surface proteins, exopolysaccharides, pili, and flagella might be interacting with the SWCNTs and transmit the signals across cell membranes. However, the exact mechanism for PVD inhibition by SWCNTs requires further investigations.

\subsubsection{SWCNTs reduce PVD production in $P$. aeruginosa biofilms}

In natural environments, microorganisms are often found as surface- or interfaceassociated assemblies encased in a self-produced polymeric matrix known as biofilms (Hall-Stoodley, Costerton et al. 2004, Cao, Majors et al. 2012, Ding, Peng et al. 2014). In addition, it has been shown that PVD is an important factor influencing biofilm formation of $P$. aeruginosa (Banin, Vasil et al. 2005). Hence, the influence of SWCNTs on $P$. aeruginosa biofilms using a GFP-tagged strain in flow cell biofilm reactors was further examined. After 96 h, mushroom-shaped multicellular towers, typical 3D structures of mature $P$. aeruginosa biofilms, could be observed (Figure 4.5). 

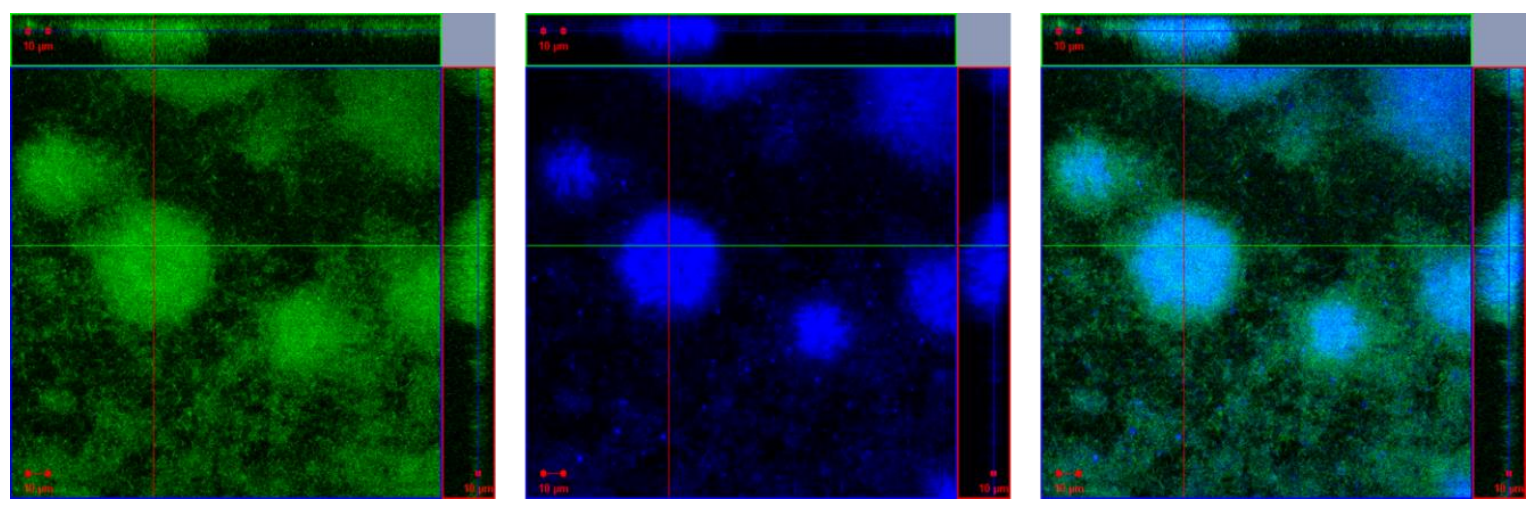

Figure 4.5 Mature biofilm structure showing PVD expression. Biofilms were grown using GFP-labeled $P$. aeruginosa for 4 days in M9 medium. CLSM images contain top-down views (x-y planes) and side views (x-z, y-z planes). Scale bar $10 \mu \mathrm{m}$. Results are representative of three separate experiment.

SWCNTs were then introduced to the pre-grown mature biofilms and PVD production in the biofilms was evaluated based on PVD fluorescence obtained from CLSM image analysis. Quantitative image analysis revealed that the PVD fluorescence (blue) in the mature biofilms (green) in the SWCNTs-treated (up to $48 \mathrm{~h}$ ) and the control biofilms was comparable (Figure 4.6), suggesting no significant influence of SWCNTs on PVD production in mature $P$. aeruginosa biofilms (all $p>0.05$ ). Intriguingly, in the presence of SWCNTs, the rate of cell detachment from the biofilms was higher and PVD fluorescence in the effluents from the SWCNTs-treated biofilms was lower than that of the control (Figure 4.7). Taken together, the results show that the exposure to SWCNTs for up to $48 \mathrm{~h}$ did not significantly influence PVD production in cells encased in mature biofilms; however, it promoted cell detachment from the biofilms and decreased PVD production of the detached cells. 

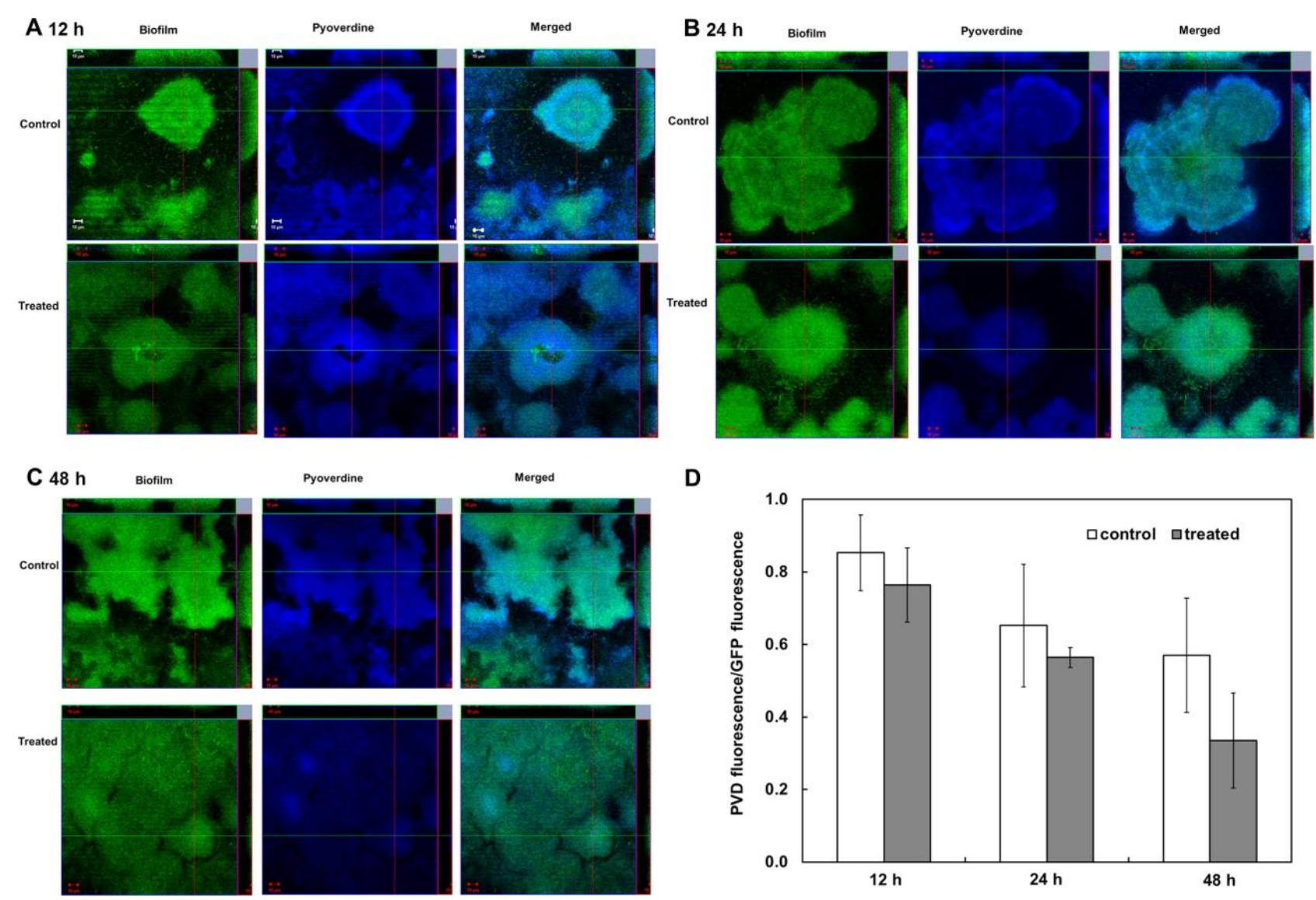

Figure 4.6 CLSM images of mature $P$. aeruginosa biofilms upon exposure to SWCNTs (20 $\mu \mathrm{g} / \mathrm{ml})$ for (A) 12 , (B) 24 , and (C) 48 $\mathrm{h}$. The control biofilms were grown in parallel with the SWCNT-treated biofilms. Controls in panels A-C were biofilms grown in the absence of SWCNTs for $108 \mathrm{~h}(96 \mathrm{~h}+12 \mathrm{~h}), 120 \mathrm{~h}(96 \mathrm{~h}+24 \mathrm{~h})$, and $144 \mathrm{~h}(96 \mathrm{~h}+48 \mathrm{~h})$, respectively. (D) Biovolume ratio of PVD-producing biomass to total biofilm biomass, indicating the amount of PVD in the unit biovolume of the biofilms. CLSM images contain top-down views ( $x-y$ planes) and side views ( $x-z$ and $y-z$ planes). The scale bar is $10 \mu \mathrm{m}$. Results are representative of three separate experiments. 

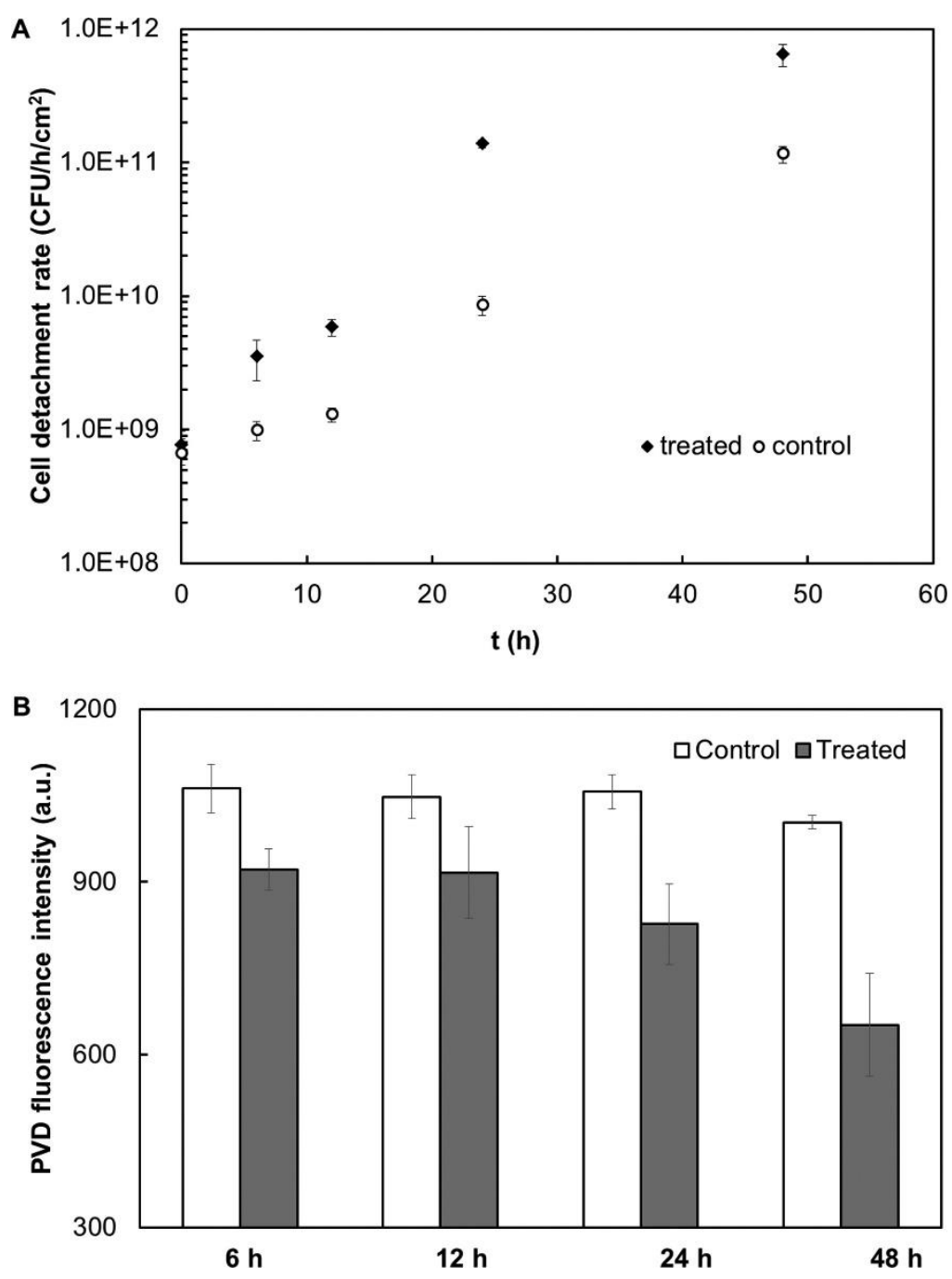

Figure 4.7 (A) Cell detachment and (B) PVD fluorescence in effluents from mature $P$. aeruginosa biofilms in the absence or presence of SWCNTs $(20 \mu \mathrm{g} / \mathrm{ml})$. Experiments were conducted in triplicate.

\subsubsection{SWCNTs inhibit PVD production in other Pseudomonas species}

Production of siderophores is a highly conserved characteristic in many environmental bacteria, especially Pseudomonas species (Meyer, Geoffroy et al. 2002). For example, $P$. fluorescence is a plant root coloniser commonly found in soils and it protects plant roots from fungal infection by scavenging iron with the help of siderophores (Leong 1986, Preston, Bertrand et al. 2001). SWCNTs could also inhibit siderophore production in $P$. fluorescence in a concentration dependent manner (Figure 4.8), suggesting that the inhibitory effect of SWCNTs on siderophore production is not limited to the model 
organism, i.e., P. aeruginosa, used in this study and similar effects may be observed for many other environmental bacteria.

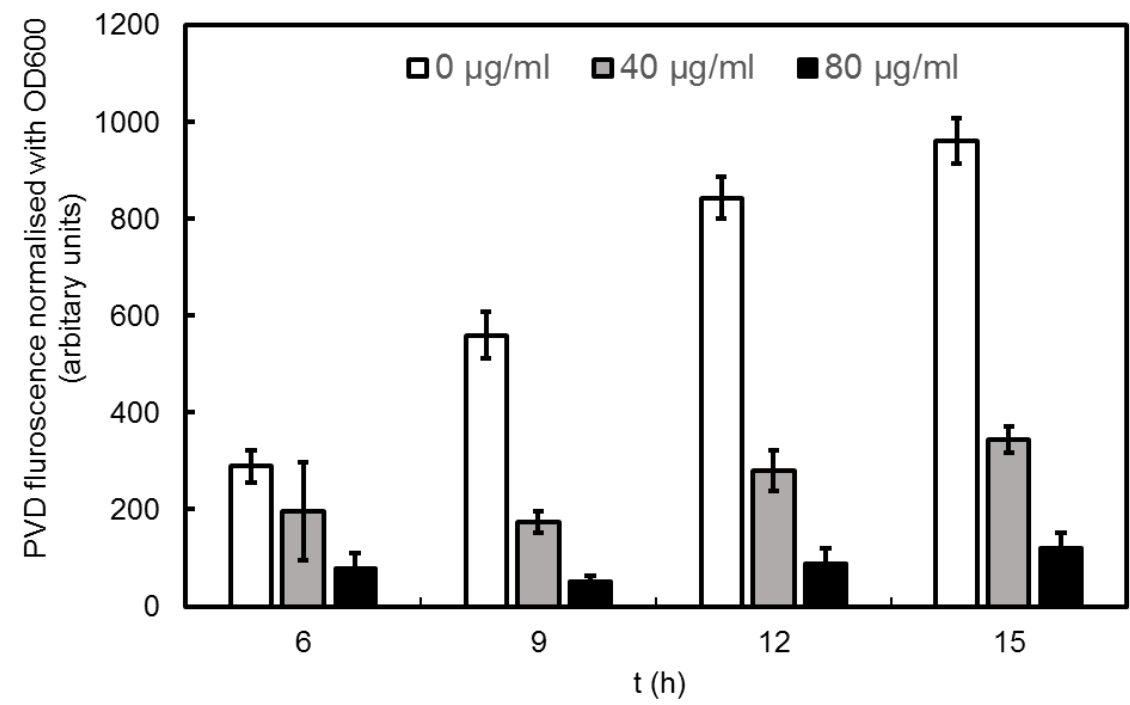

Figure 4.8 Concentration-dependent inhibitory effect of SWCNTs on PVD production in $P$. fluorescence. Relative fluorescence intensity (normalized by $\mathrm{OD}_{600}$ ) indicates the amount of PVD produced in the cultures.

\subsection{Conclusions}

Environmental bacteria in natural settings communicate, cooperate or compete with each other. These interactions are often mediated by extracellular metabolites such as siderophores. Siderophores are produced by certain environmental bacteria and can be effectively shared among closely related species and can give competitive advantage to some species over others in any ecological niche. This study reports for the first time that SWCNTs at sublethal concentrations inhibit siderophore production in an environmental bacterium. Siderophore secreted by certain environmental bacteria that can be exploited by local community members with cognate receptors and has been implicated to be key components in establishing microbial communities. The results reveals an important sublethal impact of SWCNTs on siderophore-enabled cell-cell interactions in microbial communities, which often exist and play critical roles in maintaining health of ecosystems in various natural and engineered environments. 


\section{CHAPTER 5. Impacts of Nanomaterials on Bacterial Quorum Sensing: Differential Effects on Different Signals}

This chapter has been published as Mohanty A, Tan CH, Cao B* (2016) Impacts of nanomaterials on bacterial quorum sensing: Differential effects on different signals. Environmental Science:Nano 3:351-356. Permission has been granted by the licensed content publisher "Royal Society of Chemistry" to use the published content as a chapter in this thesis.

\subsection{Introduction}

The most common approach to supply information and synchronize social activity in bacteria is the production of certain chemicals as signalling molecules. Contaminants in the environments may interact with environmental bacteria and interfere with their quorum sensing (QS) signalling systems, altering various bacteria driven processes, e.g., biogeochemical cycles, nutrient uptake by plants, wastewater treatment, and pathogenesis. One group of contaminants that are of the emerging concern is NMs, i.e., materials with a size $\leq 100 \mathrm{~nm}$ in at least one dimension (Cao 2004, Buzea, Pacheco et al. 2007). Owing to their unique physicochemical properties, NMs have been increasingly used over the past decade across various industries.(Lines 2008) This leads to the possibility of NMs release into the environments at different stages of the nanomaterial-containing product life cycle. However, to date, very limited studies exploring the impacts of NMs on bacterial QS signalling have been reported and conclusions in most studies have been drawn based on nanomaterial-induced changes in certain QS-regulated functions (Wagh, Patil et al. 2013, Naik and Kowshik 2014) rather than direct quantification of QS signals. Since each bacterial species usually produces a number of different QS signals, our knowledge on how these QS signals responds differently to NMs is lacking but required for a comprehensive understanding of the effects of NMs on bacterial QS systems.

The objective of this study was to investigate influences of NMs on different AHL-type QS signals. Gram-negative bacteria Pseudomonas syringae and Pantoea stewartii were used as model organisms and both have been reported to produce AHL-type QS signals 
(Quiñones, Dulla et al. 2005, Koutsoudis, Tsaltas et al. 2006, Tan, Koh et al. 2015). The NMs used in this study were silver nanoparticle (AgNPs) and single-wall carbon nanotubes (SWCNTs). The influences of AgNPs and SWCNTs on the production of several key AHLs in P. syringae and P. stewartii were quantitatively assessed. This study reports for the first time on the effects of NMs on the production of individual QS signals.

\subsection{Materials and methods}

\subsubsection{Bacterial strains and nanomaterials}

Stock cultures of $P$. syringae pv. tomato DC3000 (DC3000) (Buell, Joardar et al. 2003) and P. stewartii (NCBI accession no. KC252900) (Tan, Koh et al. 2015) were maintained in lysogeny broth (LB) medium with $25 \%$ glycerol at $-80^{\circ} \mathrm{C}$. Cultures were grown aerobically at $30^{\circ} \mathrm{C}$ in LB medium. The SWCNTs were synthesized using the arcdischarge method (AP-SWNT, tube diameter of $\sim 1.4 \mathrm{~nm}$, Carbon Solutions, Inc.) and purified through a centrifugation-based method as previously described (Section 4.2.1). AgNPs with sodium citrate as stabilizer with a size of $20 \mathrm{~nm}$ (TEM-based) were purchased from Sigma-Aldrich (Singapore).

\subsubsection{Cell viability assay}

P. stewartii and P.syringae were grown in LB in the presence of SWCNTs $(0-500 \mu \mathrm{g} / \mathrm{ml})$ or AgNPs $(0-2 \mu \mathrm{g} / \mathrm{ml})$ at different concentrations. The optical density at $600 \mathrm{~nm}\left(\mathrm{OD}_{600}\right)$ was used to monitor bacterial growth. Since NMs may interfere with $\mathrm{OD}_{600}$ readings, cell growth was further quantified using a Colony Forming Unit (CFU) method (Chen, Nace et al. 2003, Ding, Peng et al. 2014, Wu, Ding et al. 2014).

\subsubsection{Inductively Coupled Plasma Mass Spectroscopy (ICP-MS)}

Cells were grown in presence and absence of AgNPs at $0.5 \mu \mathrm{g} / \mathrm{ml}$ for $24 \mathrm{~h}$. The culture supernatant was harvested by centrifugation at $6000 \mathrm{~g}$ for $15 \mathrm{~min}$. The cell free supernatant was filtered through a $0.2 \mu \mathrm{m}$ syringe filter. The silver ion concentration was quantified using an ICP-MS instrument (ELAN DRC-e, Perkin Elmer; Waltham, MA) as previously described. (Section 4.2.10) 


\subsubsection{Extraction of AHLs from bacterial cultures}

P. stewartii and P.syringae were grown in LB in the presence and absence of $20 \mu \mathrm{g} / \mathrm{ml}$ SWCNTs or $0.5 \mu \mathrm{g} / \mathrm{ml} \mathrm{AgNPs} \mathrm{at} 30^{\circ} \mathrm{C}$ in a shaking incubator (200 rpm). Samples taken at $0 \mathrm{~h}$ and $24 \mathrm{~h}$ were used to quantify cell growth following the CFU method described above (Chen, Nace et al. 2003). Extraction of AHLs from each bacterial culture at the early stationary phase $(24 \mathrm{~h})$ were conducted as previously described (Shaw, Ping et al. 1997). Briefly, $100 \mathrm{ml}$ of dichloromethane was mixed with $50 \mathrm{ml}$ of the culture supernatant. The dichloromethane extract was dried in a nitrogen gas stream and then resuspended in methanol/water $(1: 1 \mathrm{v} / \mathrm{v})$ for further analysis by HPLC-MS/MS (Shimadzu, Singapore).

\subsubsection{Quantification of AHL signals}

The parameters for LC-MS/MS were set according to a previously reported procedure for AHL analysis with slight modifications (Tan, Koh et al. 2014). The XR-ODS C18 column and a flow rate of $0.3 \mathrm{ml} / \mathrm{min}$ were used for all samples. The mobile phase consisted of a linear gradient (40-95\%) of solvent B (methanol with $0.1 \%$ formic acid) and solvent A (25 $\mathrm{mM}$ ammonium formate with $0.1 \%$ formic acid). Following LC separation, samples were then ionized by electrospray ionization under positive mode and detected using the multiple reaction monitoring (MRM) approach (Morin et al., 2003; Decho et al., 2009). Each standard MRM profile, including specific LC retention time, appearance of precursor ion $\mathrm{m} / \mathrm{z}$ and two transition ions, as well as relative intensity of the two transition ions, was used as a reference. A full scan, ranging from m/z 100 to 350 was used to identify the putative AHLs, coupled with precursor ion scan mode was conducted in comparison with the standards. The following synthetic AHLs (>97\%) purchased from Sigma-Aldrich (Singapore) were used as AHL standards: $N$-butyryl-DL-homoserine lactone (C4-HSL), $N$-hexanoyl-DL-homoserine lactone (C6-HSL), N-(3-oxohexanoyl)-DL-homoserine lactone (3OC6-HSL), $N$-heptanoyl-DL-homoserine lactone (C7-HSL), N-octanoyl-DLhomoserine lactone (C8-HSL), $\mathrm{N}$-(3-oxooctanoyl)-L-homoserine lactone (3OC8-HSL), $\mathrm{N}$ decanoyl-DL-homoserine lactone (C10-HSL), $N$-(3-oxodecanoyl)-L-homoserine lactone (3OC10-HSL), $\mathrm{N}$-dodecanoyl-DL-homoserine lactone (C12-HSL), $\mathrm{N}$-(3-oxododecanoyl)- 
L-homoserine lactone (3OC12-HSL), $N$-(3 hydroxydodecanoyl)-DL-homoserine lactone (3OHC12-HSL), $\quad \mathrm{N}$-tetradecanoyl-DL-homoserine lactone $\quad$ (C14-HSL) and $\mathrm{N}$-(3oxotetradecanoyl)-Lhomoserine lactone (3OC14-HSL). The standard curves were constructed with a concentration ranging from 0.5 to $200 \mu \mathrm{g} / \mathrm{ml}$ for absolute quantification of signals in real samples. Every AHL had two transition ions which were used to identify the AHL and the transition ion with the highest intensity was employed to construct the standard curves. Post run analysis such as analyte peak areas integration was done using LabSolutions (Shimadzu). The limits of detection and quantification for each AHL were calculated with a signal-to-noise ratio of 3.3 and 10, respectively. Triplicate blank injections were performed between sample injections to avoid sample carry over.

\subsubsection{Statistical analysis}

All statistical analyses were conducted using Prism 6 Version 6.04 (GraphPad, U.S.A.) or PRIMER 6 Version 6.1.15 \& PERMANOVA+ Version 1.0.5 (PRIMER-E, United Kingdom). Method of multivariate analysis community diversity commonly used in microbial ecological studies, were adopted to determine the overall changes of AHL profiles between different treatments. The AHL profiles were clustered based on Euclidean distance with logarithm $(\mathrm{X}+1)$ transformation and visualized using nMDS plot.

\subsection{Results and discussion}

\subsubsection{Determination of sub-inhibitory concentrations for AgNPs and SWCNTs}

The AgNPs and SWCNTs inhibited growth of $P$. syringae and $P$. stewartii in a concentration dependent manner, which is consistent with previous studies on bactericidal activities of NMs (Kang, Pinault et al. 2007, Kim, Kuk et al. 2007) .The minimal inhibitory concentration (MIC) of AgNPs and SWCNTs under the above experimental conditions was $\sim 1 \mu \mathrm{g} / \mathrm{ml}$ and $\sim 200 \mu \mathrm{g} / \mathrm{ml}$ respectively. No growth inhibition was observed for AgNPs and SWCNTs at a concentration of $0.5 \mu \mathrm{g} / \mathrm{ml}$ and $20 \mu \mathrm{g} / \mathrm{ml}$, respectively, against both organisms after $24 \mathrm{~h}$ of cell growth. This was further confirmed by the CFU count method (Table 5.1). Hence, the sub-inhibitory concentrations of 0.5 $\mu \mathrm{g} / \mathrm{ml}$ and $20 \mu \mathrm{g} / \mathrm{ml}$ were used for AgNPs and SWCNTs, respectively, to examine their effects on QS signalling in $P$. syringae and $P$. stewartii. 
Table 5.1 Growth of $P$. syringae and $P$. stewartii cells in LB medium in the absence (control) and presence of $0.5 \mu \mathrm{g} / \mathrm{ml} \mathrm{AgNPs} \mathrm{or} 20 \mu \mathrm{g} / \mathrm{ml} \mathrm{SWCNTs.} \mathrm{Data} \mathrm{shown} \mathrm{are} \mathrm{mean}$ \pm standard deviation $(n=5)$.

\begin{tabular}{llll}
\hline \multirow{2}{*}{ Growth Condition } & CFU (cells/mL) & \\
& & $0 \mathrm{~h}$ & $24 \mathrm{~h}$ \\
\hline \multirow{3}{*}{ P. syringae } & Control & $1.12 \pm 0.13 \times 10^{7}$ & $4.20 \pm 0.83 \times 10^{9}$ \\
& AgNPs & $1.14 \pm 0.26 \times 10^{7}$ & $4.60 \pm 0.54 \times 10^{9}$ \\
& SWCNTs & $1.30 \pm 0.36 \times 10^{7}$ & $9.80 \pm 0.14 \times 10^{9}$ \\
& Control & $1.18 \pm 0.13 \times 10^{7}$ & $2.02 \pm 0.04 \times 10^{10}$ \\
& AgNPs & $1.14 \pm 0.16 \times 10^{7}$ & $1.96 \pm 0.08 \times 10^{10}$ \\
& SWCNTs & $1.16 \pm 0.11 \times 10^{7}$ & $2.04 \pm 0.16 \times 10^{10}$ \\
\hline
\end{tabular}

\subsubsection{Identification of key AHLs produced by $P$. syringae and $P$. stewartii}

The AHLs produced by the two bacteria were identified using LC-MS/MS based on standard curves and the mass spectra of 13 synthetic AHLs as quantitative references (Figure 5.1 A). Different AHLs profiles were obtained for these two organisms. $P$. syringae produced mostly 6 short-chain AHLs namely C4-HSL, C6-HSL, 3OC6-HSL, C7-HSL, C8-HSL, and 3OC8-HSL. Among which C6-HSL and 3OC6-HSL ( 2.23 mM each) were the most abundant QS signals (accounted for $\sim 98 \%$ of total signals) (Figure 5.1B). Whereas P. stewartii produced 11 different types of AHLs including both shortand long-chain AHLs: C4-HSL, C6-HSL, 3OC6-HSL, C7-HSL, C8-HSL, 3OC8-HSL, 3OC10-HSL, C12-HSL, 3OC12-HSL, C14-HSL, and 3OC14-HSL (Figure 5.1C). The most abundant AHL signal in P. stewartii was 3OC6-HSL (accounted for $~ 81 \%$ of total signals). 
A
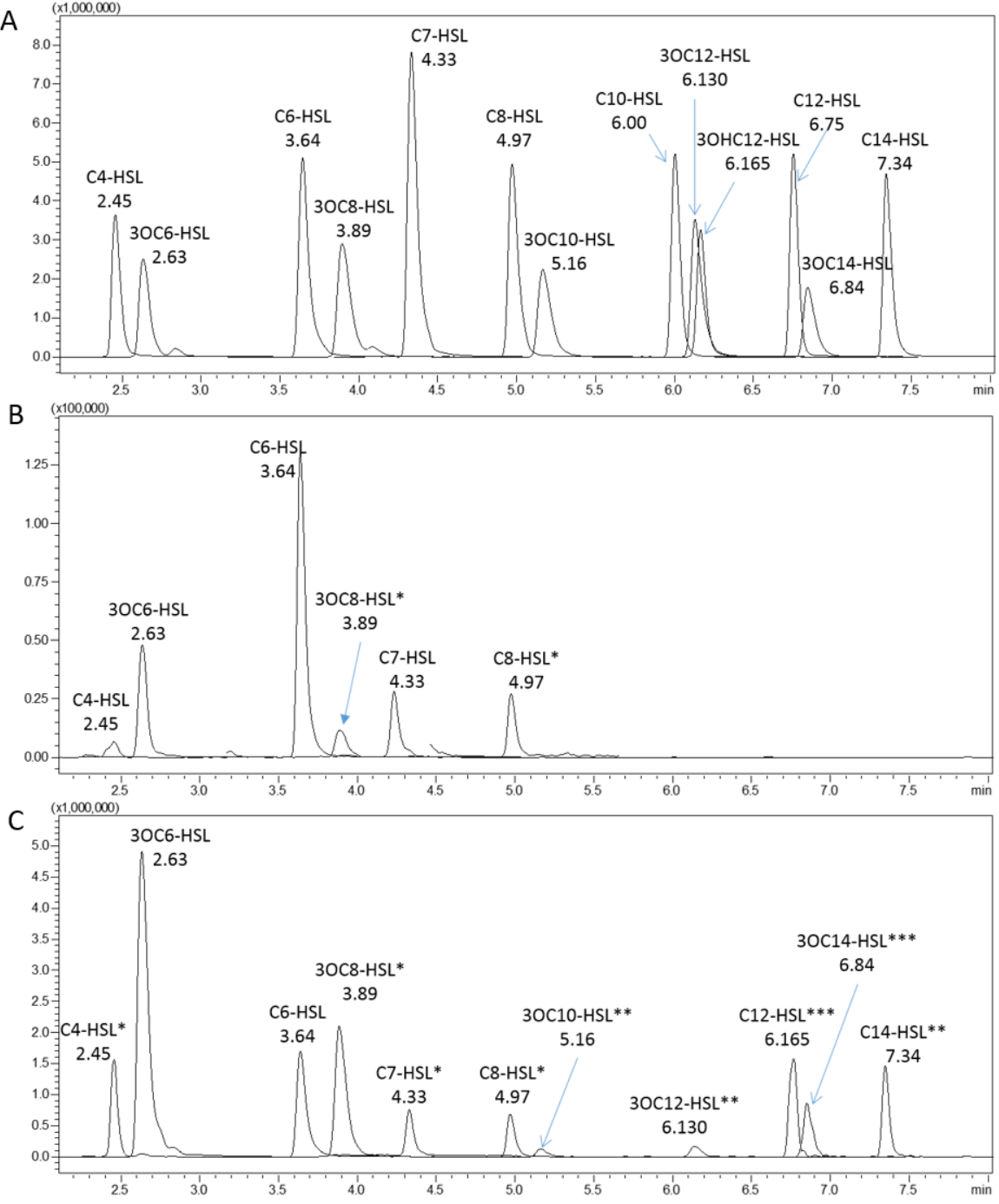

Figure 5.1 (A) Total ion chromatogram of a mixture of 13 standard AHLs (spiked into the sample matrix). (B) Profile of AHLs produced by P. syringae. (C) Profile of AHLs produced by $P$. stewartii. For a better clarity, the peaks for certain AHL signals with low abundance are shown with a $10 \times(*), 100 \times(* *)$, or $1000 \times(* * *)$ amplification.

\subsubsection{Influence of AgNPs and SWCNTs on production of different AHLs}

For $P$. syringae, in presence of $0.5 \mu \mathrm{g} / \mathrm{ml} \mathrm{AgNPs,} \mathrm{the} \mathrm{production} \mathrm{of} \mathrm{all} \mathrm{the} 6$ AHLs except 3OC8-HSL was significantly lower compared with control cultures without AgNPs (Figure 5.2). In particular, the presence of AgNPs in P. syringae cultures resulted in $>50 \%$ reduction of C4-HSL, $\sim 24 \%$ reduction of C6-HSL, and $\sim 31 \%$ reduction of 3OC6-HSL. The concentration of $\mathrm{Ag}^{+}$in the culture media containing $0.5 \mu \mathrm{g} / \mathrm{ml} \mathrm{AgNPs}$ after $24 \mathrm{~h}$ of 
incubation was determined to be $12.5 \pm 0.4 \mu \mathrm{g} / \mathrm{L}$ using ICP-MS. Then the impact of $\mathrm{AgNO}_{3}$ at a concentration of $\sim 12.5 \mu \mathrm{g} / \mathrm{L}$ was examined on the model organisms and no inhibitory effect on QS signalling could be observed. Hence, the effects reported here can be attributed to the nanoparticulate nature of AgNPs. In contrast, in the presence of 20 $\mu \mathrm{g} / \mathrm{ml} \mathrm{SWCNTs,} \mathrm{the} \mathrm{level} \mathrm{of} \mathrm{most} \mathrm{AHLs} \mathrm{remained} \mathrm{unchanged} \mathrm{except} \mathrm{for} \mathrm{C4-HSL} \mathrm{and} \mathrm{C8-}$ HSL, which exhibited a reduction of $\sim 13 \%$ and $\sim 21 \%$, respectively. Intriguingly, the production of most AHLs in P. stewartii was not significantly affected by either $0.5 \mu \mathrm{g} / \mathrm{ml}$ AgNPs or $20 \mu \mathrm{g} / \mathrm{ml} \mathrm{SWCNTs.} \mathrm{The} \mathrm{only} \mathrm{exception} \mathrm{was} \mathrm{C4-HSL,} \mathrm{which} \mathrm{was} \mathrm{observed} \mathrm{a}$ $\sim 21 \%$ reduction in the presence of AgNPs (Figure 5.3). 

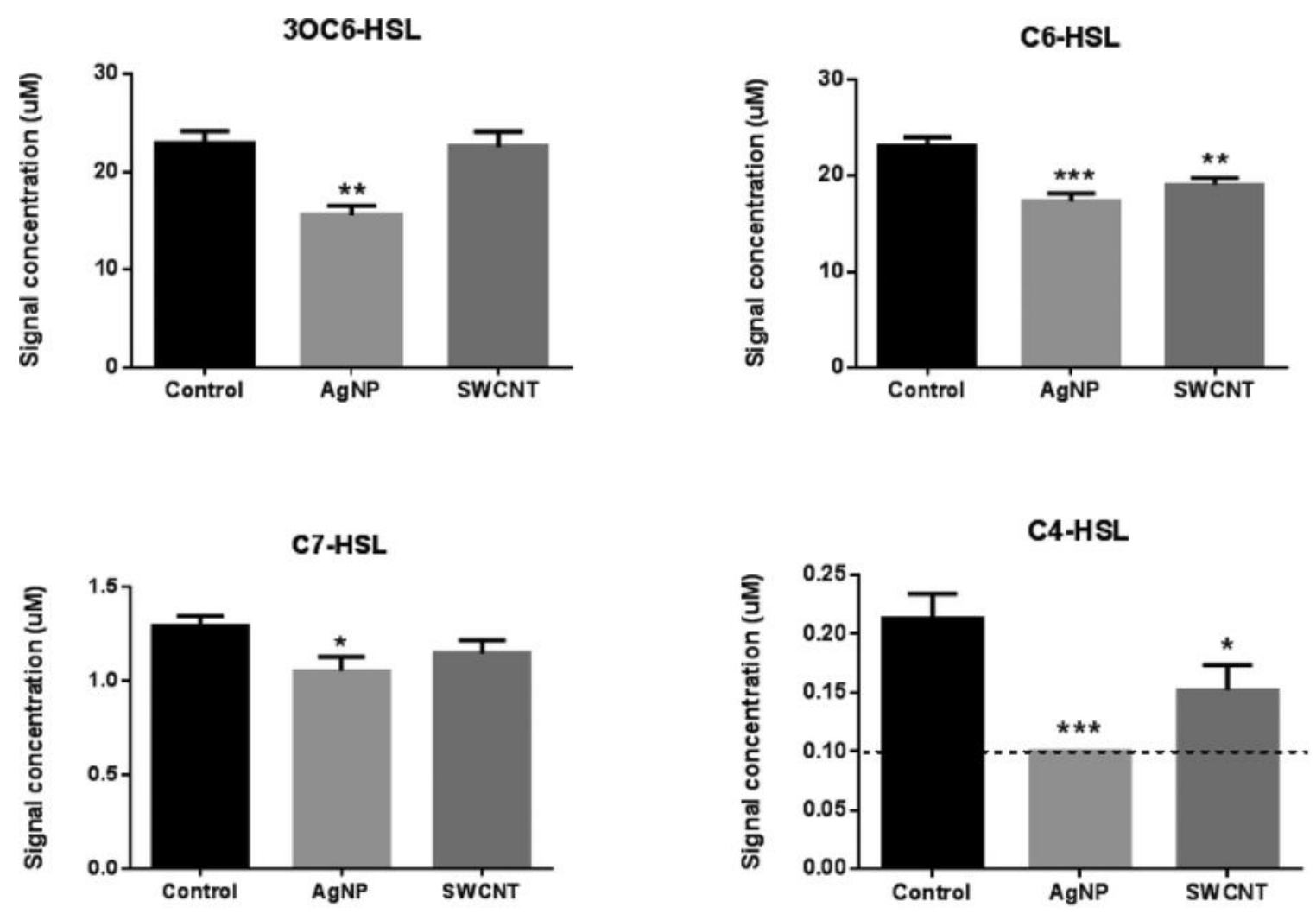

C8-HSL
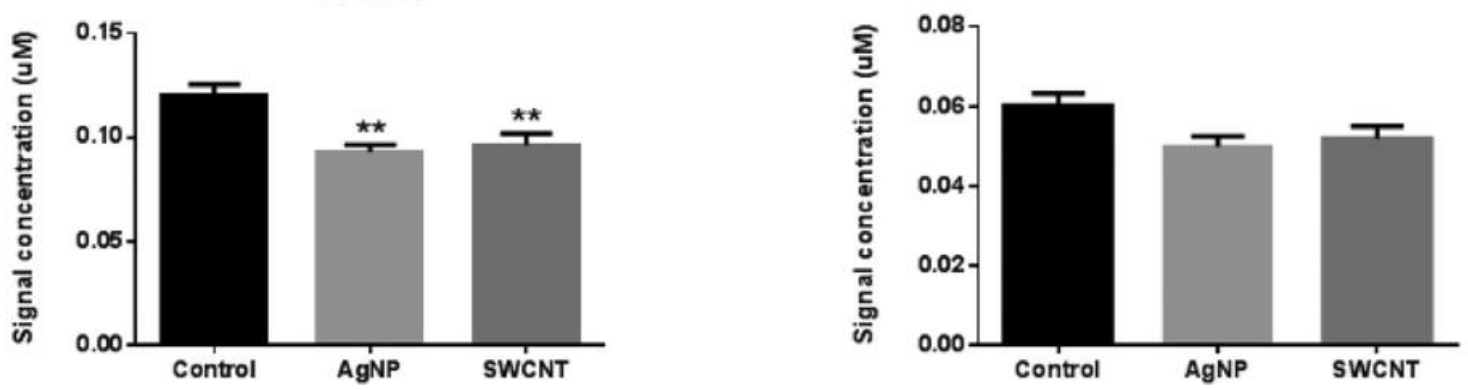

Figure 5.2 Influence of AgNPs $(0.5 \mu \mathrm{g} / \mathrm{ml})$ and SWCNTs $(20 \mu \mathrm{g} / \mathrm{ml})$ on the production of different AHLs by $P$. syringae. The identity and quantity of individual AHLs present in each sample were compared with the multiple reaction monitoring profiles of 13 standard AHLs. A total of 6 AHLs are shown (the remaining 7 AHLs were below the detection limit). $\left.{ }^{* * *} p<0.001,{ }^{*} p<0.01, * p<0.05\right)$. Error bars are defined as standard error of the mean $(n=6)$.the dotted line represents the limit of detection. 

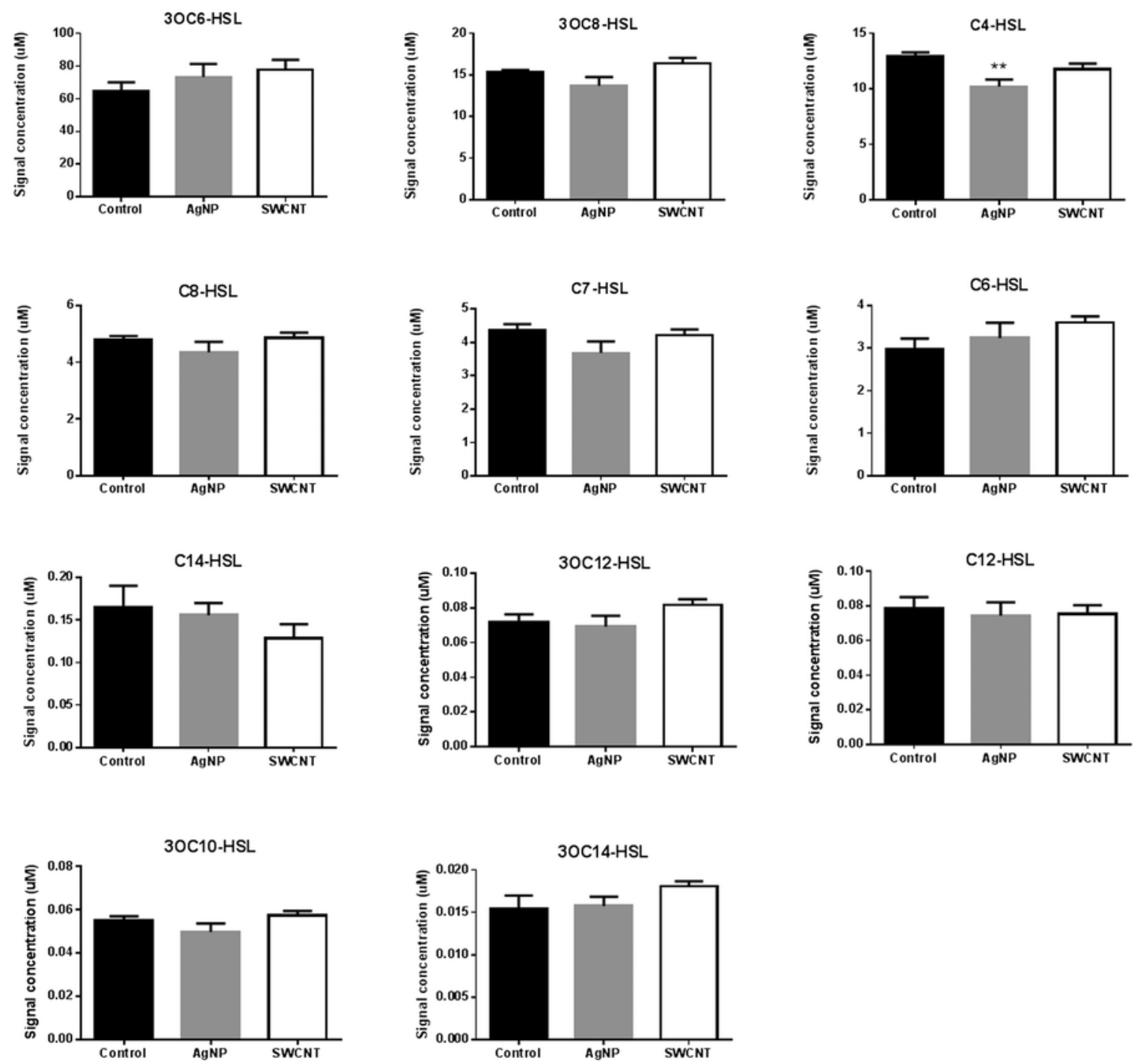

Figure 5.3 Influence of AgNPs $(0.5 \mu \mathrm{g} / \mathrm{ml})$ and SWCNTs $(20 \mu \mathrm{g} / \mathrm{ml})$ on the production of different AHLs by P. stewartii. The identity and quantity of individual AHLs present in each sample were compared with the multiple reaction monitoring profiles of 13 standard AHLs. A total of 11 AHLs are shown (the remaining 2 AHLs were below the detection limit). (**p $<0.01)$ Error bars are defined as standard error of the mean $(n=6)$.

A nonmetric Multidimensional Scaling (nMDS) analysis of the AHLs produced by both $P$. syringae and P. stewartii as impacted by AgNPs and SWCNTs is shown in Figure 5.4. In P. syringae, samples from the AgNP-treated cultures formed a distinct cluster and the tight clustering was influenced mostly by C4-HSL. 


\section{A}

Transform: $\log (X+1)$

Resemblance: D1 Euclidean distance

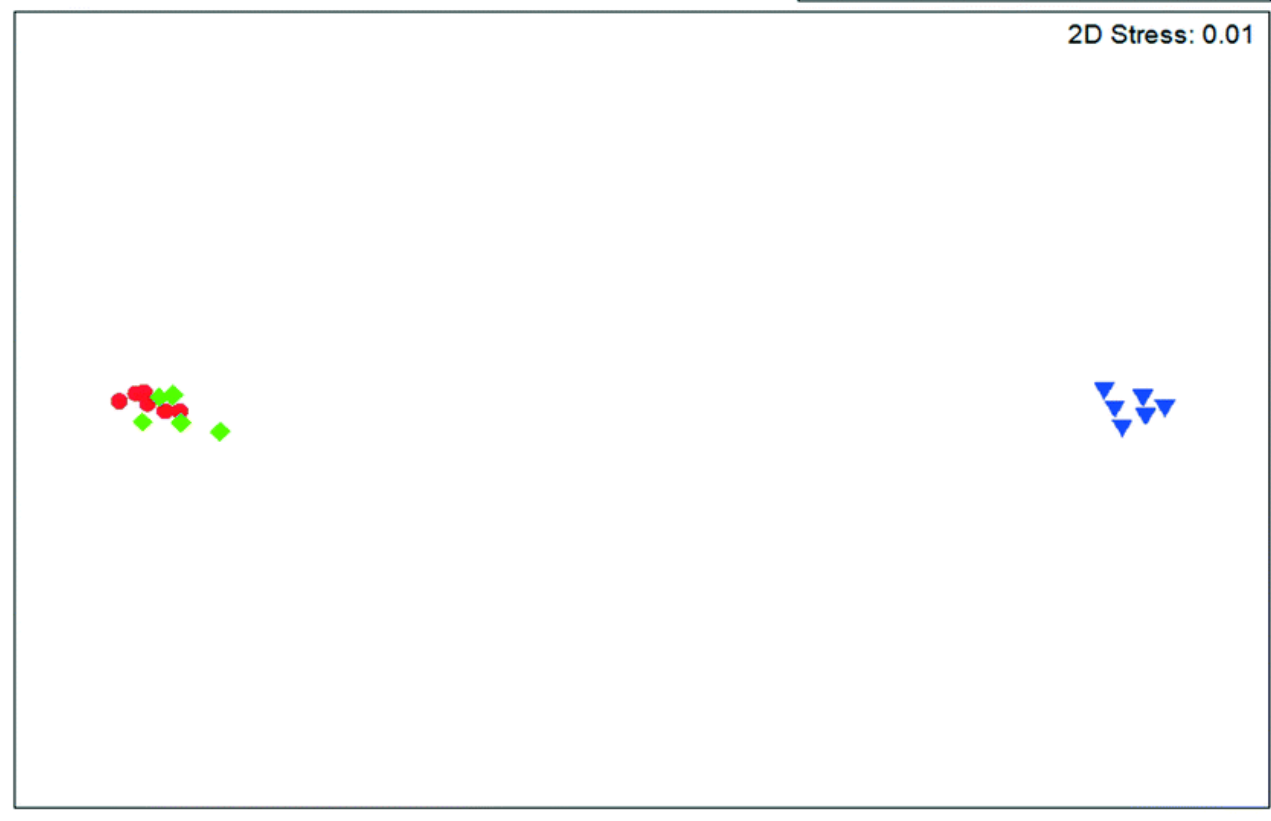

Treatment

- Control

$\checkmark$ AgNP

$\rightarrow$ SWNCT

B

Transform: $\log (\mathrm{X}+1)$

Resemblance: D1 Euclidean distance

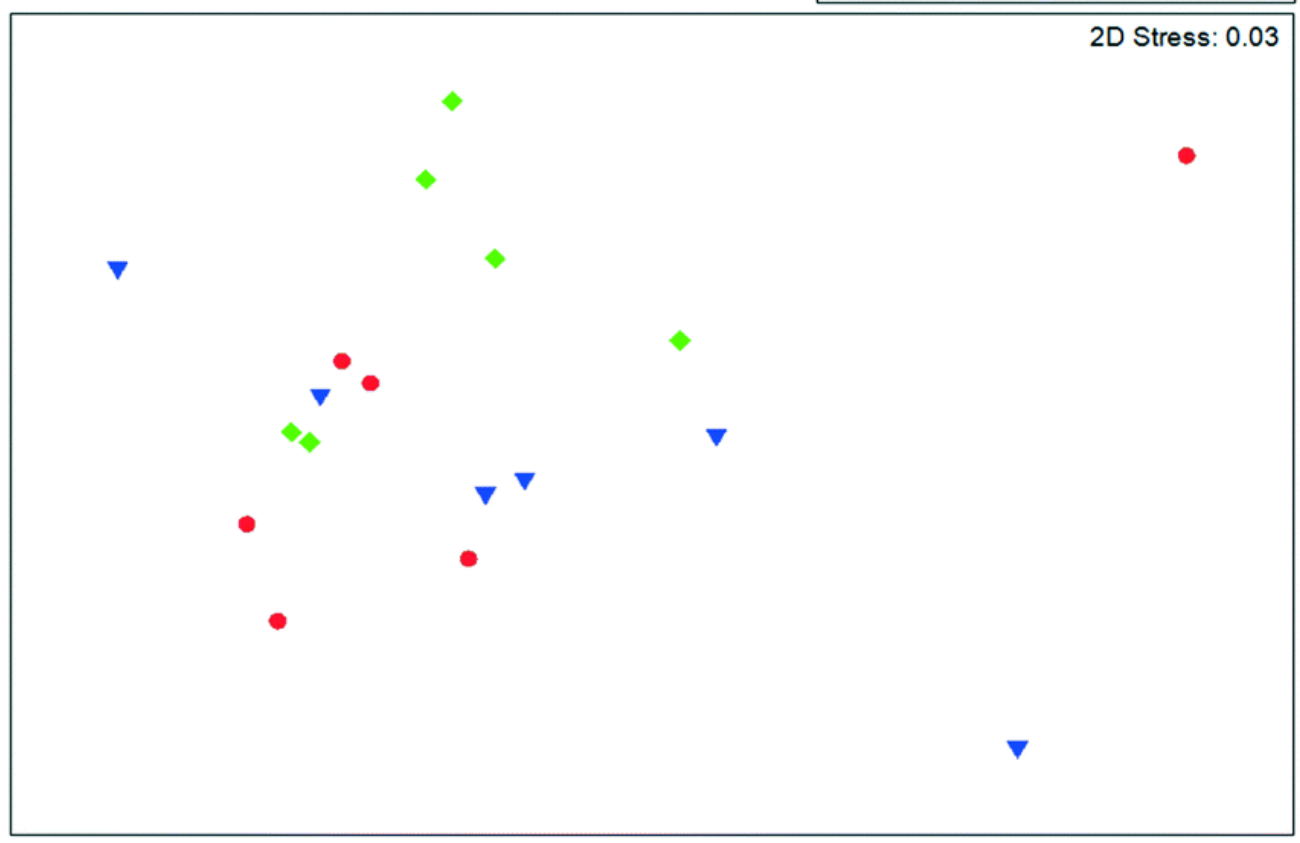

\begin{tabular}{|l|}
\hline treatment \\
- Control \\
$\nabla$ AgNP \\
SWCNT \\
\hline
\end{tabular}

Figure 5.4 Overall AHL profiles in (A) P. syringae and (B) P. stewartii by nonmetric Multidimensional Scaling (nMDS) in the nanomaterial-treated $(0.5 \mu \mathrm{g} / \mathrm{ml}$ AgNPs or 20 $\mu \mathrm{g} / \mathrm{ml}$ SWCNTs) and no-treatment control conditions. Experiments were conducted in 6 replicates. 
These results suggested a significant shift in the AHL profiles, in particular, C4-HSL, when $P$. syringae was grown in the presence of AgNPs. The samples from SWCNTtreated cultures closely resembled the control without SWCNTs and were clustered together, indicating no overall changes in the AHL profiles. In contrast, all the samples from $P$. stewartii cultures with and without AgNPs or SWCNTs were largely scattered and no discrete clusters could be found, suggesting no overall changes in the AHL profiles produced by $P$. stewartii. Taken together, the results show that the effects of NMs on bacterial QS signalling are highly dependent on the bacterial species, and more importantly, the production of different QS signals may respond differently to the contaminant exposure. The production of AHLs is a complex biological process and the exact mechanism on how NMs interfere with different AHL synthesis pathways needs further investigation.

The differential effects of different NMs on AHLs production in different species might be attributed to a combination of nanomaterial physicochemical property and bacterial response mechanism to environmental stressors. The physio-chemical properties such as sizes, shapes, compositions of both the materials used are very different which might lead to different biological effects. Previous reports have suggested different modes of action for different NMs. For example, AgNPs are known to attach to the bacterial cell membrane and alter their permeability and respiration. They also can penetrate into the cells and interact with biomolecules such as proteins (Matsumura, Yoshikata et al. 2003) and nucleic acids (Feng, Wu et al. 2000), while SWCNTs mostly act through direct physical contact or exert oxidative stress which compromises the cell membrane integrity (Kang, Pinault et al. 2007). Moreover the degree of aggregation for both the NMs, in presence of the organic matter in the culture media might be different that may in turn affect their bioavailability. These are some of the plausible reasons why the effect was seen with only AgNPs and not SWCNTs.

Furthermore, the effect of AgNPs is also different for different bacterial strains. This host specificity could be attributed to variety of bacterial processes but one plausible explanation could be, extracellular polymeric substance (EPS) might play a very crucial role in the penetration of NMs in bacterial culture media. Both the bacterial strains used in 
this study might vary in terms of their EPS composition (Nimtz, Mort et al. 1996, Keith, Keith et al. 2003) and thus might interact very differently with NMs.

In previous studies, the effects of NMs on bacterial QS signalling have been reported mostly based on the assay of QS-regulated activities such as violacein production in Chromobacter violaceum (Wagh, Patil et al. 2013, Naik and Kowshik 2014). However, a number of different QS signals are often produced concurrently and each may involve in regulating different bacterial activities. For example, violacein production has been shown to be induced by short-chain AHLs (C4-C8) and inhibited by AHLs with $N$-acyl side chains from C10 to C14 (McClean, Winson et al. 1997). The results reveal that the production of different AHL-type QS signals may respond differently to NMs at subinhibitory concentrations. Both $P$. syringae and $P$. stewartii are soil bacteria that are usually associated with plant roots (Cha, Gao et al. 1998, Dumenyo, Mukherjee et al. 1998) and the AHLs produced by these organisms have been shown to regulate various interactions between bacteria and their plant hosts (von Bodman, Bauer et al. 2003). The understanding of differential effects of NMs on the production of different AHLs would allow us to better assess their impacts on specific bacteria-host interactions. In addition, QS represents both intra- and inter-species signalling and QS-enabled cooperation is beneficial to the local population or community as a whole (Waters and Bassler 2005). Hence, differential effects exhibited by NMs on different QS signals in certain QS signal producers may result in a complex impact on the overall function of the whole community.

\subsection{Conclusions}

Taken together, the results reveal that the effects of NMs on bacterial QS signalling are highly dependent on bacterial species, and more importantly, the production of different QS signals in one species may respond differently. This study significantly advances the current knowledge toward a comprehensive understanding of the sublethal effects of NMs on bacterial QS signalling. 


\section{CHAPTER 6. Effect of Silver Nanoparticles on Collective Antibiotic Tolerance of Wastewater Sludge Microbial Community}

\subsection{Introduction}

The increased resistance of microbial biofilm communities has been widely studied and it is increasingly clear that the communal interactions and social dynamics hold the key. This type of cooperative behaviour is interesting in the context of antibiotics treatment, known as collective antibiotic tolerance. It is widely reported that resistant to antibiotics in bacteria can be intrinsic or they can acquire it as a result of genetic mutation or horizontal gene transfer via plasmids, transposons and integrons (Blair, Webber et al. 2015). Along with widespread usage of antibiotics, other toxic environmental pollutants, e.g., heavy metals (Baker-Austin, Wright et al. 2006, Seiler and Berendonk 2012), triclosan (Carey and McNamara 2015), disinfection by products (Lv, Jiang et al. 2014) also contributes to increased antibiotics resistance. This type of co-selection or cross-protection is seen in case of shared regulatory response for antibiotics and anthropogenic pollutants. Mechanisms of antibiotic tolerance at community level are clearly more complex than single cell level. Therefore, there is an increased thrust towards a full understanding of the environmental factors that lead to evolution and proliferation of antibiotics resistance in natural environment.

NMs are one of the emerging contaminants and their ever increasing usage across different industry will lead to their leaching into environment. The most commonly used $\mathrm{NM}$ in consumer products is silver, which is present in highest number of product (259 products) (Weinberg, Galyean et al. 2011). Interestingly, there have been some studies showing NMs can promote antibiotics resistance by enhancing horizontal gene transfer. Nano alumina was shown to promote conjugative transfer of the RP4 plasmid transfer across genera due to the membrane damage caused by oxidative stress (Qiu, Yu et al. 2012). However, this study was limited to laboratory based pure cultures. Very recently another study reported the effect of silver nanoparticles on antibiotic gene profile in 
wastewater bacterial community (Ma, Metch et al. 2016). Using metagenomics based approach the study finds that the silver nanoparticle treatment increases the abundance of antibiotic resistance genes (ARGs) compared to untreated control and silver ion treated reactors. But the major limitation of metagenomics information is, it is based on DNA from both live and dead cells and the increased copy number of certain genes may or may not get reflected in the respective gene expression.

Moreover, apart from the above mentioned studies there has not been much information on how NMs can affect the collective antibiotic tolerance of a complex microbial community. The objective of this study was to evaluate the effect of silver nanoparticles (AgNPs) on the antibiotics tolerance of wastewater microbial community using metatranscriptomics to study the microbial population in terms of the change in live/active population. AgNPs were used as the model NM for its universal presence and tetracycline was used as the model antibiotic because tetracycline class of antibiotics is one of the most widely used for treatment of human and live stocks (Chopra and Roberts 2001).

\subsection{Materials and Methods}

\subsubsection{Sludge collection}

The sludge was collected from a laboratory scale column-type enhanced biological phosphorus removal (EBPR) reactor with alternate anaerobic and aerobic cycle operating at $30^{\circ} \mathrm{C}$ after $\sim 60$ days of operation. The MLVSS of the sludge taken from reactor was adjusted to $1 \mathrm{~g} / \mathrm{L}$ and were grown in $250 \mathrm{~mL}$ flaks with a working volume of $50 \mathrm{~mL}$, under aerobic condition at $30^{\circ} \mathrm{C}$ with $200 \mathrm{rpm}$ shaking. MLSS and MLVSS analyses were carried using methods described previously (Eatson, Clesceri et al. 2005). The sludge microorganisms were grown in the same mineral medium used in the EBPR reactor containing $400 \mathrm{mg} \mathrm{COD} / \mathrm{L}$, the ammonia and phosphate concentrations were $20 \mathrm{mg} \mathrm{N}$ $\mathrm{NH}_{4}{ }^{+} / \mathrm{L}$ and $20 \mathrm{mg} \mathrm{P}-\mathrm{PO}_{4}{ }^{3-} / \mathrm{L}$ respectively. Every $24 \mathrm{~h}$, the sludge was allowed to settle for $1 \mathrm{~h}$ and half the volume was replaced with fresh synthetic mineral medium mentioned above, to replenish the nutrients. 


\subsubsection{Nanomaterial and antibiotic treatment}

AgNPs with sodium citrate as stabilizer with a size of $10 \mathrm{~nm}$ (TEM-based) were purchased from Sigma-Aldrich (Singapore). AgNPs and $\mathrm{Ag}^{+}\left(\mathrm{AgNO}_{3}\right.$, Merck, Singapore) with concentration $0.1 \mu \mathrm{g} / \mathrm{ml}$, along with the mineral media were added to the sludge every $24 \mathrm{~h}$ till $144 \mathrm{~h}$.

The stock solution of tetracycline antibiotic (Sigma, Singapore; purity of > 98\%) was prepared in $70 \%$ ethanol. After $144 \mathrm{~h}$, all the three groups (control, AgNP treated and $\mathrm{Ag}^{+}$ treated) were exposed to tetracycline treatment at $1000 \mu \mathrm{g} / \mathrm{ml}$ for $24 \mathrm{~h}$. Equal volume of $70 \%$ ethanol was added to the untreated samples to account for the background.

\subsubsection{Viability measurement}

The viability of the sludge microbial community was assessed by using the Live/Dead staining (LIVE/DEAD ${ }^{\circledR}$, BacLight ${ }^{\mathrm{TM}}$ Cell Viability Assays, Thermo Fisher Scientific Inc.). Briefly, $100 \mu \mathrm{L}$ of sludge was evenly mixed with $10 \mu \mathrm{L}$ of SYTO9/propidium iodide working solution (final concentration $6.68 \mu \mathrm{M}$ and $40 \mu \mathrm{M}$, respectively), after thorough mixing samples were kept in dark at room temperature for at least $30 \mathrm{~min}$. Stained samples were imaged at $488 \mathrm{~nm}$ excitation (SYTO9) as well as $561 \mathrm{~nm}$ excitation (propidium iodide) using confocal microscopy. Quantitative image analysis was done using IMARIS (Version 8.2.0; Bitplane, Zurich, Switzerland). The ratios of live and dead cells (L/D ratio) were calculated from the confocal images.

\subsubsection{Phosphate measurement using ion chromatography}

The IC system (Shimadzu Prominence) with a Conductivity detector (CDD) was used for phosphate measurement. Shodex IC-SI-90 4E 250mm x 4.0mm column and a flow rate of $1.1 \mathrm{ml} / \mathrm{min}$ was used. The mobile phase used consisted of $12 \mathrm{mM}$ Sodium Hydrogen Carbonate and 0.6 mM Sodium Carbonate. The column oven temperature was maintained at $40^{\circ} \mathrm{C}$. Run time was $23.8 \mathrm{~min} / \mathrm{sample}$. 


\subsubsection{RNA extraction}

The sludge samples were collected by centrifugation at $8,000 \mathrm{~g}$ at $4^{0} \mathrm{C}$ for $8 \mathrm{~min}$, fixed in liquid nitrogen for $30 \mathrm{~min}$ and immediately stored at $-80^{\circ} \mathrm{C}$ for subsequent RNA extraction. Total RNA was extracted from sludge using ZR Soil/Fecal RNA MicroPrep ${ }^{\mathrm{TM}}$ (Zymo Research, USA) according to the manufacturer's guidelines and DNA was removed using the TURBO DNA-free kit (Applied Biosystems, Singapore). RNA quantity and purity was determined using NanoDrop spectrophotometer (Thermo Scientific, DE, USA) and Qubit ${ }^{\circledR}$ RNA HS Assay Kit by Qubit ${ }^{\circledR} 2.0$ Fluorometer (Life Technologies) according to the manufacturer's protocol. The integrity of RNA was measured on a 2200TapeStation system (Agilent Technologies) with R6K ScreenTape.

\subsubsection{RNA sequencing}

Next-generation sequencing library preparation was performed by following TruSeq RNA Sample Preparation v2 protocol (Illumina) with modifications: 200 ng of total RNA was directly added to the elute-fragment-prime step. The PCR amplification step, which selectively enriches for library fragments that have adapters ligated on both ends, was performed according to the manufacturer's recommendation but the number of amplification cycles was reduced to 12 . Each library was uniquely tagged with one of Illumina's TruSeq LT RNA barcodes to allow library pooling for sequencing. Library quantitation was performed using Invitrogen's Picogreen assay and the average library size was determined by running the libraries on a Bioanalyzer DNA 7500 chip (Agilent). Library concentration was normalized to $4 \mathrm{nM}$ and the concentration was validated by qPCR on a ViiA-7 real-time thermocycler (Applied Biosystems), using KAPA Library Quantification Kit Illumina ${ }^{\circledR}$ platforms. Libraries were then pooled at equal volumes and sequenced in one lane of an Illumina HiSeq2500 rapid run at a final concentration of 11 pM and a read-length of $101 \mathrm{bp}$ paired-end. All raw RNA sequencing data used in this study are publicly available from NCBI under BioProjectID: SRP077608. 


\subsubsection{Sequence analysis using RiboTagger}

The raw reads were quality filtered and adapter removed, were processed for rRNA profiling using RiboTagger (available at https://github.com/xiechaos/ribotagger). Briefly, a universal primer was used to scan for the $16 \mathrm{~S}$ rRNA hypervariable region (V4) in order to detect $33 \mathrm{nt}$ sequences immediately next to the V4 region of 16S rRNA, using a position specific scoring matrix (PSSM). Short reads not able to cover the full $33 \mathrm{nt}$ region were discarded. This PCR free approach has the advantage of minimizing amplification bias (Logares, Sunagawa et al. 2014). The taxonomy of individual V4 tag was classified based on the GreenGenes and Silva 16S rRNA databases. Each different V4 tag is used as a signature sequence to represent one operational taxonomic unit.

\subsubsection{Statistical analysis}

All statistical analyses were performed using R (www.r-project.org), Prism 6 Version 6.04 (GraphPad, U.S.A.) or PRIMER 6 Version 6.1.15 \& PERMANOVA+ Version 1.0.5 (PRIMER-E, United Kingdom). For read normalization, sample reads were randomly subsampled with a replacement method to an even depth using QIIME (v.1.8). Community diversity indexes including Simpson and Shannon indexes were determined for each sample. ANOVAs and Sidak's post-tests were conducted to examine differences between samples. Adjusted p-values were reported. Read count matrixes were constructed from the evenly sampled read data, which was further normalized using $\log (\mathrm{X}+1)$ transformation. The relative abundance of each tag/OTU was estimated and expressed as a portion of the total reads in each sample. The read count matrixes were further resembled using Bray-Curtis similarity measure prior to visualization using nMDS plots.

\subsection{Result and Discussion}

\subsubsection{Effect of AgNPs on viability}

The three groups: control, $\mathrm{AgNP}$ and $\mathrm{Ag}^{+}$were seeded with the same inoculum in triplicates. Cell viability was monitored every $24 \mathrm{~h}$ using ATP measurement and Live/Dead staining. With time the cell viability decreases across all groups irrespective of treatment (Figure 6.1). At $48 \mathrm{~h}$ and $96 \mathrm{~h}$ the \% live cells are comparable across all the 
three groups. But at $144 \mathrm{~h}$ the ratio decreases slightly. $\mathrm{Ag}^{+}$or $\mathrm{AgNPs}$ treatment didn't contribute to loss of viability at any time point as values were not statistically different across all the groups. This gradual decrease in viability across all the groups might be due to nutrient limitation and toxic metabolite accumulation with time.

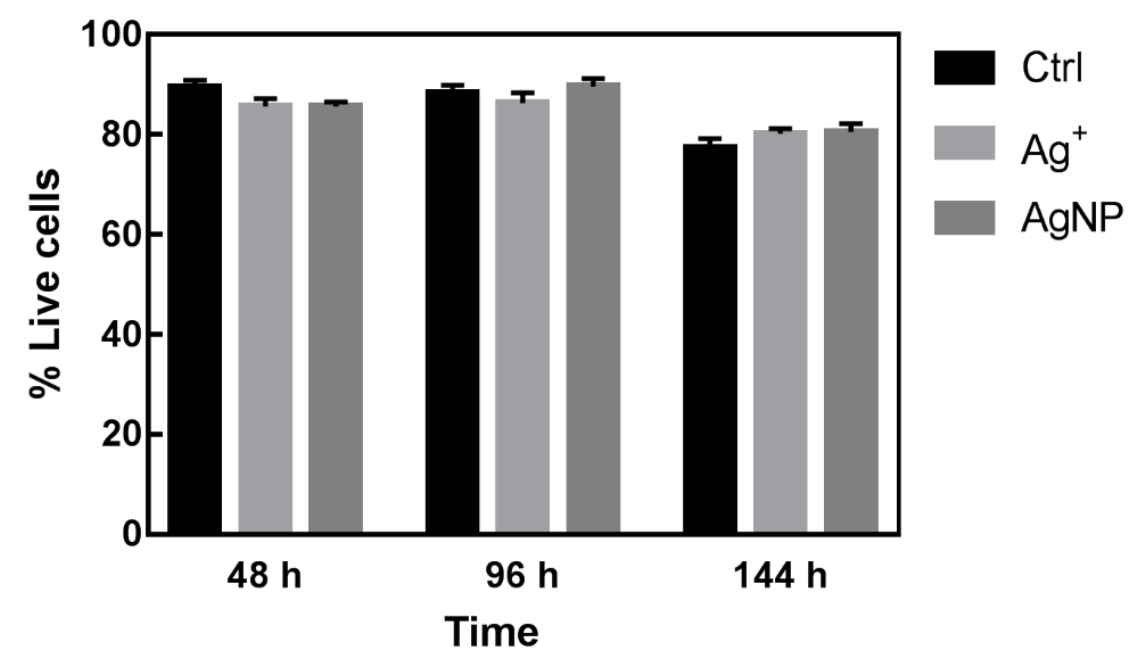

Figure 6.1 Viability of sludge biomass over time was assessed through Live/Dead staining. The total biovolume of viable (live) and non-viable (dead) communities were calculated from CLSM images. Ratio of live cells biovolume to total biovolume represents the $\%$ live cells. Error bars are defined as standard error of mean $(n=8)$.

\subsubsection{Effect of AgNPs on community function}

The activity of the microbial community was also assessed during the treatment period. As the sludge was collected from the lab scale EBPR reactor, it was expected to have phosphate $(\mathrm{P})$ release and uptake activity by phosphate accumulating organisms (PAOs). For EBPR system, cyclic anaerobic/aerobic phases are maintained which encourages $\mathrm{P}$ release and uptake by PAOs. During anaerobic phase internal phosphate is hydrolysed and orthophosphate is released into the media. The experimental conditions were different from the original reactor as the sludge was maintained under aerobic conditions but every $24 \mathrm{~h}$ during changing the spent media with fresh media, the sludge was taken out of shaker and was allowed to settle down for $1 \mathrm{~h}$ creating a transient anaerobic phase. After sludge settlement the spent media was withdrawn and phosphate levels were measured in the effluent. An apparent P release activity was observed and a decreasing trend is observed 
over time and didn't differ between the groups (Figure 6.2). This trend can be correlated with the cell viability which also decreases over time. Another possible reason for the decrease in $\mathrm{P}$ release might also be due to shift in community profile over time.

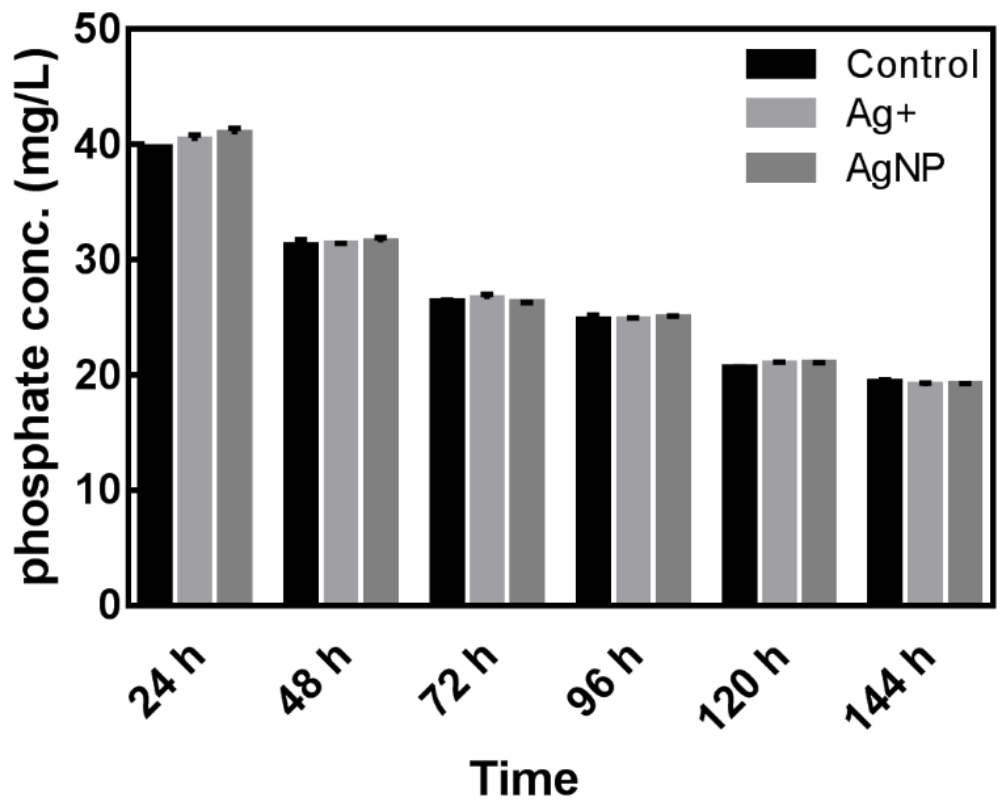

Figure 6.2 Phosphate concentration was measured in the spent media at every $24 \mathrm{~h}$ interval. A decreasing trend is observed across all the group over time. Error bars are defined as standard error of mean ( $n=3$, biological replicates).

\subsubsection{Effect of AgNPs on overall community composition}

Analysis of the total rRNA sequences was done to investigate bacterial diversity and richness using Shannon and Simpson diversity indices. In this study, Shannon and Simpson indices showed a similar pattern, i.e., the community diversity significantly increased from seed culture $(0 \mathrm{~h})$ to $144 \mathrm{~h}$ samples (Figure $6.3 \mathrm{~A}$ and $\mathrm{B}$ ). The increase in diversity after $144 \mathrm{~h}$ is regardless of the treatment type and there was no significant difference $(p>0.6)$ between control, $\mathrm{Ag}^{+}$and $\mathrm{AgNP}$ groups. As diversity also considers OTU abundances, the results show more evenly distributed abundance profiles after few days. 

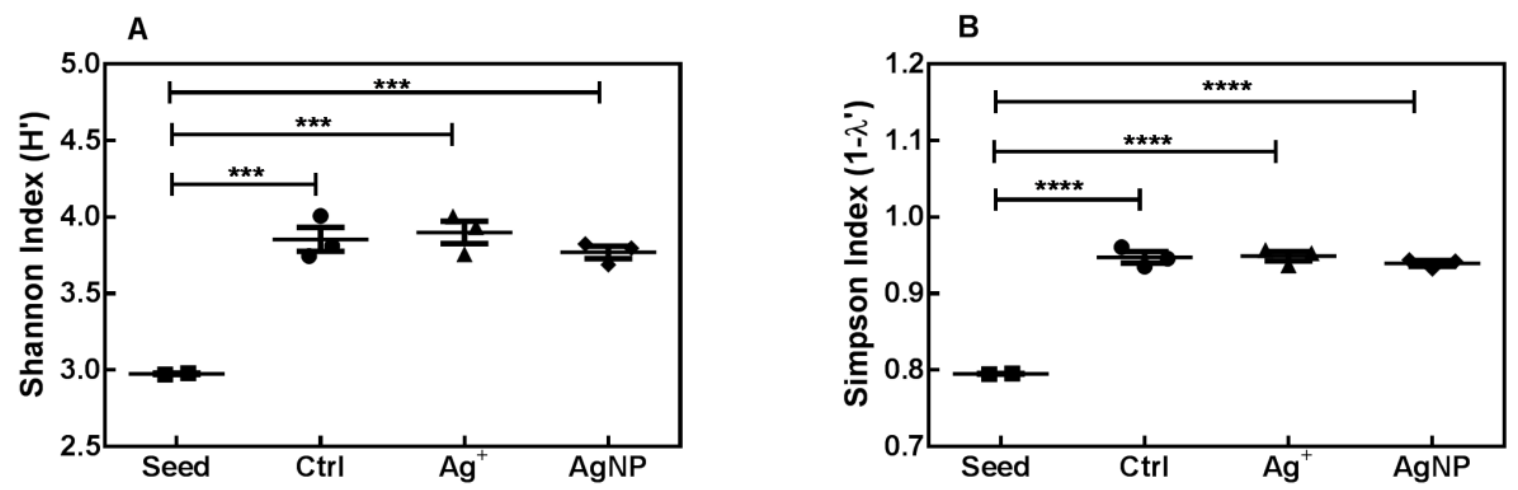

Figure 6.3 (A) Shannon index (B) Simpson index. Mean value of diversity for multiple OTUs were compared for seed culture and different groups (Ctrl, $\mathrm{Ag}^{+}$and $\mathrm{AgNP}$ ) after $144 \mathrm{~h}$ Significant differences are indicated as follows: $* * * p<0.001, * * * * p<0.0001$. Error bars defined as standard error of mean ( $n=3$, biological replicates).

The three different groups after $144 \mathrm{~h}$ were also compared with the seed culture using nonmetric multidimensional scaling (nMDS) based on the mean relative abundance of OTUs (Figure 6.4) revealed tight clustering of all the three groups and was distinctly separated from the seed culture. This further suggests no difference between AgNPs and $\mathrm{Ag}^{+}$ treatment with control after $144 \mathrm{~h}$. 


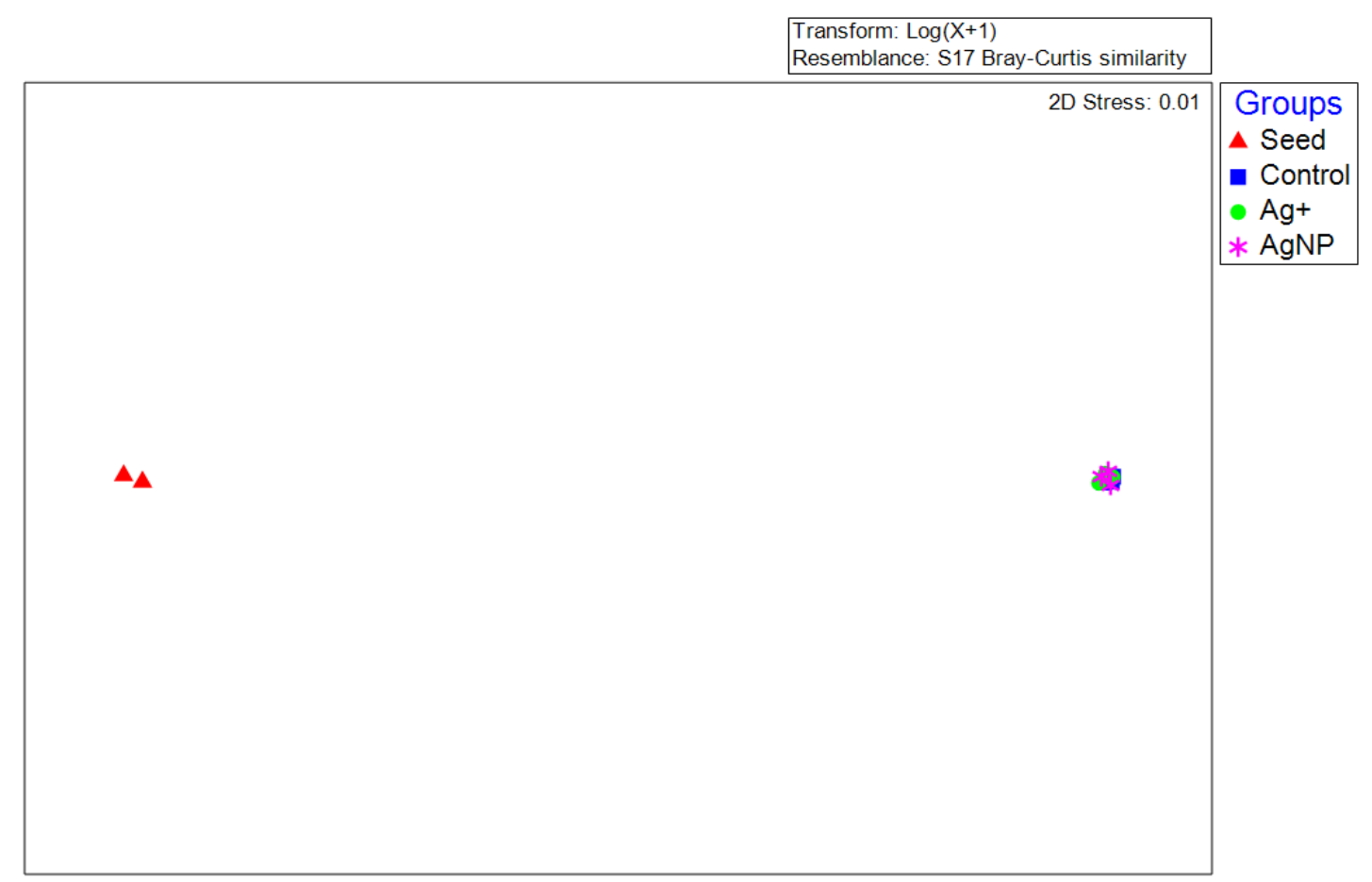

Figure 6.4 Nonmetric multidimensional scaling (nMDS) based on rRNA sequences compares the seed culture and different groups (Ctrl, Ag+ and AgNP) after $144 \mathrm{~h}$. The seed culture form a separate cluster compared to the rest of the samples.

Furthermore, the relative abundances of top 100 OTUs, which represent 90\% of the total sequences, were compared across different samples. The relative abundance of different tags in seed samples was significantly different than samples of three different groups after $144 \mathrm{~h}$ (Figure 6.5). A closer observation suggests, the major change was in family Piscirickettsiaceae (Tag 2) whose relative abundance in seed culture was $\sim 44 \%$ but it decreased significantly to $7-12 \%$ across all the groups. There is not much literature available linking it to the EBPR activity, most members of this family are aerobes found in water (Zahou, Mlika et al. 2015). The other major trend was the decrease in abundance of Candidatus Accumulibacter (hereafter referred to as Accumulibacter) represented by the Tag 6, 13 and 19. Accumulibacter is a well-known PAO and has been reported in many laboratory reactors and full scale EBPR plants (Crocetti, Hugenholtz et al. 2000, He, Gall et al. 2007). This is not very surprising as all the cultures were grown under constant shaking and it has already been reported that excessive aeration suppresses the growth of PAOs (Carvalheira, Oehmen et al. 2014). This may also be directly linked to decrease in $P$ levels with time in all the three groups (Figure 6.2). The relative abundance of other tags 
in top 20 showed overall increase across all the three groups compared to seed culture, the most significant being the genus Zoogloea (Tag 1) and Thauera (Tag 3) where 10 fold increases was observed. Both the above genus belonging to the class of betaproteobacteria are abundant in industrial waste water plants and known to be the important denitrifiers (Juretschko, Loy et al. 2002, Wagner, Loy et al. 2002, Thomsen, Kong et al. 2007). Excessive growth of Zoogloea genus has been known to negatively affect the EBPR process by causing bulking due to excessive production of extracellular polymeric substances (EPS) (Montoya, Borrás et al. 2008). 

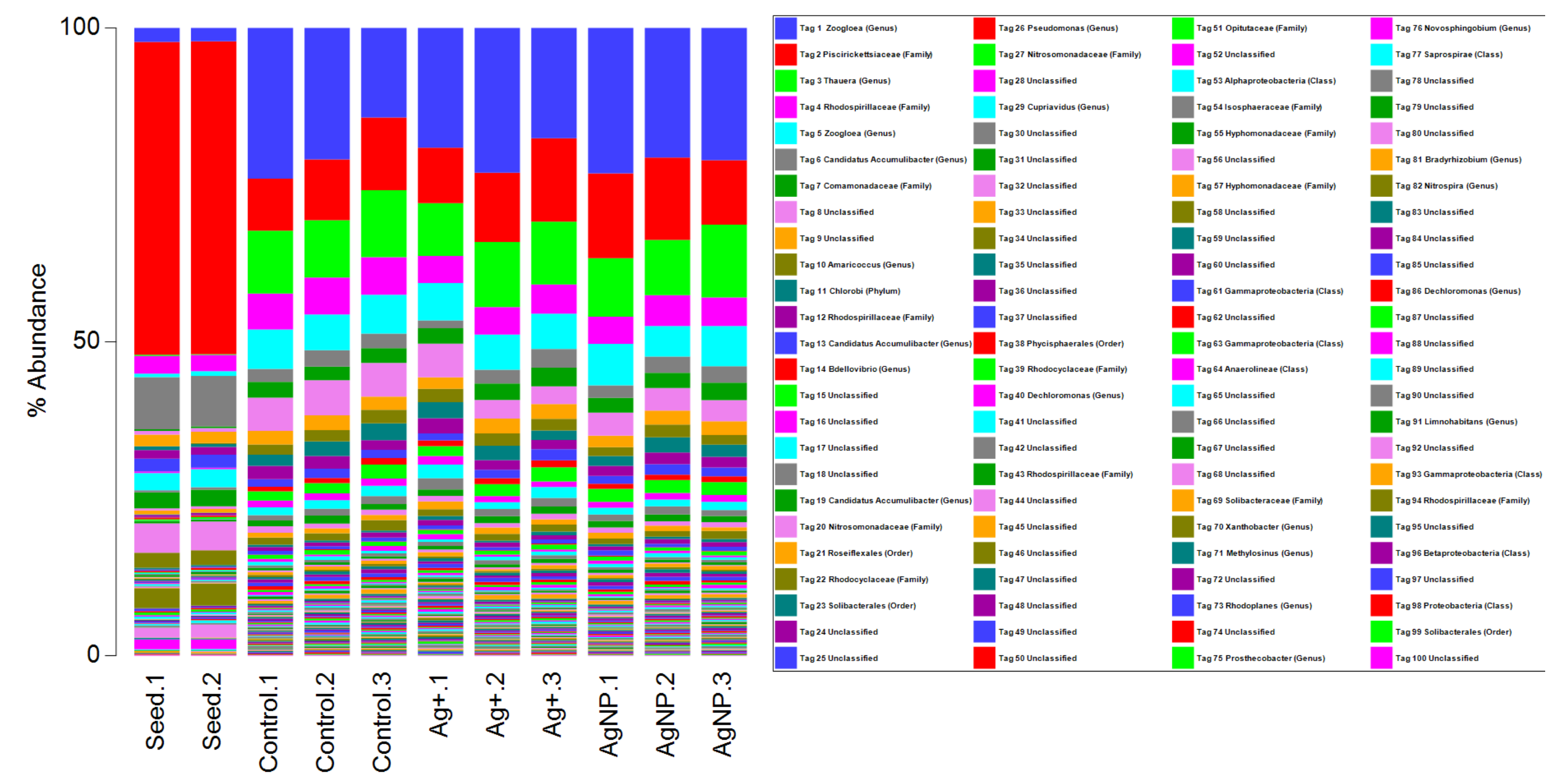

Figure 6.5 Bar chart displaying the community composition of each sample, including the 100 most abundant taxa in all samples. 
Combining all the above analysis shows that there was no significant difference in terms of active and live population composition in response to $\mathrm{AgNPs}$ or $\mathrm{Ag}^{+}$treatment. More than 50\% Tags were unclassified, which highlights an inherent problem of accurately annotating short read-length tag sequences from hypervariable region of $16 \mathrm{~S}$ rRNA (Wang, Garrity et al. 2007, Liu, DeSantis et al. 2008).

\subsubsection{Effect of AgNPs on the collective antibiotic tolerance}

To test the effect of AgNPs on collective antibiotic tolerance, sludge was treated with $\mathrm{AgNPs}$ and $\mathrm{Ag}^{+}$for $144 \mathrm{~h}$ before subjecting all the three groups to tetracycline antibiotic treatment. All the further comparisons were done among three conditions: all the three groups (ctrl, $\mathrm{Ag}^{+}$and $\mathrm{AgNP}$ ) at $144 \mathrm{~h}$ (referred to as "prior treatment" from here on), treatment with $70 \% \mathrm{EtOH}$ (the final concentration of ethanol in samples was calculated to be $3.5 \%$ ) and, treatment with tetracycline (EtOH.Tet). The effect of treatment on viability of sludge microbial community was assessed by Live/Dead staining (Figure 6.6). After 24 $\mathrm{h}$ of tetracycline treatment reduction $(\sim 25-30 \%)$ in \% live cells was observed for all the three groups: ctrl, $\mathrm{Ag}^{+}$and AgNP. There was no significant reduction in viability with $\mathrm{EtOH}$ treatment compared to prior treatment samples.

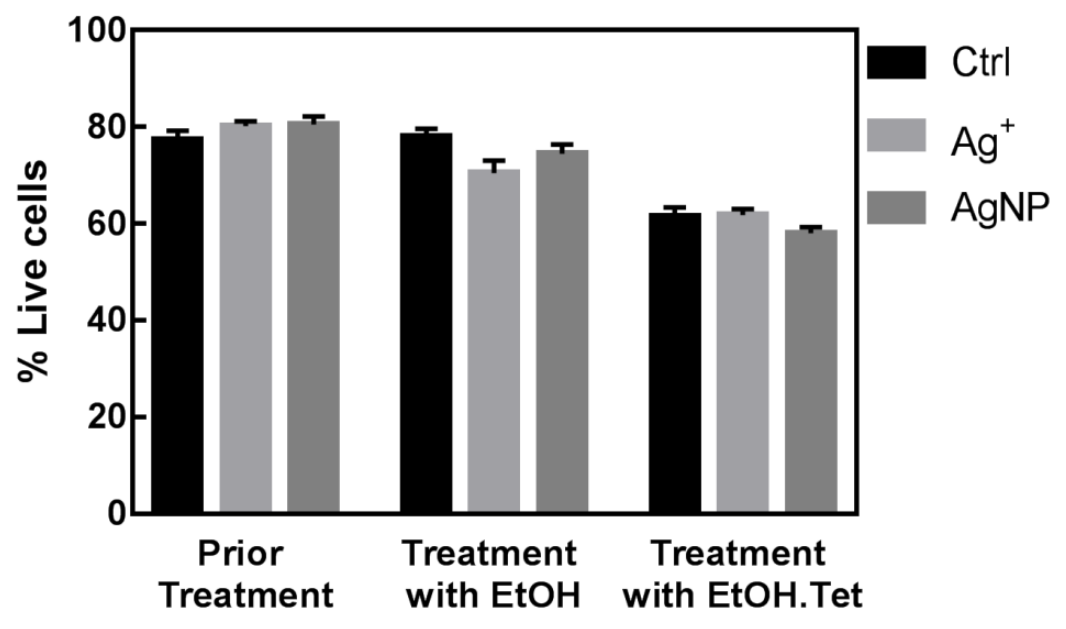

Figure 6.6 Viability of sludge biomass after tetracycline treatment was assessed through Live/Dead staining. The total biovolume of viable (live) and non-viable (dead) communities were calculated from CLSM images. Ratio of live cells biovolume to total biovolume represents the \% live cells. Error bars are defined as standard error of mean $(n=8)$. 
There was a reduction of viability in all the three groups but there still was a major fraction of live cells after $24 \mathrm{~h}$ of antibiotic treatment. However, this observation is not very surprising as wastewater treatment plants have been shown to be the hotspots for spread of ARGs and antibiotic resistance bacteria (Rizzo, Manaia et al. 2013). Because of its extensive usage the tetracycline resistance genes are frequently found in various natural (Chee-Sanford, Aminov et al. 2001, Mackie, Koike et al. 2006) and engineered environments like waste water treatment plants (Auerbach, Seyfried et al. 2007).

Further, analysis of total rRNA reads using non-metric multidimensional scaling (nMDS) based on the mean relative abundance of OTUs for all the samples showed three distinct clusters: prior treatment samples, samples with ethanol treatment and treatment with tetracycline. The three different groups: control, $\mathrm{Ag}^{+}$and $\mathrm{AgNP}$, didn't show much variation within each treatment category and all clustered together (Figure 6.7).

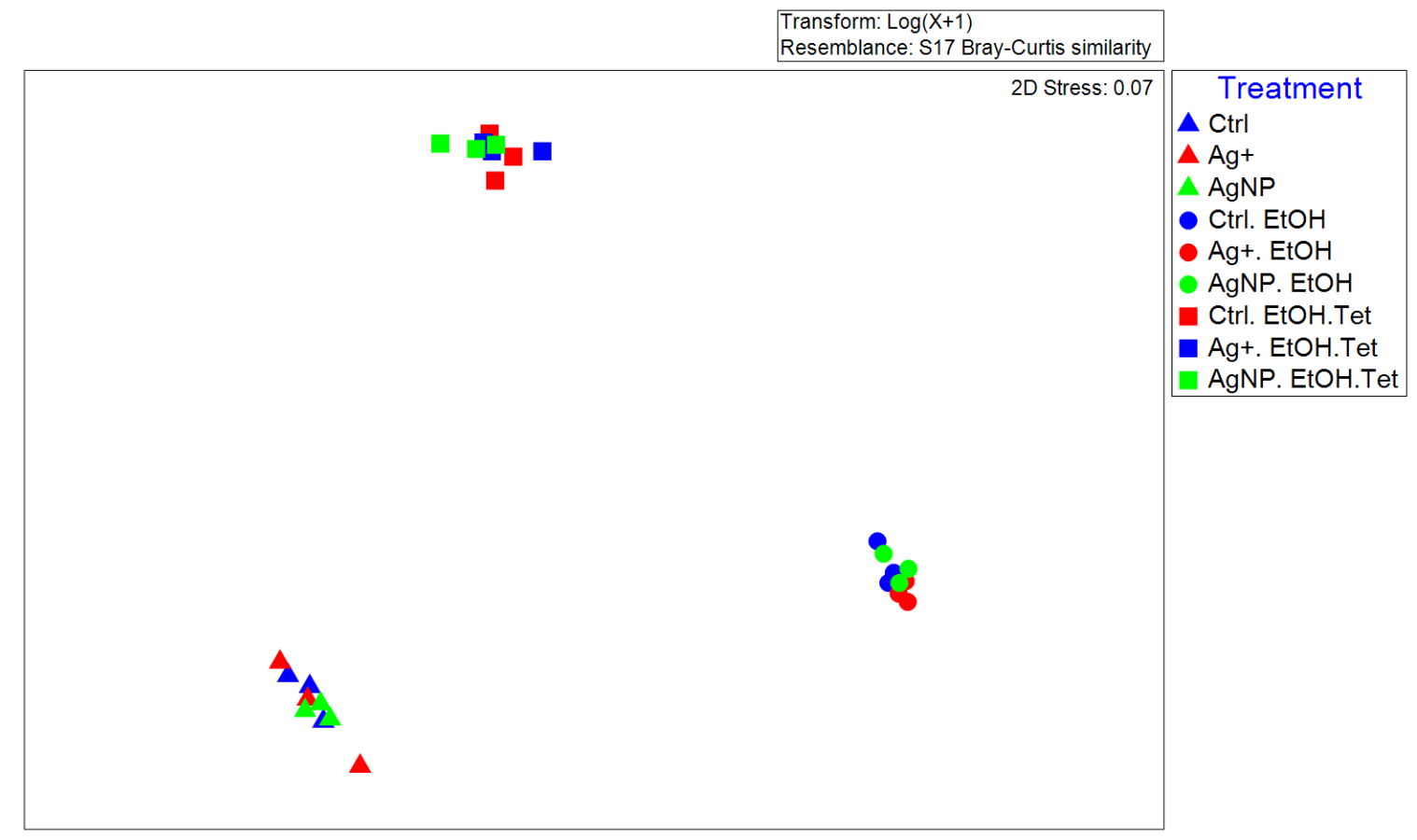

Figure 6.7 Nonmetric multidimensional scaling (nMDS) based on rRNA sequences compares the three groups (Ctrl, $\mathrm{Ag}+$ and $\mathrm{AgNP})$ before and after tetracycline treatment. Three distinct clusters are: pretreatment samples, the ethanol and tetracycline treated samples.

Further, Shannon and Simpson diversity indices were calculated for each group within the three different categories (Figure 6.8). There was no significant difference observed within 
groups post antibiotics treatment but interestingly both Shannon and Simpson index shows a significant difference post ethanol treatment, for the $\mathrm{Ag}^{+}$and $\mathrm{AgNP}$ samples the diversity indices were lower than control ( $p$-value $<0.05)$.
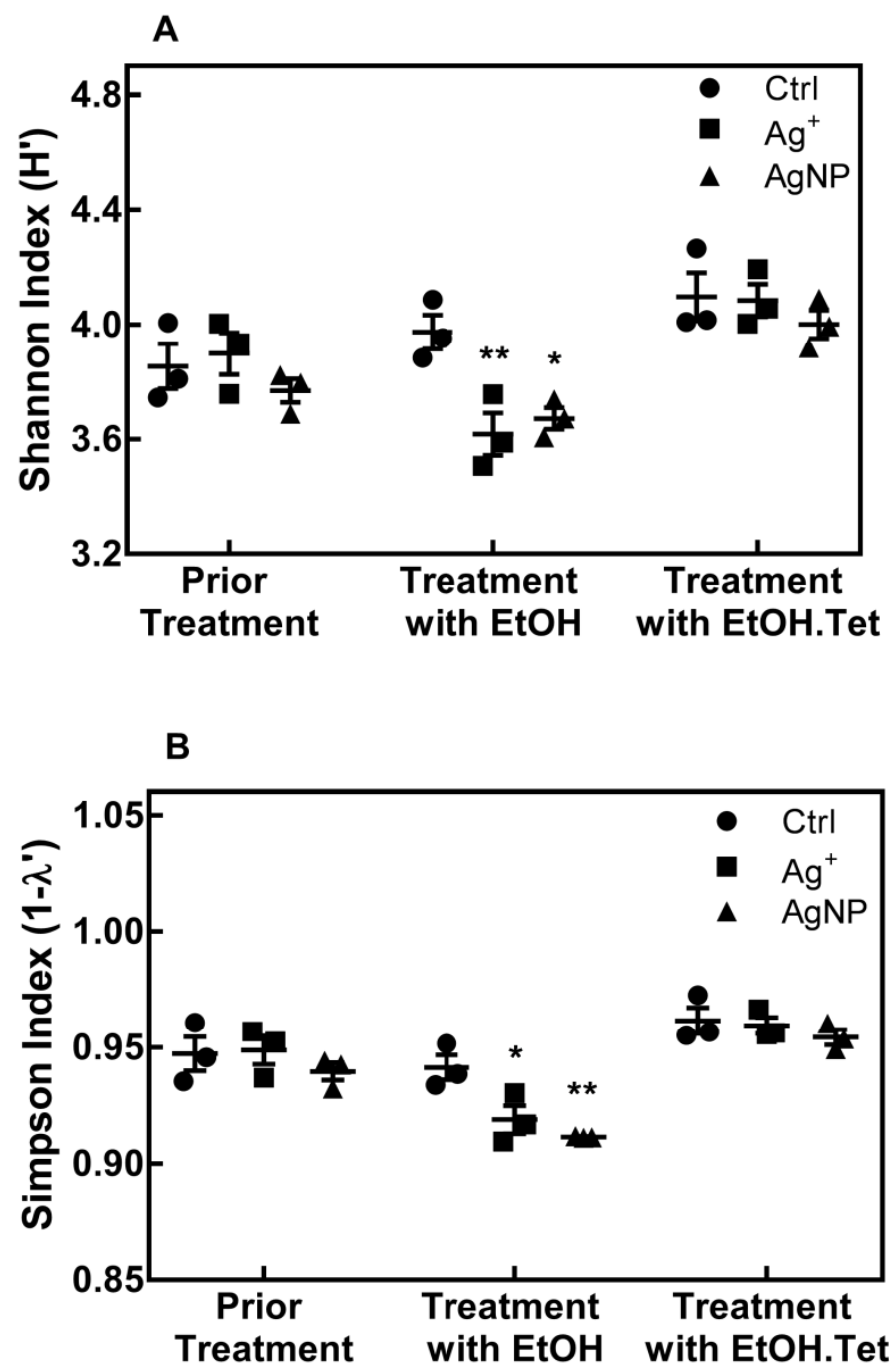

Figure 6.8 (A) Shannon index (B) Simpson index. Mean value of diversity of multiple OTUs were compared for prior treatment, ethanol treatment and tetracycline treatment for all the three groups (Ctrl, Ag+ and AgNP). Significant differences are indicated as follows: $* p<0.05$, ** $p<0.01$. Error bars are defined as standard error of mean $(n=3$, biological replicates).

To further analyse the impact of AgNPs on antibiotic tetracycline tolerance, top 10 most abundant Tags which represent $\sim 55 \%$ of the total reads were plotted (Figure 6.9). The heatmap shows the abundance of each Tag varies with the different treatments. But 
variation between control, $\mathrm{Ag}^{+}$and $\mathrm{AgNP}$ were not observed for most of them except for Tag 1 (Zoogloea) and Tag 3 (Thauera). In response to ethanol treatment the AgNP group enriched for Zoogloea species more compared to control $(p<0.0001)$. In case of Tag 3 (Thauera) both $\mathrm{Ag}^{+}$and AgNP groups have higher relative abundance compared to control $(p<0.0001)$ after ethanol treatment. Tetracycline treatment also showed, Tag 3 (Thauera) being enriched in $\mathrm{Ag}^{+}$group compared to control but this effect was not observed in AgNP group.

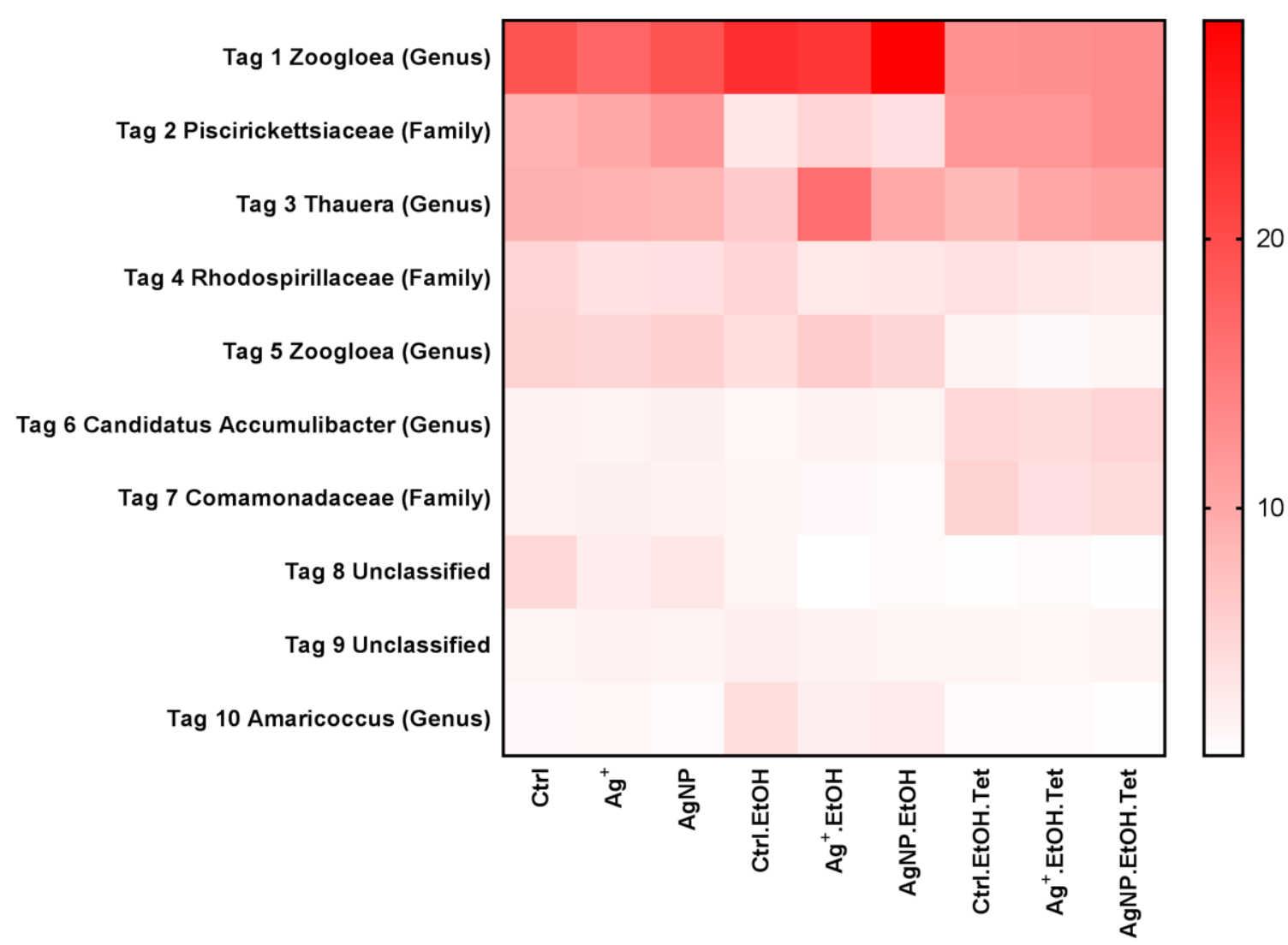

Figure 6.9 Heatmap of top 10 most abundant taxa. Each column in the heat-map represents one sample, while each row represents a taxa. The color intensity of the panel is abundance as percentage of the total community.

Overall it was seen that tetracycline treatment enriched the tags which were less abundant before treatment (Tag 6 and 7) and proportionately lowered the earlier abundant species (Tag 1, 5 and 8). But there were no significant difference among control and AgNPs treated samples. 


\subsection{Conclusions}

NMs are being considered as emerging contaminants owing to their usage across different industries. Silver nanomaterials are among the most commonly used ones and are mainly known for their antibacterial properties. Along with that, earlier studies pointed towards a possible effect of NMs on antibiotics resistance which is a major global concern. For the first time, this study uses the RNA sequencing approach to assess the live population composition of a wastewater sludge bacterial community in response to AgNPs and further to study effect on NMs treatment on subsequent antibiotic exposure. The concentration of AgNPs used in this study represents the environmentally relevant concentration with increasing dosage over few days. This study highlights that lower concentration of NMs might not show immediate acute effect on the composition and collective antibiotic tolerance of wastewater community but it will be important to look at the long term impact of NMs exposure on environmental microbial communities. 


\section{CHAPTER 7. Conclusions and Recommendations}

\subsection{Overall conclusions}

The presence of NMs in the environment is unavoidable because of an increasing use of NMs in a wide range of industries. Bacteria are important targets to consider while evaluating nanoecotoxicity, as NMs will invariably come in contact with them in water, sewage, soils, and sediments with potential consequences on overall health of the ecosystem. As most bacteria in nature exist in multi-species communities, interspecies interactions among bacteria of different species are important. Cell-cell interactions affect the overall structure and function of microbial communities. To comprehensively understand the impacts of NMs on the environment and the health of the ecosystem, it is imperative to elucidate the impacts of NMs on social behaviour of microorganisms. Impacts of NMs on different aspect of social behaviour i.e., public goods production (Chapters 3 and 4), cell-cell interaction through quorum sensing (Chapter 5), and protective interactions in the context of antibiotic tolerance (Chapter 6) were reported in this thesis.

Firstly, the impacts of NMs on pyoverdine production in a model organism $P$. aeruginosa were investigated. Tellurium nanorods (TeNRs) were found significantly inhibit pyoverdine (PVD) production in $P$. aeruginosa in both planktonic cultures and mature biofilms. Similarly, single-walled carbon nanotubes (SWCNTs) could also inhibit PVD production in $P$. aeruginosa. Interestingly, although SWCNTs has a bactericidal activity against $P$. aeruginosa, the cells that survived the treatment of SWCNTs exhibit a decrease in PVD biosynthesis. PVD plays an important role in growth of $P$. aeruginosa as it facilitates the uptake of iron into the bacterial cell and it has also been implicated in regulating virulence factors required for establishing infection.

Secondly, the impact of NMs on quorum sensing signal was evaluated using two model microorganisms, i.e., Pseudomonas syringae and Pantoea stewartii. The effect of SWCNTs and AgNPs were tested on the above two model organisms and interestingly, a differential effect was observed. The presence of AgNPs in P. syringae cultures resulted in 
overall reduction of AHLs signals. In contrast, in the presence of SWCNTs, the level of most AHLs remained unchanged except. Intriguingly, the production of most AHLs in $P$. stewartii was not significantly affected by either AgNPs or SWCNTs. Different AHLs signals are produced concurrently and are involved in regulating different bacteria activities. NMs treatment showed a differential profile compared to untreated control which might have implication in the overall activity of the organism and community as a whole.

Finally the effect of NMs were evaluated on collective antibiotic tolerance of a microbial community. AgNPs was used as the model NM and the effect was tested on sludge microbial community from an enriched EBPR reactor. It was observed that there was no significant difference in the live/active population composition in response to AgNPs treatment. Furthermore, the effect of AgNP didn't show any significant effect on collective antibiotic tolerance in terms of population composition.

Taken together, this study demonstrates sublethal impacts of NMs on bacterial functions that are critical to their social behaviours and provides novel insights into ecotoxicity of NMs.

\subsection{Recommendations for future research}

In this thesis, it was shown that NMs can influence different behaviours by interfering with production of PVD, AHLs signals, and antibiotic tolerance. The exact molecular mechanisms of the interference remains elusive. Interspecies interactions among bacteria of different species are important as most bacteria in nature exist in multi-species communities. Cell-cell interactions affect the overall structure and function of microbial communities. Future efforts should focus on studying the impacts of NMs on cell-cell interactions in microbial communities. The studies will be conducted using "defined multispecies communities" and "enriched microbial communities".

\subsubsection{Impacts of NMs on production of communal resources}

For the PVD inhibition by TeNRs and SWCNTs, it was shown that the effect was at transcriptional level as key genes involved in PVD synthesis, maturation and uptake were 
downregulated in the treated samples. Thus it is imperative to know how the signal is transmitted from outside environment to the cell and regulate gene expression. Random mutagenesis library need to be constructed and then screened for specific genes involved in this signal transduction pathway.

In this thesis, the impacts of NMs on the production of siderophores by single species planktonic culture and biofilms were evaluated. This work can be extended to examine total siderophore production by enriched microbial communities from natural and engineered ecosystems, for example, sediments from the urban waterways and sludge from Wastewater Treatment Plants. It will be interesting to see whether NMs treated producer cell and untreated cells behave differently.

\subsubsection{Impacts of NMs on cell-to-cell communication}

With respect to effect of NMs on QS signals, it has to be further explored whether the effect in $P$. syringae is at the genetic level. For that, qPCR can be used to quantify the key genes involved in the production of different AHLs. It will also be interesting to look at the other key functions like c-di-GMP level and biofilm formation ability when QS signals are downregulated.

Moreover, the effect of NMs on QS signals at the community level using will be another important step towards the comprehensive understanding of the ecotoxicity of NMs. These studies can be conducted using defined or enriched microbial communities. Specifically, the next step in studying the impact of NMs on QS will be examining the phenotypic changes occurring due to change in QS signals.

\subsubsection{Impacts of NMs on collective antibiotic tolerance}

In the last chapter, the effect of AgNP on the antibiotic tolerance of sludge microbial community using RNA sequencing was examined. By looking at the rRNA the live/active community structure of the sludge can be evaluated. In future, it would be interesting to analyse the mRNA sequences to gain an understanding into the changes in gene expression levels in response to NMs treatment. The concentration of NMs may not be very high to cause killing of the cells but may induce subtle changes at the level of gene 
expression and thus changing the function and structure of the whole community in long run. 


\section{REFERENCES}

Ahmed, B., B. Cao, B. Mishra, M. I. Boyanov, K. M. Kemner, J. K. Fredrickson and H. Beyenal (2012). "Immobilization of U (VI) from oxic groundwater by Hanford 300 area sediments and effects of Columbia river water." Water Res 46(13): 39893998.

Ahmed, E. and S. J. M. Holmström (2014). "Siderophores in environmental research: roles and applications." Microb Biotechnol 7(3): 196-208.

Ahmed, F. and D. F. Rodrigues (2013). "Investigation of acute effects of graphene oxide on wastewater microbial community: a case study." J Hazard Mater 256: 33-39.

Alito, C. L. and C. K. Gunsch (2013). "Assessing the effects of silver nanoparticles on biological nutrient removal in bench-scale activated sludge sequencing batch reactors." Environ Sci Technol 48(2): 970-976.

Alvarez, L. and F. Cervantes (2012). "Assessing the impact of alumina nanoparticles in an anaerobic consortium: methanogenic and humus reducing activity." Appl Microbiol Biotechnol 95(5): 1323-1331.

Anderson, G. and G. O'toole (2008). "Innate and induced resistance mechanisms of bacterial biofilms." Bacterial biofilms, Springer: 85-105.

André, J. B. and B. Godelle (2005). "Multicellular organization in bacteria as a target for drug therapy." Ecol Lett 8(8): 800-810.

Andreescu, S., J. Njagi, C. Ispas and M. T. Ravalli (2009). "JEM Spotlight: Applications of advanced nanomaterials for environmental monitoring." $\mathrm{J}$ Environ Monitor 11(1): $27-40$.

Andrews, S. C., A. K. Robinson and F. Rodríguez-Quiñones (2003). "Bacterial iron homeostasis." FEMS Microbiol Rev 27(2-3): 215-237.

Antoni, D., V. V. Zverlov and W. H. Schwarz (2007). "Biofuels from microbes." Appl Microbiol Biotechnol 77(1): 23-35.

Arias, L. R. and L. Yang (2009). "Inactivation of bacterial pathogens by carbon nanotubes in suspensions." Langmuir 25(5): 3003-3012.

Arrigo, K. R. (2005). "Marine microorganisms and global nutrient cycles." Nature 437(7057): 349-355.

Ash, C., J. Foley and E. Pennisi (2008). "Lost in microbial space." Science 320(5879): 1027.

Auerbach, E. A., E. E. Seyfried and K. D. McMahon (2007). "Tetracycline resistance genes in activated sludge wastewater treatment plants." Water Res 41(5): 1143 1151.

Baker-Austin, C., M. S. Wright, R. Stepanauskas and J. McArthur (2006). "Co-selection of antibiotic and metal resistance." Trends Microbiol 14(4): 176-182. 
Banin, E., M. L. Vasil and E. P. Greenberg (2005). "Iron and Pseudomonas aeruginosa biofilm formation." Proc Natl Acad Sci U.S.A. 102(31): 11076-11081.

Bartram, A. K., M. D. Lynch, J. C. Stearns, G. Moreno-Hagelsieb and J. D. Neufeld (2011). "Generation of multimillion-sequence 16S rRNA gene libraries from complex microbial communities by assembling paired-end Illumina reads." Appl Environ Microbiol 77(11): 3846-3852.

Battin, T. J., F. v. d. Kammer, A. Weilhartner, S. Ottofuelling and T. Hofmann (2009). "Nanostructured $\mathrm{TiO}_{2}$ : Transport behavior and effects on aquatic microbial communities under environmental conditions." Environ Sci Technol 43(21): 80988104.

Baughman, R. H., A. A. Zakhidov and W. A. de Heer (2002). "Carbon nanotubes-the route toward applications." Science 297(5582): 787-792.

Baun, A., N. B. Hartmann, K. Grieger and K. O. Kusk (2008). "Ecotoxicity of engineered nanoparticles to aquatic invertebrates: a brief review and recommendations for future toxicity testing." Ecotoxicology 17(5): 387-395.

Billings, N., M. R. Millan, M. Caldara, R. Rusconi, Y. Tarasova, R. Stocker and K. Ribbeck (2013). "The Extracellular matrix component Psl provides fast-acting antibiotic defense in Pseudomonas aeruginosa biofilms." PLoS Pathog 9(8): e1003526.

Binh, C. T. T., T. Tong, J.-F. Gaillard, K. A. Gray and J. J. Kelly (2014). "Common freshwater bacteria vary in their responses to short-term exposure to nano- $\mathrm{TiO}_{2}$." Environ Toxicol Chem 33(2): 317-327.

Blair, J. M. A., M. A. Webber, A. J. Baylay, D. O. Ogbolu and L. J. V. Piddock (2015). "Molecular mechanisms of antibiotic resistance." Nat Rev Micro 13(1): 42-51.

Bollinger, N., D. J. Hassett, B. H. Iglewski, J. W. Costerton and T. R. McDermott (2001). "Gene expression in Pseudomonas aeruginosa: evidence of iron override effects on quorum sensing and biofilm-specific gene regulation." J Bacteriol 183(6): 19901996.

Bradford, A., R. D. Handy, J. W. Readman, A. Atfield and M. Mühling (2009). "Impact of silver nanoparticle contamination on the genetic diversity of natural bacterial assemblages in estuarine sediments." Environ Sci Technol 43(12): 4530-4536.

Brady-Estévez, A. S., S. Kang and M. Elimelech (2008). "A Single-walled-carbonnanotube filter for removal of viral and bacterial pathogens." Small 4(4): 481-484.

Buell, C. R., V. Joardar, M. Lindeberg, J. Selengut, I. T. Paulsen, M. L. Gwinn, R. J. Dodson, R. T. Deboy, A. S. Durkin, J. F. Kolonay, R. Madupu, S. Daugherty, L. Brinkac, M. J. Beanan, D. H. Haft, W. C. Nelson, T. Davidsen, N. Zafar, L. Zhou, J. Liu, Q. Yuan, H. Khouri, N. Fedorova, B. Tran, D. Russell, K. Berry, T. Utterback, S. E. Van Aken, T. V. Feldblyum, M. D'Ascenzo, W.-L. Deng, A. R. Ramos, J. R. Alfano, S. Cartinhour, A. K. Chatterjee, T. P. Delaney, S. G. Lazarowitz, G. B. Martin, D. J. Schneider, X. Tang, C. L. Bender, O. White, C. M. Fraser and A. Collmer (2003). "The complete genome sequence of the Arabidopsis 
and tomato pathogen Pseudomonas syringae pv. tomato DC3000." Proc Natl Acad Sci U.S.A. 100(18): 10181-10186.

Buonomenna, M. G. (2013). "Nano-enhanced reverse osmosis membranes." Desalination 314(0): 73-88.

Buzea, C., I. Pacheco and K. Robbie (2007). "Nanomaterials and nanoparticles: Sources and toxicity." Biointerphases 2(4): MR17-MR71.

Cabiscol, E., J. Tamarit and J. Ros (2010). "Oxidative stress in bacteria and protein damage by reactive oxygen species." Int Microbiol 3(1): 3-8.

Camilli, A. and B. L. Bassler (2006). "Bacterial small-molecule signaling pathways." Science 311(5764): 1113-1116.

Cao, B., B. Ahmed, D. W. Kennedy, Z. Wang, L. Shi, M. J. Marshall, J. K. Fredrickson, N. G. Isern, P. D. Majors and H. Beyenal (2011). "Contribution of extracellular polymeric substances from Shewanella sp. HRCR-1 biofilms to U (VI) immobilization." Environ Sci Technol 45(13): 5483-5490.

Cao, B., P. D. Majors, B. Ahmed, R. S. Renslow, C. P. Silvia, L. Shi, S. Kjelleberg, J. K. Fredrickson and H. Beyenal (2012). "Biofilm shows spatially stratified metabolic responses to contaminant exposure." Environ Microbiol 14(11): 2901-2910.

Cao, G. (2004). Synthesis, Properties and Applications, World Scientific.

Caporaso, J. G., C. L. Lauber, W. A. Walters, D. Berg-Lyons, J. Huntley, N. Fierer, S. M. Owens, J. Betley, L. Fraser and M. Bauer (2012). "Ultra-high-throughput microbial community analysis on the Illumina HiSeq and MiSeq platforms."ISME J 6(8): 1621-1624.

Carey, D. E. and P. J. McNamara (2015). "The impact of triclosan on the spread of antibiotic resistance in the environment." Front Microbiol 5: 780.

Carvalheira, M., A. Oehmen, G. Carvalho, M. Eusebio and M. A. Reis (2014). "The impact of aeration on the competition between polyphosphate accumulating organisms and glycogen accumulating organisms." Water Res 66: 296-307.

Case, R. J., M. Labbate and S. Kjelleberg (2008). "AHL-driven quorum-sensing circuits: their frequency and function among the Proteobacteria." ISME J 2(4): 345.

Cha, C., P. Gao, Y.-C. Chen, P. D. Shaw and S. K. Farrand (1998). "Production of acylhomoserine lactone quorum-sensing signals by Gram-negative plant-associated bacteria." Mol Plant Microbe Interact 11(11): 1119-1129.

Chee-Sanford, J. C., R. I. Aminov, I. Krapac, N. Garrigues-Jeanjean and R. I. Mackie (2001). "Occurrence and diversity of tetracycline resistance genes in lagoons and groundwater underlying two swine production facilities." Appl Environ Microbiol 67(4): 1494-1502.

Chen, C. Y., G. W. Nace and P. L. Irwin (2003). "A 6 x 6 drop plate method for simultaneous colony counting and MPN enumeration of Campylobacter jejuni, Listeria monocytogenes, and Escherichia coli." J Microbiol Methods 55(2): 475479. 
Chen, Y., D. Wang, X. Zhu, X. Zheng and L. Feng (2012). "Long-term effects of copper nanoparticles on wastewater biological nutrient removal and $\mathrm{N}_{2} \mathrm{O}$ generation in the activated sludge process." Environ Sci Technol 46(22): 12452-12458.

Chevance, F. F. and K. T. Hughes (2008). "Coordinating assembly of a bacterial macromolecular machine." Nat Rev Microbiol 6(6): 455-465.

Chopra, I. and M. Roberts (2001). "Tetracycline antibiotics: mode of action, applications, molecular biology, and epidemiology of bacterial resistance." Microbiol Mol Biol Rev 65(2): 232-260.

Chua, S. L., S. Y. Tan, M. T. Rybtke, Y. Chen, S. A. Rice, S. Kjelleberg, T. TolkerNielsen, L. Yang and M. Givskov (2013). "Bis-(3'-5')-cyclic dimeric GMP regulates antimicrobial peptide resistance in Pseudomonas aeruginosa." Antimicrob Agents Chemother 57(5): 2066-2075.

Chung, H., Y. Son, T. K. Yoon, S. Kim and W. Kim (2011). "The effect of multi-walled carbon nanotubes on soil microbial activity." Ecotoxicol Environ Saf 74(4): 569575.

Colvin, K. M., V. D. Gordon, K. Murakami, B. R. Borlee, D. J. Wozniak, G. C. Wong and M. R. Parsek (2011). "The Pel polysaccharide can serve a structural and protective role in the biofilm matrix of Pseudomonas aeruginosa." PLoS Pathog 7(1): e1001264.

Cordero, O. X., L.-A. Ventouras, E. F. DeLong and M. F. Polz (2012). "Public good dynamics drive evolution of iron acquisition strategies in natural bacterioplankton populations." Proc Natl Acad Sci U.S.A. 109(49): 20059-20064.

Cornelis, P. and J. Dingemans (2013). "Pseudomonas aeruginosa adapts its iron uptake strategies in function of the type of infections." Front Cell Infect Microbiol 3: 75.

Costerton, J. W., K. J. Cheng, G. G. Geesey, T. I. Ladd, J. C. Nickel, M. Dasgupta and T. J. Marrie (1987). "Bacterial biofilms in nature and disease." Annu Rev Microbiol 41: $435-464$.

Costerton, J. W., Z. Lewandowski, D. E. Caldwell, D. R. Korber and H. M. Lappin-Scott (1995). "Microbial biofilms." Annu Rev Microbiol 49(1): 711-745.

Crespi, B. J. (2001). "The evolution of social behavior in microorganisms." Trends Ecol Evol 16(4): 178-183.

Crocetti, G. R., P. Hugenholtz, P. L. Bond, A. Schuler, J. Keller, D. Jenkins and L. L. Blackall (2000). "Identification of polyphosphate-accumulating organisms and design of 16S rRNA-directed probes for their detection and quantitation." Appl Environ Microbiol 66(3): 1175-1182.

Crusz, S. A., R. Popat, M. T. Rybtke, M. Camara, M. Givskov, T. Tolker-Nielsen, S. P. Diggle and P. Williams (2012). "Bursting the bubble on bacterial biofilms: a flow cell methodology." Biofouling 28(8): 835-842.

D'Onofrio, A., J. M. Crawford, E. J. Stewart, K. Witt, E. Gavrish, S. Epstein, J. Clardy and K. Lewis (2010). "Siderophores from neighboring organisms promote the growth of uncultured bacteria." Chem Biol 17(3): 254-264. 
Das, P., C. J. Williams, R. R. Fulthorpe, M. E. Hoque, C. D. Metcalfe and M. A. Xenopoulos (2012). "Changes in bacterial community structure after exposure to silver nanoparticles in natural waters." Environ Sci Technol 46(16): 9120-9128.

Davies, J. (1994). "Inactivation of antibiotics and the dissemination of resistance genes." Science 264(5157): 375-382.

Davies, J. and D. Davies (2010). "Origins and evolution of antibiotic resistance." Microbiol Mol Biol Rev 74(3): 417-433.

de Kievit, T. R. and B. H. Iglewski (2000). "Bacterial quorum sensing in pathogenic relationships." Infect Immun 68(9): 4839-4849.

Demot, R. and J. Vanderleyden (1991). "Purification of a root-adhesive outer-membrane protein of root-coloniziing Pseudomonas fluorescens." FEMS Microbiol Lett 81(3): 323-328.

Dimkpa, C. O., J. E. Mclean, D. W. Britt and A. J. Anderson (2012). "CuO and ZnO nanoparticles differently affect the secretion of fluorescent siderophores in the beneficial root colonizer, Pseudomonas chlororaphis O6." Nanotoxicology 6(6): 635-642.

Dimkpa, C. O., J. E. McLean, D. W. Britt, W. P. Johnson, B. Arey, A. S. Lea and A. J. Anderson (2012). "Nanospecific inhibition of pyoverdine siderophore production in Pseudomonas chlororaphis $\mathrm{O} 6$ by $\mathrm{CuO}$ nanoparticles." $\underline{\text { Chem Res Toxicol }}$ 25(5): 1066-1074.

Ding, Y., N. Peng, Y. Du, L. Ji and B. Cao (2014). "Disruption of putrescine biosynthesis in Shewanella oneidensis enhances biofilm cohesiveness and performance in Cr(VI) immobilization." Appl Environ Microbiol 80(4): 1498-1506.

Dobias, J. and R. Bernier-Latmani (2013). "Silver release from silver nanoparticles in natural waters." Environ Sci Technol 47(9): 4140-4146.

Dobretsov, S., M. Teplitski and V. Paul (2009). "Mini-review: quorum sensing in the marine environment and its relationship to biofouling." Biofouling 25(5): 413-427.

Dong, X., Y. Tang, M. Lilly, K. Aferchich and L. Yang (2012). "Antimicrobial effects of carbon nanotubes." Nano Life 2(4).

Doolette, C. L., V. V. Gupta, Y. Lu, J. L. Payne, D. J. Batstone, J. K. Kirby, D. A. Navarro and M. J. McLaughlin (2016). "Quantifying the sensitivity of soil microbial communities to silver sulfide nanoparticles using metagenome sequencing." PloS One 11(8): e0161979.

Doolette, C. L., M. J. McLaughlin, J. K. Kirby, D. J. Batstone, H. H. Harris, H. Ge and G. Cornelis (2013). "Transformation of PVP coated silver nanoparticles in a simulated wastewater treatment process and the effect on microbial communities." Chem Cent J 7(1): 46.

Dopp, E., L. M. Hartmann, A. M. Florea, A. W. Rettenmeier and A. V. Hirner (2004). "Environmental distribution, analysis, and toxicity of organometal(loid) compounds." Crit Rev Toxicol 34(3): 301-333. 
Doyle, T. B., A. C. Hawkins and L. L. McCarter (2004). "The complex flagellar torque generator of Pseudomonas aeruginosa." J Bacteriol 186(19): 6341-6350.

Drechsel, H. and G. Jung (1998). "Peptide siderophores." J Pept Sci 4(3): 147-181.

Drenkard, E. (2003). "Antimicrobial resistance of Pseudomonas aeruginosa biofilms." Microb Infect 5(13): 1213-1219.

Dubertret, B., P. Skourides, D. J. Norris, V. Noireaux, A. H. Brivanlou and A. Libchaber (2002). "In vivo imaging of quantum dots encapsulated in phospholipid micelles." Science 298(5599): 1759-1762.

Dueholm, M. S., S. V. Petersen, M. Sonderkaer, P. Larsen, G. Christiansen, K. L. Hein, J. J. Enghild, J. L. Nielsen, K. L. Nielsen and P. H. Nielsen (2010). "Functional amyloid in Pseudomonas." Mol Microbiol 77(4): 1009-1020.

Dumenyo, C. K., A. Mukherjee, W. Chun and A. Chatterjee (1998). "Genetic and physiological evidence for the production of $\mathrm{N}$-acyl homoserine lactones by Pseudomonas syringae pv. syringae and other fluorescent plant pathogenic Pseudomonas species." Eur J Plant Pathol 104(6): 569-582.

Duncan, T. V. (2011). "Applications of nanotechnology in food packaging and food safety: Barrier materials, antimicrobials and sensors." $\underline{\mathrm{J} \text { Colloid Interface Sci }}$ 363(1): 1-24.

Dunny, G. M., T. J. Brickman and M. Dworkin (2008). "Multicellular behavior in bacteria: communication, cooperation, competition and cheating." BioEssays 30(4): 296-298.

Durán, N., P. D. Marcato, M. Durán, A. Yadav, A. Gade and M. Rai (2011). "Mechanistic aspects in the biogenic synthesis of extracellular metal nanoparticles by peptides, bacteria, fungi, and plants." Applied Microbiology and Biotechnology 90(5): 16091624.

Eatson, D., S. Clesceri, E. Rice and A. Greenberg (2005). "Standard methods for the examination of water and wastewater, 21st edn edn." Centennial Edition, USA: 4138.

Eberl, L. (1999). "N-acyl homoserinelactone-mediated gene regulation in Gram-negative bacteria." Syst Appl Microbiol 22(4): 493-506.

Eisen, J. A. (2007). "Environmental shotgun sequencing: its potential and challenges for studying the hidden world of microbes." PLoS Biol 5(3): e82.

Fabrega, J., R. Zhang, J. C. Renshaw, W.-T. Liu and J. R. Lead (2011). "Impact of silver nanoparticles on natural marine biofilm bacteria." Chemosphere 85(6): 961-966.

Falkowski, P. G., T. Fenchel and E. F. Delong (2008). "The Microbial engines that drive earth's biogeochemical cycles." Science 320(5879): 1034-1039.

Feng, Q., J. Wu, G. Chen, F. Cui, T. Kim and J. Kim (2000). "A mechanistic study of the antibacterial effect of silver ions on Escherichia coli and Staphylococcus aureus." J Biomed Mater Res 52(4): 662-668. 
Flemming, H. C. and J. Wingender (2010). "The biofilm matrix." Nat Rev Microbiol 8(9): 623-633.

Frenk, S., T. Ben-Moshe, I. Dror, B. Berkowitz and D. Minz (2013). "Effect of metal oxide nanoparticles on microbial community structure and function in two different soil types." PloS One 8(12): e84441.

Friedman, L. and R. Kolter (2004). "Genes involved in matrix formation in Pseudomonas aeruginosa PA14 biofilms." Mol Microbiol 51(3): 675-690.

Fuqua, C., M. R. Parsek and E. P. Greenberg (2001). "Regulation of gene expression by cell-to-cell communication: Acyl-homoserine lactone quorum sensing." Annu Rev Genet 35(1): 439-468.

Gao, F., Q. Y. Lu, X. K. Meng and S. Komarneni (2008). "Synthesis of nanorods and nanowires using biomolecules under conventional-and microwave-hydrothermal conditions." J Mater Sci 43(7): 2377-2386.

Ge, Y., J. P. Schimel and P. A. Holden (2011). "Evidence for negative effects of $\mathrm{TiO}_{2}$ and $\mathrm{ZnO}$ nanoparticles on soil bacterial communities." Environ Sci Technol 45(4): 1659-1664.

Gode-Potratz, C. J., R. J. Kustusch, P. J. Breheny, D. S. Weiss and L. L. McCarter (2011). "Surface sensing in Vibrio parahaemolyticus triggers a programme of gene expression that promotes colonization and virulence." Mol Microbiol 79(1): 240263.

Gottschalk, F. and B. Nowack (2011). "The release of engineered nanomaterials to the environment." J Environ Monitor 13(5): 1145-1155.

Green, M. and E. Howman (2005). "Semiconductor quantum dots and free radical induced DNA nicking." Chem Commun (1): 121-123.

Greenwald, J., F. Hoegy, M. Nader, L. Journet, G. L. Mislin, P. L. Graumann and I. J. Schalk (2007). "Real time fluorescent resonance energy transfer visualization of ferric pyoverdine uptake in Pseudomonas aeruginosa. A role for ferrous iron." $\underline{\mathbf{J}}$ Biol Chem 282(5): 2987-2995.

Griffitt, R. J., J. Luo, J. Gao, J. C. Bonzongo and D. S. Barber (2008). "Effects of particle composition and species on toxicity of metallic nanomaterials in aquatic organisms." Environ Toxicol Chem 27(9): 1972-1978.

Grünenfelder, B., S. Gehrig and U. Jenal (2003). "Role of the cytoplasmic C terminus of the FliF motor protein in flagellar assembly and rotation." J Bacteriol 185(5): 1624-1633.

Haas, H., M. Eisendle and B. G. Turgeon (2008). "Siderophores in fungal physiology and virulence." Annu Rev Phytopathol 46(1): 149-187.

Hajipour, M. J., K. M. Fromm, A. Akbar Ashkarran, D. Jimenez de Aberasturi, I. R. d. Larramendi, T. Rojo, V. Serpooshan, W. J. Parak and M. Mahmoudi (2012). "Antibacterial properties of nanoparticles." Trends Biotechnol 30(10): 499-511.

Hall-Stoodley, L., J. W. Costerton and P. Stoodley (2004). "Bacterial biofilms: from the natural environment to infectious diseases." Nat Rev Microbiol 2(2): 95-108. 
Han, X. and J. D. Gu (2010). "Sorption and transformation of toxic metals by microorganisms." Environ Microbiol: 153-176.

Hannauer, M., E. Yeterian, L. W. Martin, I. L. Lamont and I. J. Schalk (2010). "An efflux pump is involved in secretion of newly synthesized siderophore by Pseudomonas aeruginosa." FEBS Lett 584(23): 4751-4755.

Harrison, F. and A. Buckling (2009). "Siderophore production and biofilm formation as linked social traits." ISME J 3(5): 632-634.

Harrison, J., H. Ceri and A. Turner (2007). "Multimetal resistance and tolerance in microbial biofilms." Nat Rev Microbiol 5: 928-938.

He, S., D. L. Gall and K. D. McMahon (2007). "“Candidatus Accumulibacter" population structure in enhanced biological phosphorus removal sludges as revealed by polyphosphate kinase genes." Appl Environ Microbiol 73(18): 5865-5874.

Heinlaan, M., A. Ivask, I. Blinova, H.-C. Dubourguier and A. Kahru (2008). "Toxicity of nanosized and bulk $\mathrm{ZnO}, \mathrm{CuO}$ and $\mathrm{TiO}_{2}$ to bacteria Vibrio fischeri and crustaceans Daphnia magna and Thamnocephalus platyurus." Chemosphere 71(7): 1308-1316.

Helland, A., P. Wick, A. Koehler, K. Schmid and C. Som (2008). "Reviewing the environmental and human health knowledge base of carbon nanotubes." Environ Health Perspect 13(2): 441-452.

Henke, J. M. and B. L. Bassler (2004). "Bacterial social engagements." Trends Cell Biol 14(11): 648-656.

Hentzer, M., H. Wu, J. B. Andersen, K. Riedel, T. B. Rasmussen, N. Bagge, N. Kumar, M. A. Schembri, Z. Song and P. Kristoffersen (2003). "Attenuation of Pseudomonas aeruginosa virulence by quorum sensing inhibitors."EMBO J 22(15): 3803-3815.

Hibbing, M. E., C. Fuqua, M. R. Parsek and S. B. Peterson (2009). "Bacterial competition: surviving and thriving in the microbial jungle." Nat Rev Microbiol 8(1): 15-25.

Hodgkinson, J. T., M. Welch and D. R. Spring (2007). "Learning the language of bacteria." ACS Chem Biol 2(11): 715-717.

Hoek, E. M. V. and A. K. Ghosh (2009). Chapter 4 - nanotechnology-based membranes for water purification. Nanotechnology Applications for Clean Water. S. Nora, D. Mamadou, D. Jeremiah et al. Boston, William Andrew Publishing: 47-58.

Iijima, S. (1991). "Helical microtubules of graphitic carbon." Nature 354(6348): 56-58.

Ingle, A. P., N. Duran and M. Rai (2014). "Bioactivity, mechanism of action, and cytotoxicity of copper-based nanoparticles: A review." Appl Microbiol Biotechnol 98(3): 1001-1009.

Irie, Y., B. R. Borlee, J. R. O’Connor, P. J. Hill, C. S. Harwood, D. J. Wozniak and M. R. Parsek (2012). "Self-produced exopolysaccharide is a signal that stimulates biofilm formation in Pseudomonas aeruginosa." Proc Natl Acad Sci U.S.A. 109(50): 20632-20636. 
Jacob, E. B., I. Becker, Y. Shapira and H. Levine (2004). "Bacterial linguistic communication and social intelligence." Trends Microbiol 12(8): 366-372.

Jang, H., L. E. Pell, B. A. Korgel and D. S. English (2003). "Photoluminescence quenching of silicon nanoparticles in phospholipid vesicle bilayers." J Photochem Photobiol 158(2): 111-117.

Jean-Marc, B., M. Tawna and O. Lewis (1994). Role of microorganisms in soil bioremediation, ACS Sym Ser. 563: 2-10.

Jeong, E., W.-T. Im, D.-H. Kim, M.-S. Kim, S. Kang, H.-S. Shin and S.-R. Chae (2014). "Different susceptibilities of bacterial community to silver nanoparticles in wastewater treatment systems." J Environ Sci Health Part A 49(6): 685-693.

Jin, L., Y. Son, J. L. DeForest, Y. J. Kang, W. Kim and H. Chung (2014). "Single-walled carbon nanotubes alter soil microbial community composition." Sci Total Environ 466-467: 533-538.

Jin, L., Y. Son, T. K. Yoon, Y. J. Kang, W. Kim and H. Chung (2013). "High concentrations of single-walled carbon nanotubes lower soil enzyme activity and microbial biomass." Ecotoxicol Environ Saf 88: 9-15.

Johansen, A., A. L. Pedersen, K. A. Jensen, U. Karlson, B. M. Hansen, J. J. ScottFordsmand and A. Winding (2008). "Effects of $\mathrm{C}_{60}$ fullerene nanoparticles on soil bacteria and protozoans." Environ Toxicol Chem 27(9): 1895-1903.

Juretschko, S., A. Loy, A. Lehner and M. Wagner (2002). "The microbial community composition of a nitrifying-denitrifying activated sludge from an industrial sewage treatment plant analyzed by the full-cycle rRNA approach." Syst Appl Microbiol 25(1): 84-99.

Kaegi, R., B. Sinnet, S. Zuleeg, H. Hagendorfer, E. Mueller, R. Vonbank, M. Boller and M. Burkhardt (2010). "Release of silver nanoparticles from outdoor facades." Environ Pollut 158(9): 2900-2905.

Kahru, A. and H.-C. Dubourguier (2010). "From ecotoxicology to nanoecotoxicology." Toxicology 269(2-3): 105-119.

Kalathil, S., J. Lee and M. Cho (2011). "Electrochemically active biofilm-mediated synthesis of silver nanoparticles in water." Green Chem 13: 1482-1485.

Kam, N. W. S., M. O'Connell, J. A. Wisdom and H. Dai (2005). "Carbon nanotubes as multifunctional biological transporters and near-infrared agents for selective cancer cell destruction." Proc Natl Acad Sci U.S.A. 102(33): 11600-11605.

Kaneko, Y., M. Thoendel, O. Olakanmi, B. E. Britigan and P. K. Singh (2007). "The transition metal gallium disrupts Pseudomonas aeruginosa iron metabolism and has antimicrobial and antibiofilm activity." J Clin Invest 117(4): 877-888.

Kang, S., M. Herzberg, D. F. Rodrigues and M. Elimelech (2008). "Antibacterial effects of carbon nanotubes: size does matter!" Langmuir 24(13): 6409-6413.

Kang, S., M. S. Mauter and M. Elimelech (2009). "Microbial cytotoxicity of carbon-based nanomaterials: implications for river water and wastewater effluent." Environ Sci Technol 43(7): 2648-2653. 
Kang, S., M. Pinault, L. D. Pfefferle and M. Elimelech (2007). "Single-walled carbon nanotubes exhibit strong antimicrobial activity." Langmuir 23(17): 8670-8673.

Keith, R. C., L. M. Keith, G. Hernandez-Guzman, S. R. Uppalapati and C. L. Bender (2003). "Alginate gene expression by Pseudomonas syringae pv. tomato DC3000 in host and non-host plants." Microbiology 149(Pt 5): 1127-1138.

Keller, L. and M. G. Surette (2006). "Communication in bacteria: an ecological and evolutionary perspective." Nat Rev Microbiol 4(4): 249-258.

Khodakovskaya, M. V., B.-S. Kim, J. N. Kim, M. Alimohammadi, E. Dervishi, T. Mustafa and C. E. Cernigla (2013). "Carbon nanotubes as plant growth regulators: Effects on tomato growth, reproductive system, and soil microbial community." Small 9(1): 115-123.

Kiers, E. T., S. A. West and R. F. Denison (2002). "Mediating mutualisms: Farm management practices and evolutionary changes in symbiont co-operation." J Appl Ecol 39(5): 745-754.

Kim, D.-H., R. A. Kanaly and H.-G. Hur (2012). "Biological accumulation of tellurium nanorod structures via reduction of tellurite by Shewanella oneidensis MR-1." Bioresource Technol 125(0): 127-131.

Kim, J. S., E. Kuk, K. N. Yu, J.-H. Kim, S. J. Park, H. J. Lee, S. H. Kim, Y. K. Park, Y. H. Park and C.-Y. Hwang (2007). "Antimicrobial effects of silver nanoparticles." Nanomed: Nanotechnol, Biol Med 3(1): 95-101.

Kittler, S., C. Greulich, J. Diendorf, M. Koller and M. Epple (2010). "Toxicity of silver nanoparticles increases during storage because of slow dissolution under release of silver ions." Chem Mater 22(16): 4548-4554.

Kjelleberg, S. and M. Givskov (2007). The biofilm mode of life: mechanisms and adaptations, Horizon Scientific Press.

Klaine, S. J., P. J. J. Alvarez, G. E. Batley, T. F. Fernandes, R. D. Handy, D. Y. Lyon, S. Mahendra, M. J. McLaughlin and J. R. Lead (2008). "Nanomaterials in the environment: Behavior, fate, bioavailability, and effects." Environ Toxicol Chem 27(9): 1825-1851.

Kloepfer, J., R. Mielke and J. Nadeau (2005). "Uptake of CdSe and CdSe/ZnS quantum dots into bacteria via purine-dependent mechanisms." Appl Environ Microbiol 71(5): 2548-2557.

Klonowska, A., T. Heulin and A. Vermeglio (2005). "Selenite and tellurite reduction by Shewanella oneidensis." Appl Environ Microbiol 71(9): 5607-5609.

Koutsoudis, M. D., D. Tsaltas, T. D. Minogue and S. B. von Bodman (2006). "Quorumsensing regulation governs bacterial adhesion, biofilm development, and host colonization in Pantoea stewartii subspecies stewartii." Proc Natl Acad Sci U.S.A. 103(15): 5983-5988.

Kumar, N., E. O. Omoregie, J. Rose, A. Masion, J. R. Lloyd, L. Diels and L. Bastiaens (2014). "Inhibition of sulfate reducing bacteria in aquifer sediment by iron nanoparticles." Water Res 51: 64-72. 
Kumar, V. and S. K. Yadav (2009). "Plant-mediated synthesis of silver and gold nanoparticles and their applications." J Chem Technol Biotechnol 84(2): 151-157.

Lamont, I. L., P. A. Beare, U. Ochsner, A. I. Vasil and M. L. Vasil (2002). "Siderophoremediated signaling regulates virulence factor production in Pseudomonas aeruginosa." Proc Natl Acad Sci U.S.A. 99(10): 7072-7077.

Lanone, S. and J. Boczkowski (2006). "Biomedical applications and potential health risks of nanomaterials: Molecular mechanisms." Curr Mol Med 6(6): 651-663.

Larsen-Basse, J., K. P. Chong, Y. de Miguel, A. Porro and P. Bartos (2006). Nanomaterials in construction and rehabilitation: Contributions and perspectives of the US National Science Foundation. NICOM 2: 2nd International Symposium on Nanotechnology in Construction, RILEM Publications SARL.

Latifi, A., M. K. Winson, M. Foglino, B. W. Bycroft, G. S. Stewart, A. Lazdunski and P. Williams (1995). "Multiple homologues of LuxR and LuxI control expression of virulence determinants and secondary metabolites through quorum sensing in Pseudomonas aeruginosa PAO1." Mol Microbiol 17(2): 333-343.

Lazazzera, B. A. (2000). "Quorum sensing and starvation: signals for entry into stationary phase." Curr Opin Microbiol 3(2): 177-182.

Leong, J. (1986). "Siderophores: their biochemistry and possible role in the biocontrol of plant pathogens." Annu Rev Phytopathol 24(1): 187-209.

Lewis, K. (2001). "Riddle of biofilm resistance." Antimicrob Agents Chemother 45(4): 999-1007.

Li, D., F. Cui, Z. Zhao, D. Liu, Y. Xu, H. Li and X. Yang (2013). "The impact of titanium dioxide nanoparticles on biological nitrogen removal from wastewater and bacterial community shifts in activated sludge." Biodegradation: 1-11.

Li, L.-L., Z.-H. Tong, C.-Y. Fang, J. Chu and H.-Q. Yu (2015). "Response of anaerobic granular sludge to single-wall carbon nanotube exposure." Water Res 70: 1-8.

Li, Q., S. Mahendra, D. Y. Lyon, L. Brunet, M. V. Liga, D. Li and P. J. Alvarez (2008). "Antimicrobial nanomaterials for water disinfection and microbial control: potential applications and implications." Water Res 42(18): 4591-4602.

Li, W.-R., X.-B. Xie, Q.-S. Shi, H.-Y. Zeng, Y.-S. Ou-Yang and Y.-B. Chen (2010). "Antibacterial activity and mechanism of silver nanoparticles on Escherichia coli." Appl Microbiol Biotechnol 85(4): 1115-1122.

Liang, Z., A. Das and Z. Hu (2010). "Bacterial response to a shock load of nanosilver in an activated sludge treatment system." Water Res 44(18): 5432-5438.

Lin, D. and B. Xing (2007). "Phytotoxicity of nanoparticles: inhibition of seed germination and root growth." Environ Pollut 150(2): 243-250.

Lin, Z. H., C. H. Lee, H. Y. Chang and H. T. Chang (2012). "Antibacterial activities of tellurium nanomaterials." Chem Asian J 7(5): 930-934.

Lines, M. (2008). "Nanomaterials for practical functional uses." J Alloy Compd 449(1): 242-245. 
Liu, J., M. N. Paddon-Row and J. J. Gooding (2004). "Heterogeneous electron-transfer kinetics for flavin adenine dinucleotide and ferrocene through alkanethiol mixed monolayers on gold electrodes." J Phys Chem B 108(24): 8460-8466.

Liu, S., L. Wei, L. Hao, N. Fang, M. W. Chang, R. Xu, Y. Yang and Y. Chen (2009). "Sharper and faster "nano darts" kill more bacteria: a study of antibacterial activity of individually dispersed pristine single-walled carbon nanotube." ACS Nano 3(12): 3891-3902.

Liu, S., T. H. Zeng, M. Hofmann, E. Burcombe, J. Wei, R. Jiang, J. Kong and Y. Chen (2011). "Antibacterial activity of graphite, graphite oxide, graphene oxide, and reduced graphene oxide: membrane and oxidative stress." ACS Nano 5(9): 69716980.

Liu, X., X. Jin, B. Cao and C. Y. Tang (2014). "Bactericidal activity of silver nanoparticles in environmentally relevant freshwater matrices: Influences of organic matter and chelating agent." J Environ Chem Eng 2(1): 525-531.

Liu, X., S. Qi, Y. Li, L. Yang, B. Cao and C. Y. Tang (2013). "Synthesis and characterization of novel antibacterial silver nanocomposite nanofiltration and forward osmosis membranes based on layer-by-layer assembly." Water Res 47(9): 3081-3092.

Liu, Z., T. Z. DeSantis, G. L. Andersen and R. Knight (2008). "Accurate taxonomy assignments from $16 \mathrm{~S}$ rRNA sequences produced by highly parallel pyrosequencers." Nucleic Acids Res 36(18): e120-e120.

Liu, Z., Z. Hu, J. Liang, S. Li, Y. Yang, S. Peng and Y. Qian (2004). "Size-controlled synthesis and growth mechanism of monodisperse tellurium nanorods by a surfactant-assisted method." Langmuir 20(1): 214-218.

Liu, Z., S. Tabakman, K. Welsher and H. Dai (2009). "Carbon nanotubes in biology and medicine: In vitro and in vivo detection, imaging and drug delivery." Nano Res 2(2): $85-120$.

Livak, K. J. and T. D. Schmittgen (2001). "Analysis of relative gene expression data using real-time quantitative PCR and the 2(-Delta Delta C(T)) Method." Methods 25(4): 402-408.

Logares, R., S. Sunagawa, G. Salazar, F. M. Cornejo-Castillo, I. Ferrera, H. Sarmento, P. Hingamp, H. Ogata, C. de Vargas, G. Lima-Mendez, J. Raes, J. Poulain, O. Jaillon, P. Wincker, S. Kandels-Lewis, E. Karsenti, P. Bork and S. G. Acinas (2014). "Metagenomic 16S rDNA Illumina tags are a powerful alternative to amplicon sequencing to explore diversity and structure of microbial communities." Environ Microbiol 16(9): 2659-2671.

Lorenz, C., L. Windler, N. von Goetz, R. Lehmann, M. Schuppler, K. Hungerbühler, M. Heuberger and B. Nowack (2012). "Characterization of silver release from commercially available functional (nano) textiles." Chemosphere 89(7): 817-824.

Lowry, G. V., K. B. Gregory, S. C. Apte and J. R. Lead (2012). "Transformations of nanomaterials in the environment." Environ Sci Technol 46(13): 6893-6899. 
Lu, F., L. Gu, M. J. Meziani, X. Wang, P. G. Luo, L. M. Veca, L. Cao and Y.-P. Sun (2009). "Advances in Bioapplications of Carbon Nanotubes." Adv Mater 21(2): $139-152$.

Luo, Z., Z. Chen, Z. Qiu, Y. Li, G. D. Laing, A. Liu and C. Yan (2015). "Gold and silver nanoparticle effects on ammonia-oxidizing bacteria cultures under ammoxidation." Chemosphere 120: 737-742.

Lv, L., T. Jiang, S. Zhang and X. Yu (2014). "Exposure to mutagenic disinfection byproducts leads to increase of antibiotic resistance in Pseudomonas aeruginosa." Environ Sci Technol 48(14): 8188-8195.

Lyon, D. Y., L. K. Adams, J. C. Falkner and P. J. J. Alvarez (2006). "Antibacterial activity of fullerene water suspensions: effects of preparation method and particle size." Environ Sci Technol 40(14): 4360-4366.

Lyon, D. Y., L. Brunet, G. W. Hinkal, M. R. Wiesner and P. J. Alvarez (2008). "Antibacterial activity of fullerene water suspensions (nC60) is not due to ROSmediated damage." Nano Lett 8(5): 1539-1543.

Ma, H., P. M. Bertsch, T. C. Glenn, N. J. Kabengi and P. L. Williams (2009). "Toxicity of manufactured zinc oxide nanoparticles in the nematode Caenorhabditis elegans." Environ Toxicol Chem 28(6): 1324-1330.

Ma, Y., J. W. Metch, E. P. Vejerano, I. J. Miller, E. C. Leon, L. C. Marr, P. J. Vikesland and A. Pruden (2015). "Microbial community response of nitrifying sequencing batch reactors to silver, zero-valent iron, titanium dioxide and cerium dioxide nanomaterials." Water Res 68: 87-97.

Ma, Y., J. W. Metch, Y. Yang, A. Pruden and T. Zhang (2016). "Shift in antibiotic resistance gene profiles associated with nanosilver during wastewater treatment." FEMS Microbiol Ecol 92(3).

Mackie, R. I., S. Koike, I. Krapac, J. Chee-Sanford, S. Maxwell and R. I. Aminov (2006). "Tetracycline residues and tetracycline resistance genes in groundwater impacted by swine production facilities." Anim Biotechnol 17(2): 157-176.

Madigan, M. T., J. M. Martinko, J. Parker and T. D. Brock (1997). Biology of microorganisms, prentice hall Upper Saddle River, NJ.

Madsen, J. S., M. Burmølle, L. H. Hansen and S. J. Sørensen (2012). "The interconnection between biofilm formation and horizontal gene transfer." FEMS Immunol Med Microbiol 65(2): 183-195.

Mann, E. E. and D. J. Wozniak (2012). "Pseudomonas biofilm matrix composition and niche biology." FEMS Microbiol Rev 36(4): 893-916.

Marambio-Jones, C. and E. V. Hoek (2010). "A review of the antibacterial effects of silver nanomaterials and potential implications for human health and the environment." $\mathrm{J}$ Nanopart Res 12(5): 1531-1551.

Martínez, J. L. (2008). "Antibiotics and antibiotic resistance genes in natural environments." Science 321(5887): 365-367. 
Mashino, T., N. Usui, K. Okuda, T. Hirota and M. Mochizuki (2003). "Respiratory chain inhibition by fullerene derivatives: hydrogen peroxide production caused by fullerene derivatives and a respiratory chain system." Bioorg Med Chem 11(7): 1433-1438.

Masrahi, A., A. VandeVoort and Y. Arai (2014). "Effects of Silver nanoparticle on soilnitrification processes." Arch Environ Contam Toxicol 66(4): 504-513.

Matsumura, Y., K. Yoshikata, S.-i. Kunisaki and T. Tsuchido (2003). "Mode of bactericidal action of silver zeolite and its comparison with that of silver nitrate." Appl Environ Microbiol 69(7): 4278-4281.

Mauter, M. S. and M. Elimelech (2008). "Environmental applications of carbon-based nanomaterials." Environ Sci Technol 42(16): 5843-5859.

McClean, K. H., M. K. Winson, L. Fish, A. Taylor, S. R. Chhabra, M. Camara, M. Daykin, J. H. Lamb, S. Swift, B. W. Bycroft, G. S. A. B. Stewart and P. Williams (1997). "Quorum sensing and Chromobacterium violaceum: Exploitation of violacein production and inhibition for the detection of $\mathrm{N}$-acylhomoserine lactones." Microbiology 143(12): 3703-3711.

Meredith, H. R., J. K. Srimani, A. J. Lee, A. J. Lopatkin and L. You (2015). "Collective antibiotic tolerance: mechanisms, dynamics and intervention." Nat Chem Biol 11(3): 182-188.

Meyer, J.-M., V. A. Geoffroy, N. Baida, L. Gardan, D. Izard, P. Lemanceau, W. Achouak and N. J. Palleroni (2002). "Siderophore typing, a powerful tool for the identification of fluorescent and nonfluorescent pseudomonads." Appl Environ Microbiol 68(6): 2745-2753.

Miller, M. B. and B. L. Bassler (2001). "Quorum sensing in bacteria." Annu Rev Microbiol 55(1): 165-199.

Miller, M. B., K. Skorupski, D. H. Lenz, R. K. Taylor and B. L. Bassler (2002). "Parallel quorum sensing systems converge to regulate virulence in Vibrio cholerae." Cell 110(3): 303-314.

Miralles, P., T. L. Church and A. T. Harris (2012). "Toxicity, uptake, and translocation of engineered nanomaterials in vascular plants." Environ Sci Technol 46(17): 92249239.

Mohanpuria, P., N. K. Rana and S. K. Yadav (2008). "Biosynthesis of nanoparticles: technological concepts and future applications." J Nanoparticle Res 10(3): 507517.

Mohanty, S. R., P. Rajput, B. Kollah, D. Chourasiya, A. Tiwari, M. Singh and A. S. Rao (2014). "Methane oxidation and abundance of methane oxidizers in tropical agricultural soil (vertisol) in response to $\mathrm{CuO}$ and $\mathrm{ZnO}$ nanoparticles contamination." Environ Monit Assess 186(6): 3743-3753.

Montoya, T., L. Borrás, D. Aguado, J. Ferrer and A. Seco (2008). "Detection and prevention of enhanced biological phosphorus removal deterioration caused by Zoogloea overabundance." Environ Technol 29(1): 35-42. 
Moore, J. D., J. P. Stegemeier, K. Bibby, S. M. Marinakos, G. V. Lowry and K. B. Gregory (2016). "Impacts of pristine and transformed $\mathrm{Ag}$ and $\mathrm{Cu}$ engineered nanomaterials on surficial sediment microbial communities appear short-lived." Environ Sci Technol 50(5): 2641-2651.

Morones, J. R., J. L. Elechiguerra, A. Camacho, K. Holt, J. B. Kouri, J. T. Ramirez and M. J. Yacaman (2005). "The bactericidal effect of silver nanoparticles." Nanotechnology 16(10): 2346-2353.

Mortazavi, A., B. A. Williams, K. McCue, L. Schaeffer and B. Wold (2008). "Mapping and quantifying mammalian transcriptomes by RNA-Seq." Nat Methods 5(7): 621628.

Moscoso, H., C. Saavedra, C. Loyola, S. Pichuantes and C. Vasquez (1998). "Biochemical characterization of tellurite-reducing activities of Bacillus stearothermophilus V." Res Microbiol 149(6): 389-397.

Mu, L. and R. L. Sprando (2010). "Application of nanotechnology in cosmetics." Pharm Res 27(8): 1746-1749.

Murty, B., P. Shankar, B. Raj, B. Rath and J. Murday (2013). Applications of nanomaterials. Textbook of Nanoscience and Nanotechnology, Springer: 107-148.

Naik, K. and M. Kowshik (2014). "Anti-quorum sensing activity of $\mathrm{AgCl}^{-\mathrm{TiO}_{2}}$ nanoparticles with potential use as active food packaging material." J Appl Microbiol 117(4): 972-983.

Narayanan, K. B. and N. Sakthivel (2010). "Biological synthesis of metal nanoparticles by microbes." Adv Coll Int Sci 156(1-2): 1-13.

Narihiro, T. and Y. Sekiguchi (2007). "Microbial communities in anaerobic digestion processes for waste and wastewater treatment: a microbiological update." Curr Opin Biotechnol 18(3): 273-278.

Neal, A. (2008). "What can be inferred from bacterium-nanoparticle interactions about the potential consequences of environmental exposure to nanoparticles?" Ecotoxicology 17(5): 362-371.

Nealson, K. and J. W. Hastings (1979). "Bacterial bioluminescence: its control and ecological significance." Microbiol Rev 43(4): 496.

Neilands, J. (1995). "Siderophores: structure and function of microbial iron transport compounds." J Biol Chem 270(45): 26723-26726.

Ng, C. K., K. Sivakumar, X. Liu, M. Madhaiyan, L. Ji, L. Yang, C. Tang, H. Song, S. Kjelleberg and B. Cao (2013). "Influence of outer membrane c-type cytochromes on particle size and activity of extracellular nanoparticles produced by Shewanella oneidensis." Biotechnol Bioeng 110(7): 1831-1837.

Nimtz, M., A. Mort, V. Wray, T. Domke, Y. Zhang, D. L. Coplin and K. Geider (1996). "Structure of stewartan, the capsular exopolysaccharide from the corn pathogen Erwinia stewartii." Carbohydr Res 288: 189-201.

Nogueira, V., I. Lopes, T. Rocha-Santos, A. L. Santos, G. M. Rasteiro, F. Antunes, F. Gonçalves, A. M. V. M. Soares, A. Cunha, A. Almeida, N. N. C. M. Gomes and R. 
Pereira (2012). "Impact of organic and inorganic nanomaterials in the soil microbial community structure." Sci Total Environ 424: 344-350.

Nowack, B., J. F. Ranville, S. Diamond, J. A. Gallego-Urrea, C. Metcalfe, J. Rose, N. Horne, A. A. Koelmans and S. J. Klaine (2012). "Potential scenarios for nanomaterial release and subsequent alteration in the environment." Environ Toxicol Chem 31(1): 50-59.

Nyberg, L., R. F. Turco and L. Nies (2008). "Assessing the impact of nanomaterials on anaerobic microbial communities." Environ Sci Technol 42(6): 1938-1943.

O'Toole, G., H. B. Kaplan and R. Kolter (2000). "Biofilm formation as microbial development." Annu Rev Microbiol 54(1): 49-79.

Oberdörster, G., A. Maynard, K. Donaldson, V. Castranova, J. Fitzpatrick, K. Ausman, J. Carter, B. Karn, W. Kreyling and D. Lai (2005). "Principles for characterizing the potential human health effects from exposure to nanomaterials: elements of a screening strategy." Part Fibre Toxicol 2(1): 1.

Parsek, M. R. and E. P. Greenberg (2005). "Sociomicrobiology: the connections between quorum sensing and biofilms." Trends Microbiol 13(1): 27-33.

Pawlett, M., K. Ritz, R. A. Dorey, S. Rocks, J. Ramsden and J. A. Harris (2013). "The impact of zero-valent iron nanoparticles upon soil microbial communities is context dependent." Environ Sci Pollut Res Int 20(2): 1041-1049.

Peralta-Videa, J. R., L. J. Zhao, M. L. Lopez-Moreno, G. de la Rosa, J. Hong and J. L. Gardea-Torresdey (2011). "Nanomaterials and the environment: A review for the biennium 2008-2010." J Hazard Mater 186(1): 1-15.

Petersen, E. J., L. Zhang, N. T. Mattison, D. M. O’Carroll, A. J. Whelton, N. Uddin, T. Nguyen, Q. Huang, T. B. Henry and R. D. Holbrook (2011). "Potential release pathways, environmental fate, and ecological risks of carbon nanotubes." Environ Sci Technol 45(23): 9837-9856.

Peulen, T.-O. and K. J. Wilkinson (2011). "Diffusion of nanoparticles in a biofilm." Environ Sci Technol 45(8): 3367-3373.

Preston, G. M., N. Bertrand and P. B. Rainey (2001). "Type III secretion in plant growthpromoting Pseudomonas fluorescens SBW25." Mol Microbiol 41(5): 999-1014.

Puay, N.-Q., G. Qiu and Y.-P. Ting (2015). "Effect of Zinc oxide nanoparticles on biological wastewater treatment in a sequencing batch reactor." J Clean Prod 88: $139-145$.

Qiu, Z., Y. Yu, Z. Chen, M. Jin, D. Yang, Z. Zhao, J. Wang, Z. Shen, X. Wang and D. Qian (2012). "Nanoalumina promotes the horizontal transfer of multiresistance genes mediated by plasmids across genera." Proc Natl Acad Sci U.S.A. 109(13): 4944-4949.

Qu, X., P. J. J. Alvarez and Q. Li (2013). "Applications of nanotechnology in water and wastewater treatment." Water Res 47(12): 3931-3946. 
Qu, Y., Q. Ma, J. Deng, W. Shen, X. Zhang, Z. He, J. D. V. Nostrand, J. Zhou and J. Zhou (2015). "Responses of microbial communities to single-walled carbon nanotubes in phenol wastewater treatment systems." Environ Sci Technol 49(7): 4627-4635.

Quiñones, B., G. Dulla and S. E. Lindow (2005). "Quorum sensing regulates exopolysaccharide production, motility, and virulence in Pseudomonas syringae." Mol Plant Microbe Interact 18(7): 682-693.

Rai, M., A. Yadav and A. Gade (2009). "Silver nanoparticles as a new generation of antimicrobials." Biotechnology Adv 27(1): 76-83.

Rejeski., D. (2009). "Woodrow Wilson International Center for Scholars. Nanotechnology and Consumer Products."

Rizzo, L., C. Manaia, C. Merlin, T. Schwartz, C. Dagot, M. C. Ploy, I. Michael and D. Fatta-Kassinos (2013). "Urban wastewater treatment plants as hotspots for antibiotic resistant bacteria and genes spread into the environment: A review." Sci Total Environ 447: 345-360.

Roduner, E. (2006). "Size matters: why nanomaterials are different." 35(7): 583-592.

Rybtke, M. T., P. O. Jensen, N. Hoiby, M. Givskov, T. Tolker-Nielsen and T. Bjarnsholt (2011). "The implication of Pseudomonas aeruginosa biofilms in infections." Inflamm Allergy Drug Targets 10(2): 141-157.

Saha, R., N. Saha, R. S. Donofrio and L. L. Bestervelt (2013). "Microbial siderophores: A mini review." J Basic Microbiol 53(4): 303-317.

Salata, O. (2004). "Applications of nanoparticles in biology and medicine." Nanobiotechnology 2(1): 3 .

Schalk, I. J. and L. Guillon (2013). "Pyoverdine biosynthesis and secretion in Pseudomonas aeruginosa: Implications for metal homeostasis." Environ Microbiol 15(6): 1661-1673.

Schofield, E. J., H. Veeramani, J. O. Sharp, E. Suvorova, R. Bernier-Latmani, A. Mehta, J. Stahlman, S. M. Webb, D. L. Clark and S. D. Conradson (2008). "Structure of biogenic uraninite produced by Shewanella oneidensis strain MR-1." Environ Sci Technol 42(21): 7898-7904.

Seil, J. T. and T. J. Webster (2012). "Antimicrobial applications of nanotechnology: methods and literature." Int J Nanomedicine 7: 2767.

Seiler, C. and T. U. Berendonk (2012). "Heavy metal driven co-selection of antibiotic resistance in soil and water bodies impacted by agriculture and aquaculture." Front Microbiol 3.

Shah, V. and I. Belozerova (2009). "Influence of metal nanoparticles on the soil microbial community and germination of lettuce seeds." Water Air Soil Pollut 197(1-4): 143 148.

Shah, V., J. Jones, J. Dickman and S. Greenman (2014). "Response of soil bacterial community to metal nanoparticles in biosolids." J Hazard Mater 274: 399-403. 
Shahjamali, M. M., M. Bosman, S. W. Cao, X. Huang, S. Saadat, E. Martinsson, D. Aili, Y. Y. Tay, B. Liedberg, S. C. J. Loo, H. Zhang, F. Boey and C. Xue (2012). "Gold coating of silver nanoprisms." Adv Funct Mater 22(4): 849-854.

Sharifi, S., S. Behzadi, S. Laurent, M. L. Forrest, P. Stroeve and M. Mahmoudi (2012). "Toxicity of nanomaterials." Chem Soc Rev 41(6): 2323-2343.

Shaw, P. D., G. Ping, S. L. Daly, C. Cha, J. E. Cronan, K. L. Rinehart and S. K. Farrand (1997). "Detecting and characterizing N-acyl-homoserine lactone signal molecules by thin-layer chromatography." Proc Natl Acad Sci U.S.A. 94(12): 6036-6041.

Sheng, Z. and Y. Liu (2011). "Effects of silver nanoparticles on wastewater biofilms." Water Res 45(18): 6039-6050.

Shimkets, L. J. (1999). "Intercellular signaling during fruiting-body development of Myxococcus xanthus." Annu Rev Microbiol 53(1): 525-549.

Shrestha, B., V. Acosta-Martinez, S. B. Cox, M. J. Green, S. Li and J. E. Cañas-Carrell (2013). "An evaluation of the impact of multiwalled carbon nanotubes on soil microbial community structure and functioning." J Hazard Mater 261: 188-197.

Shrout, J. D. and R. Nerenberg (2012). "Monitoring bacterial twitter: does quorum sensing determine the behavior of water and wastewater treatment biofilms?" Environ Sci Technol 46(4): 1995-2005.

Simonin, M., J. P. Guyonnet, J. M. F. Martins, M. Ginot and A. Richaume (2015). "Influence of soil properties on the toxicity of $\mathrm{TiO}_{2}$ nanoparticles on carbon mineralization and bacterial abundance." J Hazard Mater 283: 529-535.

Singh, R. S., V. K. Rangari, S. Sanagapalli, V. Jayaraman, S. Mahendra and V. P. Singh (2004). "Nano-structured $\mathrm{CdTe}, \mathrm{CdS}$ and $\mathrm{TiO}_{2}$ for thin film solar cell applications." Sol Energ Mat Sol Cells 82(1): 315-330.

Sintubin, L., W. Verstraete and N. Boon (2012). "Biologically produced nanosilver: current state and future perspectives." Biotechnol Bioeng 109(10):2422-2436.

Sozer, N. and J. L. Kokini (2009). "Nanotechnology and its applications in the food sector." Trends Biotechnol 27(2): 82-89.

Srilatha, B. (2011). "Nanotechnology in agriculture." J Nanomed Nanotechnol.

Staupendahl, G. and K. Schindler (1982). "Optical tuning of a tellurium cavity: optical modulation and bistability in the infrared region at room temperature." Opt Quant Electron 14(2): 157-167.

Stewart, P. S. (2003). "Diffusion in biofilms." J Bacteriol 185(5): 1485-1491.

Stewart, P. S. and J. William Costerton (2001). "Antibiotic resistance of bacteria in biofilms." Lancet 358(9276): 135-138.

Stintzi, A., K. Evans, J.-m. Meyer and K. Poole (1998). "Quorum-sensing and siderophore biosynthesis in Pseudomonas aeruginosa: lasRllasI mutants exhibit reduced pyoverdine biosynthesis." FEMS Microbiol Lett 166(2): 341-345.

Stoimenov, P. K., R. L. Klinger, G. L. Marchin and K. J. Klabunde (2002). "Metal oxide nanoparticles as bactericidal agents." Langmuir 18(17): 6679-6686. 
Stoodley, P., K. Sauer, D. Davies and J. W. Costerton (2002). "Biofilms as complex differentiated communities." Annu Rev Microbiol 56(1): 187-209.

Sun, X., Z. Sheng and Y. Liu (2013). "Effects of silver nanoparticles on microbial community structure in activated sludge." Sci Total Environ 443: 828-835.

Suresh, A. K., D. A. Pelletier and M. J. Doktycz (2013). "Relating nanomaterial properties and microbial toxicity." Nanoscale 5(2): 463-474.

Suzuki, Y., S. D. Kelly, K. M. Kemner and J. F. Banfield (2002). "Radionuclide contamination: Nanometre-size products of uranium bioreduction." Nature 419(6903): 134-134.

Takenaka, S., K. Yamashita, M. Takagi, T. Hatta, A. Tanaka and O. Tsuge (1999). "Study of the DNA interaction with water-soluble cationic fullerene derivatives." $\underline{\text { Chem }}$ Lett 28: 319-320.

Tan, C., R. P. Smith, J. K. Srimani, K. A. Riccione, S. Prasada, M. Kuehn and L. You (2012). "The inoculum effect and band-pass bacterial response to periodic antibiotic treatment." Mol Syst Biol 8(1): 617.

Tan, C. H., K. S. Koh, C. Xie, M. Tay, Y. Zhou, R. Williams, W. J. Ng, S. A. Rice and S. Kjelleberg (2014). "The role of quorum sensing signalling in EPS production and the assembly of a sludge community into aerobic granules." ISME J 8(6): 11861197.

Tan, C. H., K. S. Koh, C. Xie, J. Zhang, X. H. Tan, G. P. Lee, Y. Zhou, W. J. Ng, S. A. Rice and S. Kjelleberg (2015). "Community quorum sensing signalling and quenching: microbial granular biofilm assembly." Npj Biofilms Microbiomes 1: 15006.

Thill, A., O. Zeyons, O. Spalla, F. Chauvat, J. Rose, M. Auffan and A. M. Flank (2006). "Cytotoxicity of $\mathrm{CeO}_{2}$ nanoparticles for Escherichia coli. Physico-chemical insight of the cytotoxicity mechanism." Environ Sci Technol 40(19): 6151-6156.

Thomsen, T. R., Y. Kong and P. H. Nielsen (2007). "Ecophysiology of abundant denitrifying bacteria in activated sludge." FEMS Microbiol Ecol 60(3): 370-382.

Tiraferri, A., C. D. Vecitis and M. Elimelech (2011). "Covalent binding of single-walled carbon nanotubes to polyamide membranes for antimicrobial surface properties." ACS Appl Mater Interfaces 3(8): 2869-2877.

Tong, Z., M. Bischoff, L. Nies, B. Applegate and R. F. Turco (2007). "Impact of Fullerene $\left(\mathrm{C}_{60}\right)$ on a soil microbial community." Environ Sci Technol 41(8): 2985-2991.

Trutko, S. M., V. K. Akimenko, N. E. Suzina, L. A. Anisimova, M. G. Shlyapnikov, B. P. Baskunov, V. I. Duda and A. M. Boronin (2000). "Involvement of the respiratory chain of Gram-negative bacteria in the reduction of tellurite." Arch Microbiol 173(3): 178-186.

Tsao, N., P. P. Kanakamma, T.-Y. Luh, C.-K. Chou and H.-Y. Lei (1999). "Inhibition of Escherichia coli-induced meningitis by carboxyfullerence." Antimicrob Agents Chemother 43(9): 2273-2277. 
Tsiulyanu, D., S. Marian, V. Miron and H. D. Liess (2001). "High sensitive tellurium based $\mathrm{NO}_{2}$ gas sensor." Sens Actuators B: Chem 73(1): 35-39.

Turner, R. J., R. Borghese and D. Zannoni (2012). "Microbial processing of tellurium as a tool in biotechnology." Biotechnol Adv 30(5): 954-963.

Valle, A., M. J. Bailey, A. S. Whiteley and M. Manefield (2004). "N-acyl-L-homoserine lactones (AHLs) affect microbial community composition and function in activated sludge." Environ Microbiol 6(4): 424-433.

Van Der Heijden, M. G. A., R. D. Bardgett and N. M. Van Straalen (2008). "The unseen majority: soil microbes as drivers of plant diversity and productivity in terrestrial ecosystems." Ecol Lett 11(3): 296-310.

Vecitis, C. D., K. R. Zodrow, S. Kang and M. Elimelech (2010). "Electronic-structuredependent bacterial cytotoxicity of single-walled carbon nanotubes." Acs Nano 4(9): 5471-5479.

Vega, N. M. and J. Gore (2014). "Collective antibiotic resistance: mechanisms and implications." Curr Opin Microbiol 21: 28-34.

Ventola, C. L. (2015). "The antibiotic resistance crisis: Part 1: Causes and threats." $\underline{\mathrm{P} T}$ 40(4): 277-283.

Visca, P., A. Ciervo and N. Orsi (1994). "Cloning and nucleotide sequence of the pvdA gene encoding the pyoverdin biosynthetic enzyme L-ornithine N5-oxygenase in Pseudomonas aeruginosa." J Bacteriol 176(4): 1128-1140.

Vishal, S., C. Daniel, K. W. Virginia and S. Shreya (2014). "The impact of engineered cobalt, iron, nickel and silver nanoparticles on soil bacterial diversity under field conditions." Environ Res Lett 9(2): 024001.

Vittori Antisari, L., S. Carbone, A. Gatti, G. Vianello and P. Nannipieri (2013). "Toxicity of metal oxide $\left(\mathrm{CeO}_{2}, \mathrm{Fe}_{3} \mathrm{O}_{4}, \mathrm{SnO}_{2}\right)$ engineered nanoparticles on soil microbial biomass and their distribution in soil." Soil Biol Biochem 60: 87-94.

von Bodman, S. B., W. D. Bauer and D. L. Coplin (2003). "Quorum sensing in plantpathogenic bacteria." Annu Rev Phytopathol 41(1): 455-482.

Wagh, M., R. Patil, D. Thombre, M. Kulkarni, W. Gade and B. Kale (2013). "Evaluation of anti-quorum sensing activity of silver nanowires." Appl Microbiol Biotechnol 97(8): 3593-3601.

Wagner, M. and A. Loy (2002). "Bacterial community composition and function in sewage treatment systems." Curr Opin Biotechnol 13(3): 218-227.

Wagner, M., A. Loy, R. Nogueira, U. Purkhold, N. Lee and H. Daims (2002). "Microbial community composition and function in wastewater treatment plants." Antonie Van Leeuwenhoek 81(1-4): 665-680.

Wagner, V. E. and B. H. Iglewski (2008). "P. aeruginosa biofilms in CF infection." Clin Rev Allergy Immunol 35(3): 124-134.

Wandersman, C. and P. Delepelaire (2004). "Bacterial iron sources: from siderophores to hemophores." Annu. Rev. Microbiol. 58: 611-647. 
Wang, J. (2005). "Nanomaterial-based electrochemical biosensors." Analyst 130(4): 421426.

Wang, Q., G. M. Garrity, J. M. Tiedje and J. R. Cole (2007). "Naive Bayesian classifier for rapid assignment of rRNA sequences into the new bacterial taxonomy." Appl Environ Microbiol 73(16): 5261-5267.

Wang, V. B., S.-L. Chua, B. Cao, T. Seviour, V. J. Nesatyy, E. Marsili, S. Kjelleberg, M. Givskov, T. Tolker-Nielsen and H. Song (2013). "Engineering PQS biosynthesis pathway for enhancement of bioelectricity production in Pseudomonas aeruginosa microbial fuel cells." PloS One 8(5): e63129.

Wang, Z., M. D. Shirley, S. T. Meikle, R. L. D. Whitby and S. V. Mikhalovsky (2009). "The surface acidity of acid oxidised multi-walled carbon nanotubes and the influence of in-situ generated fulvic acids on their stability in aqueous dispersions." Carbon 47(1): 73-79.

Waters, C. M. and B. L. Bassler (2005). "Quorum sensing: cell-to-cell communication in bacteria." Annu Rev Cell Dev Biol 21: 319-346.

Webber, D. H. and R. L. Brutchey (2009). "Photolytic preparation of tellurium nanorods." Chem Commun (38): 5701-5703.

Wei, L., L.-J. Li, M. B. Chan-Park, Y. Yang and Y. Chen (2010). "Aggregation-dependent photoluminescence sidebands in single-walled carbon nanotube." J Phys Chem $\mathrm{C}$ 114(14): 6704-6711.

Weinberg, H., A. Galyean and M. Leopold (2011). "Evaluating engineered nanoparticles in natural waters." Trends Anal Chem 30(1): 72-83.

Weiss, J., P. Takhistov and D. J. McClements (2006). "Functional materials in food nanotechnology." J Food Sci 71(9): R107-R116.

West, S. A., S. P. Diggle, A. Buckling, A. Gardner and A. S. Griffin (2007). "The social lives of microbes." Annu Rev Ecol Evol Syst: 53-77.

West, S. A., A. S. Griffin, A. Gardner and S. P. Diggle (2006). "Social evolution theory for microorganisms." Nat Rev Microbiol 4(8): 597-607.

Wiesner, M. R., G. V. Lowry, P. Alvarez, D. Dionysiou and P. Biswas (2006). "Assessing the risks of manufactured nanomaterials." Environ Sci Technol 40(14): 4336-4345.

Wilder, C. N., S. P. Diggle and M. Schuster (2011). "Cooperation and cheating in Pseudomonas aeruginosa: the roles of the las, rhl and pqs quorum-sensing systems." ISME J 5(8): 1332-1343.

Williams, P. and M. Cámara (2009). "Quorum sensing and environmental adaptation in Pseudomonas aeruginosa: a tale of regulatory networks and multifunctional signal molecules." Curr Opin Microbiol 12(2): 182-191.

Williams, P., M. Camara, A. Hardman, S. Swift, D. Milton, V. J. Hope, K. Winzer, B. Middleton, D. I. Pritchard and B. W. Bycroft (2000). "Quorum sensing and the population-dependent control of virulence." Philos Trans R Soc Lond B: Biol Sci 355(1397): 667-680. 
Wong, Y., C. Yuen, M. Leung, S. Ku and H. Lam (2006). "Selected applications of nanotechnology in textiles." AUTEX Res J 6(1): 1-8.

Wörle-Knirsch, J., K. Pulskamp and H. Krug (2006). "Oops they did it again! Carbon nanotubes hoax scientists in viability assays." Nano Lett 6(6): 1261-1268.

Wu, Y., Y. Ding, Y. Cohen and B. Cao (2014). "Elevated level of the second messenger cdi-GMP in Comamonas testosteroni enhances biofilm formation and biofilm-based biodegradation of 3-chloroaniline " Appl Microbiol Biotechnol 99(4):1967-1976.

www.nanotechproject.org/consumerproducts.

Xie, Y. P., Y. P. He, P. L. Irwin, T. Jin and X. M. Shi (2011). "Antibacterial activity and mechanism of action of Zinc Oxide nanoparticles against Campylobacter jejuni." Appl Environ Microbiol 77(7): 2325-2331.

Xu, X.-H. N., W. J. Brownlow, S. V. Kyriacou, Q. Wan and J. J. Viola (2004). "Real-time probing of membrane transport in living microbial cells using single nanoparticle optics and living cell imaging." Biochemistry 43(32): 10400-10413.

Yang, L., M. Nilsson, M. Gjermansen, M. Givskov and T. Tolker-Nielsen (2009). "Pyoverdine and PQS mediated subpopulation interactions involved in Pseudomonas aeruginosa biofilm formation." Mol Microbiol 74(6): 1380-1392.

Yang, Y., Q. Chen, J. D. Wall and Z. Hu (2012). "Potential nanosilver impact on anaerobic digestion at moderate silver concentrations." Water Res 46(4): 11761184.

Yang, Y., J. Quensen, J. Mathieu, Q. Wang, J. Wang, M. Li, J. M. Tiedje and P. J. J. Alvarez (2014). "Pyrosequencing reveals higher impact of silver nanoparticles than $\mathrm{Ag}^{+}$on the microbial community structure of activated sludge." Water Res 48: 317-325.

Yang, Y., M. Xu, J. D. Wall and Z. Hu (2012). "Nanosilver impact on methanogenesis and biogas production from municipal solid waste." Waste Manag 32(5): 816-825.

Yates, E. A., B. Philipp, C. Buckley, S. Atkinson, S. R. Chhabra, R. E. Sockett, M. Goldner, Y. Dessaux, M. Camara, H. Smith and P. Williams (2002). "Nacylhomoserine lactones undergo lactonolysis in a $\mathrm{pH}-$, temperature-, and acyl chain length-dependent manner during growth of Yersinia pseudotuberculosis and Pseudomonas aeruginosa." Infect Immun 70(10): 5635-5646.

Ye, L., T. Zhang, T. Wang and Z. Fang (2012). "Microbial structures, functions, and metabolic pathways in wastewater treatment bioreactors revealed using highthroughput sequencing." Environ Sci Technol 46(24): 13244-13252.

Yeterian, E., L. W. Martin, L. Guillon, L. Journet, I. L. Lamont and I. J. Schalk (2010). "Synthesis of the siderophore pyoverdine in Pseudomonas aeruginosa involves a periplasmic maturation." Amino Acids 38(5): 1447-1459.

Yurkov, V., J. Jappé and A. Verméglio (1996). "Tellurite resistance and reduction by obligately aerobic photosynthetic bacteria." Appl Environ Microbiol 62(11): 41954198. 
Zahou, I., R. Mlika, R. Ben Chaabane and H. Ben Ouada (2015). "Effect of MWCNT loading on the morphological, optical and electrical properties of Nickel phtalocyanine based composites." Synth Met 202: 39-48.

Zak, D. R., W. E. Holmes, D. C. White, A. D. Peacock and D. Tilman (2003). "Plant diversity, soil microbial communities, and ecosystem function: are there any links?" Ecology 84(8): 2042-2050.

Zhang, C., Z. Liang and Z. Hu (2014). "Bacterial response to a continuous long-term exposure of silver nanoparticles at sub-ppm silver concentrations in a membrane bioreactor activated sludge system." Water Res 50: 350-358.

Zhang, L., Y. Jiang, Y. Ding, M. Povey and D. York (2007). "Investigation into the antibacterial behaviour of suspensions of $\mathrm{ZnO}$ nanoparticles ( $\mathrm{ZnO}$ nanofluids)." $\mathrm{J}$ Nanopart Res 9(3): 479-489.

Zhang, T., M.-F. Shao and L. Ye (2011). "454 Pyrosequencing reveals bacterial diversity of activated sludge from 14 sewage treatment plants." ISME J 6(6): 1137-1147.

Zhang, Y., C. K. Ng, Y. Cohen and B. Cao (2014). "Cell growth and protein expression of Shewanella oneidensis in biofilms and hydrogel-entrapped cultures." Mol BioSyst 10(5): 1035-1042.

Zhao, X., A. Striolo and P. T. Cummings (2005). "C60 binds to and deforms nucleotides." Biophys J 89(6): 3856-3862.

Zheng, X., Y. Chen and R. Wu (2011). "Long-term effects of titanium dioxide nanoparticles on nitrogen and phosphorus removal from wastewater and bacterial community shift in activated sludge." Environ Sci Technol 45(17): 7284-7290.

Zhou, Y. and W. N. Chen (2011). "iTRAQ-coupled 2-D LC-MS/MS analysis of membrane protein profile in Escherichia coli incubated with apidaecin IB." PloS One 6(6): e20442.

Zhu, Y. J., W. W. Wang, R. J. Qi and X. L. Hu (2004). "Microwave-assisted synthesis of single-crystalline tellurium nanorods and nanowires in ionic liquids." Angew Chemie 116(11): 1434-1438. 